\title{
Planejamento instrucional automatizado em aprendizagem colaborativa com suporte computacional utilizando planejamento hierárquico
}

\author{
Geiser Chalco Challco \\ DisSERTAÇÃO APRESENTADA \\ AO \\ Instituto De MatemáticA e Estatística \\ DA \\ Universidade De SÃo Paulo \\ PARA \\ OBTENÇÃO DO TÍTULO \\ $\mathrm{DE}$ \\ Mestre em CiÊnCIAS \\ Programa: Ciência da Computação \\ Orientador: Prof. Dr. Marco Aurélio Gerosa
}

Durante o desenvolvimento deste trabalho o autor recebeu auxílio financeiro do CNPq

São Paulo, Novembro de 2012 


\section{Planejamento instrucional automatizado em aprendizagem colaborativa com suporte computacional utilizando planejamento hierárquico}

Esta versão da dissertação contém as correções e alterações sugeridas pela Comissão Julgadora durante a defesa da versão original do trabalho, realizada em 11/09/2012. Uma cópia da versão original está disponível no Instituto de Matemática e Estatística da Universidade de São Paulo.

Comissão Julgadora:

- Prof. Dr. Marco Aurélio Gerosa (orientador) - IME-USP

- Prof ${ }^{\mathrm{a}}$. Dra ${ }^{\mathrm{a}}$. Leliane Nunes de Barros - IME-USP

- Prof. Dr. Seiji Isotani - ICMC-USP 


\section{Agradecimentos}

Em primeiro lugar, gostaria de agradecer a meu orientador, Prof. Dr. Marco Aurélio Gerosa por seu apoio ao longo dos meus anos no mestrado. Independentemente de quanto ele tinha que fazer, estava sempre disponível para discutir ideias e sugestões. Eu também sou profundamente grato por sua paciência e cuidados na revisão desta dissertação.

Gostaria também de agradecer a Profa. Dra. Leliane Nunes de Barros por seu grande interesse e entusiasmo em aplicações de planejamento em Inteligência Artificial que inspirou minha pesquisa desde o início. Meu agradecimento especial para o Prof. Dr. Seiji Isotani pelas sugestões e contribuições durante a defensa. Espero que a minha pesquisa tenha superado todas as expetativas da banca examinadora.

Na Universidade de São Paulo, tive o privilégio de ser membro de dois grupos, primeiro do grupo Groupware Workbench e depois do grupo ATP, grupos que escutaram meus discursos e criticaram minha pesquisa durante todo o tempo, fazendo-me pensar novamente sobre minhas ideias e crenças. Um grande obrigado para Straus Michalsky, Carlos Leonardo Herrera Muñoz, Edith Zaida Sonco Mamani, Lucas Santos de Oliveira, Victoriano Alfonso Phocco Diaz, Ewout ter Haar, André Tierno Yamin, Talita Raquel Romero e Helbert dos Santos.

Finalmente, agradeço profundamente aos meus pais, cujo apoio econômico e emocional tornaram meus estudos possíveis. 


\section{Resumo}

\section{Planejamento instrucional automatizado em aprendizagem colaborativa com su- porte computacional utilizando planejamento hierárquico}

Em Aprendizagem Colaborativa com Suporte Computacional (ACSC), o planejamento instrucional consiste em obter uma sequência de interações instrucionais que definem o conteúdo instrucional como a representação do que deve ser ensinado e da forma em que os participantes devem interagir, denominada informação de planejamento instrucional. O desenvolvimento, adaptação e personalização de unidades concisas de estudo compostas por recursos instrucionais e informação de planejamento instrucional, denominadas unidades de aprendizagem, envolve um processo de planejamento instrucional complexo que consome muito tempo e apresenta um conjunto de tarefas repetitivas a serem efetuadas pelos projetistas instrucionais.

Neste trabalho, o planejamento instrucional em ACSC é modelado como um problema de planejamento hierárquico para dar suporte ao desenvolvimento, adaptação e personalização das unidades de aprendizagem de forma automática. A modelagem consiste na representação do domínio a ser ensinado, das caraterísticas dos estudantes e das estratégias de planejamento instrucional na linguagem do sistema JSHOP2ip, um sistema de planejamento hierárquico desenvolvido para dar solução aos problemas específicos de planejamento instrucional.

Para avaliar a modelagem proposta, efetuamos o desenvolvimento de um gerador de cursos colaborativos como um serviço Web usando a modelagem proposta e o sistema JSHOP2ip, no qual foram avaliados o desempenho, a modelagem das estratégias e a saída do planejador. Além disso, para demonstrar a viabilidade do modelo proposto em situações reais, efetuamos o desenvolvimento de uma ferramenta de autoria de unidades de aprendizagem que emprega o gerador de cursos colaborativos.

Palavras-chave: aprendizagem colaborativa, planejamento instrucional, planejamento em inteligência artificial, planejamento hierárquico, roteiros colaborativos, gerador de cursos. 


\section{Abstract}

\section{Automated instructional design in computer-supported collaborative learning using hierarchical planning}

In Computer Supported Collaborative Learning (CSCL), the goal of instructional design is to obtain a instructional interaction sequence that define the instructional content as a representation of what should be taught and the way in which participants must interact, called instructional planning information. The development, adaptation and personalization of basic units of study comprised of the instructional resources and instructional planning information, called units of learning, that involves a complex instructional planning process, time consuming and repetitive.

In this work, the instructional design in CSCL is modeled as hierarchical planning problem to support the development, adaptation and personalization for units of learning. The modeling is the representation of the domain to be taught, the characteristics of students and instructional strategies in JSHOP2ip, an independent hierarchical planning system designed to solve problems of instructional design.

To evaluate the proposed model, we developed a collaborative course generator as a Web service using the proposed model and JSHOP2ip system, upon which we evaluated the performance, modeling strategies and the output scheduler. Furthermore, to demonstrate the feasibility of the proposed model in real situations, we developed an authoring tool for units of learning employing the collaborative course generator.

Keywords: collaborative learning, instructional design, automated planning, hierarchical task network planning, collaborative scripts, adaptive courseware generator. 


\section{Sumário}

Lista de Abreviaturas viii

Lista de Figuras $\quad$ ix

Lista de Tabelas $\quad$ xiv

1 Introdução 1

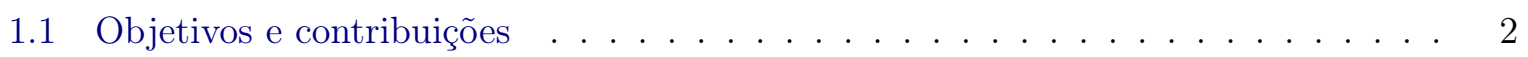

1.2 Organização do trabalho . . . . . . . . . . . . . . . . . . . 3

2 Referencial teórico $\quad 4$

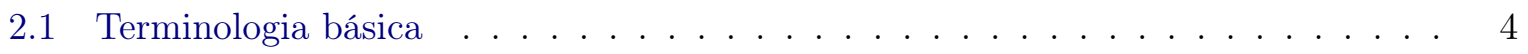

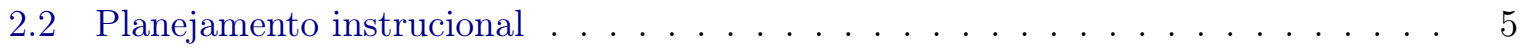

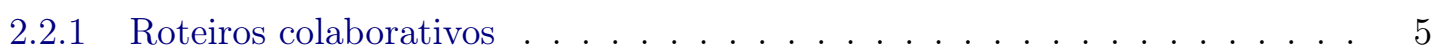

2.2.2 Representação computacional de roteiros colaborativos . . . . . . . . . . . 12

2.2.3 Planejamento instrucional usando padrões de roteiros . . . . . . . . . . . 15

2.3 Sistemas tutores inteligentes . . . . . . . . . . . . . . . . . . 17

2.3.1 Modelo clássico dos sistemas tutores inteligentes . . . . . . . . . . . . 18

2.3.2 Tarefas e métodos instrucionais . . . . . . . . . . . . . . . . 18

2.3.3 Tipos de métodos instrucionais . . . . . . . . . . . . . . . . . . . . 19

2.4 Planejamento hierárquico . . . . . . . . . . . . . . . . . . . . . 21

2.4.1 Introdução ao planejamento em Inteligência Artificial . . . . . . . . . . . . 21

2.4.2 Processo de planejamento hierárquico . . . . . . . . . . . . . 23

2.4.3 Sistema de planejamento hierárquico JSHOP2ip . . . . . . . . . . . . . 27

2.5 Considerações finais . . . . . . . . . . . . . . . . . . . . 32

3 Modelagem de planejamento instrucional em ACSC $\quad 34$

3.1 Estado Inicial: Modelo de domínio a ser ensinado e modelo de estudante . . . . . 35

3.1 .1 Modelo de domínio a ser ensinado . . . . . . . . . . . . . . . . 36

3.1 .2 Modelo de estudante . . . . . . . . . . . . . . . . . . . . 42

3.2 Problema de planejamento instrucional . . . . . . . . . . . . . . . . . . 44

3.2 .1 Objetivos educacionais . . . . . . . . . . . . . . . . . . . 44

3.2.2 Rede de tarefa inicial: Tarefa de planejamento instrucional pública . . . . 45

3.3 Domínio de planejamento . . . . . . . . . . . . . . . . . . 45 
3.3.1 Axiomas e operadores de propósito geral . . . . . . . . . . . . . . . . 46

3.3.2 Axiomas de consulta aos modelos de estudante e de domínio a ser ensinado 46

3.3.3 Axiomas de planejamento instrucional . . . . . . . . . . . . . . . . . . . 49

3.3.4 Tarefas básicas e operadores que representam as interações instrucionais . 52

3.3.5 Representação das estratégias de planejamento instrucional como tarefas e métodos hierárquicos . . . . . . . . . . . . . . . . . . 68

3.4 Componente de conversão . . . . . . . . . . . . . . . . . . . . . . 74

3.4.1 Função de conversão dos operadores de planejamento . . . . . . . . . . . . 74

3.4 .2 Algoritmo de geração de roteiros colaborativos . . . . . . . . . . . . . . 75

4 Modelo pedagógico: Estratégias de planejamento instrucional $\quad 78$

4.1 Elementos básicos de roteiros colaborativos . . . . . . . . . . . . 78

4.1 .1 Serviço de conferência . . . . . . . . . . . . . . . . . . . 78

4.1 .2 Objeto de aprendizagem . . . . . . . . . . . . . . . . 80

4.1 .3 Ambiente de apoio à aprendizagem . . . . . . . . . . . . . . . . . . 81

4.1 .4 Grupo de estudantes . . . . . . . . . . . . . . . . . . . . . . 81

4.2 Microrroteiros: Cenários colaborativos . . . . . . . . . . . . . . . . . 83

4.2 .1 Eventos IL . . . . . . . . . . . . . . . . . . . . . . . . . . . 83

4.2 .2 Fluxo de interações direcionadas e cíclicas . . . . . . . . . . . . . . . . 85

4.2 .3 Padrões de interação . . . . . . . . . . . . . . . . . . . . . 87

4.2 .4 Papéis dos estudantes . . . . . . . . . . . . . . . . . . . . . 87

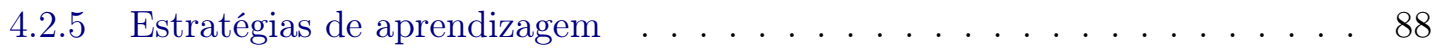

$4.2 .6 \quad$ Fases nos cenários colaborativos . . . . . . . . . . . . . . . . . . . . . . 89

4.2 .7 Cenários colaborativos . . . . . . . . . . . . . . . . . . . 90

4.3 Macrorroteiros: CLFPs . . . . . . . . . . . . . . . . . . . . . . . . . . . 92

4.3.1 Sessões de aprendizagem . . . . . . . . . . . . . . . . . . . 92

4.3 .2 Atividades de grupo . . . . . . . . . . . . . . . . . . . . . 95

$4.3 .3 \quad$ Fases . . . . . . . . . . . . . . . . . . . . . . . . . . 95

4.3.4 Macrorroteiros colaborativos . . . . . . . . . . . . . . . . . . . . 97

4.3.5 Integração de macrorroteiros e microrroteiros . . . . . . . . . . . . . . 98

4.3.6 Combinação dos padrões de macrorroteiro . . . . . . . . . . . . . . . . . 100

4.4 Unidades de aprendizagem . . . . . . . . . . . . . . . . . . . . . 102

5 Implementação $\quad 104$

5.1 Implementação do gerador de cursos colaborativos . . . . . . . . . . . . . . . . 104

5.1 .1 Processo de geração de cursos . . . . . . . . . . . . . . . . . . . 106

5.1 .2 Mediador de consultas . . . . . . . . . . . . . . . . . . . . . . . . . 109

5.1 .3 Integração do gerador de cursos com CopperCore . . . . . . . . . . . . . . 111

5.2 Modelo conceitual da ferramenta de autoria . . . . . . . . . . . . . . . . . . 111

5.2 .1 Edição do modelo de estudante . . . . . . . . . . . . . . . . . . . . . . . . 112

5.2 .2 Edição do modelo do domínio a ser ensinado . . . . . . . . . . . . . . . 113 
5.2 .3 Gerenciamento de cursos . . . . . . . . . . . . . . . . . . . . . . . . 114

6 Avaliações

6.1 Avaliação de desempenho . . . . . . . . . . . . . . . . . . . . . 115

6.2 Avaliação da modelagem de estratégias . . . . . . . . . . . . . . . . . . . 117

6.2.1 Exemplo de microrroteiro: Peer tutoring . . . . . . . . . . . . . . . 117

6.2 .2 Exemplo de macrorroteiro: Jigsaw . . . . . . . . . . . . . . . . . 126

6.3 Avaliação da saída do planejador . . . . . . . . . . . . . . . . . . . . 133

6.3.1 Plano de seções para um objetivo educacional . . . . . . . . . . . . . . . 135

6.3.2 Plano de sessões práticas para uma seção prática . . . . . . . . . . . . . . 137

6.3.3 Plano de sessões definidas pelo macrorroteiro jigsaw . . . . . . . . . . . . 143

6.3.4 Plano de interações definidas pelo microrroteiro distributed cognition . . . 148

7 Trabalhos relacionados $\quad 152$

7.1 Sistemas tutores inteligentes . . . . . . . . . . . . . . . . . . . 152

7.1 .1 O sistema GTE . . . . . . . . . . . . . . . . . . . 153

$7.1 .2 \quad \mathrm{O}$ sistema DCG . . . . . . . . . . . . . . . . . . . . 153

$7.1 .3 \quad$ O sistema PAIGOS . . . . . . . . . . . . . . . . . . . . 154

$7.1 .4 \quad$ O sistema PASER . . . . . . . . . . . . . . . . . . . 155

$7.1 .5 \quad$ O sistema ADAPTAPLAN . . . . . . . . . . . . . . 155

7.2 Ferramentas de autoria de autoria das unidades de aprendizagem . . . . . . . 156

7.2 .1 COOL MODES . . . . . . . . . . . . . . . . . 156

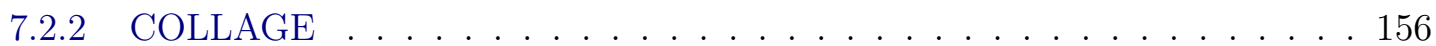

7.2 .3 CHOCOLATO . . . . . . . . . . . . . . . . 157

7.3 Considerações finais . . . . . . . . . . . . . . . . . . . . 158

8 Conclusões e trabalhos futuros $\quad 159$

8.1 Trabalhos futuros . . . . . . . . . . . . . . . . . . . 160

8.2 Produções ao longo do mestrado . . . . . . . . . . . . . . . . . . . . . . . . 161

A Planejamento clássico $\quad 162$

A.1 Representação em teoria de conjuntos . . . . . . . . . . . . . . . . . . . . . 163

A.2 Representação clássica . . . . . . . . . . . . . . . . . . . . . . . . . 164

B Formalismo da linguagem JSHOP2ip 166

B.1 Símbolos . . . . . . . . . . . . . . . . . . . . . . . . . 166

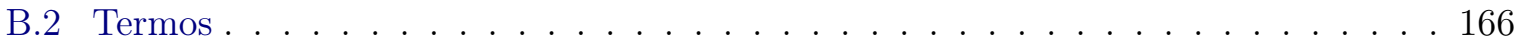

B.3 Átomos lógicos . . . . . . . . . . . . . . . . . . . . . . . . . 167

B.4 Expressão lógica ． . . . . . . . . . . . . . . . . . . . . . . . 167

B.5 Pré-condições lógicas . . . . . . . . . . . . . . . . . . . . . . . . . . 168

B.6 Axiomas . . . . . . . . . . . . . . . . . . . . . . 168

B.7 Um átomo de tarefa . . . . . . . . . . . . . . . . . . . . 168 
B.8 Lista de tarefas . . . . . . . . . . . . . . . . . . . . . . . . . 168

B.9 Operador . . . . . . . . . . . . . . . . . . . . . . . . 169

B.10 Métodos . . . . . . . . . . . . . . . . . . . . . . . 170

B.11 Domínio de planejamento . . . . . . . . . . . . . . . . . 171

B.12 Problema de planejamento . . . . . . . . . . . . . . . . . . . . . . 171

B.13 Plano . . . . . . . . . . . . . . . . . . . . . . 171

C Especificação IMS-LD $\quad 172$

C.1 Metáfora de roteiro de teatro . . . . . . . . . . . . . . . . . . . . . . 172

C.2 Elementos da especificação . . . . . . . . . . . . . . . . . . . . . . 173

C.2.1 Elementos do nível A . . . . . . . . . . . . . . . . . . . . . . . . 173

C.2.2 Elementos dos níveis B e C . . . . . . . . . . . . . . . . . . . . . 181

C.3 Relação com outras especificações . . . . . . . . . . . . . . . . . . . . . . . . . . . 189

D Axiomas e operadores de propósito geral 190

D.1 Teste de igualdade e não igualdade . . . . . . . . . . . . . . . . . . . . 190

D.2 Manipulação de listas . . . . . . . . . . . . . . . . . . . . . . . . . 190

D.3 Substituição iterativa de um símbolo variável com os termos de uma lista . . . . . 190

D.4 Manipulação do estado corrente . . . . . . . . . . . . . . . . . . . . . . . 192

E Axiomas de planejamento instrucional 193

E.1 Ordenação topológica . . . . . . . . . . . . . . . . . . . . . . . . . . . 193

E.2 Ordenação dos elementos de domínio pelo histórico do estudante . . . . . . . . 193

E.3 Filtrar elementos usando condições . . . . . . . . . . . . . . . . . . . . . 193

E.4 Construção de condições para consultas . . . . . . . . . . . . . . . . . 193

E.5 Comparar e obter valores de um nível de competência . . . . . . . . . . . . . . 194

E.6 Avaliação do tipo de elemento de conhecimento associado a uma competência . . 194

E.7 Obter uma elemento auxiliar que cumpre as condições . . . . . . . . . . . . . 196

E.8 Obter condições de consultas de acordo as características dos estudantes . . . . . 196

E.9 Obter competências e níveis de competência da lista de objetivos educacionais . . 198

E.10 Obter objetivo educacional de um elemento de conhecimento de tipo auxiliar . . 198

E.11 Obter objetivos individuais dos estudantes . . . . . . . . . . . . . . . . . 198

E.12 Filtragem de objetivos e grupos por competência cognitiva . . . . . . . . . . . . . 199

E.13 Avaliar objetivos educacionais e níveis de competências . . . . . . . . . . . . . 200

$\begin{array}{ll}\text { Referências Bibliográficas } & 201\end{array}$ 


\section{Lista de Abreviaturas}

ACSC Aprendizagem Colaborativa com Suporte Computacional

ALD Projeto de Aprendizagem Automático (Automated Learning Design)

AVA Ambiente Virtual de Aprendizagem

IA Inteligência Artificial

IL Instrucional e Aprendizagem (Instructional and Learning)

STI Sistemas Tutores Inteligentes 


\section{Lista de Figuras}

2.1 Ilustração gráfica do arcabouço desenvolvido por Kobbe et al. (2007) . . . . . . 6

2.2 Exemplo de macrorroteiro Jigsaw . . . . . . . . . . . . . . . . . . . . . . . . 9

2.3 Exemplo de fluxo de interação Peer-Tutoring (Isotani, 2009) . . . . . . . . . . . 10

2.4 Exemplo de relação entre diálogo-rótulo e diálogo-tipo (Inaba et al., 2003b) . . 10

2.5 Elementos de um evento IL (Isotani e Mizoguchi, 2007) . . . . . . . . . . . . . 11

2.6 Representação do microrroteiro peer-tutoring como eventos IL (Isotani, 2009) . . 11

2.7 Exemplo da representação de formação de grupos e subgrupos . . . . . . . . . . 12

2.8 Exemplo de representação do mecanismo de distribuição de tarefas . . . . . . . . 13

2.9 Exemplo da representação de um mecanismo de sequenciamento . . . . . . . . . . 14

2.10 Relações entre padrões de roteiros colaborativos (Leo et al., 2007) . . . . . . . 15

2.11 Exemplo das etapas de planejamento instrucional usando o padrão ArgueScript . 17

2.12 Modelo clássico de sistemas tutores inteligentes . . . . . . . . . . . . . . 18

2.13 Tarefa instrucional remediar-exercício e métodos instrucionais associados . . . . . 19

2.14 Exemplos do métodos decomposição e decomposição repetitiva . . . . . . . . . 20

2.15 Exemplo do método de decomposição distributiva . . . . . . . . . . . . . . . . 20

2.16 Exemplo do método de execução . . . . . . . . . . . . . . . . . . 20

2.17 Modelo conceitual do problema de planejamento em IA . . . . . . . . . . . . . 21

2.18 Exemplo de decomposição da tarefa transportar dois pacotes $p_{1}$ e $p_{2} \ldots \ldots$. . . 23

2.19 Problema de planejamento logístico de entrega de dois pacotes . . . . . . . . . . 24

2.20 Exemplo de decomposição de tarefas hierárquicas . . . . . . . . . . . . . 26

2.21 Processo de planejamento no sistema de planejamento JSHOP2ip . . . . . . . . . 27

2.22 Representação do problema de logística de entrega de pacotes em JSHOP2ip . . . 28

2.23 Representação do domínio de logística de entrega de pacotes em JSHOP2ip . . 28

2.24 Exemplo de representação de condições relativas . . . . . . . . . . . . . . 30

2.25 Versão simplificada do algoritmo JSHOP2ip . . . . . . . . . . . . . . . . . . . 31

2.26 Estratégias de criação de elementos de roteiros f . . . . . . . . . . . . . . 32

3.1 Planejamento instrucional em ACSC como um problema de planejamento hierár-

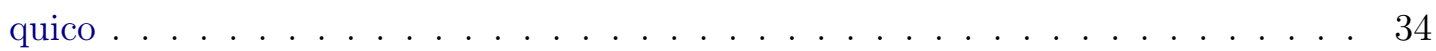

3.2 Representação do recurso instrucional "valor absoluto" . . . . . . . . . . . . . . . 35

3.3 Representação da estrutura de competências no domínio de matemática . . . . . 37

3.4 Modelo de crescimento do estudante (Isotani e Mizoguchi, 2007) . . . . . . . . 38

3.5 Representação de níveis de competência . . . . . . . . . . . . . . . . . . . . 38 
3.6 Elementos de conhecimento de tipo fundamental identificadas na página web "va-

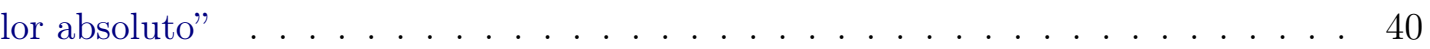

3.7 Representação da estrutura de elementos de conhecimento da Figura 3.6 . . . . . 40

3.8 Representação da estrutura de elementos de conhecimento . . . . . . . . . . . . . 42

3.9 Exemplo de representação do modelo estudante . . . . . . . . . . . . . . . . . . 43

3.10 Esquema do problema de planejamento . . . . . . . . . . . . . . . . . . 44

3.11 Esquema de axiomas de consultas aos modelos de estudante e de domínio a ser ensinado . . . . . . . . . . . . . . . . . . . . . 46

3.12 Exemplo de seleção de elementos no domínio a ser ensinado . . . . . . . . . . . 47

3.13 Exemplo de seleção de elementos relacionados, arestas representam relações isRe-

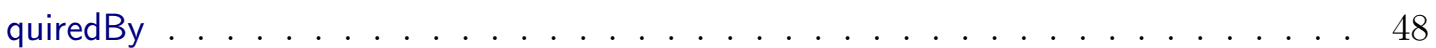

3.14 Operadores !startLDElement e !endLDElement básicos . . . . . . . . . . . . 53

3.15 Operador !startLDElement com informação de meta-dados . . . . . . . . . . . . 54

3.16 Operador !startLDElement com informações de meta-dados, atitudes e habilidades 55

3.17 Operador !endLDElement para elementos de roteiros colaborativos . . . . . . . . 56

3.18 Tarefa de criação de um elemento de roteiros que atualiza os níveis de competência 57

3.19 Operador !!changeCurrentLDElement que altera o elemento corrente de planejamento 58

3.20 Operador utilizado para alterar o tipo de recurso instrucional . . . . . . . . 59

3.21 Operador utilizado para alterar a competência fundamental . . . . . . . . . . . 59

3.22 Operador !!changeCLGrouping que altera a informação de agrupamento . . . . . . 60

3.23 Tarefas básicas e operadores utilizados na adição e remoção de papéis . . . . . . 62

3.24 Tarefas básicas e operadores utilizado na adição e remoção de um grupo . . . . . 63

3.25 Inserção de um texto . . . . . . . . . . . . . . . . . . . . . . . . . 64

3.26 Tarefa básica de criação de um rótulo titulo com o nome do elemento IMS-LD . . 64

3.27 Esquema de valores empregados na geração de textos . . . . . . . . . . . . . . . 64

3.28 Inserção de um elemento de domínio a ser ensinado . . . . . . . . . . . . . . . 65

3.29 Inserção de recurso instrucional . . . . . . . . . . . . . . . . . . . . . 65

3.30 Inserção de um único recurso instrucional por unidade de aprendizagem . . . . . 66

3.31 Alteração do registro histórico mediante a inserção de elementos de domínio . . . 66

3.32 Tarefa básica de criação do elemento $<$ item $>$. . . . . . . . . . . . . . 67

3.33 Tarefa básica de criação do elemento $<$ item $>$ em eventos IL . . . . . . . . . . . . 67

3.34 Esquema de definição de interações instrucionais nos método hierárquicos ... 69

3.35 Definição de interações instrucionais associadas à tarefa createLDPracticeSessions 69

3.36 Exemplo de representação de regras de planejamento instrucional . . . . . . . . . 71

3.37 Esquema de representação de tarefas opcionais e críticas . . . . . . . . . . . . . 72

3.38 Tarefas opcionais e críticas associadas à estratégia de criação da descrição do evento IL . . . . . . . . . . . . . . . . . . . . . . . . 73

3.39 Método de decomposição distributiva da tarefa createLDLearningObject . . . . . . 73

3.40 Exemplo de elementos XML obtidos usando o plano P e a função convert $\left(h_{i}\right) \quad$. $\quad 75$

3.41 Algoritmo de geração de roteiros colaborativos . . . . . . . . . . . . 76

3.42 Estrutura de roteiro colaborativo na especificação IMS-LD . . . . . . . . . . . 77 
4.1 Representação da estratégia de criação de um serviço de conferência . . . . . . . 78

4.2 Representação da estratégia de criação de um serviço de conferência assíncrona . 79

4.3 Representação da estratégia de criação de um objeto de aprendizagem . . . . . . 80

4.4 Representação da estratégia de criação de um ambiente de apoio à aprendizagem 81

4.5 Representação da estratégia de criação de um grupo de estudantes . . . . . . . . . 82

4.6 Esquema de representação de estratégias de criação de eventos IL . . . . . . . . . 83

4.7 Esquema de representação das estratégias de criação de ações associadas aos eventos IL . . . . . . . . . . . . . . . . . . . . . . 84

4.8 Esquema de representação das estratégias de criação de ambiente de apoio à

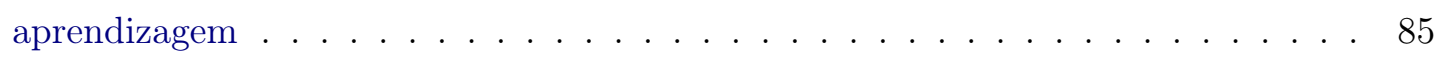

4.9 Esquema de representação da estratégia de criação de um fluxo de interações . 86

4.10 Esquema de representação da estratégia de criação de padrões de interação . . . . 87

4.11 Esquema de representação das estratégia de criação de papéis . . . . . . . . . . 88

4.12 Esquema de representação das estratégias de criação de estratégias de aprendizagem 89

4.13 Esquema de representação das estratégias de criação de fases nos cenários cola-

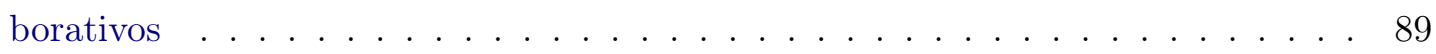

4.14 Esquema de representação das estratégias de criação de cenários colaborativos . . 90

4.15 Esquema de representação dos métodos associados à tarefa createNameCLScenario 91

4.16 Esquema de representação das estratégias de criação de sessões de aprendizagem 92

4.17 Representação da estratégia de criação de recursos de entrada em sessões . . . . . 93

4.18 Esquema de representação das estratégias de criação de recursos de saída em sessões 93

4.19 Esquema de representação de estratégias de criação das atividades em sessões . . 94

4.20 Esquema de representação de estratégias de criação de descrições de sessões .. 94

4.21 Esquema de representação de estratégias de criação de atividades de grupo . . . . 95

4.22 Representação da fase aprendizagem de papéis $($ Role $) \ldots \ldots$. . . . . . . . 96

4.23 Esquema de representação das estratégias de criação de criação de macrorroteiros 97

4.24 Esquema de representação dos métodos associados à tarefa createNameScript . . . 98

4.25 Integração de macrorroteiros e microrroteiros (Villasclaras-Fernández et al., 2009) 98

4.26 Tarefas e métodos hierárquicos que definem a integração de macro e microrroteiros 99

4.27 Métodos associados à tarefa createJigsawScript . . . . . . . . . . . . . . . 100

4.28 Exemplificação da combinação dos macrorroteiro Jigsaw e Pyramid . . . . . . . . 101

4.29 Método de cominação associados à tarefa createLDScriptCLScenario! . . . . . . . . . 101

4.30 Esquema dos métodos associados à tarefa createLDScriptCLScenario! . . . . . . . . 102

4.31 Esquema de representação da estratégia de criação de unidades de aprendizagem 103

5.1 Visão geral das classes relevantes no gerador de cursos colaborativos . . . . . . . 105

5.2 Diagrama de sequência que ilustra a geração do curso . . . . . . . . . . . . . . 106

5.3 Exemplo de descrição do conjunto de tarefas públicas . . . . . . . . . . . . . . . 107

5.4 Exemplo do metadado de um curso . . . . . . . . . . . . . . . . . . . 109

5.5 Visão geral do mediador dos modelos de domínio a ser ensinado e de estudante . 109

5.6 Ambiente de execução da unidade de aprendizagem de CopperCore . . . . . . . . 111 
5.7 Tela inicial da ferramenta de autoria ALD . . . . . . . . . . . . . . . . . . . 112

5.8 Tela de edição do modelo de estudante . . . . . . . . . . . . . . . . . . . . . 112

5.9 Tela de edição de propriedades do modelo de estudante . . . . . . . . . . . . . . . 113

5.10 Tela de edição do modelo de domínio a ser ensinado . . . . . . . . . . . . . . 113

5.11 Tela de edição das relações do modelo de domínio a ser ensinado . . . . . . . . . . 114

5.12 Tela inicial do gerenciamento de cursos . . . . . . . . . . . . . . . . . . . 114

6.1 Gráfico do número de objetivos e tempo necessário para a geração de cursos . . 116

6.2 Gráfico do número de objetivos e tamanho do plano para a geração de cursos . 117

6.3 Representação gráfica do microrroteiro Peer-Tutoring (Isotani, 2009) . . . . . . . 118

6.4 Representação da estratégia de criação do cenário colaborativo Peer Tutoring . 119

6.5 Representação dos métodos associados à tarefa createPeerTutoringCLScenario . . . 119

6.6 Esquema de representação da estratégia de criação da fase Peer tutoring . . . . . 120

6.7 Representação da estratégia de criação da estratégia aprendizagem por ensino . . 120

6.8 Representação da estratégia de criação do papel Peer tutor . . . . . . . . . . . . 121

6.9 Representação da estratégia de criação do padrão de interação Peer tutoring . . . 122

6.10 Representação da estratégia de criação do fluxo de interações meta-reconhecimento123

6.11 Representação da estratégia de criação do evento IL Monitorar (Monitoring) . . . 124

6.12 Representação da estratégia de criação de ações associadas ao evento IL Monitorar 125

6.13 Representação da estratégia de criação do ambiente no evento IL Monitorar .. 125

6.14 Diagrama do macrorroteiro Jigsaw . . . . . . . . . . . . . . . . 126

6.15 Representação da estratégia de criação do macrorroteiro Jigsaw . . . . . . . . . 127

6.16 Métodos associados à tarefa createJigsawScript . . . . . . . . . . . . . . . . . 128

6.17 Representação da fase Jigsaw . . . . . . . . . . . . . . . . . . . . . . 128

6.18 Representação da estratégia de criação da atividades de grupo Jigsaw . . . . . . 129

6.19 Representação da estratégia de criação da sessão de aprendizagem discussão . . 130

6.20 Representação da estratégia de criação de resumos de discussão . . . . . . . . . . 130

6.21 Esquema de representação de estratégias de criação das atividades em sessões . 131

6.22 Representação da estratégia de criação da descrição na sessão discussão . . . . . . 131

6.23 Método de combinação do padrão Jigsaw . . . . . . . . . . . . . . . . . . . . . . 132

6.24 Habilidades (esquerda) e elementos de conhecimento de tipo fundamental (direita) 133

6.25 Relações entre competência e exercícios usados na validação da saída do planejador 133

6.26 Processo de planejamento hierárquico usado para obter o plano de seções . . . . . 136

6.27 Interface de usuário no CopperCore do plano de seções para um objetivo educacional137

6.28 Processo de planejamento hierárquico usado para obter tarefas de criação de sessões139

6.29 Processo de planejamento hierárquico usado para obter o plano de sessões na seção prática . . . . . . . . . . . . . . . . . . . . . . . . 140

6.30 Processo de planejamento hierárquico usado para obter o plano de sessões definidas pelo macrorroteiro jigsaw na sessão prática . . . . . . . . . . . . . . . . . 145

6.31 Processo de planejamento hierárquico usado para obter o plano de interações definidas pelo microrroteiro distributed cognition . . . . . . . . . . . . . . 150 


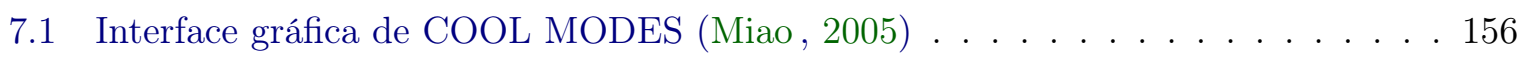

7.2 Interface gráfica de COLLAGE . . . . . . . . . . . . . . . . . 157

7.3 Interface principal de CHOCOLATO (Isotani et al., 2010b) . . . . . . . . . 158

A.1 Exemplo de representação em teoria de conjuntos . . . . . . . . . . . . . . . . . . 164

A.2 Exemplo de representação clássica . . . . . . . . . . . . . . . . . . . . . . 164

B.1 Exemplo de um operador hierárquico . . . . . . . . . . . . . . . . . . . 170

B.2 Exemplo da representação de um método hierárquico . . . . . . . . . . . . . . . 170

C.1 Diagrama dos elementos de roteiro como metáfora de roteiro de teatro . . . . . . 172

C.2 Estrutura básica do arquivo manifesto . . . . . . . . . . . . . . . . . . . 173

C.3 Modelo conceitual dos elementos da especificação IMS-LD . . . . . . . . . . . . 174

C.4 Exemplo do elemento título na especificação IMS-LD . . . . . . . . . . . . . . . . 174

C.5 Exemplo de objetivos de aprendizagem e pré-requisitos na especificação IMS-LD . 175

C.6 Exemplo de papéis na especificação IMS-LD . . . . . . . . . . . . . . . . 176

C.7 Exemplo de atividades de aprendizagem e de suporte na especificação IMS-LD . . 176

C.8 Exemplo de ambientes de apoio à aprendizagem na especificação IMS-LD . . . . 177

C.9 Exemplo de peças de teatro na especificação IMS-LD . . . . . . . . . . . . . . . 178

C.10 Exemplo de atos na especificação IMS-LD . . . . . . . . . . . . . . . . . . . 179

C.11 Exemplo de elementos papel-parte na especificação IMS-LD . . . . . . . . . . . . 180

C.12 Exemplo de propriedades na especificação IMS-LD . . . . . . . . . . . . . . . 181

C.13 Exemplo dos elementos globais $<$ view-property $>$ e $<$ set-property $>$. . . . . . . . 183

C.14 Exemplo de serviço de monitoramento na especificação IMS-LD . . . . . . . . . . 183

C.15 Exemplo de cálculo numérico na especificação IMS-LD . . . . . . . . . . . . . . . 184

C.16 Exemplo de condições na especificação IMS-LD . . . . . . . . . . . . . . . . . . 185

C.17 Exemplo do elemento $<$ when-property-value-is-set $>$. . . . . . . . . . . . . . 186

C.18 Exemplo do elemento $<$ change-property-value $>$. . . . . . . . . . . . . . . 187

C.19 Exemplo de notificação na especificação IMS-LD . . . . . . . . . . . . . . . . . 188

C.20 Integração da especificação IMS-CP e IMS-LD . . . . . . . . . . . . . . . . . . 189

D.1 Teste de igualdade e não igualdade, axiomas same e different . . . . . . . . . . . 190

D.2 Axiomas de manipulação de listas . . . . . . . . . . . . . . . . . . . . . . . . 191

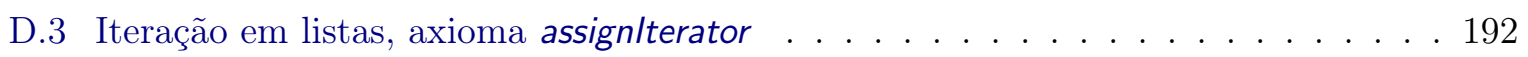

D.4 Operadores !!addInWorldState e !!removeFromWorldState . . . . . . . . . . . . . . 192

E.1 Axioma de obtenção do nível de competência cognitiva corrente . . . . . . . . . . 195

E.2 Axioma para filtrar estudantes por nivel de competência . . . . . . . . . . . . . . 195

E.3 Axioma para obter um elemento de conhecimento de tipo auxiliar . . . . . . . . 196

E.4 Axioma para obter ou criar um elemento de conhecimento de tipo auxiliar . . . . 196

E.5 Axioma para obter condições de consultas de acordo as características dos estudantes 197

E.6 Axioma para obter o tipo de recurso instrucional a ser apresentado . . . . . . . . 199

E.7 Axioma para avaliar objetivos educacionais e níveis de competência . . . . . . . . 200 


\section{Lista de Tabelas}

2.1 Exemplo de roteiro colaborativo ArgueGraph (Kobbe, 2005) . . . . . . . . . 7

3.1 Propriedades utilizadas em elementos de conhecimento . . . . . . . . . . . . . . 39

3.2 Características utilizadas no registro de preferências dos estudantes . . . . . . . . 43

3.3 Identificadores de tarefas de planejamento instrucional públicas . . . . . . . . . . 45

3.4 Axiomas e operadores de propósito geral . . . . . . . . . . . . . . . 46

3.5 Axiomas de planejamento instrucional . . . . . . . . . . . . . . . . . 50

3.6 Tarefas básicas e operadores que representam as interações instrucionais . . . . . 52

6.1 Tempo em segundos empregado na geração da tarefa createLDFundamentaUoL . . 115

6.2 Tamanho do plano gerado pela tarefa createLDFundamentaUoL . . . . . . . . . . . 116

6.3 Informação do modelo de estudante usada na validação da saída do planejador . 134

6.4 Resultado esperado das seções a serem obtidas para um objetivo educacional . . 135

6.5 Resultado esperado das sessões a serem obtidas para uma seção prática . . . . . . 138

6.6 Interfaces de usuário no CopperCore do plano de sessões práticas para uma seção prática . . . . . . . . . . . . . . . . . . . . . . . . . 142

6.7 Resultado esperado das sessões definidas pelo macrorroteiro jigsaw em uma sessão prática . . . . . . . . . . . . . . . . . . . . . . . . . . 144

6.8 Interfaces de usuário no CopperCore do plano de sessões definidas pelo macrorroteiro jigsaw . . . . . . . . . . . . . . . . . . . . . . 147

6.9 Resultado esperado das interações definidas pelo microrroteiro distributed cognition 149

6.10 Interfaces de usuário no CopperCore definidas pelo microrroteiro distributed cognition . . . . . . . . . . . . . . . . . . . . . . 151 


\section{Capítulo 1}

\section{Introdução}

No enfoque de aprendizagem colaborativa, aprender é uma experiência de caráter social, na qual os estudantes são encorajados a explicar, justificar e argumentar suas ideias (Vygotsky , 1978). Com o advento das tecnologias de informação e internet na década de 1990, surge a oportunidade de trazer os benefícios desse enfoque no contexto de aprendizado eletrônico, dando surgimento à área de estudo interdisciplinar "Aprendizagem Colaborativa com Suporte Computacional" (ACSC). A área tem por objetivo fornecer suporte computacional ao trabalho em grupo para que estudantes elaborem seu próprio conhecimento negociando e compartilhando informação (Stahl et al. , 2006).

A área de planejamento instrucional estuda métodos e técnicas que possibilitam a organização coerente do conteúdo mediante uma sequência de interações instrucionais definida de acordo com objetivos educacionais e características individuais dos estudantes (Wasson, 1996). Em ACSC, a sequência de interações instrucionais que definem o conteúdo instrucional, denominado informação de planejamento instrucional ou learning design, como a representação do que deve ser ensinado e da forma em que os participantes devem interagir mediante: o sequenciamento das atividades a serem efetuadas pelos participantes (estudantes e docentes); e a estruturação dos recursos instrucionais integrados as atividades.

Desenvolver, adaptar e personalizar uma unidade de aprendizagem em ACSC, definida como uma unidade concisa de estudo composta por recursos instrucionais e informação de planejamento instrucional, não é trivial, principalmente para pessoas não especialistas. Nesse sentido, pesquisas atuais são voltadas ao desenvolvimento de ferramentas de autoria das unidades de aprendizagem que utilizam diagramas de grafos (Pinkwart, 2003) e padrões de roteiro (Hernández-Leo et al., 2006; Isotani et al., 2010b). A utilização de padrões de roteiros nas ferramentas de autoria fornecem um conjunto de estratégias de planejamento instrucional extraídas das melhores práticas e teorias de aprendizagem.

No entanto, a autoria de unidades de aprendizagem em ACSC é dificultada, se o objetivo é desenvolver, adaptar ou personalizar unidades levando em consideração as características individuais de cada participante e do domínio a ser ensinado. Por exemplo, se um projetista instrucional está interessado em desenvolver uma unidade de aprendizagem corresponde ao tópico "métodos de validade" do curso "lógica básica" para oito estudantes, de forma que ao término do tópico, os estudantes sejam capazes de considerar as relações com outros conhecimentos e de continuar com um aperfeiçoamento na aplicação dos métodos de validade, então, o projetista 
deverá efetuar primeiro a geração do sequenciamento de objetivos educacionais; e para cada objetivo, mediante uma análise do conhecimento possuído por cada estudante serão definidas seções do tópico mediante a seleção de um cenário pedagógico adequado.

Obtida a sequencia de seções, para cada seção o projetista irá efetuar a criação de sessões de aprendizagem definidas em um conjunto de fases mediante a formação de grupos. Cada um dos grupos são definidos pelo projetista mediante uma análises dos estágios de desenvolvimento da habilidade e adquisição de conhecimento dos estudantes. Definidas as sessões, o projetista efetua a busca dos recursos instrucionais adequados para cada grupo em diferentes repositórios. A busca dos recursos é efetuada usando palavras chaves e analisando cada um dos itens, o que consume muito tempo. Além da busca de recursos, o projetista efetua a seleção das atividades associadas às sessões com a definição dos recursos de entrada e saída integradas às atividades. Finalmente, para cada atividade definida nas sessões é efetuada a seleção de um padrão de roteiro, efetuando a definição de como deve ser realizada a atividade.

Em Inteligência Artificial (IA), a área de planejamento estuda o processo de geração automática de sequências de ações denominadas planos. Os planos ao serem executados a partir de um estado inicial conduzem à satisfação de determinados objetivos. Planejamento hierárquico é uma técnica que utiliza métodos de decomposição das tarefas em subtarefas como representação das estratégias de domínio específico possibilitando a obtenção de planos consistentes e coerentes.

Portanto, percebe-se a existência de uma relação direta entre planejamento instrucional e planejamento hierárquico, no que as estratégias de planejamento instrucional podem ser representadas como um conjunto de tarefas e métodos hierárquicos a serem utilizados no desenvolvimento, adaptação e personalização de unidades de aprendizagem. Assim, desde a década de 80 tem se desenvolvido diferentes Sistemas Tutores Inteligentes (SIT) que efetuam o processo de planejamento instrucional de forma automática utilizando a técnica de planejamento hierárquico (Van Marcke, 1998; Vassileva, 1998) e (Ullrich, 2008). No entanto, não foi encontrada na literatura nenhum modelo, arquitetura ou STI que possibilite efetuar planejamento instrucional em ACSC de forma automática.

\subsection{Objetivos e contribuições}

Para dar suporte ao desenvolvimento, adaptação e personalização das unidades de aprendizagem de forma automática no contexto de ACSC este trabalho tem como objetivo a modelagem do planejamento instrucional em ACSC como um problema de planejamento hierárquico utilizando como referência o modelo clássico de STI. Nesse sentido, foram efetuadas:

(1) O desenvolvimento de um sistema de planejamento hierárquico para domínios de planejamento instrucional denominado JSHOP2ip (Java Simple Hierarchical Order Planner for Instructional Planning). O sistema de planejamento é uma versão modificada de JSHOP2 desenvolvida para dar solução aos problemas específicos de planejamento instrucional. 
(2) A modelagem das estratégias de planejamento instrucional usando padrões de roteiros colaborativos como tarefas e métodos hierárquicos. Para efetuar a modelagem empregamos um conjunto de princípios e esquemas de representação das estratégias de planejamento instrucional.

(3) O desenvolvimento de um componente de conversão do plano de ações para unidades de aprendizagem, que efetua a transformação das ações em elementos das especificações IMSLD e IMS-CP. Assim, cada unidade é uma composição da informação de planejamento instrucional, definida pela especificação IMS-LD, e um conjunto de recursos contidos em um pacote de conteúdo representado pela especificação IMS-CP.

(4) O desenvolvimento de um gerador de cursos colaborativos como um serviço Web a ser utilizado como componente de sistemas educacionais.

(5) O desenvolvimento de uma ferramenta de autoria das unidades de aprendizagem, denominada ALD (Automated Learning Design). Ferramenta utilizada pelo projetista instrucional para desenvolver unidades de aprendizagem adaptadas às caraterísticas dos estudantes. A ferramenta apresenta um editor de informações dos estudantes e do domínio a ser ensinado.

\subsection{Organização do trabalho}

Neste capítulo foram apresentados o contexto, a motivação, os objetivos e as contribuições da presente pesquisa. No Capítulo 2 é apresentado o referencial teórico empregado no presente trabalho. O capítulo aborda uma visão geral sobre planejamento instrucional e planejamento em IA, em especial sobre o processo de desenvolvimento das unidades de aprendizagem usando padrões de roteiros colaborativos e a técnica de planejamento hierárquico.

No Capítulo 3 apresentamos a modelagem de planejamento instrucional em ACSC como um problema de planejamento hierárquico, apresentando detalhes do modelo de estudante e do domínio a ser ensinado, os princípios de representação das estratégias de planejamento instrucional e detalhes do componente de conversão do plano de ações.

No Capítulo 4 é apresentado o conjunto de esquemas de representação das estratégias de planejamento instrucional. Esquemas a serem usados para representar estratégias extraídas dos padrões de macrorroteiros e microrroteiros.

No Capítulo 5 apresentamos a implementação do gerador de cursos colaborativos e da ferramenta de autoria das unidades de aprendizagem.

No Capítulo 6 apresentamos as avaliações efetuadas na modelagem de planejamento instrucional em ACSC como um problema de planejamento hierárquico. Apresentamos a avaliação de desempenho no gerador de cursos colaborativos, a avaliação da representação proposta de estratégias de planejamento instrucional e a avaliação da saída do planejador.

No Capítulo 7 apresentamos as diferenças entre nossa proposta e os trabalhos relacionados. Finalmente, no Capítulo 8 apresentamos as conclusões e trabalhos futuros. 


\section{Capítulo 2}

\section{Referencial teórico}

Este capítulo apresenta o referencial teórico relacionado ao planejamento instrucional em ACSC que situa o leitor no contexto desta dissertação. Na Seção 2.1 apresentamos definições básicas dos termos utilizados neste trabalho. Na Seção 2.2 apresentamos os conceitos da área de planejamento instrucional. Na Seção 2.3 apresentamos conceitos dos STI usados como modelo de referência em nossa modelagem proposta. A Seção 2.4 mostra os princípios básicos da técnica de planejamento hierárquico. Finalmente, a Seção 2.5 apresenta as considerações finais.

\subsection{Terminologia básica}

Objeto de aprendizagem: Wiley (2002) define um objeto de aprendizagem como "qualquer elemento digital que pode ser reutilizado para dar apoio à aprendizagem".

- Digital: um objeto de aprendizagem tem que estar disponível em formato digital, ou seja, ele é armazenado em uma mídia digital (por exemplo uma página Web).

- Reutilização: um objeto de aprendizagem pode ser usado em um contexto diferente para o qual foi originalmente projetado.

- Apoio à aprendizagem: um objeto de aprendizagem é projetado para servir como apoio ao processo de ensino-aprendizagem.

Recurso instrucional: Um recurso instrucional é um objeto de aprendizagem identificável e acessível por meio de uma URL ${ }^{1}$ (identificador uniforme de recurso).

Serviço de apoio à aprendizagem: Um serviço de apoio à aprendizagem ou serviço é uma ferramenta de software de apoio aos estudantes na comunicação, coordenação e cooperação que é utilizada durante o processo de ensino-aprendizagem.

Ambiente: Um ambiente é uma coleção de objetos de aprendizagem, serviços e subambientes na qual as atividades são efetuadas pelos estudantes (Van Es e Koper, 2006).

${ }^{1} \mathrm{URL}$ - Uniform Resource Identifier 
Unidade de aprendizagem: Uma unidade de aprendizagem é um termo abstrato utilizado para se referir a qualquer unidade concisa de estudo, como tópicos, módulos e lições, composta por recursos instrucionais e informação de planejamento instrucional. Na unidade de aprendizagem, a informação de planejamento instrucional ou learning design consistente na representação do que deve ser ensinado e da forma em que os participantes (estudantes e docentes) devem interagir a fim de atingir determinados objetivos educacionais, da maneira mais efetiva (Koper e Olivier, 2003).

\subsection{Planejamento instrucional}

Planejamento instrucional é definido por Wasson (1996) como o processo de geração de uma sequência de interações instrucionais que oferece consistência, coerência e continuidade no processo de ensino-aprendizagem. Interação instrucional pode ser definida como qualquer forma de interação entre o estudante e o conteúdo instrucional, ou a interação mediada pelo computador entre estudantes que colaboram entre si ou com o professor.

No enfoque de aprendizagem colaborativa, Dillenbourg (2002) argumenta que a prescrição da colaboração mediante planejamento instrucional diminui a flexibilidade do processo de aprendizagem. Goodyear et al. (2004) argumenta que os planos obtidos em planejamento instrucional não consideram a complexidade da aprendizagem colaborativa devido à falta de dependência contextual e social. Consequentemente, a comunidade de ACSC tem adaptado as ideias de planejamento instrucional de modo que o objetivo principal é projetar roteiros colaborativos. Assim, a seguir apresentamos, a descrição e classificação de roteiros colaborativos, a representação computacional dos roteiros e o processo de planejamento instrucional usando padrões de roteiros.

\subsubsection{Roteiros colaborativos}

O grupo de pesquisas europeu CoSSICLE 2 descreve os roteiros colaborativos como: "roteiros de suporte computacional que facilitam processos sociais e cognitivos da aprendizagem colaborativa por meio da definição da forma como os estudantes interagem uns com outros." (Weinberger et al., 2005). Roteiros colaborativos são similares a roteiros de peça de teatro nas quais participantes atuam de acordo com as instruções prescritas neles (Kirschner et al. , 2004).

De acordo com o arcabouço desenvolvido por Kobbe et al. (2007), ilustrado na Figura 2.1, os componentes necessários para definir um roteiro colaborativo são:

(1) Participantes definidos como uma lista de estudantes e docentes.

(2) Atividades a serem efetuadas pelos participantes para atingir os objetivos educacionais.

(3) Papéis que podem ser assumidos pelos participantes durante as atividades. Os participantes podem assumir um ou mais papéis em um determinado momento.

(4) Recursos que podem ser usados pelos participantes nas atividades. Neste trabalho, os recursos são restritos unicamente a recursos instrucionais.

\footnotetext{
${ }^{2}$ Computer-Supported Scripting of Interaction in Collaborative Learning Environments http://cossicle.noe-kaleidoscope.org/
} 
(5) Grupos de participantes que são definidos geralmente na forma de estruturas hierárquicas que definem a formação de grupos grandes compostos de grupos menores.

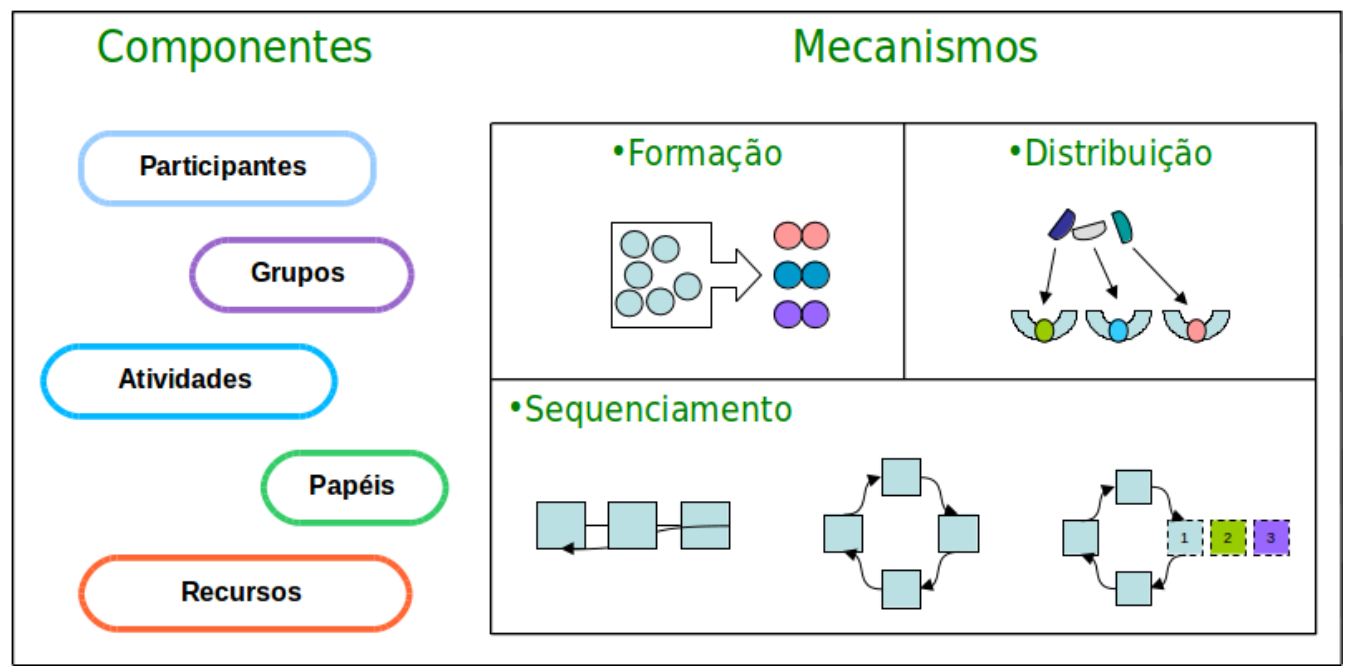

Figura 2.1: Ilustração gráfica do arcabouço desenvolvido por Kobbe et al. (2007)

No arcabouço desenvolvido por Kobbe et al. (2007), os mecanismos de colaboração utilizados para definir um roteiro são:

(1) Distribuição de tarefas - Consiste no mapeamento entre participantes e atividades, e no mapeamento entre recursos e participantes.

(2) Formação de grupos - Consiste em especificar a forma de agrupamento dos participantes.

(3) Sequenciamento - Consistente em definir a ordem de execução das atividades.

A Tabela 2.1 apresenta como exemplo a representação do roteiro colaborativo ArgueGraph para quatro estudantes com a definição dos componente e mecanismos em forma textual.

De acordo com a granularidade das atividades, os roteiros colaborativos são classificados em macrorroteiros e microrroteiros. Enquanto, as atividades dos macrorroteiros descrevem o modelo pedagógico do processo de ensino-aprendizagem, as atividades dos microrroteiros descrevem o modelo dialógico. 


\begin{tabular}{|c|c|}
\hline Participantes: & Quatro estudantes com identificadores $11,12,13$ e 14. \\
\hline Atividades: & $\begin{array}{l}\text { 1. Justificar opiniões e construir argumentos. } \\
\text { 2. Comparar, avaliar e elaborar resultados. } \\
\text { 3. Negociar e construir argumentos. } \\
\text { 4. Explicar e justificar opiniões. } \\
\text { 5. Resumir e construir conexões de argumentos. }\end{array}$ \\
\hline Papéis: & Nenhum. \\
\hline Recursos: & $\begin{array}{l}\text { Um questionário para cada participante e uma cópia adicional por grupo pequeno. } \\
\text { Uma folha argumentativa por item de questionário. }\end{array}$ \\
\hline Grupos: & Sala: (11, l2, 13 e 14); e Pares: (11 12), (11 13), ... e (13 14). \\
\hline Distribuição de tarefas: & $\begin{array}{l}\text { Na fase de inspeção, todos os participantes da sala recebem uma cópia do questionário. } \\
\text { Nas fases de discussão e elaboração, cada par recebe uma cópia do questionário. Na } \\
\text { fase de reflexão, cada participante recebe uma folha de argumentação. }\end{array}$ \\
\hline Formação de grupos: & $\begin{array}{l}\mathrm{Na} \text { fase de inspeção, todos os participantes formam parte do grupo sala. Na fase } \\
\text { de discussão e elaboração, os participantes são agrupados em pares formados por } \\
\text { estudantes que têm máxima divergência de opinião entre as respostas. }\end{array}$ \\
\hline Sequenciamento: & $\begin{array}{l}\text { - Na fase de inspeção: } \\
\text { - } \text { Todos os participantes na aula, de forma individual, preenchem a pri- } \\
\text { meira cópia do questionário. } \\
\text { - } \text { O tutor apresenta os resultados obtidos do questionário para os partici- } \\
\text { pantes. } \\
\text { - } \text { Os participantes na aula discutem conjuntamente os resultados do ques- } \\
\text { tionário. } \\
\text { - Na fase de discussão: } \\
\text { - Grupos de pares são formados de acordo as respostas do questionário. } \\
\text { - } \text { Cada par preenche a segunda cópia do questionário, ou seja, negociam } \\
\quad \text { em uma escolha única o argumento comum. } \\
\text { - Fase de elaboração: } \\
\text { - O tutor coleta todos os questionários. } \\
\text { - } \text { Para cada par, o tutor efetua pergunta aos participantes para comentar } \\
\quad \text { seus argumentos e apresenta um conselho de como seus argumentos são } \\
\text { relacionados com teorias e conceitos. } \\
\text { - } \text { Por cada item do questionário, o tutor recompila todas as escolhas e } \\
\text { argumentos de cada par numa folha de argumentos. } \\
\text { - Na fase de reflexão: }\end{array}$ \\
\hline
\end{tabular}

Tabela 2.1: Exemplo de roteiro colaborativo ArgueGraph (Kobbe, 2005) 


\section{Macrorroteiros colaborativos}

Os macrorroteiros colaborativos estruturam a colaboração entre os participantes mediante a descrição do modelo pedagógico a ser utilizado durante o processo de ensino-aprendizagem (Dillenbourg, 2002). Assim, as atividades descrevem o modelo pedagógico como a estruturação do conteúdo instrucional a ser ensinado que visa produzir interações desejadas entre os participantes.

Definição 2.1. O mecanismo de sequenciamento é formalizado como uma estrutura linear de fases definida como a lista

$$
S=\left[F_{1}, F_{2}, \ldots, F_{n}\right]
$$

na qual cada fase $F_{i}$ especifica pontos de sincronização para o início das atividades a serem efetuadas pelos participantes. Cada uma das fases $F_{i}=\left\{e_{1}, e_{2}, \ldots, e_{m}\right\}$ é representada formalmente como n-uplas $e_{i}=(T, g, m$, time $)$ denominadas atividades de grupo que definem:

- uma lista de tarefas $T=\left[\right.$ taref $_{1}$, taref $_{2}, \ldots$, taref $\left.a_{k}\right]$, em que cada tarefa tarefa $a_{i}$ denominada sessão de aprendizagem é uma n-upla (Entrada, atividade, Saída) $\in T$, onde:

- Entrada é um conjunto de recursos instrucionais a ser empregado pelos estudantes durante a execução da atividade;

- atividade é um identificador da atividade; e

- Saída é um conjunto de recursos instrucionais a serem criados pelos estudantes durante a execução da atividade.

- um grupo g definido no componente grupos;

- um modo opcional $m$ que define as características de: tipo de mídia (textual, gráfica, áudio ou vídeo); tipo de comunicação (síncrono ou assíncrono); e modelo de comunicação (um para um, um para muitos ou muitos para muitos); e

- um aspeto temporal opcional time que define a duração ou prazo de término de cada fase.

Exemplo 2.1. O mecanismo de sequenciamento do macrorroteiro Jigsaw (Leo et al., 2004) da Figura 2.2 é formalizado como a lista $S=\left[F_{1}, F_{2}, F_{3}\right]$, na qual: $F_{1}$ é a fase individual, $F_{2}$ é a fase de especialização e $F_{3}$ é a fase jigsaw. No exemplo, a fase $F_{2}$ é definida como:

$$
F_{2}=\left\{\left([\text { tarefa } a], g_{e_{1}}\right),\left(\left[\text { taref }_{b}\right], g_{e_{2}}, m, \text { temp }\right)\right\}, \text { tal que: }
$$


- taref $_{a}=\left(\left\{r_{i_{1}}, r_{i_{2}}\right\}, a_{1},\left\{r_{e_{1}}\right\}\right)$ representa uma sessão de aprendizagem denominada trabalho no tópico 1, no qual:

- os recursos de entrada $r_{i_{1}}$ e $r_{i_{2}}$ são resumo elaborado pelo especialista 1 no tópico 1 e resumo elaborado pelo especialista 2 no tópico1;

- a atividade $a_{1}$ a ser efetuada é elaborar um resumo do tópico 1; e

- o recurso de saída $r_{e_{1}}$ é resumo do tópico 1.

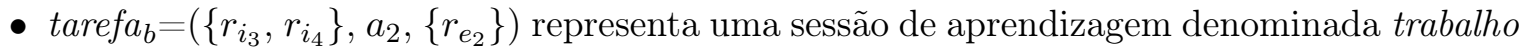
no tópico 2, na qual:

- os recursos de entrada $r_{i_{3}}$ e $r_{i_{4}}$ são resumo elaborado pelo especialista 1 no tópico $2 \mathrm{e}$ resumo elaborado pelo especialista 2 no tópico 2 ;

- a atividade $a_{2}$ a ser efetuada é elaborar um resumo do tópico 2; e

- o recurso $r_{e_{2}}$ de saída é resumo do tópico 2.

- $g_{e_{1}}$ representa o grupo de especialistas no tópico 1 e $g_{e_{2}}$ representa o grupo de especialistas no tópico 2.

- $m=\{$ textual, assíncrono $\}$ representa a necessidade de ferramentas assíncronas de suporte a mídias textuais durante a execução da fase $F_{3}$.

- $t e m p=\left\{\right.$ "12/02/2011" $\vee$ " $r_{e_{2}}$ " $\}$ representa o prazo da fase $F_{3}$ na data "12/02/2011" ou envio do recurso $r_{e_{2}}$.

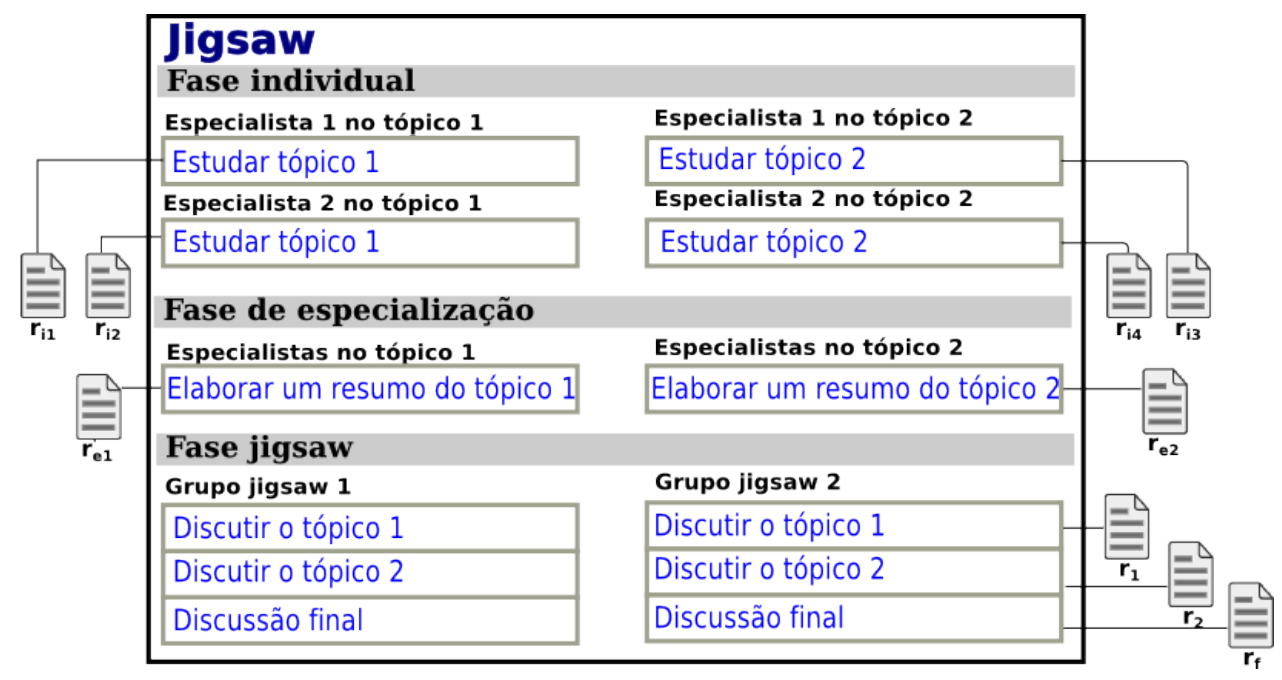

Figura 2.2: Exemplo de macrorroteiro Jigsaw

Definição 2.2. A distribuição de tarefas é representada por cada par $(T, g)$ definido no conjunto de n-uplas $e_{i}=(T, g, m$, time $)$ de cada fase $F_{j}$; na qual a lista de sessões $T=\left[\right.$ taref $a_{1}, \ldots$, taref $\left._{k}\right]$ é efetuada de forma linear pelo grupo de participantes $g$ durante a execução da fase $F_{j}$. 
Exemplo 2.2. No exemplo de macrorroteiro Jigsaw mostrado na Figura 2.2, a distribuição de tarefas na fase "fase jigsaw" $F_{3}$ é definida pelas n-uplas $e_{1}=\left(T_{j_{1}}, g_{j_{1}}\right)$ e $e_{2}=\left(T_{j_{2}}, g_{j_{2}}\right)$, onde a n-upla $e_{1}=\left(T_{j_{1}}, g_{j_{1}}\right)$ representa a distribuição da tarefa $T_{j_{1}}$ para o grupo $g_{j_{1}}$. A tarefa $T_{j_{1}}$ é definida como a lista de sessões:

$$
\begin{aligned}
T_{j_{1}}= & {\left[\left(\{\}, \text { discutir o tópico } 1,\left\{r_{1}\right\}\right),\right.} \\
& \left(\{\}, \text { discutir o tópico } 2,\left\{r_{2}\right\}\right), \\
& \left.\left(\left\{r_{1}, r_{2}\right\}, \text { discussão final, }\left\{r_{f}\right\}\right)\right]
\end{aligned}
$$

\section{Microrroteiros colaborativos}

Os microrroteiros colaborativos estruturam a colaboração entre os participantes mediante a descrição do modelo dialógico a ser utilizado durante o processo de ensino-aprendizagem (Dillenbourg e Jermann, 2007). Assim, as atividades descrevem o modelo dialógico como interações que definem a transmissão e recepção de mensagens utilizados pelos participantes.

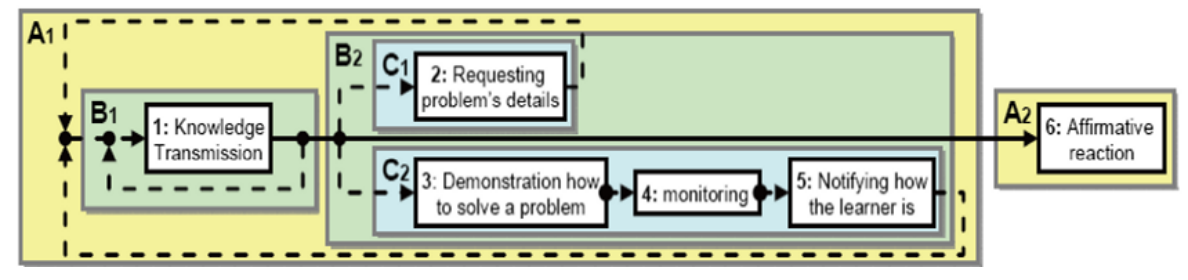

Figura 2.3: Exemplo de fluxo de interação Peer-Tutoring (Isotani, 2009)

O mecanismo de sequenciamento de um microrroteiro é representado como um fluxo de interações necessárias e complementares. Na Figura 2.3 apresentamos a representação do mecanismo de sequenciamento do roteiro peer-tutoring, no qual as interações necessárias são ilustradas com linhas sólidas, enquanto interações complementares são ilustradas com linhas tracejadas.

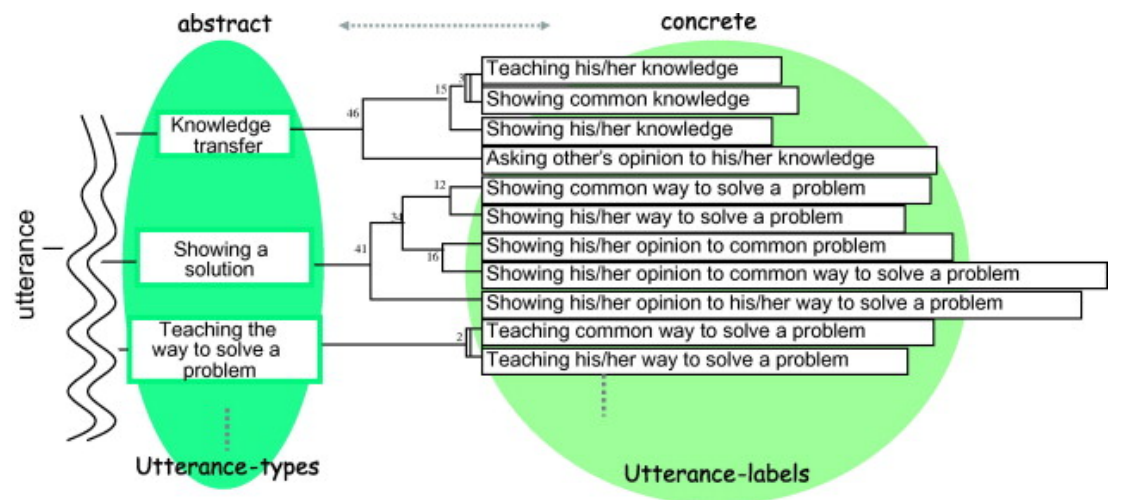

Figura 2.4: Exemplo de relação entre diálogo-rótulo e diálogo-tipo (Inaba et al., 2003b)

As interações são formalizadas mediante um vocabulário de diálogos-tipo que representa o agrupamento de diálogos específicos denominados diálogos-rótulo (Inaba et al., 2003b). Um exemplo do agrupamento dos diálogos-rótulo em diálogos-tipo é apresentado na Figura 2.4, na qual são definidas os diálogos-tipo "transmissão de conhecimento" (knowledge transmission), "mostrar uma solução" (showing a solution) e "ensinar como resolver um problema" (teaching the 
way to solve a problem). Assim, usando a relação de reciprocidade dos diálogo-rótulo identificada por Hayashi et al. (2006), pela qual cada diálogo-tipo apresenta dois diálogos-rótulo recíprocos, uma interação é representada como um evento $I L$.

Um evento IL mostrado na Figura 2.5 é definida como a composição de um evento de aprendizagem e um evento instrucional, nos quais são definidas ações como diálogos-rótulo a serem efetuados pelo participante para atingir objetivos educacionais desempenhando um papel de instrutor ou aprendiz (Isotani et al., 2010a).

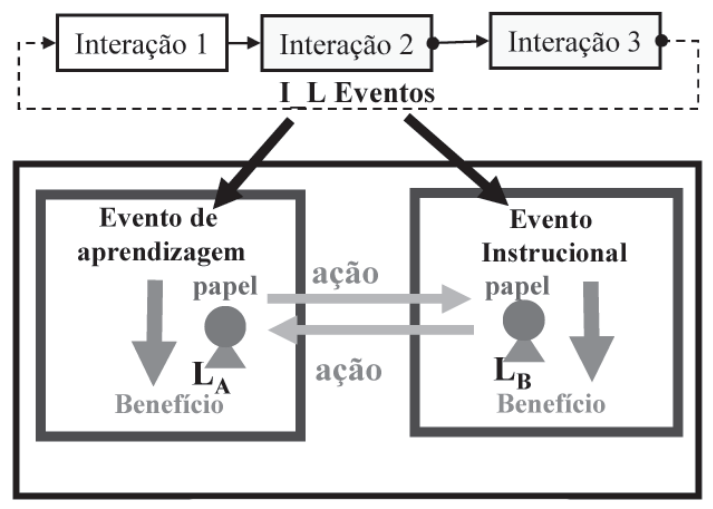

Figura 2.5: Elementos de um evento IL (Isotani e Mizoguchi, 2007)

A Figura 2.6 apresenta a representação do microrroteiro peer-tutoring como eventos IL, no qual o evento IL "notificar andamento do estudante" (notifying how the learner is) é representado como um evento instrucional com o diálogo-rótulo "dar-infomação" (giving information) e um evento de aprendizagem com o diálogo-rótulo "receber informação" (receiving information).

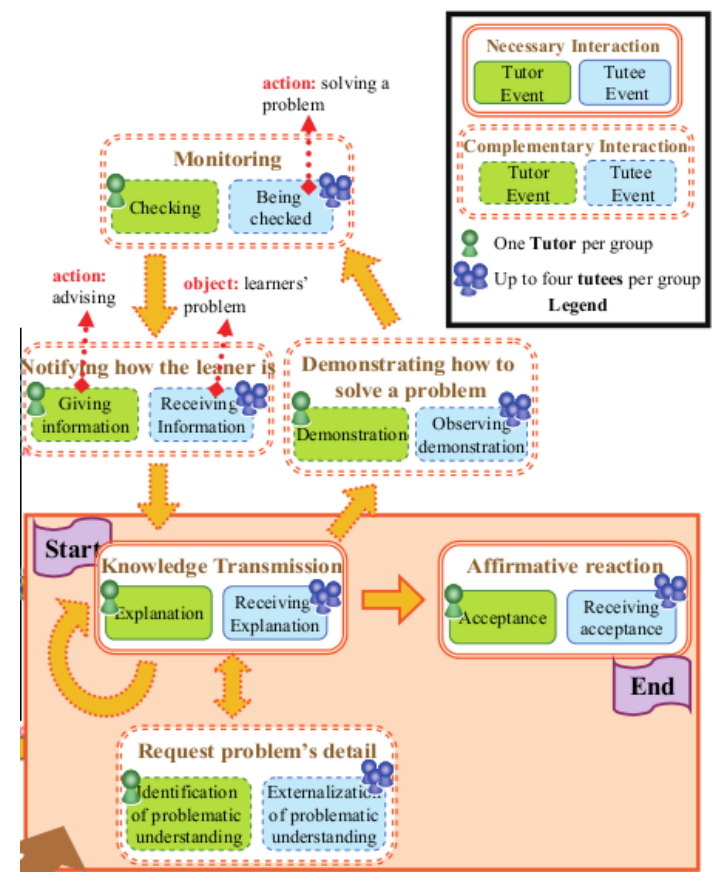

Figura 2.6: Representação do microrroteiro peer-tutoring como eventos IL (Isotani, 2009) 


\subsubsection{Representação computacional de roteiros colaborativos}

Com o propósito de possibilitar o reúso e interoperabilidade de roteiros colaborativos durante o processo de planejamento instrucional, a linguagem de modelagem pedagógica IMS-LD (detalhada no Apêndice C) é empregada para efetuar a representação computacional de roteiros. A linguagem IMS-LD descreve a informação de planejamento instrucional mediante o sequenciamento das atividades (como resolução de problemas, pesquisa, discussão e avaliação) a serem efetuadas pelos participantes e a estruturação dos recursos instrucionais integrados as atividades.

De acordo com Leo et al. (2004) e Hernández-leo et al. (2005) a representação computacional de roteiros consiste na representação dos mecanismos de colaboração do roteiro como elementos da especificação IMS-LD detalhados a seguir.

\section{Mecanismo de formação de grupos}

A formação de grupos e subgrupos é definida como elementos <learner >. A Figura 2.7, mostra a representação de dois grupos temáticos de discussão de câncer (g-thematic-cancer, linhas 2-13) e AIDS (g-thematic-aids, linhas 14-16). O grupo de discussão de câncer é dividido em dois subgrupos, um referido ao câncer de mama (g-breast-cancer, linhas 4-6) e outro referido ao câncer de pulmão (g-lung-cancer, linhas 7-12).

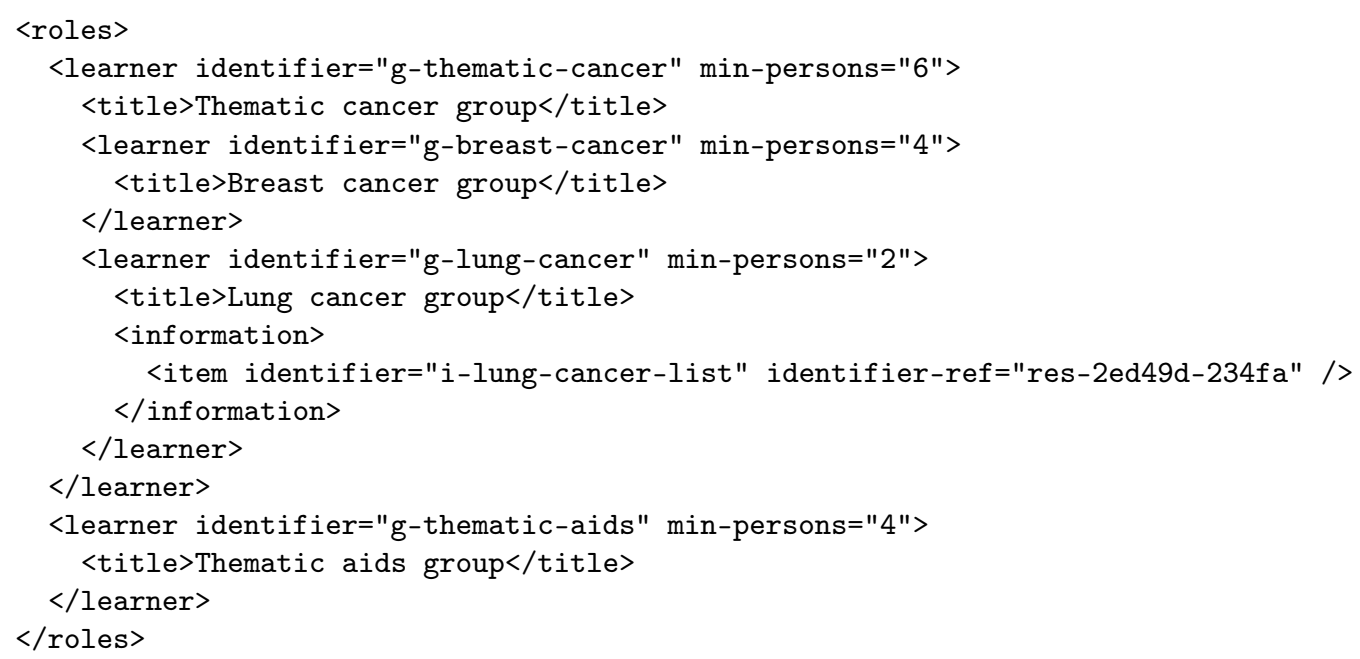

Figura 2.7: Exemplo da representação de formação de grupos e subgrupos

Para representar a formação de grupos, a especificação IMS-LD apresenta limitações devido à falta de elementos que possibilitem definir características e condições necessárias dos participantes. No entanto, as limitações são mitigadas: (1) mediante a inclusão de atributos min-persons e max-persons que definem o número mínimo e máximo de participantes que podem ser associados ao papel; e (2) mediante a inclusão de recurso instrucional que efetua a descrição dos participantes que serão atribuídos a cada grupo. Na Figura 2.7, o subgrupo de discussão de câncer de pulmão apresenta um número mínimo de dois participantes e utiliza o recurso instrucional res-2ed49d-234fa para apresentar a lista de participantes associada ao grupo (linha10). 


\section{Mecanismo de distribuição de tarefas}

O mecanismo de distribuição de tarefas é representado mediante elementos $<$ role-part $>$, no qual o grupo de estudantes é representado mediante o elemento < role-ref $>$ e a lista de tarefas é representada mediante elementos $<$ learning-activity-structure $>$ e $<$ activity-structure-ref $>$.

A Figura 2.8 mostra a representação da distribuição de tarefas definidas no ato de discussão (linhas 13-26), na qual: o grupo de discussão de câncer é associado à atividade de aprendizagem discussão livre de câncer (la-free-discussion-cancer, linhas 16-17); e o grupo de discussão de AIDS é associado às tarefas discussão livre de AIDS (as-free-discussion-aids, linhas 20-21).

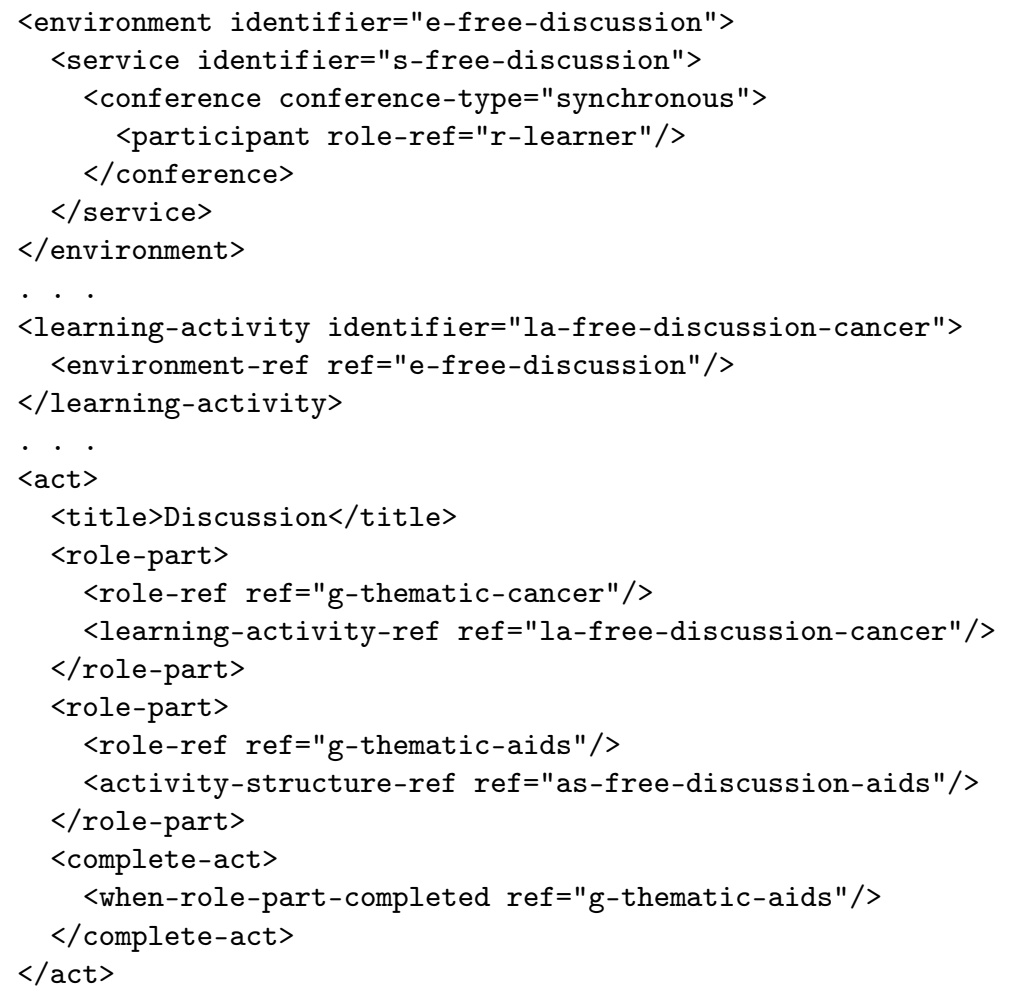

Figura 2.8: Exemplo de representação do mecanismo de distribuição de tarefas

Os atributos conference-type (tipo de conferência) e type (tipo de mídia) nos elementos $<$ conference $>$ e $<$ learning-object $>$ são utilizados para representar o tipo de comunicação e tipo de mídia da distribuição de tarefas nos macrorroteiros. Na Figura 2.8, o tipo de comunicação da distribuição de tarefas para o grupo de discussão de câncer é síncrona (linha 3).

$\mathrm{O}$ aspeto temporal na distribuição de tarefas é definido no elemento < complete-act $>$ para definir a finalização das atividades. Na Figura 2.8, o aspeto temporal da distribuição de tarefas é a finalização das atividades do grupo de discussão AIDS (linhas 23-25). 


\section{Mecanismo de sequenciamento}

O mecanismo de sequenciamento é representado no elemento $<$ play $>$ como elementos $<$ act $>$ e elementos $<$ activity-structure $>$ definidos no elemento < activity-structure $>$. Os elementos $<$ act $>$ definem o mecanismo de sequenciamento como atividades ou estruturas de atividades a serem efetuadas pelos participantes em forma sequencial. Nas estruturas de atividades $<$ activitystructure $>$ o mecanismo de sequenciamento é definido como uma estrutura de tipo sequencial ou de tipo seleção, o tipo de estrutura é definido no atributo activity-structure mediante valores sequence (sequencial) e selection (seleção).

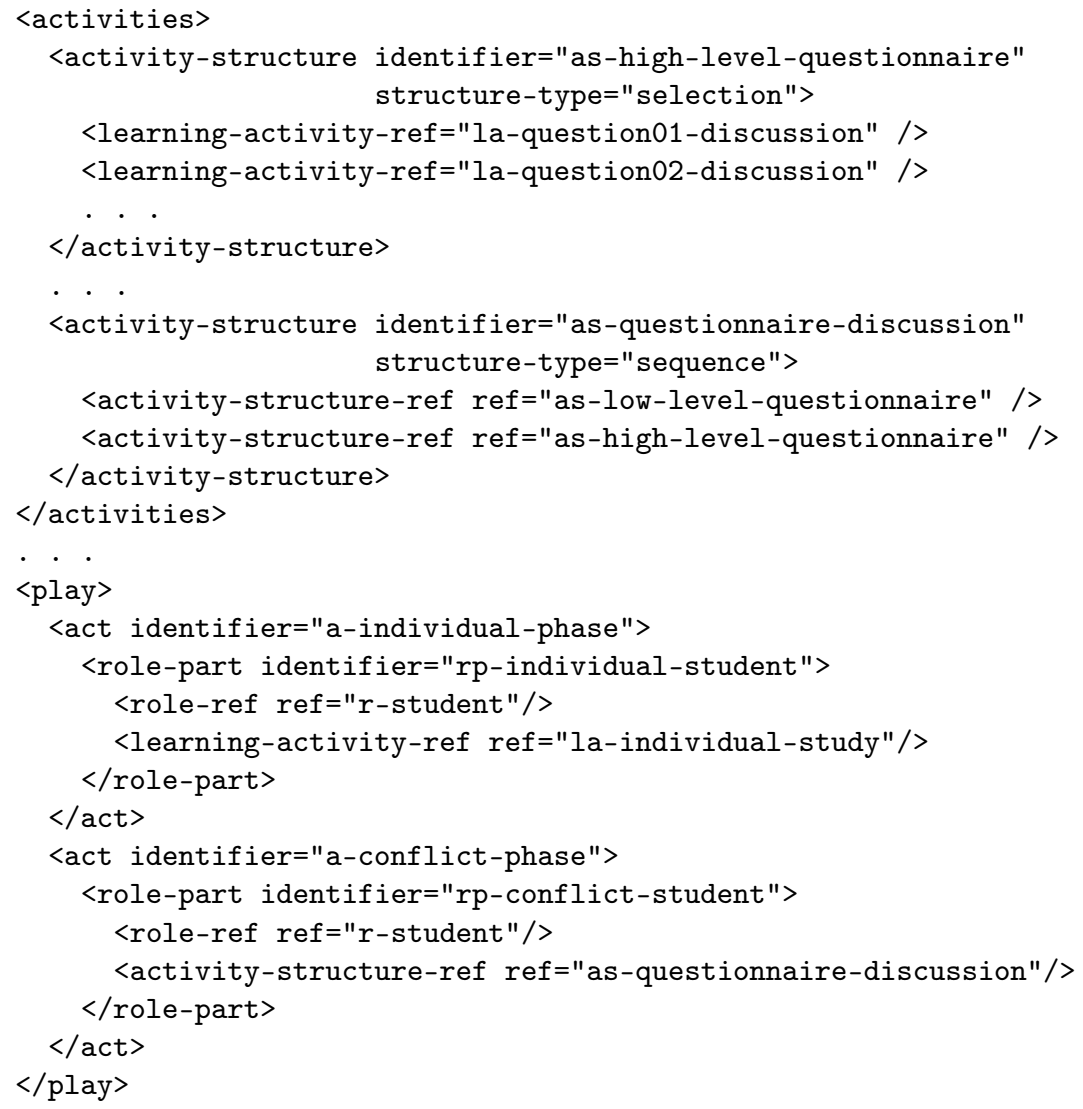

Figura 2.9: Exemplo da representação de um mecanismo de sequenciamento

A Figura 2.9 mostra um exemplo de representação do mecanismo de sequenciamento de um roteiro, no que o grupo de estudantes r-student (linha 16-29) efetuam as atividades estudo individual la-individual-study (linha 20) e a estrutura de atividades discussão de questionários as-questionnaire-discussion (linha 26). A estrutura de atividades discussão de questionários (linhas 9-13) é definida como uma sequência linear de uma estrutura de atividades discussão de questionários de baixo nível as-low-level-questionnaire (linha 11), e uma estrutura de atividades discussão de questionários de alto nível as-high-level-questionnaire (linha 12) 


\subsubsection{Planejamento instrucional usando padrões de roteiros}

"Um padrão descreve a solução de um problema recorrente, de forma que possa ser reutilizado e adaptado muitas vezes em diferentes situações ..." (Alexander et al., 1977). Padrões de roteiros colaborativos são utilizados para descrever roteiros colaborativos que fornecem solução às diferentes situações recorrentes de aprendizagem colaborativa.

\section{Padrões de roteiros colaborativos}

Hernández-Leo et al. (2008) classifica os padrões de roteiros colaborativos mediante a estrutura mostrada na Figura 2.10, na qual são definidos três níveis de agregação e um nível de papéis e mecanismos comuns. Os três níveis de agregação representados por planos horizontais são: um nível de fluxo de aprendizagem colaborativa que agrupa padrões de macrorroteiros; um nível de atividade que agrupa padrões de microrroteiros; e um nivel de recursos que agrupa padrões de sequenciamento de recursos. O nível de papéis e mecanismos comuns representado por um plano perpendicular agrupa padrões de formação de grupos, padrões de atribuição de papéis e padrões de suporte à execução de roteiros.

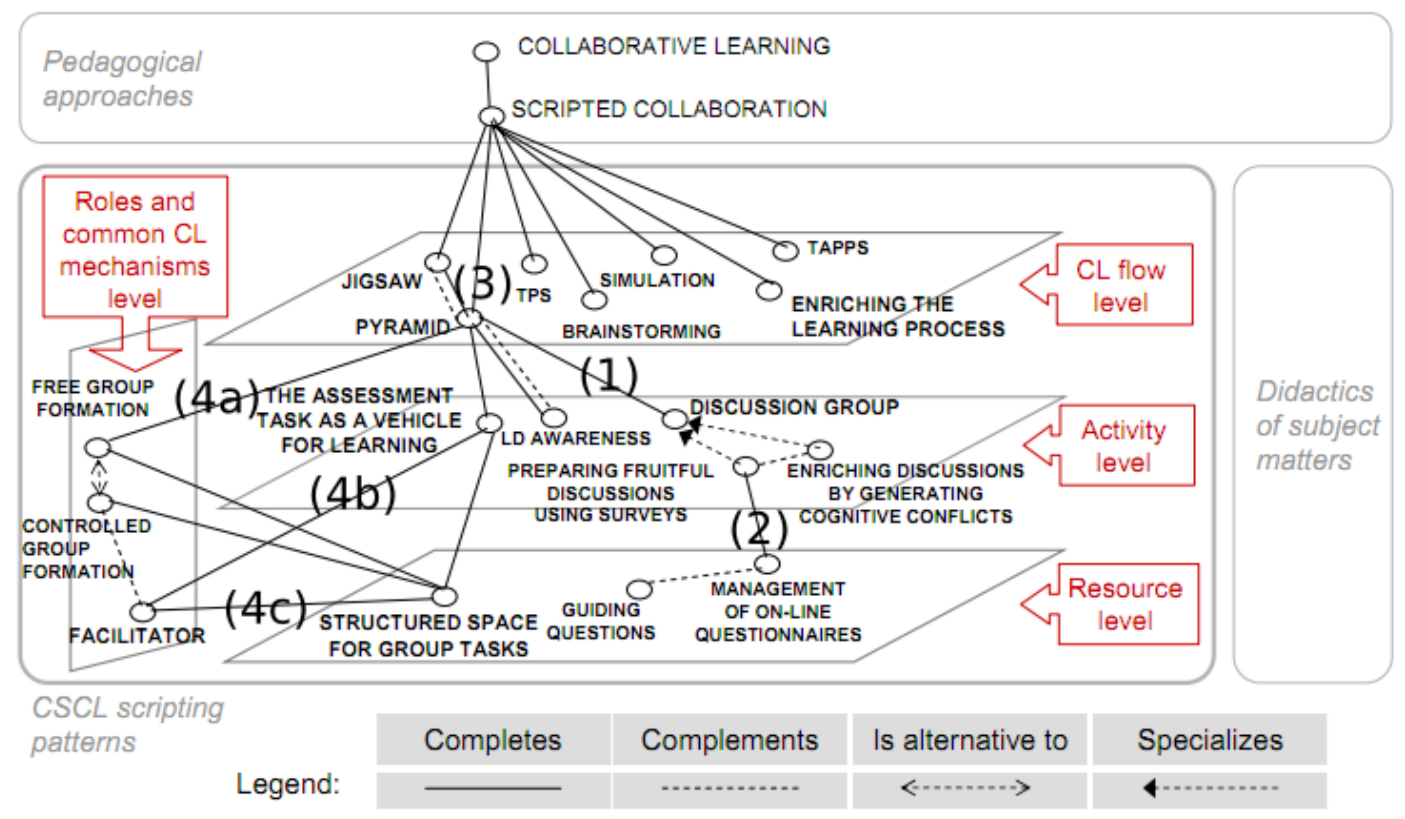

Figura 2.10: Relações entre padrões de roteiros colaborativos (Leo et al., 2007)

De acordo com Leo et al. (2007), os padrões de roteiros apresentam as relações de:

Aperfeiçoar. Representam relações de associação que definem: (1) o detalhamento das atividades de um padrão do nível de fluxo de aprendizagem colaborativa usando padrões do nível de atividade; (2) o detalhamento dos diálogos de um padrão do nível de atividade usando padrões do nível de recursos; (3) o detalhamento das fases de um padrão do nível de fluxo de aprendizagem colaborativa usando outro padrão do nível de fluxo de aprendizagem colaborativa; 
(4a) o detalhamento das atividades de um padrão do nível de fluxo de aprendizagem colaborativa usando padrões do nível de papéis e mecanismos comuns; (4b) o detalhamento dos diálogos de um padrão do nível de atividades usando padrões do nível de papéis e mecanismos comuns; e (4c) o detalhamento das sequências de recursos instrucionais usando padrões do nível de papéis e mecanismos comuns de aprendizagem.

Complementar. Representam relações de associação que definem adições de atividades, diálogos ou sequências de recursos no mecanismo de colaboração dos padrões.

Alternativa. Representam relações de associação que definem soluções alternativas para atingir o mesmo conjunto de objetivos educacionais.

Especialização. Representam relações de associação entre padrões do mesmo nível mediante a qual se definem variações específicas, isto é definir padrões mais dependentes do domínio a ser ensinado.

Exemplos de padrões de roteiros colaborativos no nível de fluxo de aprendizagem são "jigsaw" e "pyramid"; no nível de atividades são "discussion group" e "peer tutoring"; no nível de recursos são "guiding questions" e "structure space for group task"; e no nível de papéis e mecanismos comuns são "free group formation" e "controlled group formation".

\section{Etapas do processo de planejamento instrucional usando padrões}

Dillenbourg e Jermann (2007); Hernández-Leo et al. (2009) e Villasclaras-Fernández et al. (2009) definem o processo de planejamento instrucional usando padrões de roteiros colaborativos como uma abordagem intermediária entre desenvolvimento top-down e botton-up. O processo de desenvolvimento top-down efetua a seleção e adaptação dos componentes e mecanismos de colaboração de um padrão de roteiros até que todos os elementos sejam compostos de recursos instrucionais. O processo de desenvolvimento botton-up efetuada adaptações dos roteiros colaborativos em função de necessidades que surgem durante sua execução.

As quatro etapas do processo de planejamento instrucional exemplificado na Figura 2.11 mediante o uso do padrão ArgueScript são:

(a) Edição dos roteiros. Consiste na seleção e adaptação de padrões de roteiros. A adaptação de padrões é feita mediante definições dos mecanismos de colaboração. Finalizada a etapa, os roteiros obtidos são nomeados classes de roteiros (script classe), um tipo de roteiro que apresenta solução a um conjunto de objetivos educacionais independente do domínio a ser ensinado.

(b) Instanciação dos roteiros. Consiste na seleção e sequenciamento dos recursos instrucionais a serem utilizados no roteiro. A organização dos recursos é efetuada mediante a avaliação dos mecanismos de colaboração da classe de roteiro, objetivos educacionais e características individuais dos participantes. Os roteiros obtidos na etapa são nomeados instâncias de roteiros (script instance). 


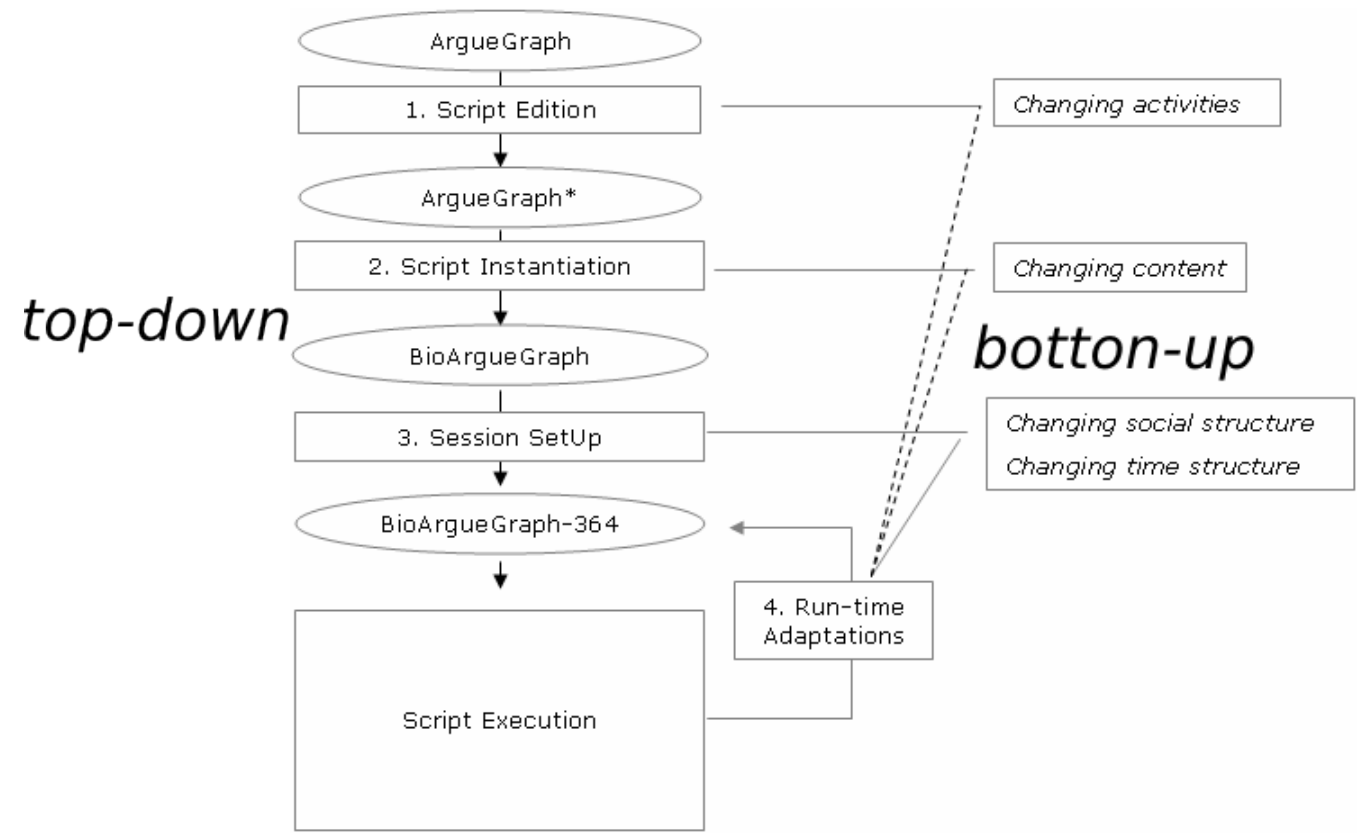

Figura 2.11: Exemplo das etapas de planejamento instrucional usando o padrão ArgueScript

As instâncias de roteiros são empacotadas para sua execução em uma unidade de aprendizagem, na qual são incluídos os recursos necessários para sua execução em um AVA.

(c) Configuração da unidade de aprendizagem. Consiste na definição da estrutura social e temporal das instâncias de roteiros efetuada no ambiente virtual de aprendizagem empregado. A estrutura social é definida mediante a atribuição de papéis e grupos aos participantes, enquanto a estrutura temporal é definida mediante a especificação do aspeto temporal nas fases dos roteiros.

(d) Execução do roteiro. Consiste na execução sequencial das atividades e interações definidas no roteiro em um ambiente virtual de aprendizagem. Nesta etapa podem ser efetuadas adaptações em tempo de execução (run-time) para definir mudanças nas atividades, no conteúdo e na estrutura social e temporal dos roteiros.

\subsection{Sistemas tutores inteligentes}

Sistemas Tutores Inteligentes (STI) são programas de software que dão suporte às atividades de aprendizagem usando técnicas de inteligência artificial (Gamboa e Fred, 2001; Wenger , 1987). Esses sistemas ao longo dos anos tem desenvolvido arquiteturas e aplicações que automatizam o processo de planejamento instrucional mediante a manipulação automática das interações instrucionais que especificam o que deve ser feito para ensinar.

A seguir são apresentados o modelo de sistemas tutores inteligentes; a representação das tarefas e métodos instrucionais; e os tipos de métodos instrucionais. 


\subsubsection{Modelo clássico dos sistemas tutores inteligentes}

Nos sistemas de tutores inteligentes, usando as técnicas de planejamento em IA, se obtêm um plano de ações que definem o sequenciamento de recursos adaptado aos estudantes. Para realizar a tarefa, os STIs devem possuir conhecimento de vários aspetos do processo de ensinoaprendizagem como conhecimentos do domínio a ser ensinado, da informação do estudante, da pedagogia e da comunicação (Woolf, 2008).

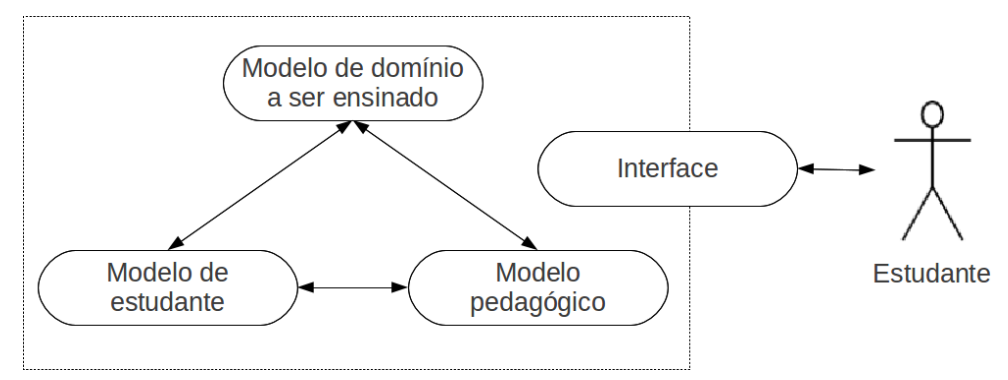

Figura 2.12: Modelo clássico de sistemas tutores inteligentes

O modelo clássico dos STIs (Kaplan e Rock, 1995) mostrado na Figura 2.12 é composto de um modelo de domínio a ser ensinado, um modelo de estudante, um modelo pedagógico e uma interface.

Modelo de domínio a ser ensinado. Contém a representação do conteúdo instrucional usando recursos instrucionais (atividades, exercícios, exemplos etc.) a serem utilizados durante o processo de ensino-aprendizagem.

Modelo de estudante. Contém a representação de características dos estudantes, abrangendo informação do conhecimento do estudante sobre o domínio a ser ensinado, histórico e preferências.

Modelo pedagógico. Contém a representação das estratégias pedagógicas a serem empregadas no processo de ensino-aprendizagem.

Interface. Contém a representação das interações instrucionais que definem a comunicação dos STIs com o estudante. Em planejamento instrucional, o modelo de interface consiste em um conjunto de funções fornecido pelo mecanismo de execução ou mecanismo de adaptação do AVA em que é executado o plano de interação (Brusilovsky e Vassileva, 2003).

\subsubsection{Tarefas e métodos instrucionais}

Segundo Van Marcke (1998) e Vassileva (1998), as estratégias pedagógicas são representadas no modelo pedagógico como um conjunto de tarefas e métodos instrucionais. As tarefas instrucionais são atividades de diferentes níveis de granularidade a serem efetuadas por um instrutor durante o processo de ensino-aprendizagem, enquanto os métodos instrucionais definem as várias maneiras como a tarefa deve ser efetuada. Consequentemente, a tarefa descreve um objetivo pedagógico e o método descreve como atingir esse objetivo. 
Os métodos e tarefas instrucionais podem ser empregados em diferentes contextos com diferentes elementos de domínio a ser ensinado e diferentes estudantes. No entanto, nem sempre as circunstancias do contexto são as apropriadas para aplicar um método, assim os métodos são associados a diferentes condições que definem a aplicabilidade de cada método. Dessa maneira, uma tarefa é associada a diferentes métodos, representando a característica de um projetista humano com diferentes alternativas para resolver a mesma tarefa.

A Figura 2.13 mostra a representação gráfica da tarefa instrucional "remediar-exercício" e dos métodos instrucionais associados à tarefa. A tarefa apresenta três métodos associados que decompõe a tarefa em: (1) "explicar" e "dar-solução"; (2) "explicar", "dar-subexercícios" e "repetir"; e (3) "dar-dica", "repetir" e verificar.
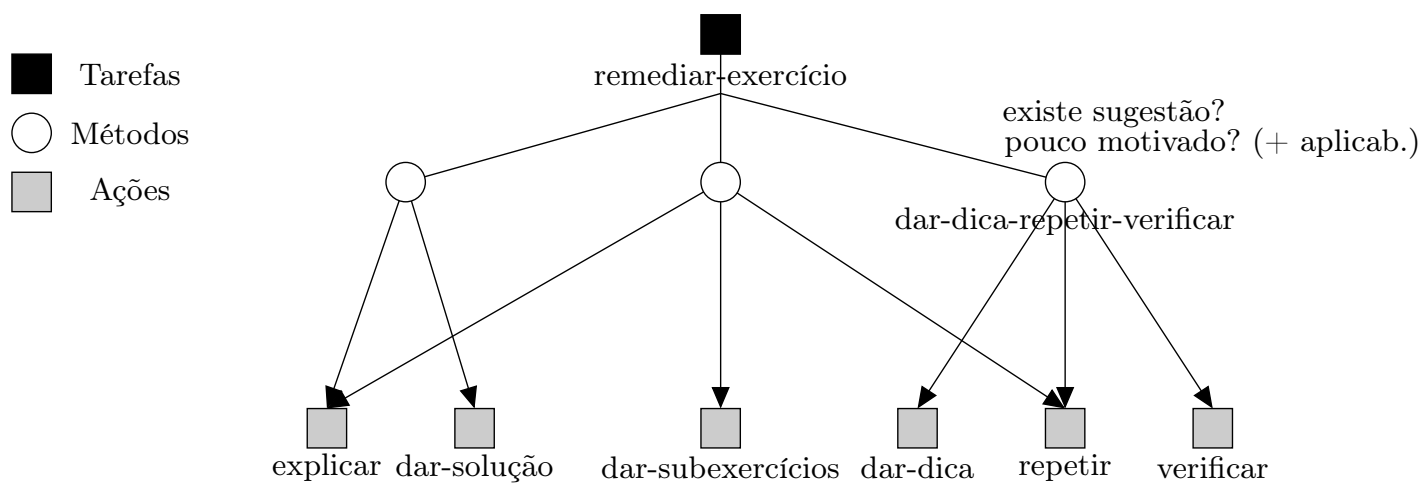

Figura 2.13: Tarefa instrucional remediar-exercício e métodos instrucionais associados

Van Marcke (1998) identifica três tipos de condições: absolutas, relativas e de preferência. As condições absolutas devem necessariamente ser satisfeitas para que o método possa ser aplicado. Por exemplo, o método "dar-dica-repetir-verificar" associado à tarefa remediar (Figura 2.13) apresenta como condição absoluta a existência de uma sugestão para o exercício. As condições relativas e de preferência são condições não necessárias que aumentam ou diminuem a aplicabilidade de um método quando são satisfeitas. Por exemplo, o método apresentado anteriormente tem uma condição relativa que incrementa a aplicabilidade, se o estudante está pouco motivado.

\subsubsection{Tipos de métodos instrucionais}

De acordo com Van Marcke (1998), os métodos de planejamento instrucional podem ser de quatro tipos: métodos de decomposição, métodos de decomposição repetitiva, métodos de decomposição distributiva e métodos de execução.

Os métodos de decomposição e métodos de decomposição repetitiva decompõem uma tarefa instrucional em um conjunto de subtarefas, o primeiro método efetua a decomposição da tarefa apenas uma vez, enquanto o segundo método efetua a decomposição da tarefa várias vezes. Como exemplo, o método de decomposição "esclarecer por analogia" decompõe a tarefa "esclarecer conceito" em duas subtarefas "apresentar analogia" e "demostrar analogia" (Figura 2.14a). Enquanto, o método de decomposição repetitiva "método completo" decompõe a tarefa "demonstrar analogia" nas tarefas "demonstrar relações" e "demonstrar analogia" (Figura 2.14b) 


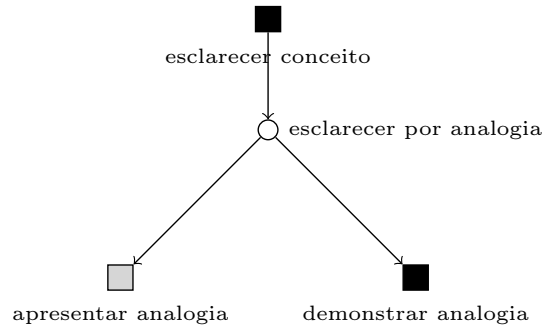

(a) método de decomposição

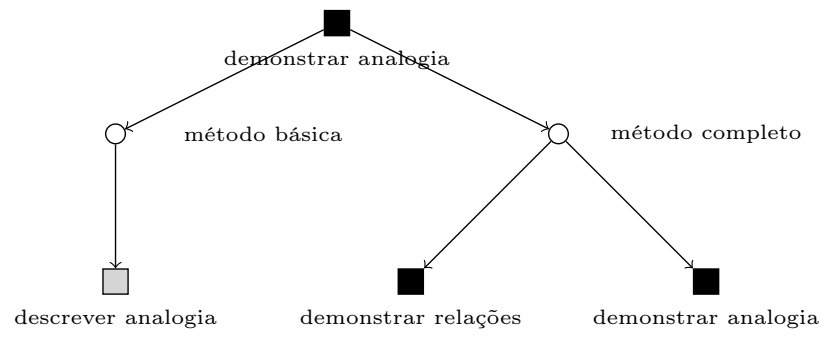

(b) método de decomposição repetitiva

Figura 2.14: Exemplos do métodos decomposição e decomposição repetitiva

Os métodos de decomposição distributiva de tarefas decompõe a tarefa instrucional em um número idêntico de subtarefas, na que cada uma opera sob um elemento de uma sequência. Por exemplo, o método "dar exercício para cada subproblema" mostrado na Figura 2.15 decompõe a tarefa "apresentar exercício" nas subtarefas "apresentar exercício" para cada subproblema $p_{i}$.

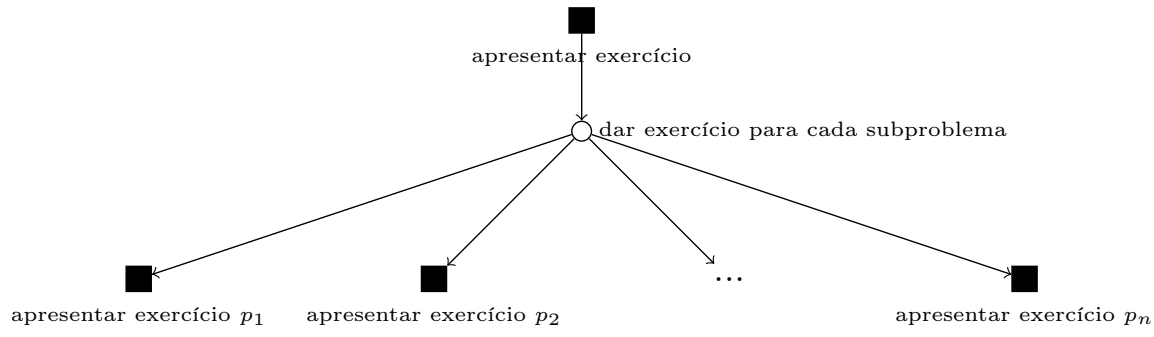

Figura 2.15: Exemplo do método de decomposição distributiva

Os métodos de execução são métodos que efetuam a decomposição de uma tarefa instrucional em ações instrucionais que não podem ser decompostas. A Figura 2.16 mostra o método de execução "dar-dica-repetir-verificar" que decompõe a tarefa "remediar-exercicio" nas ações "dardica", "repetir" e "verificar".

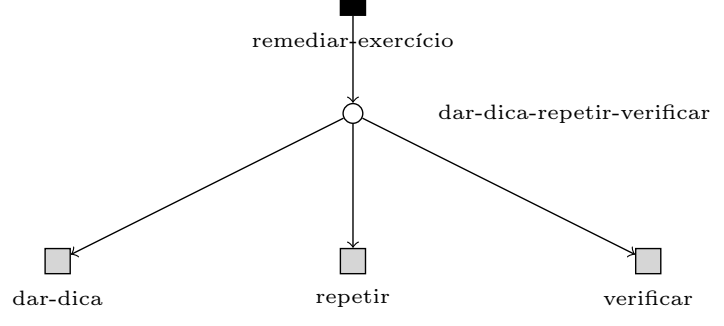

Figura 2.16: Exemplo do método de execução 


\subsection{Planejamento hierárquico}

Nesta seção, descrevemos o sistema de planejamento hierárquico JSHOP2ip utilizado na modelagem de planejamento instrucional em ACSC. Iniciamos com uma visão geral de planejamento em IA apresentando os conceitos básicos na Subseção 2.4.1. A Subseção 2.4.2 apresenta os conceitos do processo de planejamento hierárquico. Finalmente, na Subseção 2.4.3 apresentamos detalhes do sistema de planejamento hierárquico JSHOP2ip.

\subsubsection{Introdução ao planejamento em Inteligência Artificial}

Planejamento em IA consiste na geração automática de uma sequência de ações, chamada de plano, que ao ser executado por um agente a partir de um estado inicial alcança um estado meta no que os objetivos do agente são atingidos (Ghallab et al., 2004).

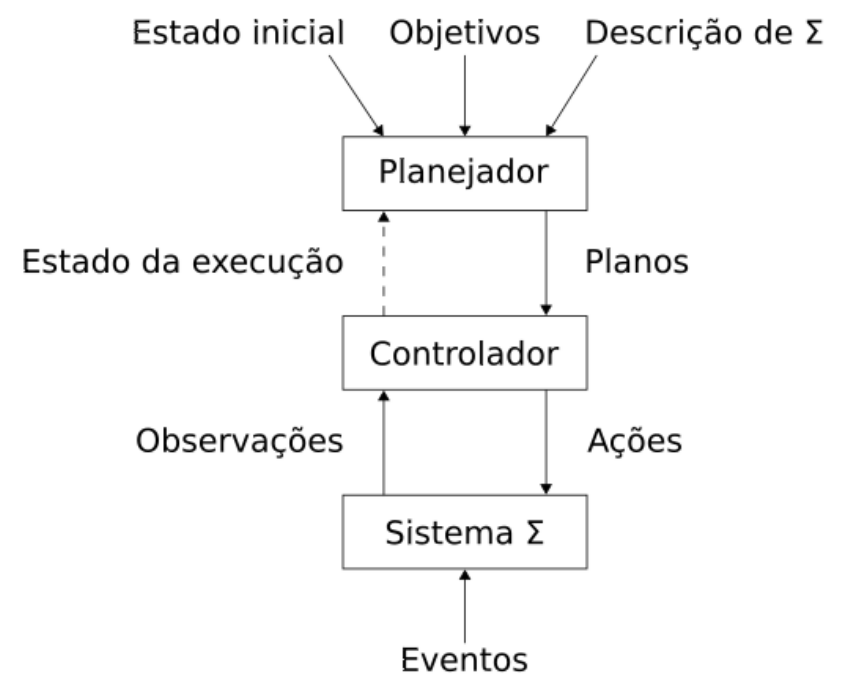

Figura 2.17: Modelo conceitual do problema de planejamento em IA

De forma geral, o modelo conceitual do problema de planejamento em IA, mostrado na Figura 2.17, consiste de:

- Um sistema de transição de estados $\Sigma$ que muda de acordo com sua função de transição de estados $\gamma$, reagindo aos eventos e ações que acontecem no sistema;

- Um algoritmo de planejamento, chamado de planejador, cujas entradas são a descrição do sistema $\Sigma$ denominada domínio de planejamento, a situação inicial chamada de estado inicial $s_{0}$ e um conjunto de objetivos $G$ que se deseja atingir; e

- Um controlador que executa as ações definidas em algum plano fornecido pelo planejador. O controlador recebe como entrada, o estado da execução de ações, denominado estado corrente $s$, obtido por meio de observações.

Se durante o processo de execução de algum plano, utiliza a informação fornecida pelo controlador acerca do estado da execução das ações, denominada monitoramento, o processo é chamado de planejamento online, caso contrário, é conhecido como planejamento offline. 


\section{Planejador dependente e independente de domínio}

Uma abordagem para resolver problemas de planejamento em IA é o desenvolvimento de planejadores dependentes de dominio, no que são desenvolvidas técnicas específicas para cada problema. O desenvolvimento desses planejadores oferece oportunidades para adequar o mecanismo de planejamento a cada domínio específico obtendo uma eficiência maior na resolução de problemas. Por exemplo, um sistema de planejamento para o jogo de xadrez, pode conter sequências prescritas de movimentos definidas por estratégias táticas, possibilitando obter planos para o jogo em segundos.

Os planejadores independentes de domínio separam o mecanismo de planejamento da descrição do sistema $\Sigma$. Para resolver um problema específico, a descrição do sistema $\Sigma$ é definida por meio de uma representação declarativa. Assim, um planejador independente de domínio utiliza como entrada as especificações do problema e do domínio de planejamento. Para melhorar o desempenho de um planejador independente de domínio, os sistemas de planejamento empregam em geral um compilador para obter planejadores dependentes de domínio, usando como entrada a descrição do domínio de planejamento.

\section{Linguagem de planejamento}

Em um sistema de planejamento independente de domínio, a linguagem de planejamento $L$ é usada para descrever o problema e domínio de planejamento. A linguagem $L$ define os tipos de problemas que podem ser resolvidos pelo planejador, assim, a linguagem deve ser suficientemente expressiva para representar uma variedade ampla de problemas, e ao mesmo tempo deve ser suficientemente restritiva para obter planejadores dependentes do domínio eficientes.

Nesta dissertação, a modelagem de planejamento instrucional em ACSC utiliza a representação clássica detalhada no Apêndice A, na qual é usada uma notação proveniente da linguagem de primeira ordem com símbolos de variáveis, predicados e constantes. Assim, um estado corrente $s$ é representado usando átomos lógicos, enquanto, as ações são representadas como operadores.

\section{Átomos lógicos e operadores de planejamento}

Um átomo lógico é uma fórmula que não pode ser dividida em subfórmulas, ou seja, uma fórmula sem conectivos que representa uma proposição. Em linguagem natural, um exemplo de átomo lógico é "Jaqueline é inteligente". A estrutura utilizada para representar um átomo lógico depende da linguagem $L$. No presente trabalho, um átomo lógico tem a forma: $\left(p t_{1} t_{2} \ldots t_{n}\right)$, onde $\mathrm{p}$ é um símbolo predicado e $\mathrm{t}_{i}$ são termos.

Os operadores de planejamento são generalizações das ações executadas pelo controlador. Um operador consiste de um conjunto de pré-condições e efeitos. As pré-condições são representadas por expressões lógicas que definem a aplicabilidade das ações no estado corrente $s$. Enquanto, os efeitos, representados mediante literais, definem o conjunto de átomos lógicos a serem adicionados e removidos do estado corrente $s$. 


\subsubsection{Processo de planejamento hierárquico}

Planejamento hierárquico, ou planejamento em rede hierárquica de tarefas (Hierarchical Task Network Planning, HTN), é uma técnica de planejamento em IA na qual o problema de planejamento é resolvido por meio da decomposição sucessiva de tarefas em subtarefas até atingir um nível de tarefas primitivas, chamado de plano, (Ghallab et al., 2004).

Um exemplo de decomposição utilizando métodos hierárquicos é mostrado na Figura 2.18, na qual a tarefa "transportar dois pacotes $p_{1}$ e $p_{2}$ " é decomposta nas subtarefas "transportar pacote $p_{1}$ " e "transportar pacote $p_{2}$ " que não apresentam relações de ordem parcial entre elas.

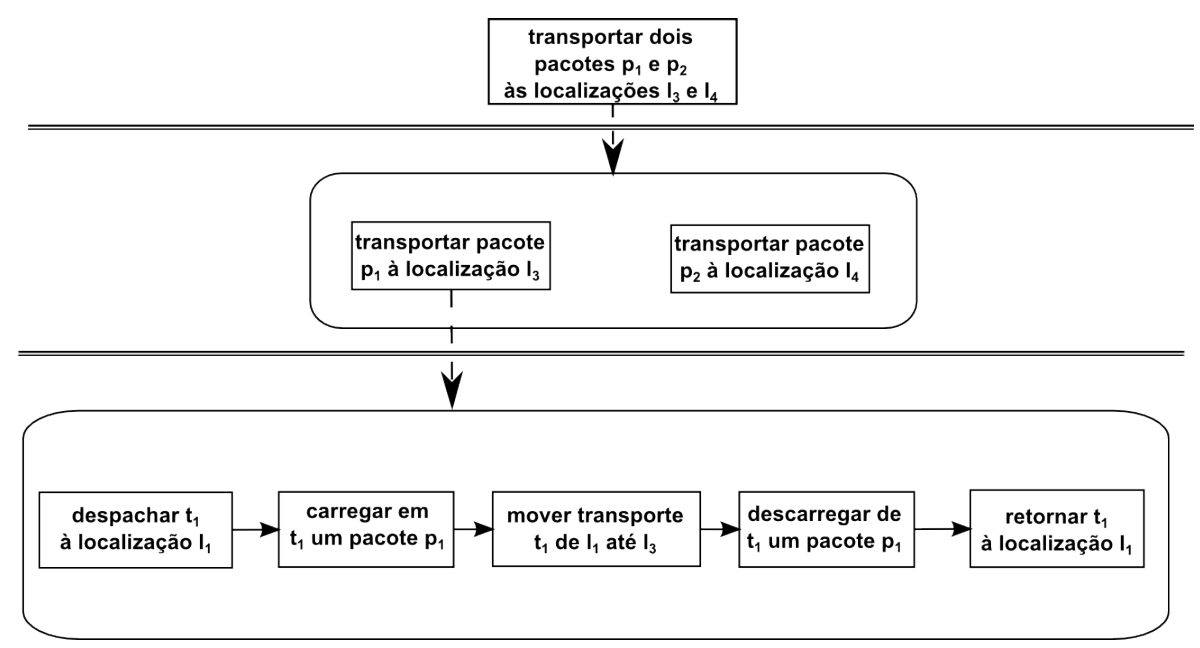

Figura 2.18: Exemplo de decomposição da tarefa transportar dois pacotes $p_{1}$ e $p_{2}$

As definições de planejamento hierárquico apresentadas a seguir correspondem ao caso restrito de planejamento com redes simples de tarefas (Simple Task Network Planning, STN). As redes simples de tarefas representam restrições na ordem de execução das tarefas, podendo ser tanto de ordem parcial quanto total, assemelhando-se a um plano parcialmente ordenado.

Definição 2.3. O problema de planejamento hierárquico é formalizado como a tripla $P=\left\langle s_{0}, w_{0}, D\right\rangle$, em que:

- $s_{0}$ é o estado inicial que utiliza átomos lógicos;

- $w_{0}$ é a rede de tarefas inicial; e

- $D$ é o domínio de planejamento.

Definição 2.4. Uma rede simples de tarefas $w$ é formalizada como um dígrafo acíclico $w=$ $(U, E)$, no qual: $U$ é um conjunto de nós tarefas nas quais cada nó $u \in U$ contém uma tarefa $t_{u}$; e $E$ é um conjunto de arestas que representam as restrições de ordem. Uma rede é totalmente instanciada se todas as tarefas $\left\{t_{u} \mid u \in U\right\}$ são instanciadas; caso contrário, a rede é parcialmente instanciada. Uma rede de tarefas é primitiva se todas as tarefas $\left\{t_{u} \mid u \in U\right\}$ são primitivas.

Exemplo 2.3. A rede de tarefas inicial $w_{0}=(U, E)$ da Figura 2.18 é definida por $U=\left\{u_{1}\right\}$ e $E=\{\}$, onde: $u_{1}=\left\{t_{1}\right\}$ é um nó tarefa que contém a tarefa $t_{1}$ "transportar dois pacotes $p_{1}$ e $p_{2}$ às localizações $l_{3}$ e $l_{4}$ ". 
Definição 2.5. Uma tarefa hierárquica é uma expressão da forma $\left(t r_{1} \ldots r_{k}\right)$, na qual: $t$ é um símbolo único de tarefa, e $r_{1}, \ldots, r_{k}$ são termos. Dessa maneira, distinguimos dois tipos de tarefas:

- uma tarefa primitiva na qual $t$ é um símbolo de operador; e

- uma tarefa composta na qual $t$ não é um símbolo de operador.

O domínio de planejamento $D=(O, M)$ consiste em um conjunto de operadores $O$ e métodos hierárquicos $M$ que representam explicitamente receitas de solução às tarefas aproveitando a natureza hierárquica inerente a muitos problemas.

Definição 2.6. Um método hierárquico é a n-upla: $m=\langle$ nome $(m), \operatorname{tarefa}(m), \operatorname{precond}(m)$, rede $(m)\rangle$, na qual:

- nome $(m)$ é o nome do método;

- tare $f a(m)$ é uma tarefa não primitiva;

- $\operatorname{precond}(m)$ é um conjunto de literais que especificam as pré-condições do método; e

- rede $(m)$ é uma rede de tarefas contendo as subtarefas na qual a tarefa é decomposta.

Na definição do método, nome $(m)$ é um nome único, tare $f a(m)$ é a tarefa na qual o método $m$ pode ser aplicado, precond $(m)$ especifica as condições que o estado corrente deve satisfazer para que o método $m$ seja aplicável e rede $(m)$ especifica a rede de subtarefas a serem realizadas para efetuar a tarefa tare $f a(m)$.

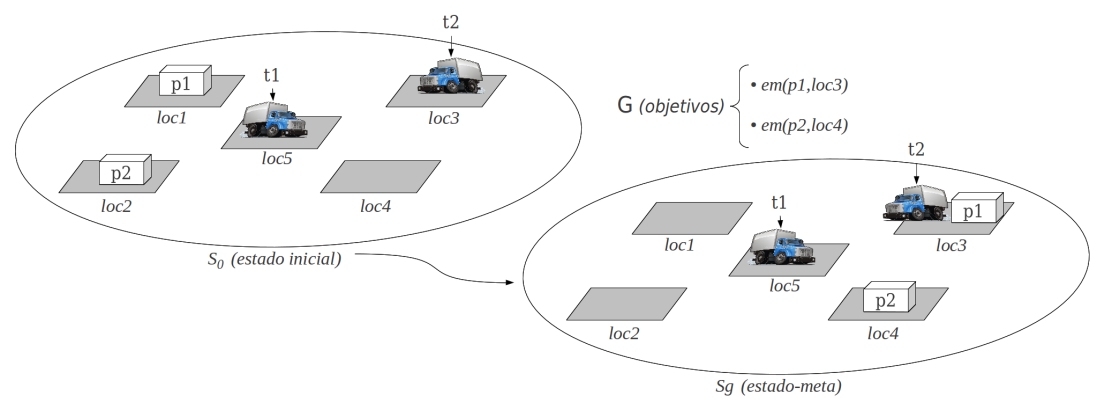

Figura 2.19: Problema de planejamento logístico de entrega de dois pacotes

Exemplo 2.4. No domínio de planejamento logístico de entrega de pacotes da Figura 2.19, identificamos os seguintes métodos hierárquicos:

(a) despachar o transporte $t$ à localização $l$

$\begin{array}{llll}\text { nome: } & \text { despachar-no-lugar } & \text { nome: } & \text { despachar-em-outro-lugar } \\ \text { tarefa: } & (\text { despachar } t l) & \text { tarefa: } & \text { (despachar } t l) \\ \text { precond: } & (\text { em } t l) & \text { precond: } & (\text { em } t x), x \neq l \\ \text { rede: } & u_{1}=(\operatorname{reservar} t) & \text { rede: } & u_{1}=(\text { reservar } t) \\ & E=\{\} & & u_{2}=(\operatorname{mover} t x l) \\ & & & E=\left\{\left(u_{1} \prec u_{2}\right)\right\}\end{array}$


(b) retornar o transporte $t$ à localização $l$

$\begin{array}{llll}\text { nome: } & \text { retornar-no-lugar } & \text { nome: } & \text { retornar-em-outro-lugar } \\ \text { tarefa: } & (\text { retornar } t l) & \text { tarefa: } & (\text { retornar } t l) \\ \text { precond: } & (\text { em } t l) & \text { precond: } & (\text { em } t x), x \neq l \\ \text { rede: } & u_{1}=(\text { disponibilizar } t) & \text { rede: } & u_{1}=(\text { mover } t x l) \\ & E=\{\} & & u_{2}=(\text { disponibilizar } t) \\ & & & E=\left\{\left(u_{1} \prec u_{2}\right)\right\}\end{array}$

(c) transportar o pacote $p$ com $t$ da localização $l_{1}$ à localização $l_{2}$

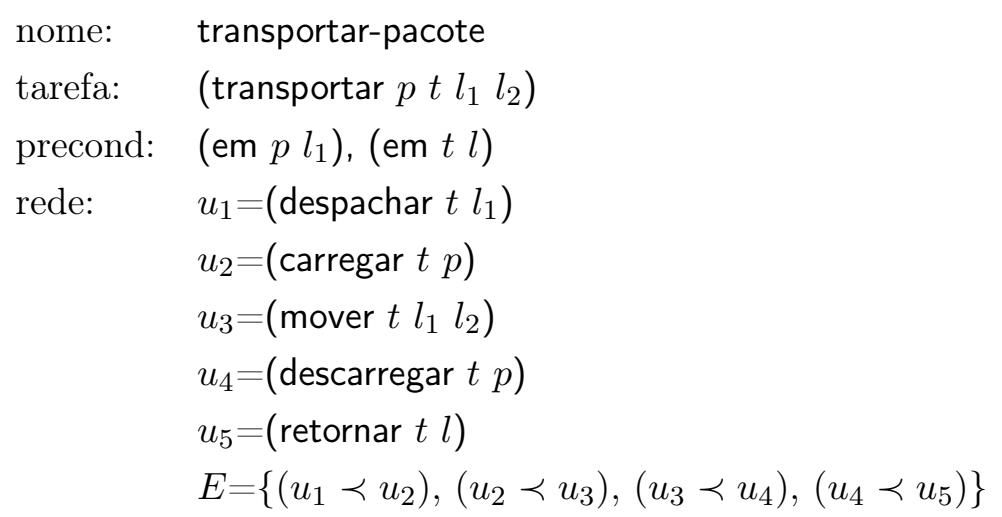

(d) efetuar o transporte de dois pacotes $p_{1}$ e $p_{2}$ das localizações $l_{1}$ e $l_{2}$ às localizações $l_{3}$ e $l_{4}$ nome: transportar-duplo

tarefa: (transportar-duplo $p_{1} p_{2} l_{1} l_{2} l_{3} l_{4}$ )

precond: (disponível $t_{1}$ ), (disponível $\left.t_{2}\right), t_{1} \neq t_{2}$

rede: $\quad u_{1}=\left(\right.$ transportar $\left.p_{1} t_{1} l_{1} l_{2}\right)$

$u_{2}=\left(\right.$ transportar $\left.p_{2} t_{2} l_{3} l_{4}\right)$

$E=\{\}$

No planejamento com redes simples de tarefas, as restrições associadas às tarefas são restrições de ordem e pré-condição, de maneira que o único tipo de procedimento de planejamento viável é a decomposição progressiva (Ghallab et al., 2004). Quando um método $m$ é utilizado para decompor uma tarefa $t$, tal que $t$ é parte de um nó $u$ de uma rede de tarefas $w$, obtemos a nova rede de tarefas por meio da decomposição $\delta(w, u, m, \sigma)$. Na decomposição, um nó $u$ é removido da rede de tarefas $w$, uma cópia da rede de tarefas $w_{u}$ do método $m$ é inserida na rede $w$ no lugar de $u$ e as restrição de ordem $\prec$ que aplicava a $u$ passa a valer para todo $w_{u}$.

Definição 2.7. Seja $w=(U, E)$ uma rede simples de tarefas, na qual $u \in U$ é um nó sem predecessores e $m$ é um método relevante para a tarefa $t_{u}$ contida no nó $u$ em alguma substituição $\sigma$; seja $\operatorname{succ}(u)=\left\{u^{\prime} \in U \mid\left(u, u^{\prime}\right) \in E\right\}$ o conjunto de todos os sucessores imediatos de $u$; seja $\operatorname{succ}_{1}(u)$ o conjunto de sucessores imediatos para os quais $u$ é o único predecessor; seja $\left(U^{\prime}, E^{\prime}\right)$ o resultado da remoção de $u$ e todas as arestas que contenham $u$; e seja $\left(U_{m}, E_{m}\right)$ uma cópia da rede de tarefas rede $(m)$ contendo as subtarefas na qual a tarefa do método $m$ é decomposta. 
Se $\left(U_{m}, E_{m}\right)$ não é vazio, então a função de decomposição $\delta$ de $u$ em $w$ sob a substituição $\sigma$ é o conjunto de redes de tarefas:

$$
\delta(w, u, m, \sigma)=\left\{\left(\sigma\left(U^{\prime} \cup U_{m}\right), \sigma\left(E_{v}\right)\right) \mid v \in \text { subtarefas }(m)\right\},
$$

onde:

$$
E_{v}=E_{m} \cup\left(U_{m} \times \operatorname{succ}(u)\right) \cup\left\{\left(v, u^{\prime}\right) \mid u^{\prime} \in \operatorname{succ}_{1}(u)\right\}
$$

Caso contrário, $\delta(w, u, m, \sigma)=\left\{\left(\sigma\left(U^{\prime}\right), \sigma\left(E^{\prime}\right)\right)\right\}$.

Exemplo 2.5. Na Figura 2.20 é mostrado o processo de decomposição de tarefas hierárquicas para o problema de planejamento logístico de transporte de pacotes da Figura 2.19 utilizando os métodos hierárquicos definidos no Exemplo 2.4.

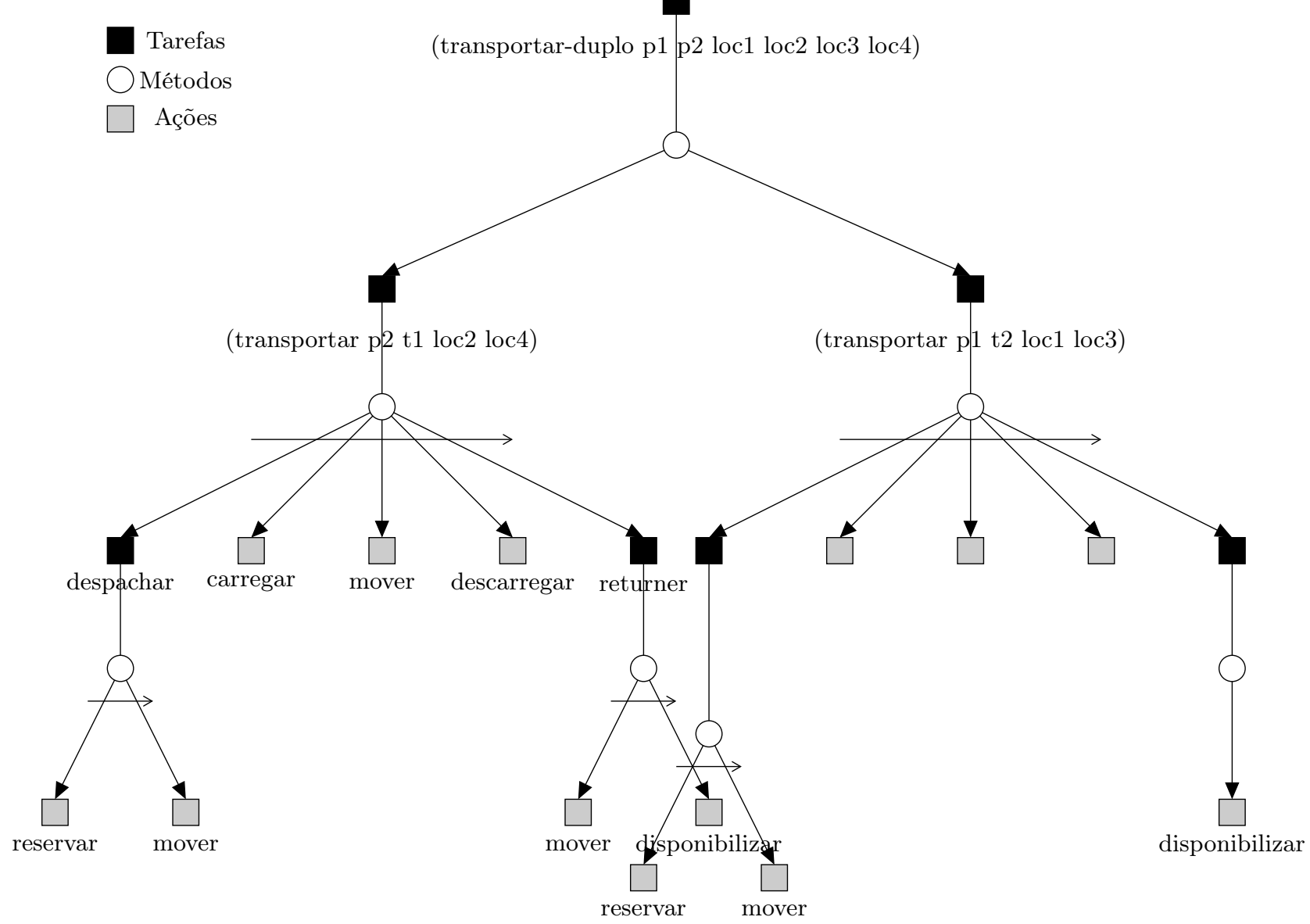

Figura 2.20: Exemplo de decomposição de tarefas hierárquicas 


\subsubsection{Sistema de planejamento hierárquico JSHOP2ip}

Java Simple Hierarquical Ordered Planner 2 for Instructional Planning (JSHOP2ip) é uma versão modificada do sistema de planejamento JSHOP2 que possibilita representar condições relativas nos métodos hierárquicos. As condições relativas são condições que não precisam ser satisfeitas para efetuar a decomposição de uma tarefa, mas aumentam ou diminuem a aplicabilidade de um método hierárquico quando existe mais de um método que possa ser aplicado.

A seguir apresentamos as características compartilhadas dos sistemas JSHOP2 e JSHOP2ip, a extensão efetuada na linguagem JSHOP2 para representar condições relativas, e finalmente apresentamos o algoritmo de planejamento JSHOP2ip.

\section{Características dos sistemas JSHOP2 e JSHOP2ip}

JSHOP2 é um sistema de planejamento hierárquico independente de domínio, desenvolvido pelo grupo de Planejamento Automatizado da Universidade de Maryland, que utiliza o caso restrito de planejamento com redes simples de tarefas (Ilghami, 2006).

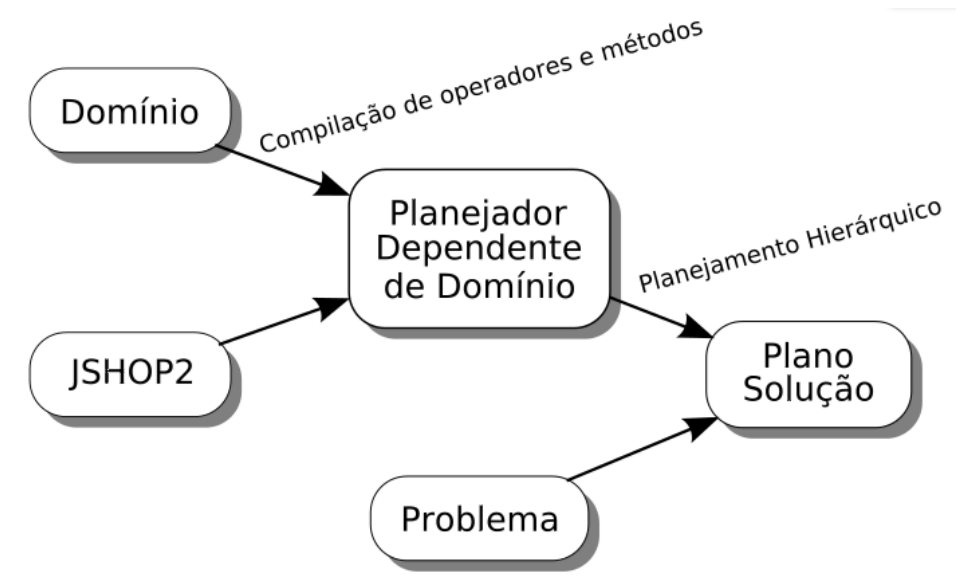

Figura 2.21: Processo de planejamento no sistema de planejamento JSHOP2ip

O sistema JSHOP2ip também apresenta o processo de planejamento mostrado na Figura 2.21 que utiliza um arquivo com a descrição do dominio de planejamento para efetuar a compilação de operadores e métodos em um planejador dependente de domínio de código JAVA. Então, o plano de solução a um problema planejamento é obtido pelo planejador usando um arquivo com a descrição do problema de planejamento. A compilação em código JAVA torna mais eficiente o processo de planejamento hierárquico ao serem empregadas estruturas de dados fixas para representar operadores e métodos (Nau et al., 2003).

O termo de chamada (call $f \mathrm{p}_{1} \ldots \mathrm{p}_{n}$ ) nos sistemas de planejamento efetuam chamadas de funções externas, na qual $f$ é o nome da função externa e $\mathrm{p}_{1} \ldots \mathrm{p}_{n}$ é a lista de parâmetros da função. O termo de chamada é empregado para realizar cálculos complexos ou efetuar consultas à informação localizada externamente durante o processo de planejamento.

Para efetuar a representação do domínio e problema de planejamento, o sistema JSHOP2ip apresenta uma linguagem similar à linguagem LISP, que é detalhado no Apêndice B. 
Usando a linguagem JSHOP2ip, o problema de planejamento logístico de entrega de dois pacotes apresentado na Figura 2.19 é representado pela estrutura mostrada na Figura 2.22.

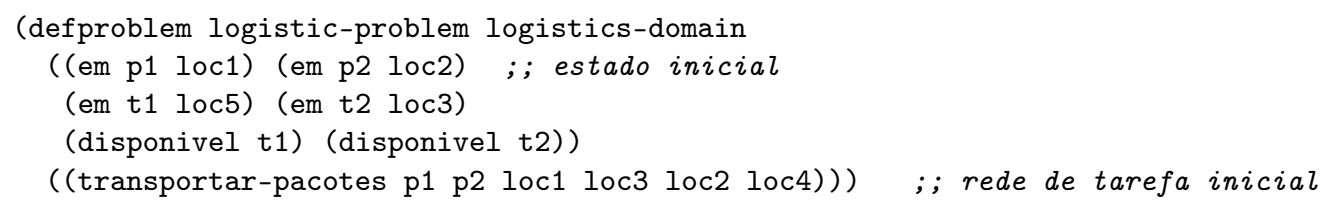

Figura 2.22: Representação do problema de logística de entrega de pacotes em JSHOP2ip

O domínio de planejamento para o planejamento logístico de entrega de dois pacotes é mostrado na Figura 2.23, no qual é mostrado parte da representação apresentado: os métodos de decomposição das tarefas transportar-pacotes e transportar; e os operadores !mover e !carregar.

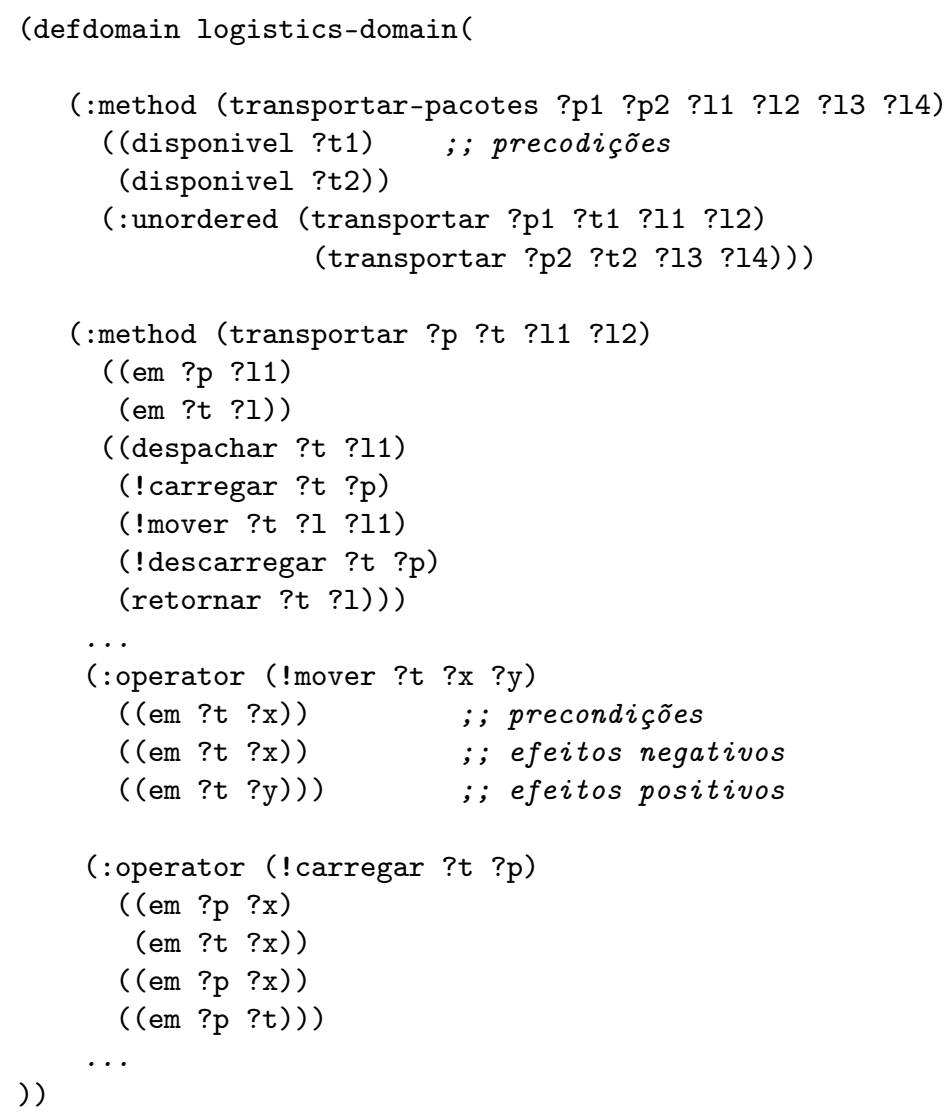

Figura 2.23: Representação do dominio de logistica de entrega de pacotes em JSHOP2ip 


\section{Extensão da linguagem JSHOP2 para JSHOP2ip}

A extensão da linguagem JSHOP2 ao sistema de planejamento JSHOP2ip é efetuada na representação dos métodos hierárquicos mediante a estrutura:

$$
\begin{aligned}
& \text { (:method h [ name } 1] \mathrm{L}_{1}\left[\begin{array}{lllll}
\mathrm{R}_{1_{1}} & \mathrm{R}_{1_{2}} & \ldots & \mathrm{R}_{1_{m_{1}}}
\end{array} \mathrm{~T}_{1}\right.
\end{aligned}
$$

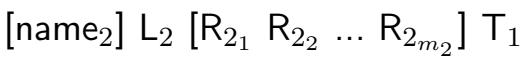

$$
\begin{aligned}
& \text {... } \\
& {\left[\begin{array}{lllll}
\text { name }_{n} & \mathrm{~L}_{n}
\end{array}\left[\begin{array}{llll}
\mathrm{R}_{n_{1}} & \mathrm{R}_{n_{2}} & \ldots & \mathrm{R}_{n_{m_{n}}}
\end{array}\right] \mathrm{T}_{n}\right)}
\end{aligned}
$$

onde:

- h é o átomo de tarefa composta;

- cada name $i$ é um nome opcional de cada estrutura $\left(\mathrm{L}_{i}\left[\begin{array}{lllll}\mathrm{R}_{i_{1}} & \mathrm{R}_{i_{2}} & \ldots & \mathrm{R}_{i_{m_{i}}}\end{array}\right] \mathrm{T}_{i}\right)$;

- cada $\mathrm{L}_{i}$ (pré-condição do método) é uma pré-condição lógica;

- cada $\left[\begin{array}{lllll}\mathrm{R}_{i_{1}} & \mathrm{R}_{i_{2}} & \ldots & \mathrm{R}_{i_{m_{i}}}\end{array}\right]$ é uma lista de condições relativas; e

- cada $T_{i}$ é uma lista de tarefas na qual o método decomposição da tarefa $h$.

As condições relativas são representadas mediante a estrutura:

(:relative a L)

onde:

- a é um valor numérico que representa a aplicabilidade ao ser satisfeita a condição L; e

- L é uma expressão lógica.

A Figura 2.24 mostra um exemplo de representação das condições relativas associadas aos métodos de transportar um pacote ?p com o transporte ?t da localização ?l1 à localização ?l2. Nos métodos, as condições relativas são associadas ao tipo de motor do transporte ?t (linhas $4,14)$; se durante o planejamento o motor do transporte ?t é Diesel, o valor da aplicabilidade do primeiro método é incrementado em 2; no caso em que o tipo de motor do transporte ?t seja gás, a aplicabilidade do segundo método é diminuída em 1. 


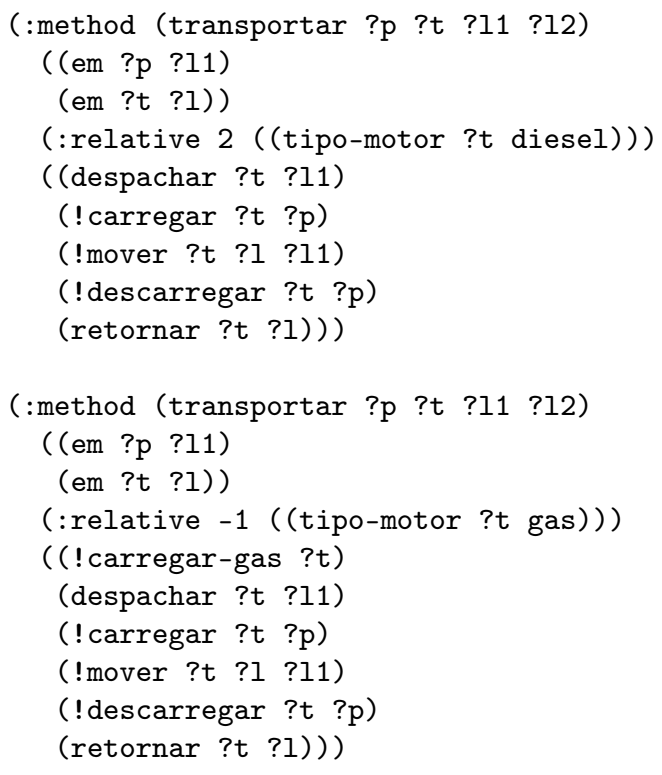

Figura 2.24: Exemplo de representação de condições relativas

\section{Algoritmo de planejamento JSHOP2ip}

O algoritmo de planejamento JSHOP2ip mostrado na Figura 2.25 é uma versão modificada do algoritmo de planejamento JSHOP2 (Nau et al., 2003). No algoritmo, a lista de métodos $M_{0}$ é implementada como uma fila de prioridade para simplificar a escolha do método $m$ e a substituição $\sigma$ a ser aplicados à tarefa $t$ (linha 12-14). A ordem na fila de prioridade é determinada efetuando a avaliação das condições relativas que são satisfeitas no estado corrente. Se uma condição relativa (:relative value condition) é satisfeita, o valor de aplicabilidade $a_{m}$ de um método $m$ é atualizado, isto é

$$
a_{m}=a_{m}+\text { value. }
$$




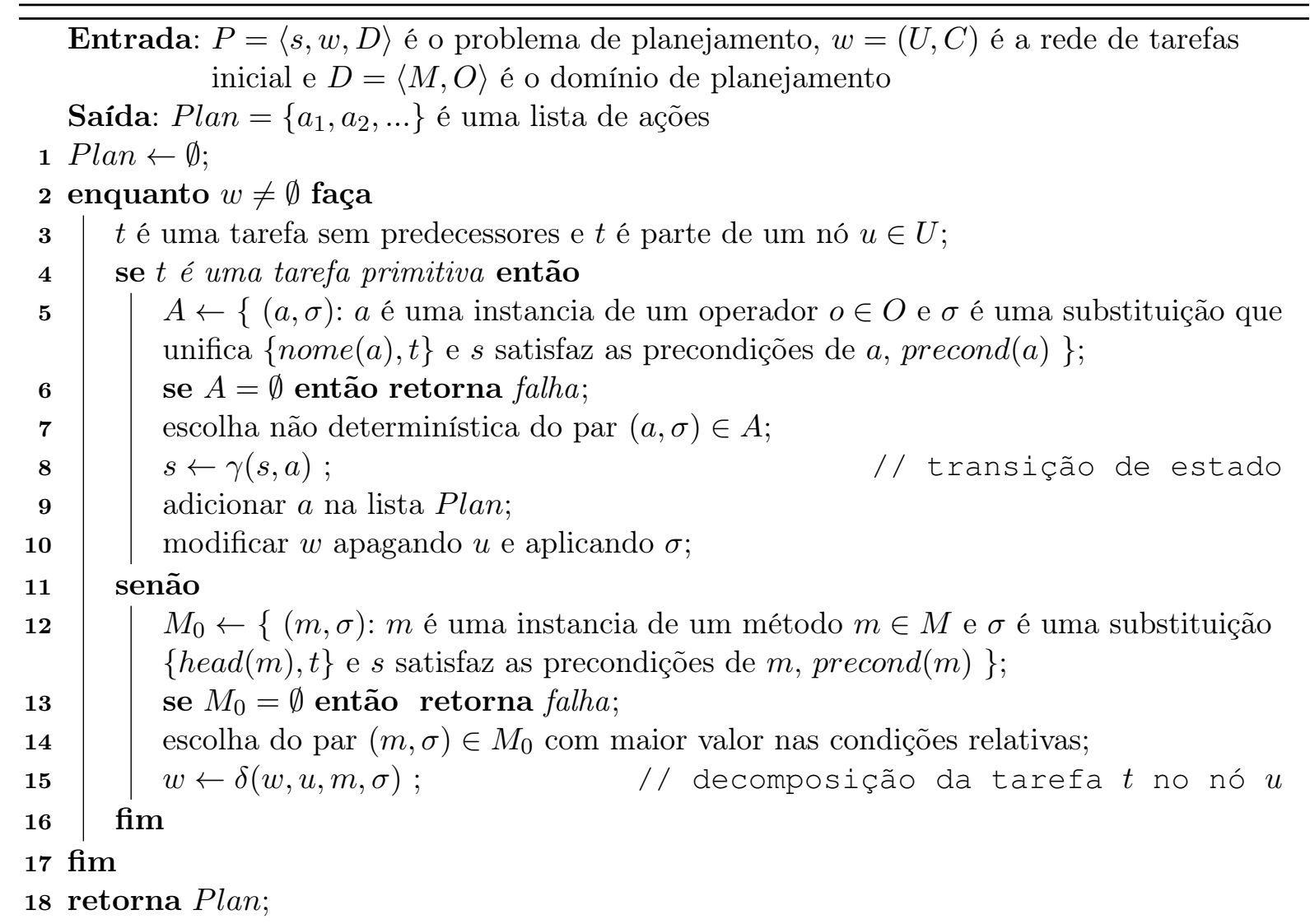




\subsection{Considerações finais}

Neste trabalho, o processo de planejamento instrucional usando padrões de roteiros é simplificado a uma abordagem top-down usando unicamente padrões de roteiros colaborativos do nível de fluxo de aprendizagem colaborativa (macrorroteiros) e padrões do nível de atividade (microrroteiros). Se efetuarmos a modelagem das estratégias de planejamento instrucional mediante a representação da criação de elementos de roteiros como tarefas e métodos hierárquicos, o processo de planejamento mantém uma forte semelhança com planejamento hierárquico.

A Figura 2.26 mostra o processo de planejamento instrucional usando estratégias de criação de elementos de roteiros extraídas do planejamento instrucional usando padrões de roteiro.

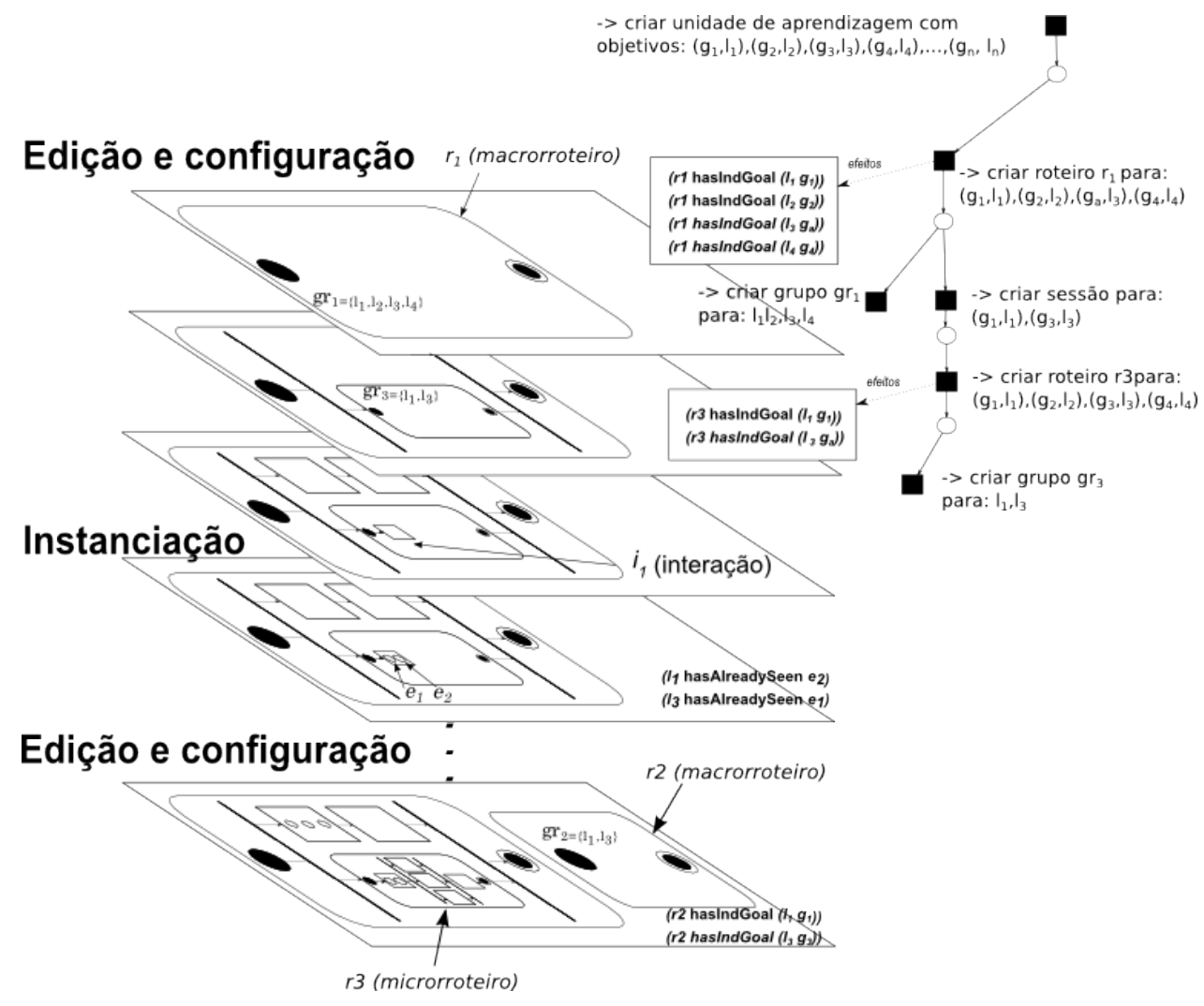

Figura 2.26: Estratégias de criação de elementos de roteiros

O objetivo de projetar roteiros colaborativos é possibilitar aos estudantes alcançar objetivos educacionais definidos pelos projetistas instrucionais. Assim, na modelagem de planejamento instrucional como problema de planejamento hierárquico, os operadores de planejamento utilizado na fase de edição efetuaram mudanças dos níveis de competência dos estudantes. Para isso, os operadores deveram conter informações dos objetivos educacionais a serem alcançados pelos estudantes ao término das atividades e interações. A Figura 2.26 mostra como as informação dos objetivos são incluídas nos roteiros colaborativos $r_{1}$ e $r_{2}$. 
Diferente do processo de planejamento instrucional original, a fase de configuração é efetuada antes da execução do roteiro em um AVA para definir a seleção e sequenciamento dos recursos instrucionais de acordo com as características individuais dos participantes. Os registros do modelo de estudante relativos à estrutura social são atualizados para definir a formação de grupos e atribuição de papéis. Na Figura 2.26, a configuração da estrutura social é efetuada mediante a definição do grupo $g r_{1}$ no qual os estudantes $l_{1}$ e $l_{3}$ são selecionados durante o planejamento do roteiro $r_{1}$, logo no planejamento do roteiro $r_{3}$ a estrutura social dos estudantes $l_{1}$ e $l_{3}$ é modificada mediante a atribuição dos papéis tutor e tutee respetivamente.

$\mathrm{Na}$ fase de instanciação de roteiros, as informações do modelo de estudante relativas ao histórico são atualizadas ao ser definidos recursos instrucionais associados às atividades e interações. A Figura 2.26 mostra como os estudantes $l_{3}$ e $l_{1}$ mudam seus registro históricos ao serem definidos os recursos $e_{1}$ e $e_{2}$ durante a interação $i_{1}$.

No capítulo seguinte mostraremos como é efetuada a modelagem de planejamento instrucional em ACSC como um problema de planejamento hierárquico, a modelagem utiliza o processo de planejamento usando padrões apresentado nesta seção. 


\section{Capítulo 3}

\section{Modelagem de planejamento instrucional em ACSC}

De acordo com OASIS (2006), "Um modelo de referência é um arcabouço abstrato utilizado para o entendimento de entidades e relações significativas existentes em um ambiente que possibilita o desenvolvimento de arquiteturas específicas usando padrões consistentes ou características próprias de cada ambiente". Um modelo de referência que possibilite efetuar a modelagem do planejamento instrucional em ACSC como problema de planejamento hierárquico ainda não foi desenvolvido. Assim, usando como referência o modelo clássico de STI apresentado no capítulo anterior, a Figura 3.1 mostra a nossa modelagem proposta.

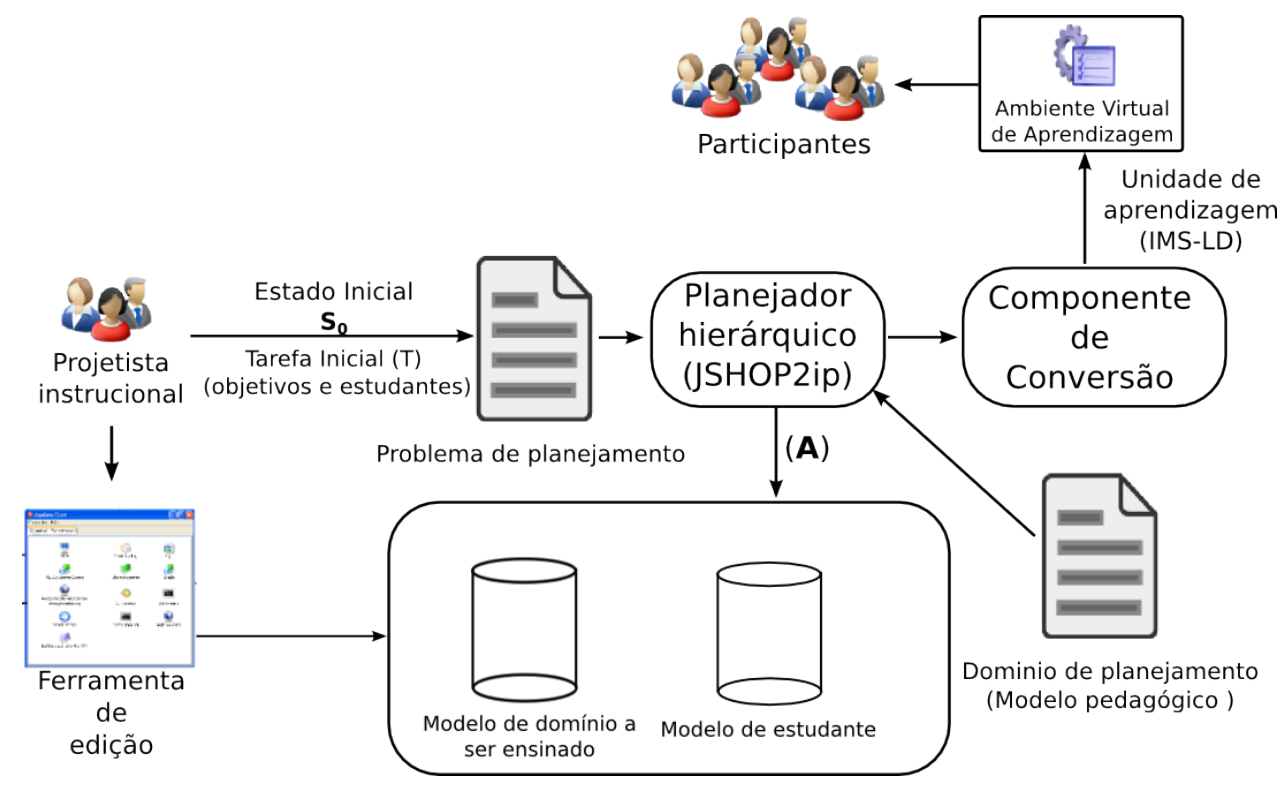

Figura 3.1: Planejamento instrucional em ACSC como um problema de planejamento hierárquico

Em nossa modelagem proposta, o problema de planejamento é definido pelo projetista instrucional mediante a seleção dos estudantes e dos objetivos educacionais que definem a rede de tarefa inicial $\left(w_{0}\right)$; enquanto, o estado inicial $\left(s_{0}\right)$ é definido mediante uma ferramenta de edição dos modelos de estudante e de domínio a ser ensinado. O domínio de planejamento é definido mediante a representação do modelo pedagógico como tarefas e métodos hierárquicos. 
Efetuada a definição do problema e do domínio de planejamento, o planejador hierárquico JSHOP2ip obtém um plano de solução usando axiomas de consultas aos modelos de estudante e de domínio a ser ensinado $(A)$. Para sua execução em um AVA, o plano de solução mediante um componente de conversão será transformado em uma unidade de aprendizagem. A unidade de aprendizagem é definida como um pacote ZIP que contém um conjunto de roteiros colaborativos na especificação IMS-LD com todos os recursos instrucionais necessários.

Neste capítulo, a seguir apresentamos a representação na linguagem JSHOP2ip do estado inicial na Seção 3.1, a representação do problema de planejamento na Seção 3.2 e a representação do domínio de planejamento na Seção 3.3. Finalmente, na Seção 3.4 é apresentado detalhes do componente de conversão.

\subsection{Estado Inicial: Modelo de domínio a ser ensinado e modelo de estudante}

A modelagem do domínio a ser ensinado e das caraterísticas dos estudante é fundamentada na definição de competências como fatores de aprendizagem relativos ao planejamento instrucional em ACSC. Nesse contexto, o modelo de domínio a ser ensinado e o modelo de estudante utilizam a representação detalhada a seguir.

Definição 3.1. Os recursos instrucionais $R=\left\{r_{1}, \ldots, r_{n}\right\}$ são representados mediante os átomos lógicos (class Resource $r_{i}$ ), (property $r_{i}$ hasTitle title), (property $r_{i}$ hasType type) e (property $r_{i}$ hasHref href), onde:

- $r_{i}$ é o rotulo global único que identifica o recurso instrucional;

- title é o nome dado ao recurso instrucional;

- href especifica o endereço destino do recurso instrucional mediante uma URI; e

- type é o tipo de conteúdo no endereço destino do recurso podendo ser conteúdo web (webcontent) ou conteúdo imsld (imsldcontent).

A Figura 3.2 mostra a representação do recurso instrucional valor absoluto (linha 1) localizado na URI http://mathworld.wolfram.com/AbsoluteValue.html (linha 4).

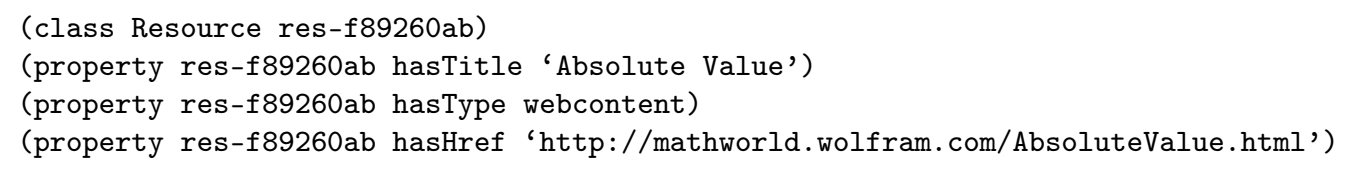

Figura 3.2: Representação do recurso instrucional "valor absoluto" 


\subsubsection{Modelo de domínio a ser ensinado}

O modelo de domínio a ser ensinado é representado mediante uma estrutura de elementos de competência, níveis de competência e uma estrutura de elementos de conhecimento.

\section{Estrutura de elementos de competência}

A estrutura de competências apresentada a seguir e resultado da análise dos trabalhos propostos por Melis et al. (2008); Sicilia (2005); Wilkinson (2001), que definem competência como a caraterística multidimensional composta de habilidades, conhecimento e atitudes que possibilitam a integração dos modelos de estudante e de domínio a ser ensinado. A habilidade é uma característica de aprendizagem adquirida por treinamento; enquanto uma atitude é um estado mental complexo que envolve opinião (convicção, crença e confiança), sentimentos (impressão, percepção e sentido), valores inatos e disposição mental para atuar adequadamente.

As competências cognitivas são definidas como estruturas mentais que associam uma habilidade com um elemento de conhecimento para definir o processo de aprendizagem como: situações de trabalho que dão origem aos requerimentos de competências e análises de competências carentes dos participantes (Sicilia, 2005).

Definição 3.2. A estrutura de elementos de competência é representada mediante a n-upla $C S=\left\langle S, A, C, R_{S}, R_{A}\right\rangle$, na qual elementos do conjunto $S$ são habilidades, elementos do conjunto $A$ são atitudes, elementos do conjunto $C$ são competências cognitivas, elementos do conjunto $R_{S}$ são relações de associação entre habilidades e elementos do conjunto $R_{A}$ são relações de associação entre atitudes.

Uma habilidade $s \in S$ com identificador $s_{i}$ é representado pelos átomos lógicos (class Skill $s_{i}$ ), (property $s_{i}$ hasTitle title) e (property $s_{i}$ hasResource res), no que title é o nome da habilidade e res é o identificador do recurso instrucional associado à habilidade.

Uma atitude $a \in A$ com identificador $a_{i}$ é representado pelos átomos lógicos (class Attitude $a_{i}$ ), (property $a_{i}$ hasTitle title) e (property $a_{i}$ hasResource res), no que title é o nome da atitude e res é o identificador do recurso instrucional associado à atitude.

Uma competência cognitiva $c \in C$ com identificador $c_{i}$ que associa a habilidade $s_{i}$ com o elemento de conhecimento $k_{i}$ é representado mediante átomos lógicos (class Competency $c_{i}$ ), (property $c_{i}$ hasTitle title), (property $c_{i}$ hasSkill $s_{i}$ ) e (property $c_{i}$ hasKnowledge $k_{i}$ ), na qual:

- title é o nome dado à competência cognitiva;

- $s_{i} \in S$ é um identificador de habilidade pertence ao conjunto de habilidades; e

- $k_{i} \in K$ é um identificador de elemento de conhecimento pertencente à estrutura de elementos de conhecimento $K S$.

Uma relação de associação $r_{s} \in R_{S}$ entre duas habilidades $s_{i}$ e $s_{j}$ é representado como um átomo lógico (relation $s_{i}$ type $s_{j}$ ), no que type é o tipo de associação podendo ser de tipo pré-requisito (isRequiredBy) ou variação (isVariantOf). 
Uma relação de associação $r_{a} \in R_{A}$ entre duas atitudes $a_{i}$ e $a_{j}$ é representado como um átomo lógico (relation $a_{i}$ type $a_{j}$ ), no que type é o tipo de associação podendo ser unicamente de tipo variação (is VariantOf).

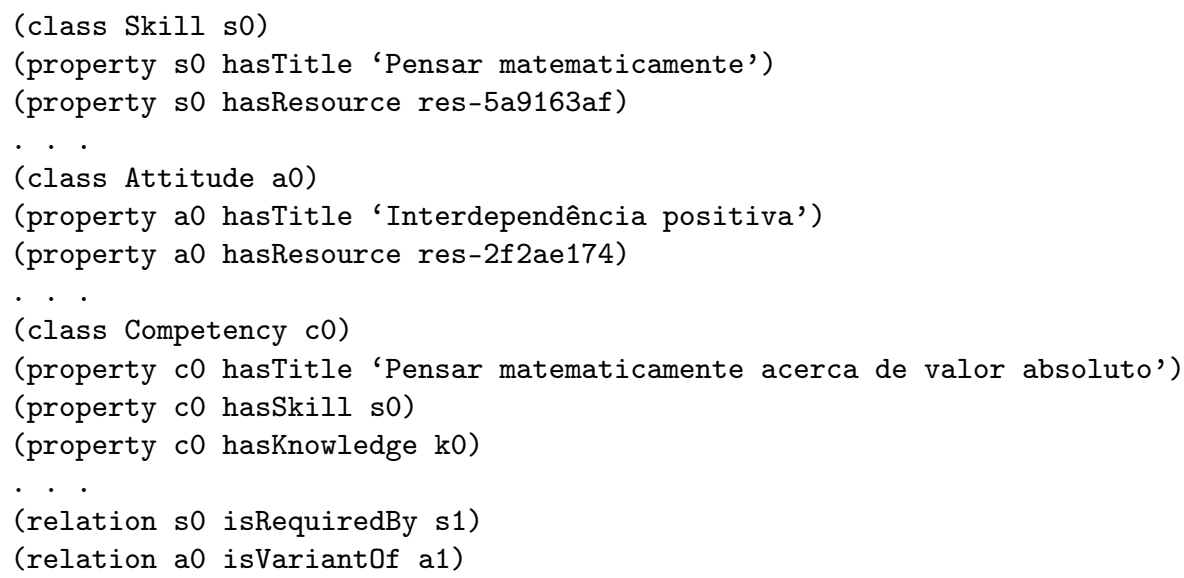

Figura 3.3: Representação da estrutura de competências no domínio de matemática

A Figura 3.3 apresenta parte da representação da estrutura de competências definida no domínio de ensino de matemática, no qual são representadas a habilidade "pensar matematicamente" (linhas 1-3), a atitude "interdependência positiva" (linhas 5-7), a competência cognitiva "pensar matematicamente acerca do tópico valor absoluto" (linhas 9-12) e relações de associação entre habilidades e atitudes (linhas 14-15).

\section{Níveis de competência}

Os níveis de competência definem um conjunto de estágios possíveis de desenvolvimento de habilidades e de aquisição de conhecimento definidos em competências cognitivas.

Definição 3.3. Os níveis de competência $C L=\left\{c l_{1}, \ldots, c l_{n}\right\}$ são representados mediante átomos lógicos (class Level $c l_{i}$ ), (property $c l_{i}$ hasSkillLevel slevel) e (property $c l_{i}$ hasKnowledgeLevel klevel), onde: $c l_{i}$ é o identificador global único do nível de competência; slevel é o estágio de desenvolvimento de uma habilidade; e klevel é o estágio de aquisição de um conhecimento.

O modelo de crescimento do estudante (Learner's Growth Model, mostrado na Figura 3.4) representa de modo simplificado o processo de aquisição de uma competência como um dígrafo acíclico, no qual os nós representam níveis de competência, enquanto arestas representam possíveis transições entre os estágios (Inaba et al., 2003a; Isotani e Mizoguchi, 2006). Assim, em nossa modelagem proposta definimos 20 níveis de competência, nos que: 


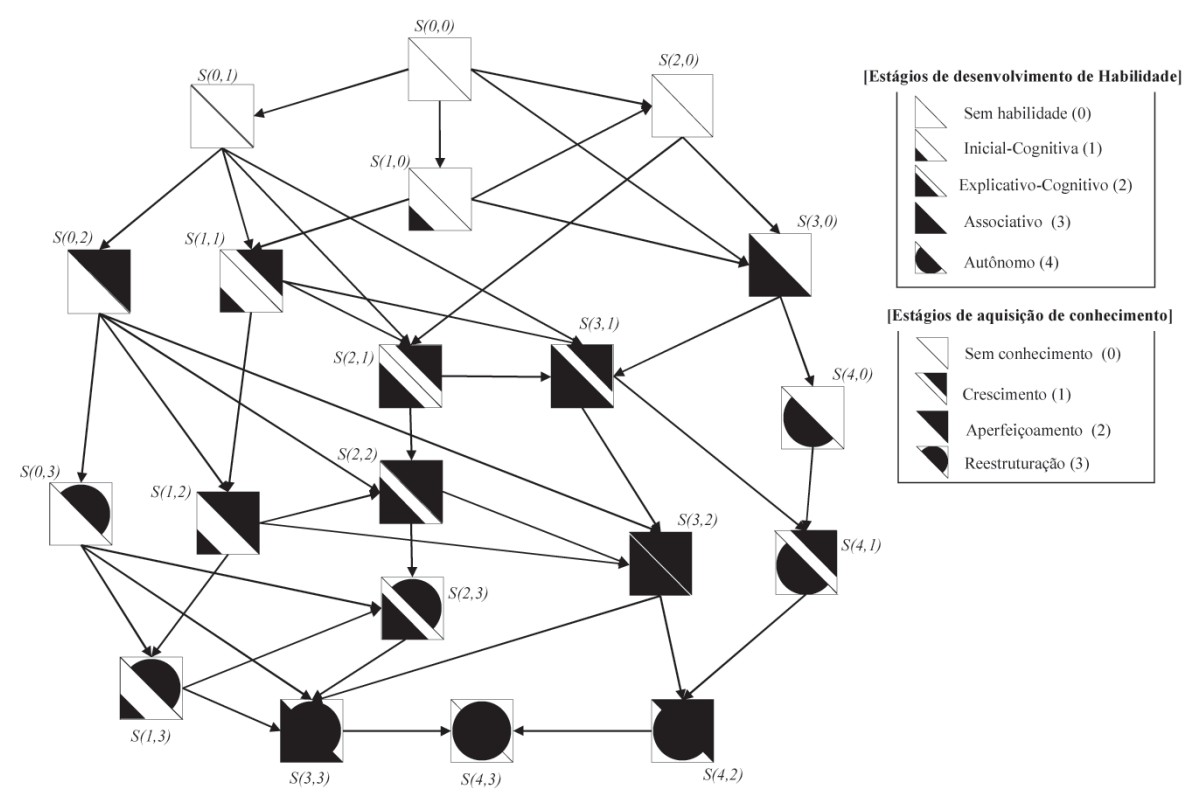

Figura 3.4: Modelo de crescimento do estudante (Isotani e Mizoguchi, 2007)

- o identificador de nível de competência definido como sxky; e

- os níveis de desenvolvimento de uma habilidade $x$ apresentam os cinco estágios de: sem habilidade ( 0 , nothing), cognitivo inicial (1, rough), cognitivo explicativo (2, explanatory), associativo (3, associative) e autônomo (4, autonomous); enquanto, os níveis de aquisição de conhecimento $y$ apresentam quatro estágios de: sem conhecimento (0, nothing), crescimento natural (1, accretion), aperfeiçoamento (2, tuning) e restruturação (3, restructuring).

(class Level s0k0)

(property s0k0 hasSkillLevel nothing)

(property sOk0 hasKnowledgeLevel nothing)

. . .

(class Level s4k3)

(property s4k3 hasSkillLevel autonomous)

(property s4k3 hasknowledgeLevel restructuring)

Figura 3.5: Representação de niveis de competência

A Figura 3.5 mostra parte da representação de níveis de competência que apresentada o nível sem habilidade e sem conhecimento (linhas 1-3) e o nível autônomo e restruturação (linhas 5-7).

\section{Estrutura de elementos de conhecimento}

A estrutura de elementos de conhecimento representa toda peça central de informação do domínio a ser ensinado contida em livros, resumos ou páginas web. Os quais são classificados como fundamentais e auxiliares. 
- Fundamental. Um elemento de conhecimento de tipo fundamental contém informações centrais do domínio a ser ensinado que um aluno deve aprender durante o processo de ensino-aprendizagem. Exemplos de elementos de conhecimento de tipo fundamental são teoremas, fatos, e definições.

- Auxiliar. Um elemento de conhecimento do tipo auxiliar contém informações acera dos elementos de conhecimento de tipo fundamental. Os elementos de tipo auxiliar são empregados no processo de ensino-aprendizagem para atingir objetivos educacionais. Exemplo de elementos de tipo auxiliar são demonstrações, exemplos e exercícios.

Definição 3.4. A estrutura de elementos de conhecimento é representada mediante a n-upla $K S=\langle K, P, R\rangle$, na qual elementos do conjunto $K$ são elementos de conhecimento, elementos do conjunto $P$ são propriedades e elementos do conjunto $R$ são relações.

Um elemento de conhecimento $k \in K$ com identificador $k_{i}$ é representado pelos átomos lógicos (class Knowledge $k_{i}$ ), (class type $k_{i}$ ), no que type é o tipo de elemento de conhecimento podendo ser auxiliar (Auxiliary) ou fundamental (Fundamental).

Uma propriedade $p \in P$ de um elemento de conhecimento $k_{i}$ é representado por um átomo lógico (property $k_{i}$ name value), no que name é o nome da propriedade e value é o valor da propriedade. A Tabela 3.1 apresenta o conjunto de propriedades, o tipo de dado e seus possíveis valores.

\begin{tabular}{|l|l|l|}
\hline Propriedade & Tipo de dado & Espaço de valores (val) \\
\hline \hline hasTitle & Cadeia de caracteres & \\
\hline hasResource & Recurso & \\
\hline hasContext & Vocabulário & training, higher-education, school, other \\
\hline hasDifficult & Vocabulário & very-easy, easy, medium, difficult, very-difficult \\
\hline hasLearningResourceType & Vocabulário (PISA, 2001) & $\begin{array}{l}\text { Para elementos de tipo auxiliar: explanation, introduc- } \\
\text { tion, remark, conclusion, interactivity, exercise, explo- } \\
\text { ration, invitation, real-world-problem, evidence, proof, } \\
\text { demonstration, illustration, counter-example, example. } \\
\end{array}$ \\
& & $\begin{array}{l}\text { Para elementos de tipo fundamental: law, theorem, law- } \\
\text { of-nature, definition, fact, process, policy, procedure. }\end{array}$ \\
\hline
\end{tabular}

Tabela 3.1: Propriedades utilizadas em elementos de conhecimento

Uma relação $r \in R$ entre dois elementos de conhecimento $k_{i}$ e $k_{j}$ é representada como um átomo lógico (relation $k_{i}$ type $k_{j}$ ), no que type é o tipo da relação podendo ser do tipo pré-requisito (isRequiredBy), agregação (isPartOf) e variação (isVariantOf).

A Figura 3.6a mostra o grafo da estrutura de elementos de conhecimento de tipo fundamental identificada na página web "valor absoluto" (Figura 3.6b), no qual as relações de agregação são identificadas com linhas sólidas e relações de pré-requisito são identificadas com linhas tracejadas. A Figura 3.7 mostra a representação da estrutura de elementos de conhecimento de tipo fundamental na linguagem JSHOP2ip. 


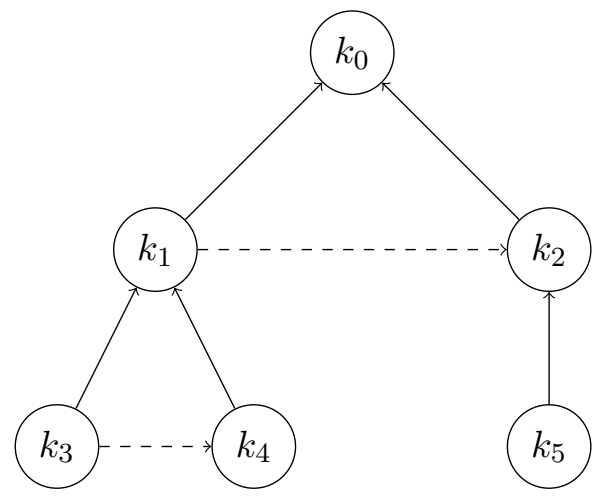

(a)

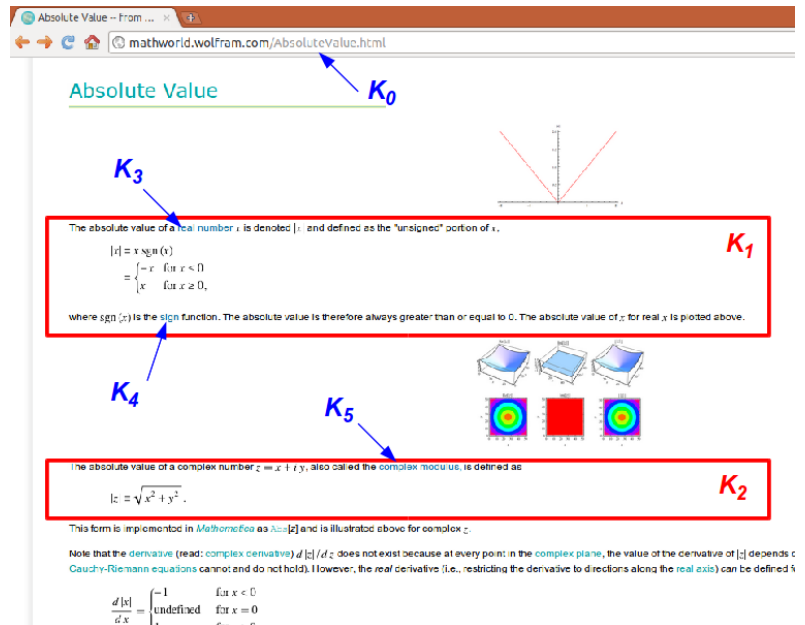

(b)

Figura 3.6: Elementos de conhecimento de tipo fundamental identificadas na página web "valor absoluto"

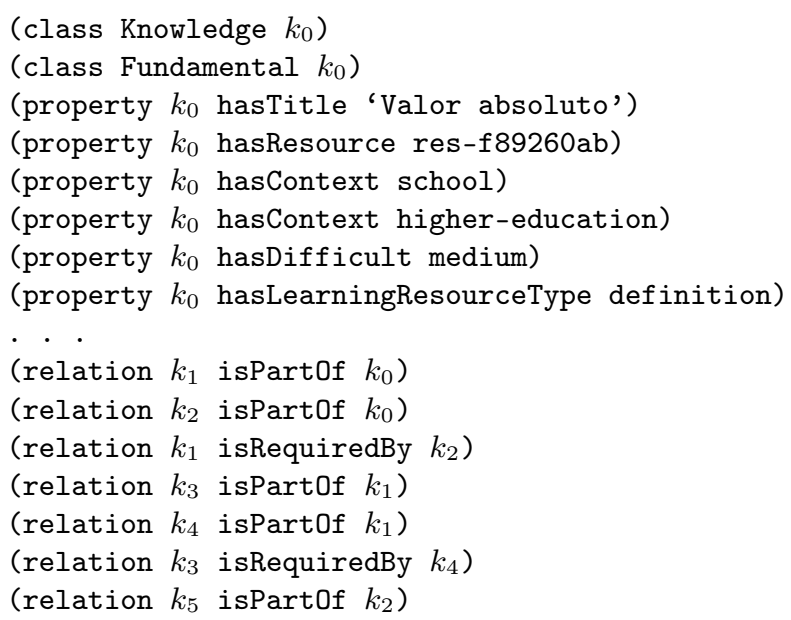

Figura 3.7: Representação da estrutura de elementos de conhecimento da Figura 3.6 


\section{Pré-requisitos e objetivos de aprendizagem}

Os elementos de conhecimento de tipo auxiliar são relacionados com elementos de conhecimento de tipo fundamental mediante a definição das propriedades pré-requisitos e objetivos de aprendizagem. Os pré-requisitos de aprendizagem representam níveis mínimos de competência que os participantes devem possuir para tirar proveito da utilização de elementos de tipo auxiliar. Enquanto, os objetivos de aprendizagem representam níveis de competência atingidos pelos participantes após a utilização dos elementos.

Definição 3.5. Um pré-requisito de aprendizagem de um elemento de conhecimento auxiliar $k_{i}$ é representado pelo átomo lógico (property $k_{i}$ hasPrerequisite $\left(c_{j} c l_{h}\right)$ ), no que:

- $c_{j}$ é uma competência cognitiva associada a um elemento de conhecimento de tipo fundamental; e

- $c l_{h}$ é um identificador de nível de competência pertencente ao conjunto de níveis de competência $C L$.

Definição 3.6. Um objetivo de aprendizagem de um elemento de conhecimento auxiliar $k_{i}$ é representado pelo átomo lógico (property $k_{i}$ hasLearningObjective $\left(c_{j} c l_{h}\right)$ ), no que:

- $c_{j}$ é uma competência cognitiva associada a um elemento de conhecimento de tipo fundamental; e

- $c l_{h}$ é um identificador de nível de competência pertencente ao conjunto de níveis de competência $C L$.

A Figura 3.8 mostra as propriedades de pré-requisitos (linhas 18-19) e objetivos de aprendizagem (linhas 8-9, 20-21) de dois elementos de conhecimento de tipo auxiliar "exemplo interativo de valor absoluto" $\left(k_{10}\right)$ e "exercício 01 de valor absoluto" $\left(k_{15}\right)$ que são relacionados às competências cognitivas "pensar matematicamente acerca de valor absoluto" $\left(c_{0}\right)$ e "pensar matematicamente acerca da função signo" $\left(c_{1}\right)$. 


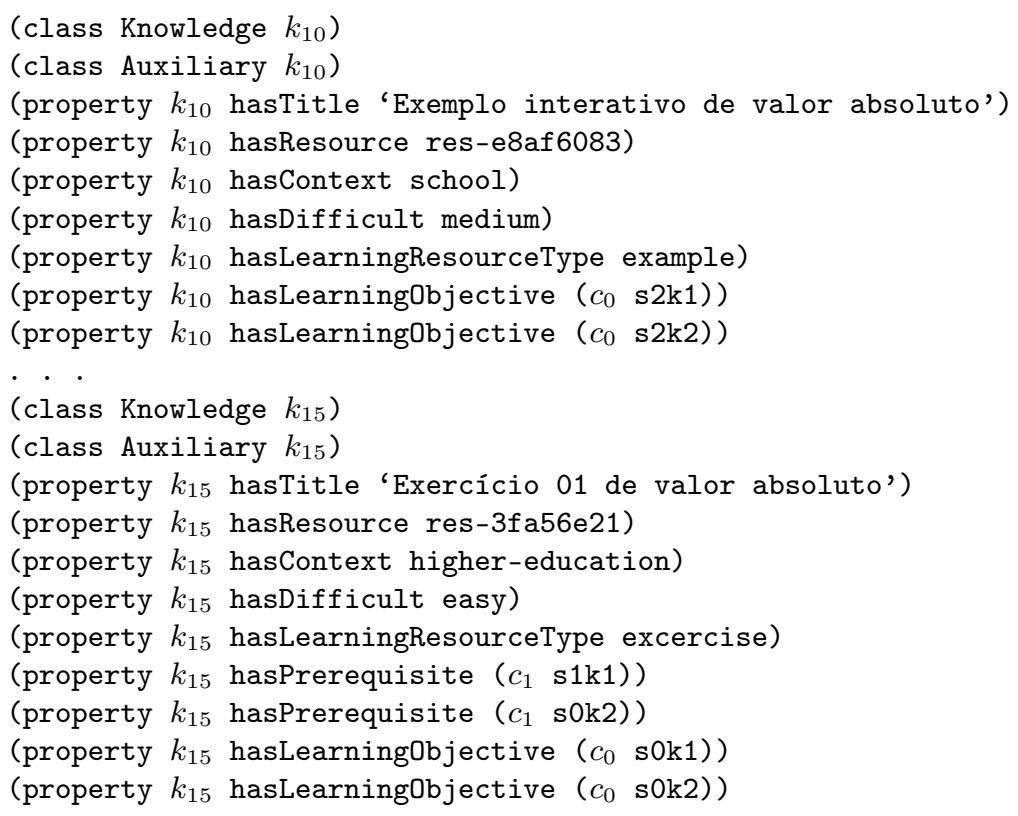

Figura 3.8: Representação da estrutura de elementos de conhecimento

\subsubsection{Modelo de estudante}

O modelo de estudante é definido como a sobreposição do modelo de domínio a ser ensinado. A sobreposição define o modelo de estudante como um nível de associação entre estudantes e elementos de conhecimento mediante um conjunto de registros.

Definição 3.7. O modelo de estudante é representada pela n-upla $L M=\langle L, C R, H R, P R\rangle$, na qual $L$ é o conjunto de estudantes, $C R$ é o conjunto de registros de competências, $H R$ é o conjunto de registros históricos e $P R$ é o conjunto de registros de preferências.

Um estudante $l \in L$ com identificador $l_{i}$ é representado pelo átomo lógico (class Learner $l_{i}$ ).

Um registro de competência $c r \in C R$ definem:

- uma habilidade com identificador $s$ possuída pelo estudante $l_{i}$ é representado pelo átomo lógico (property $l_{i}$ hasSkill $s$ );

- uma atitude com identificador $a$ possuída pelo estudante $l_{i}$ é representado pelo átomo lógico (property $l_{i}$ hasAttitude $a$ ); e

- um nível de competência $c l$ da competência cognitiva $c$ atingido pelo estudante $l_{i}$ é representado pelo átomo lógico (property $l_{i}$ hasCompetencyLevel $(c c l)$ ).

Um registro histórico $h r \in H R$ que define o uso de um elemento de conhecimento $k$ por um estudante $l_{i}$ é representado pelo átomo lógico (property $l_{i}$ hasAlreadySeen $k$ ). 
Um registro de preferência $p r \in P R$ que define uma caraterística individual do estudante $l_{i}$ é representado pelo átomo lógico (property $l_{i}$ name value), no que name é o nome da característica e value é o valor da propriedade. A Tabela 3.2 apresenta o conjunto de características, o tipo de dado e seus possíveis valores empregados no presente trabalho.

\begin{tabular}{|l|l|l|}
\hline Propriedade & Tipo de dado & Espaço de valores (val) \\
\hline \hline hasPersonality & Vocabulário & introversion, extraversion, ambiversion \\
\hline hasCLExperience & Vocabulário & very-low, low, medium, high, very-high \\
\hline hasEducationalLevel & Vocabulário & training, higher-education, school, other \\
\hline hasMotivation & N-upla: $(c, l)$ & $\begin{array}{l}-c \text { é o identificador de uma competência cognitiva; e } \\
-l \text { é o nível: very-low, low, medium, high, very-high. }\end{array}$ \\
\hline hasAnxiety & N-upla: $(c, l)$ & $\begin{array}{l}-c \text { é o identificador de uma competência cognitiva; e } \\
-l \text { é o nível: very-low, low, medium, high, very-high. }\end{array}$ \\
\hline
\end{tabular}

Tabela 3.2: Características utilizadas no registro de preferências dos estudantes

\section{Registro das estruturas sociais}

O modelo de estudante apresenta um registro de estruturas sociais que definem durante o processo de planejamento os grupos e papéis aos quais os estudantes pertencem.

Definição 3.8. O registro das estruturas sociais é representado mediante a n-upla $S R=$ $\langle G r, R o\rangle$, na qual $G r$ é o conjunto de grupos e Ro é o conjunto de papéis.

- Um grupo gr $\in G r$ formado por o conjunto de estudantes $g r=\left\{l_{1}, \ldots, l_{n}\right\}$ é definido mediante átomos lógicos (property $l_{i}$ hasGroup $g r$ ).

- Um papel ro $\in R$ Ro formado por o conjunto de estudantes $r o=\left\{l_{1}, \ldots, l_{n}\right\}$ é definido mediante átomos lógicos (property $l_{i}$ hasRole ro).

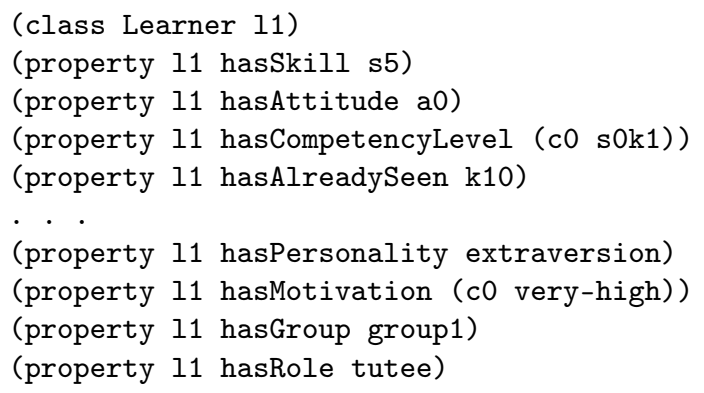

Figura 3.9: Exemplo de representação do modelo estudante 
A Figura 3.9 mostra parte da representação do modelo de estudante, nesse exemplo é mostrada a informação do estudante com identificador 11 quem apresenta: uma habilidade individual "discussão", s5 (linha 2); uma atitude "interdependência positiva", a0 (linha 3); um nível de competência sem habilidade e crescimento natural na competência cognitiva "pensar matematicamente acerca de valor absoluto", (c0 s0k1) (linha 4); e um registro de estrutura social que define a atribuição do papel aprendiz, tutee (linha 10).

\subsection{Problema de planejamento instrucional}

O problema de planejamento hierárquico $P=\left\langle s_{0}, w_{0}, D\right\rangle$ é representado pelo projetista instrucional usando o esquema mostrado na Figura 3.10, assim: um estado inicial $s_{0}$ representa o estado corrente dos modelos de estudante e de domínio a ser ensinado (linhas 3-8); e uma rede de tarefas inicial $w_{0}$ representa a tarefa de planejamento instrucional pública (linhas 10-11).

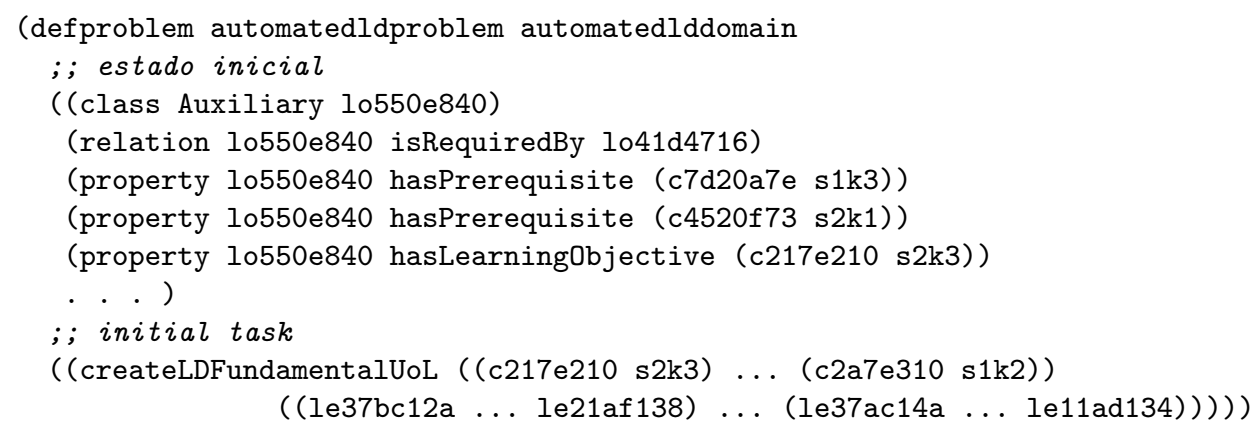

Figura 3.10: Esquema do problema de planejamento

\subsubsection{Objetivos educacionais}

Os objetivos educacionais $G=\left\{g_{1}, g_{2}, \ldots\right\}$ definem um conjunto de níveis de competências a serem atingidos pelos estudantes, os quais são definidos pelo projetista instrucional na tarefa de planejamento instrucional pública.

Definição 3.9. Um objetivo educacional $g \in G$ é representado como uma n-upla (c I), na que:

- c é um identificador de uma competência cognitiva; e

- I é um nível de aquisição da competência cognitiva que representa estágios de desenvolvimento de habilidade e aquisição de conhecimento "s $x$ k $y$ ".

Exemplo 3.1. Os objetivos educacionais "entendimento do laço while no nível explicativo e aperfeiçoamento", "compreensão do laço for no nível autônomo e restruturação" e "entendimento do laço while no nível inicial e aperfeiçoamento" são representados como a lista

$$
G=\{(\operatorname{comp} 1 \mathrm{~s} 2 \mathrm{k} 2),(\text { comp2 s4k3), (comp1 s1k2)\}, }
$$

na qual: comp1 é o identificador da competência cognitiva "entendimento do laço while" e comp2 é o identificador da competência cognitiva "compreensão do laço for". 


\subsubsection{Rede de tarefa inicial: Tarefa de planejamento instrucional pública}

A rede de tarefas inicial $w_{0}=\left(\left\{t_{0}\right\},\{\}\right)$ é definida como uma tarefa $t_{0}$ de planejamento instrucional pública $t_{0} \in T$. As tarefas de planejamento instrucional públicas $T=\left\{t_{1}, t_{2}, \ldots\right\}$ são definidas como meio de comunicação entre o sistema de planejamento e o projetista instrucional.

Definição 3.10. Uma tarefa de planejamento instrucional pública $t \in T$ é definida como uma n-upla (s G L), na qual:

- s é um identificador de tarefa de planejamento instrucional pública;

- $\mathrm{G}=\left(\begin{array}{llll}\mathrm{g}_{1} & \mathrm{~g}_{2} & \ldots & \mathrm{g}_{n}\end{array}\right)$ é uma lista de objetivos pedagógicos a ser atingidos; e

- $H=\left(\begin{array}{llll}h_{1} & h_{2} & \ldots & h_{n}\end{array}\right)$ é uma lista de grupos de estudantes, na que cada grupo de estudantes $\mathrm{h}_{i}$ é representado por uma lista de identificadores $\left(l_{1} \mathrm{l}_{2} \ldots \mathrm{I}_{m}\right)$.

\begin{tabular}{|l|l|}
\hline Identificador & Descrição \\
\hline \hline createLDFundamentalUoL & Criação de uma unidade de aprendizagem. \\
\hline createLDScript & Criação de um roteiro colaborativo. \\
\hline createLDCLScenario & Criação de uma sessão de aprendizagem. \\
\hline
\end{tabular}

Tabela 3.3: Identificadores de tarefas de planejamento instrucional públicas

A Tabela 3.3 apresenta o conjunto de identificadores das tarefas de planejamento instrucional pública e uma breve descrição correspondente a cada tarefa.

Exemplo 3.2. A tarefa de planejamento instrucional inicial "criação de um roteiro colaborativo" (createLDScript) definida para os grupos de estudantes $h_{1}=\{l e 1, l e 2\}$ e $h_{2}=\{l e 3$, le4, le5 $\}$ é representada como a n-upla:

(createLDFundamentalScript ((comp2 s4k3) (comp1 s1k2)) ((le1 le2) (le3 le4 le5))),

na qual, os objetivos são "compreensão do laço for no nível autônomo e restruturação" (comp2 s4k3) e "entendimento do laço while no nível inicial e aperfeiçoamento" (comp1 s1k2).

\subsection{Domínio de planejamento}

O dominio de planejamento $D$ é definido mediante: (1) axiomas e operadores de propósito geral, (2) axiomas de consulta aos modelos de estudante e de domínio a ser ensinado, (3) axiomas de planejamento instrucional, (4) operadores e tarefas básicas que representam interações instrucionais, e (5) tarefas e métodos hierárquicos que representam o modelo pedagógico como estratégias de planejamento instrucional. 


\subsubsection{Axiomas e operadores de propósito geral}

Axiomas e operadores de propósito geral efetuam a manipulação de átomos no estado corrente e podem ser utilizados em quaisquer outro domínio de planejamento. A Tabela 3.4 apresentada um resumo do conjunto de axiomas e operadores de propósito geral detalhados no Apêndice D.

\begin{tabular}{|l|l|}
\hline Axiomas e operador & Descrição \\
\hline \hline (same ?x ?y) & Teste de igualdade. \\
\hline (different ?x ?y) & Teste de não igualdade. \\
\hline (first ?first ?list) & Substituição do primeiro elemento da lista ?list no símbolo variável ?first. \\
\hline (last ?last ?list) & Substituição do ultimo elemento da lista ?list no símbolo variável ?last. \\
\hline (rest ?rest ?list) & $\begin{array}{l}\text { Substituição dos elementos da lista ?list excluindo o primeiro elemento } \\
\text { no símbolo variável ?rest. }\end{array}$ \\
\hline (length ?length ?list) & Calcula a longitude da lista ?list no símbolo variável ?length. \\
\hline (exist ?e ?list) & Teste que verifica a existência de um elemento ?e na lista ?list. \\
\hline (remove ?var ?list1 ?list2) & $\begin{array}{l}\text { Elimina os termos da lista ?list1 que existem na lista ?list2 efetuando a } \\
\text { substituição do resultado no símbolo variável ?var. }\end{array}$ \\
\hline (divide ?var ?list ?n) & $\begin{array}{l}\text { Divide a lista ?list em um número ?n de sublistas efetuando a substituição } \\
\text { do resultado no símbolo variável ?var. }\end{array}$ \\
\hline (duplicate ?var ?list [?n]) & $\begin{array}{l}\text { Duplicar a lista ?list um número ?n de vezes efetuando a substituição do } \\
\text { resultado no símbolo variável ?var. }\end{array}$ \\
\hline (sublist ?var ?list ?n) & $\begin{array}{l}\text { Obtém os ?n primeiros elementos da lista ?list, devolvendo o resultado } \\
\text { no símbolo variável ?var. }\end{array}$ \\
\hline (assignlterator ?var ?list) & $\begin{array}{l}\text { Substituição iterativa do símbolo variável ?var com todos os elementos } \\
\text { da lista ?list. }\end{array}$ \\
\hline (!!addlnWorldState atom) & Efetua a adição de um átomo atom no estado corrente. \\
\hline (!!removeFromWorldState atom) & Efetua a remoção de um átomo atom no estado corrente. \\
\hline
\end{tabular}

Tabela 3.4: Axiomas e operadores de propósito geral

\subsubsection{Axiomas de consulta aos modelos de estudante e de domínio a ser ensinado}

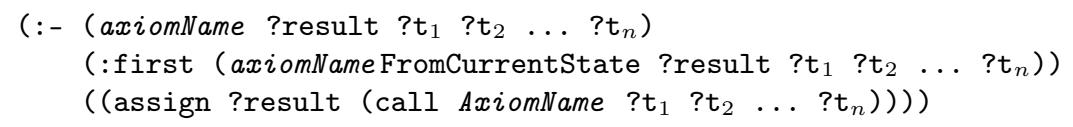

Figura 3.11: Esquema de axiomas de consultas aos modelos de estudante e de dominio a ser ensinado

Os axiomas apresentados a seguir empregam o esquema da Figura 3.11 para realizar primeiro consultas no estado corrente (linha 2). Se não existem dados no estado corrente são efetuadas consultas em repositórios externos mediante termos de chamada (call $f \mathrm{t}_{1} \mathrm{t}_{2} \ldots \mathrm{t}_{n}$ ) (linha 3 ).

\section{Seleção de elementos}

O axioma (getElements ?result ?query) efetua a seleção de elementos dos modelos de estudante e de domínio a ser ensinado que satisfazem as condições da lista ?query. Cada termo da lista ?query pode ser definida como:

- Uma condição de classificação representada pela n-upla (class ?t), na qual ?t é um termo constante ou uma lista de termos que definem a classificação do elemento; 
- Uma condição de propriedade representada pela n-upla (property ?name [?d] ?v), na qual ?name é o nome da propriedade, ?d é o identificador de um elemento de domínio a ser ensinado e ?v é um termo constante ou uma lista de termos que definem valores possíveis da propriedade; e

- Uma condição de relação representada pela n-upla (relation ?name ?e), na qual ?e é um termo constante ou uma lista de termos que definem os elementos ao qual os resultados encontram-se relacionados mediante a relação ?name.

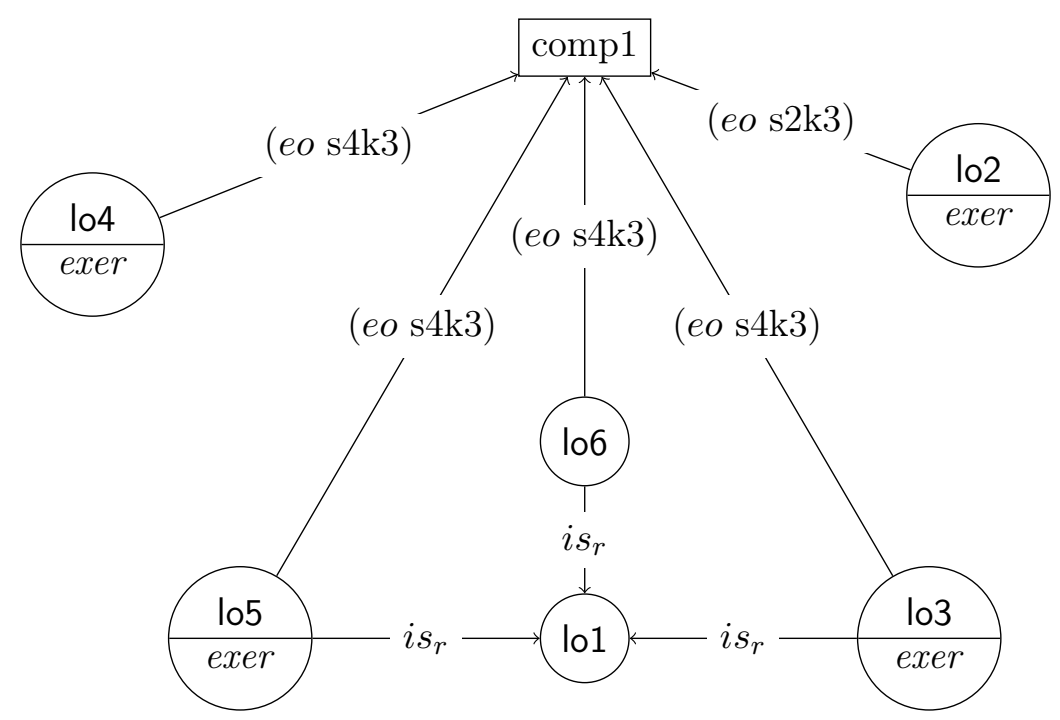

Figura 3.12: Exemplo de seleção de elementos no domínio a ser ensinado

Exemplo 3.3. Sejam os elementos e relações mostrados na Figura 3.12 parte do modelo de domínio a ser ensinado, na qual competências cognitivas são representado como retângulos, elementos de conhecimento de tipo auxiliar são representados por círculos (com tipo de recurso instrucional definido em itálico), as relações de objetivos de aprendizagem (hasLearningObjective) são marcadas com eo e as relações de pré-requisitos (isRequiredBy) são marcadas com $i s_{r}$. O axioma de seleção de elementos

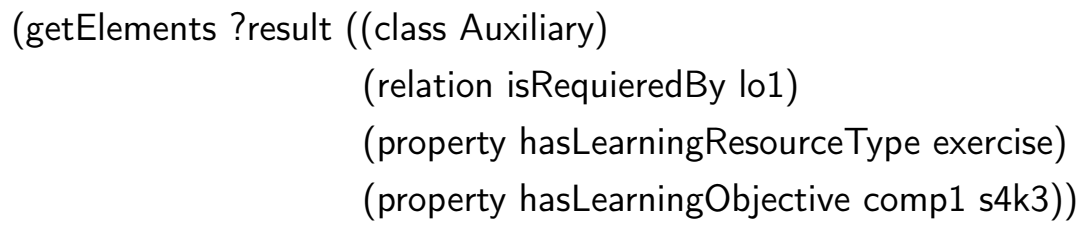

devolve como resultado a lista de identificadores (lo3 lo5) no símbolo de variável ?result.

O axioma (getElement ?result ?query) é uma variante do axioma getElements que efetua a seleção de um único elemento que satisfaz as condições da lista ?query. 


\section{Valores de classificação de elementos}

O axioma (getTypes ?result ?e) obtém os valores de classificação de um elemento ?e ou de uma lista de elementos ?e.

Exemplo 3.4. O axioma (getTypes ?result comp1) usando o modelo de domínio a ser ensinado da Figura 3.12 devolve como resultado a lista (Competency ForFundamental).

O axioma (getType ?result ?e) é uma variante do axioma getTypes que obtém um único valor de classificação de um elemento ?e.

\section{Valores de uma propriedade}

O axioma (getPropertyValues ?result ?e ?name [?d]) obtém os valores das propriedades com nome ?name que pertence a um elemento ?e ou a uma lista de elementos ?e. O atributo opcional ?d é um elemento do domínio a ser ensinado ao qual as propriedades são relacionadas; isto é que os valores obtidos são as substituições de ?v nos átomos (property ?e ?name (?d ?v)).

Exemplo 3.5. Seja o estado corrente $S=\{$ (class Auxiliary lo2), (property lo2 hasDifficult high), (property lo2 hasLearningObjective (c0 s1k2)), (property lo2 hasLearningObjective (c0 s2k3))\}. O axioma (getPropertyValues ?result lo2 hasLearningObjective $\mathrm{c} 0$ ) devolve como resultado a lista de termos (s1k2 s2k3) no símbolo variável ?result.

O axioma (getPropertyValue ?result ?e ?name [?d]) é uma variante do axioma getPropertyValues que obtém um único valor da propriedade ?name de um elemento ?e.

\section{Elementos relacionados}

O axioma (getRelateds ?result ?e ?name) é empregado para obter os elementos relacionados a um elemento ?e ou uma lista de elementos ?e mediante a relação ?name.

O axioma (getRelateds ?result ?e ?d ?name [?query]) efetua a seleção de elementos relacionados à lista de elementos ?e que apresentam a relação ?name em uma distância máxima ?d. O parâmetro opcional ?query é empregado para efetuar a filtragem dos resultados usando as condições definidas na lista ?query.

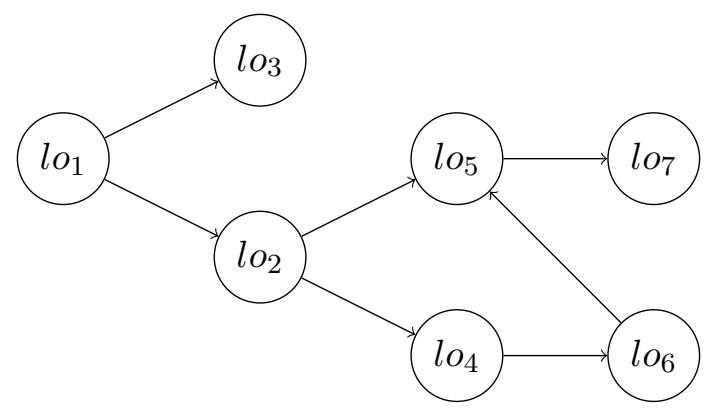

Figura 3.13: Exemplo de seleção de elementos relacionados, arestas representam relações isRequiredBy

Exemplo 3.6. Seja parte do modelo de domínio a ser ensinado representado pelo grafo da Figura 3.13, no qual cada aresta representa a relação isRequiredBy. O axioma (getRelateds ?result (lo1 
lo2) isRequiredBy) devolve como resultado os elementos (lo3 lo2 lo4 lo5) no símbolo de variável ?result, enquanto o axioma (getRelateds ?result (lo4) -1 isRequiredBy) retorna como resultado os elementos (lo5 lo6 lo7).

O axioma (getRelated ?result ?e ?relation) é uma variante do axioma getRelateds que obtém um elemento relacionado ao elemento ?e mediante a relação ?name.

\section{Criação de um novo elemento no domínio a ser ensinado}

O termo de chamada (call BuildElement ?query [?id] [?n]) efetua a construção de um novo elemento no modelo de domínio a ser ensinado de acordo com as características da lista ?query. O parâmetro opcional ?id define o identificado a ser empregado para o elemento. Se o parâmetro opcional ?n é definido será efetuada a construção de n-elementos usando as características da lista ?query com ?id como prefixo desses elementos.

Exemplo 3.7. Seja o estado corrente $S=\{\}$. O termo de chamada

(assign ?result (call BuildElement ((class Output)

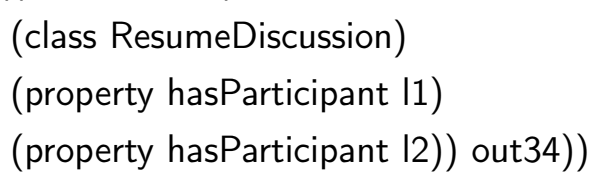

devolve como resultado o identificador out34 no símbolo de variável ?result e muda o estado corrente para $S=\{($ class Output out34), (class ResumeDiscussion out34), (property out34 hasParticipant I1), (property out34 hasParticipant I2)\}.

\subsubsection{Axiomas de planejamento instrucional}

Os axiomas de planejamento instrucional apresentados a seguir são utilizados para definir as precondições e condições relativas de cada método hierárquico. A Tabela 3.5 apresentam um resumo dos axiomas de planejamento instrucional detalhados no Apêndice E. 


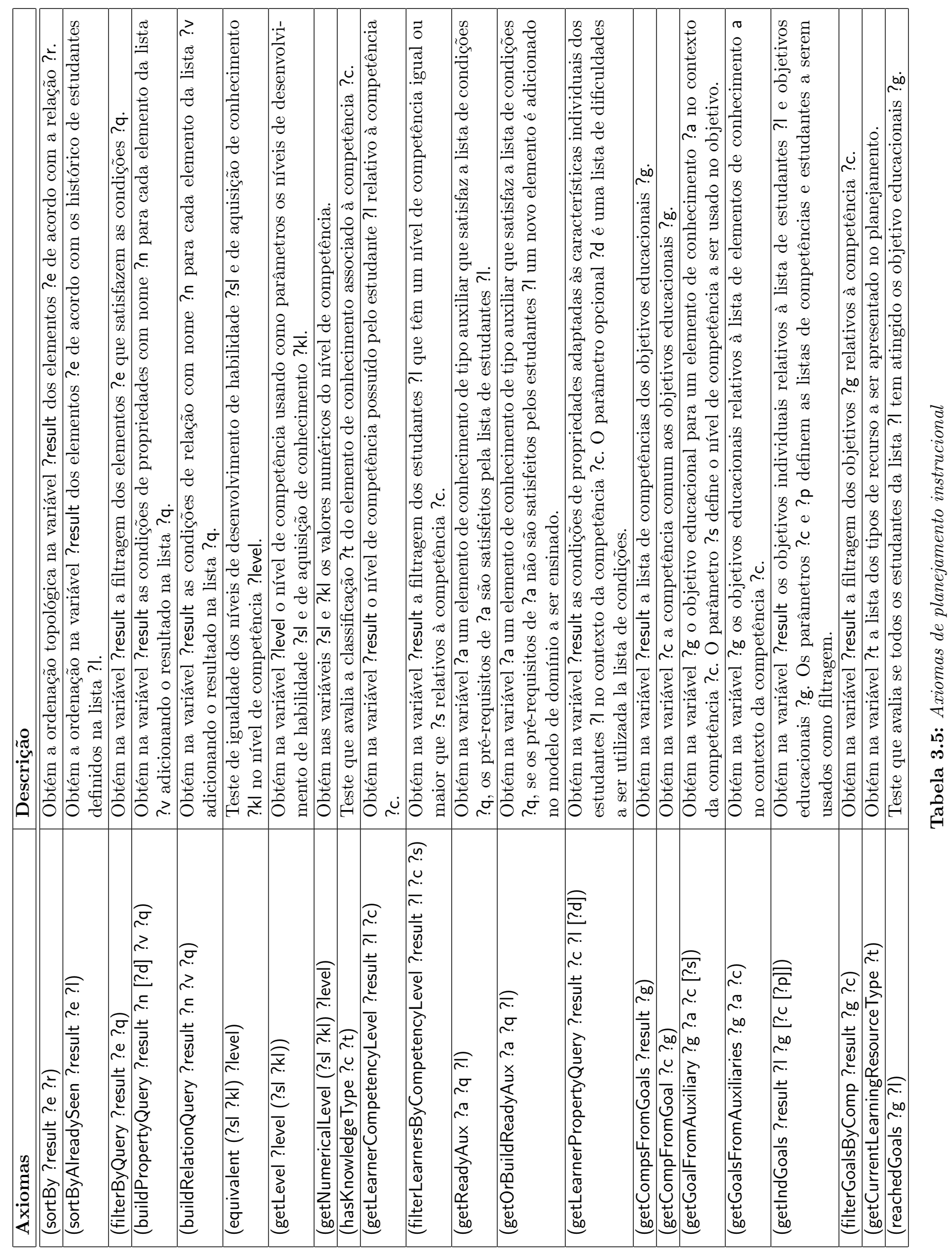




\section{Formação de grupos}

O termo de chamada (call GetCLGrouping ?indGoals [?nro]) efetua a formação de grupos utilizando as diferentes teorias de aprendizagem mediante o algoritmo de formação de grupos definido por Isotani (2009) (nas página 113-114). O parâmetro ?indGoal é a lista de objetivos individuais dos participantes e o parâmetro opcional ?nro define o número de grupos a serem formados pelo algoritmo.

A estrutura de dados empregada para representa a formação de grupos é definida como a lista de termos $\left(\mathrm{clg}_{1} \mathrm{clg}_{2} \ldots \mathrm{clg}_{n 1}\left[\mathrm{ilg}_{1} \mathrm{ilg}_{2} \ldots \mathrm{ilg}_{n 2}\right]\right)$ na qual cada termo $\mathrm{clg}_{i}$ representa um grupo de estudantes associado a uma teoria de aprendizagem e cada termo $i_{g}$ representa um grupo de estudantes não associado a alguma teoria.

Os grupos $\operatorname{clg}_{1}, \operatorname{clg}_{2}, \ldots, \operatorname{clg}_{n 1}$ são representados mediante a estrutura

$$
\text { (theory }\left(\left(\text { strategy }_{1} g_{1} P_{1}\right) \ldots\left(\text { strategy }_{n} g_{n} P_{n}\right)\right) \text { ), }
$$

na qual, theory é o nome da teoria de aprendizagem empregada para definir a formação do grupo e a lista de termos (strategy $\mathrm{g}_{i} \mathrm{P}_{i}$ ) representa a relação de uma estratégia de aprendizagem strategy $_{i}$ empregada pelos participantes $\mathrm{P}_{i}$ para atingir um objetivo educacional $\mathrm{g}_{i}$. Os grupos ilg 1 , ilg $2, \ldots$, ilg n2 $_{2}$ são representados mediante a estrutura

$$
\text { (independent }\left(\left(\text { indstrategy } \mathrm{g}_{1} \mathrm{P}_{1}\right) \ldots\left(\text { indstrategy } \mathrm{g}_{n 2} \mathrm{P}_{n 2}\right)\right) \text { ), }
$$

na qual, a lista de termos (indstrategy $\mathrm{g}_{j} \mathrm{P}_{j}$ ) representa a relação entre participantes $\mathrm{P}_{j}$ e seu correspondente objetivo $\mathrm{g}_{j}$.

Exemplo 3.8. O axioma

(assign ?result (call GetCLGrouping ((I1 (c1 s2k1s2k2)) (I2 (c1 s2k2s2k3)) (I3 (c1 s2k1s3k1))

$$
(14(\mathrm{c} 1 \mathrm{~s} 2 \mathrm{k} 2 \mathrm{~s} 2 \mathrm{k} 3))(15(\mathrm{c} 1 \mathrm{~s} 3 \mathrm{k} 0 \mathrm{~s} 3 \mathrm{k} 1)))))
$$

devolve no símbolo de variável ?result como resultado a lista de termos

((cognitive-flexibility ((learning-by-reflection (c1 s2k3) (I2 14))

(learning-by-selfexpression (c1 s3k1) (I3))))

(peer-tutoring ((learning-by-teaching (c1 s2k2) (I5))

(learning-by-being-taught (c1 s3k1) (I1))))).

A lista representa a formação de dois grupos $G_{1}=\{\mid 2,13,14\}$ e $G_{2}=\{11,15\}$ usando as teorias de aprendizagem cognitive-flexibility e peer-tutoring. No grupo $G_{1}$, os estudantes 12 e 14 empregam a estratégias de aprendizagem learning-by-reflection para atingir o objetivo (c1 s2k3), enquanto o estudante 13 emprega a estratégia de aprendizagem learning-by-selfexpression.

Os axiomas (getGoalsFromCLGrouping ?result ?clg) e (getGroupsFromCLGrouping ?result ?clg) obtém a lista de objetivos educacionais e grupos a partir de um termo da estrutura de formação de grupos ?clg, devolvendo o resultado no símbolo de variável ?result. Usando o primeiro elemento da estrutura mostrada no exemplo anterior relativo à teoria de aprendizagem cognitive-flexibility, o axioma getGoalsFromCLGrouping devolve como resultado a lista ((c1 s2k3) (c1 s3k1)), enquanto getGroupsFromCLGrouping devolve como resultado a lista ((I2 I4) (I3)). 


\subsubsection{Tarefas básicas e operadores que representam as interações instrucionais}

As tarefas básicas e os operadores de planejamento apresentados a seguir representam as interações instrucionais. Os operadores e tarefas básicas (resumidas na Tabela 3.6) são classificadas de acordo com as etapas de planejamento instrucional em edição, configuração e instanciação.

\begin{tabular}{|c|c|}
\hline Identificador & Descrição \\
\hline \multicolumn{2}{|l|}{ (a) Etapa: Edição } \\
\hline !startLDElement & Criação da etiqueta de abertura de um elemento IMS-LD. \\
\hline !endLDElement & Criação da etiqueta de fechamento de um elemento IMS-LD. \\
\hline startLDElement! & $\begin{array}{l}\text { Criação da etiqueta de abertura de um elemento IMS-LD, } \\
\text { incluindo informação dos objetivos individuais. }\end{array}$ \\
\hline !!changelndGoals & Alterar os objetivos individuais no elemento IMS-LD corrente. \\
\hline !!changeCurrentLDElement & Alterar os elementos IMS-LD correntes. \\
\hline !!changeLearningResourceType & Alterar o tipo de recurso instrucional no elemento IMS-LD corrente. \\
\hline !!changeFundCompetency & Alterar a competência fundamental no elemento IMS-LD corrente. \\
\hline !!changeCLGrouping & Alterar informação do agrupamento no elemento IMS-LD corrente. \\
\hline \multicolumn{2}{|l|}{ (b) Etapa: Configuração } \\
\hline !addUsersToRole & Atribuição de um papel a um participante. \\
\hline addUsersToRole & Atribuição de um papel a um conjunto de participante. \\
\hline !removeUserFromRole & Remoção de um papel de um participante. \\
\hline removeUsersFromRole & Remoção de um papel a um conjunto de participantes. \\
\hline !addUserToGroup & Adição de um participante a um grupo. \\
\hline addUsersToGroup & Adição de um conjunto de participantes a um grupo. \\
\hline !removeUserFromGroup & Remoção de um um participante de um grupo. \\
\hline removeUsersFromGroup & Remoção de um conjunto de participante de um grupo. \\
\hline \multicolumn{2}{|l|}{ (c) Etapa: Instanciação } \\
\hline !text & Inserir um texto. \\
\hline createLDTitle & Criação de um rotulo com o nome do elemento IMS-LD. \\
\hline !insertElement & Inserção de um elemento do domínio a ser ensinado. \\
\hline ! insertResource & Criação do elemento < resource > na unidade de aprendizagem. \\
\hline insertResourceOnce & Inserção de um recurso instrucional (uma única inserção por UoL). \\
\hline !!addInWorldStateAsAlreadySeen & Alterar registro histórico do modelo de estudante. \\
\hline createLDItem & Criação do elemento $<$ item $>$. \\
\hline createLDInstructltem & Criação do elemento < item $>$ no evento instrucional. \\
\hline createLDLearningltem & Criação do elemento <item $>$ no evento de aprendizagem. \\
\hline
\end{tabular}

Tabela 3.6: Tarefas básicas e operadores que representam as interações instrucionais

\section{Tarefas básicas e operadores de planejamento utilizados na fase de edição}

As tarefas básicas e operadores de planejamento apresentados a seguir irão definir a criação dos elementos de roteiros colaborativos descritos na especificação IMS-LD. Assim, os operadores !startLDElement e !endLDElement mostrados na Figura 3.14 são utilizados para definir a criação de uma etiqueta de abertura e fechamento de um elemento XML, onde:

- O símbolo de variável ?tag é um nome do marcador; e

- O símbolo de variável ?params é uma lista ((attribute value $\left._{1}\right) \ldots\left(\right.$ attribute $_{n}$ value $\left.\left._{n}\right)\right)$ que representam atributos attribute $_{i}=$ "value" no elemento XML. 


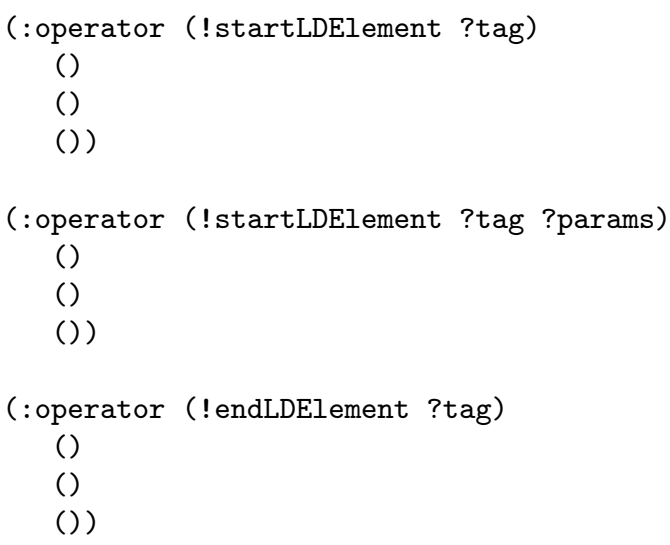

Figura 3.14: Operadores !startLDElement e !endLDElement básicos

Além dos operadores !startLDElement básicos apresentados na Figura 3.14, definimos os operadores !startLDElement mostrados nas Figuras 3.15 e 3.16, que efetuam a criação da etiqueta de abertura de um elemento de roteiro com identificador ?id. Os operadores adicionam no estado corrente informações de metadado (linhas 9-15), atitudes (linhas 38-39, Figura 3.16) e habilidades (linhas 36-37, Figura 3.16). As informações de metadado são classificação ?types (linhas 9-10), objetivos educacionais ?goals (linhas 11-13) e participantes ?learners (linhas 14-15).

Outras informações obtidas dos elementos de roteiro corrente ?parents (linha 4) a ser incluída pelos operadores !startLDElement no estado corrente são competências relativas aos elementos de conhecimento fundamental ?c (linhas 17-19), tipos de recurso instrucional t (linhas 21-23) e informações de agrupamento (linhas 25-34). A informações de agrupamento são nome da teoria de aprendizagem ?cn (linha 31), estratégias de aprendizagem ?sn (linha 32), objetivos educacionais da estratégia ?g (linha 33) e participantes da estratégia ?ls (linha 34).

Os operadores !startLDElement mudam os valores dos elementos de roteiro colaborativo corrente mediante a remoção dos átomos lógicos (class CurrentLDElement ?e) (linhas 6-7) e adição do átomo (class CurrentLDElement ?id) (linha 42, Figura 3.15; linha 45, Figura 3.16). Finalmente, os operadores efetuam a definição da estrutura de roteiro mediante a adição de átomos lógicos (relation ?id isPartOf ?p) (linhas 36-42, Figura 3.15) (linhas 41-45, Figura 3.16).

Além do operador !endLDElement básico apresentados na Figura 3.14, definimos o operador !endLDElement mostrado na Figura 3.17 para efetuar a criação da etiqueta de fechamento de um elemento do roteiro com identificador ?id. O operador remove do estado corrente as informações de agrupamento (linhas 17-22) e os objetivos individuais (linhas 9-11). O operador também atualiza os níveis de competência dos estudantes (linhas 12-15, 27-31) mediante a substituição dos níveis de competência corrente por níveis definidos nos objetivos individuais ?indGoals. 


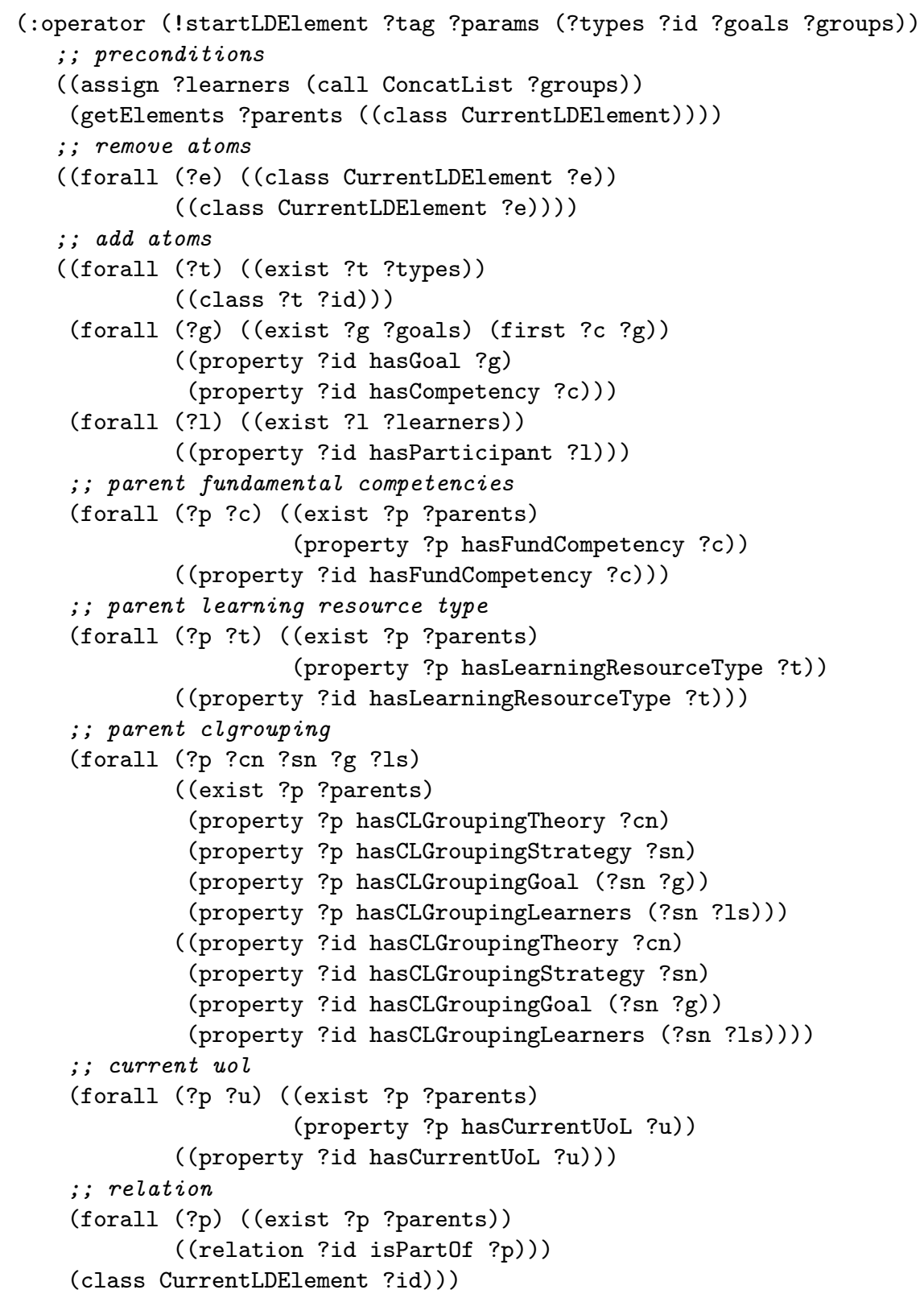

Figura 3.15: Operador !startLDElement com informação de meta-dados 


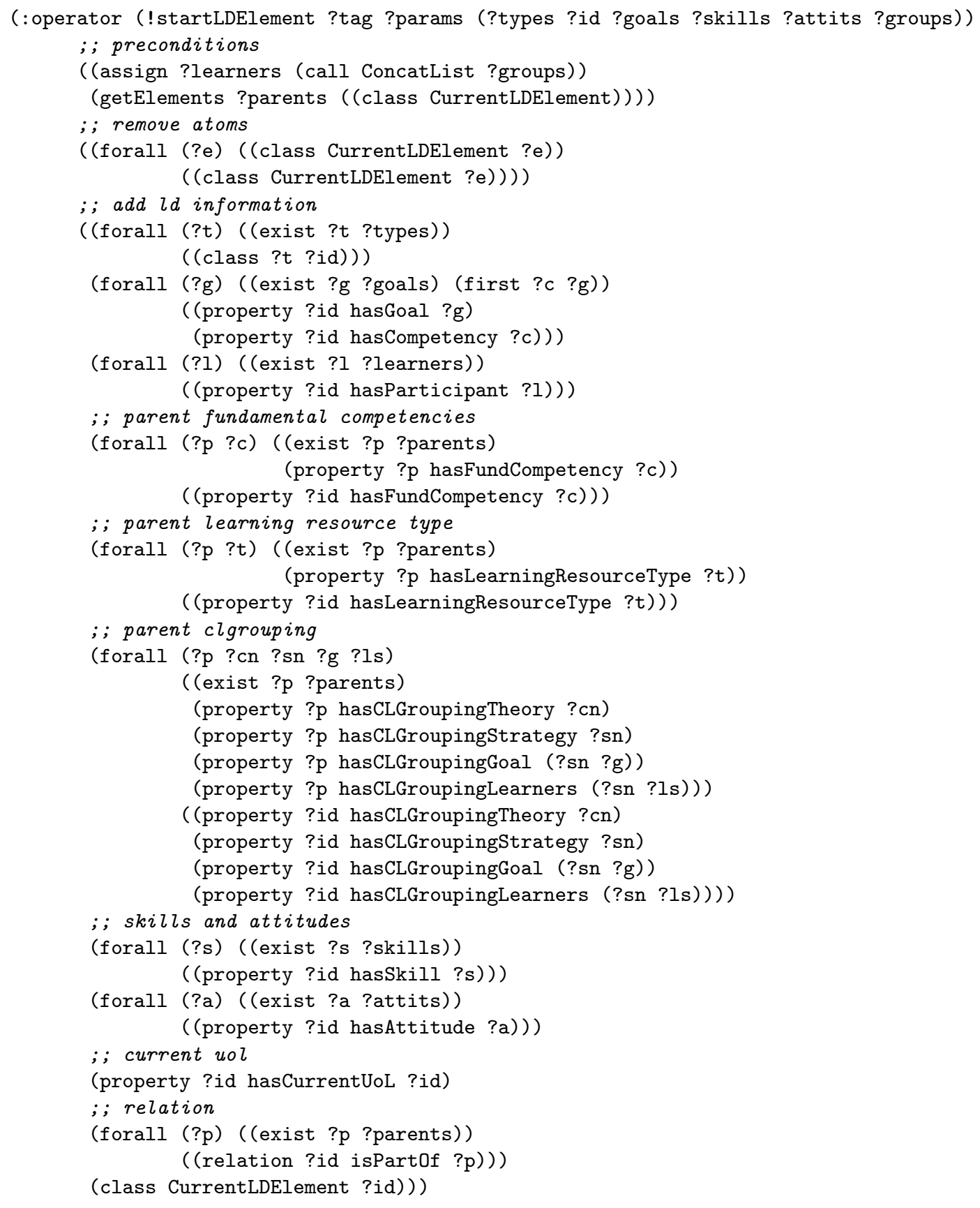

Figura 3.16: Operador !startLDElement com informações de meta-dados, atitudes e habilidades 


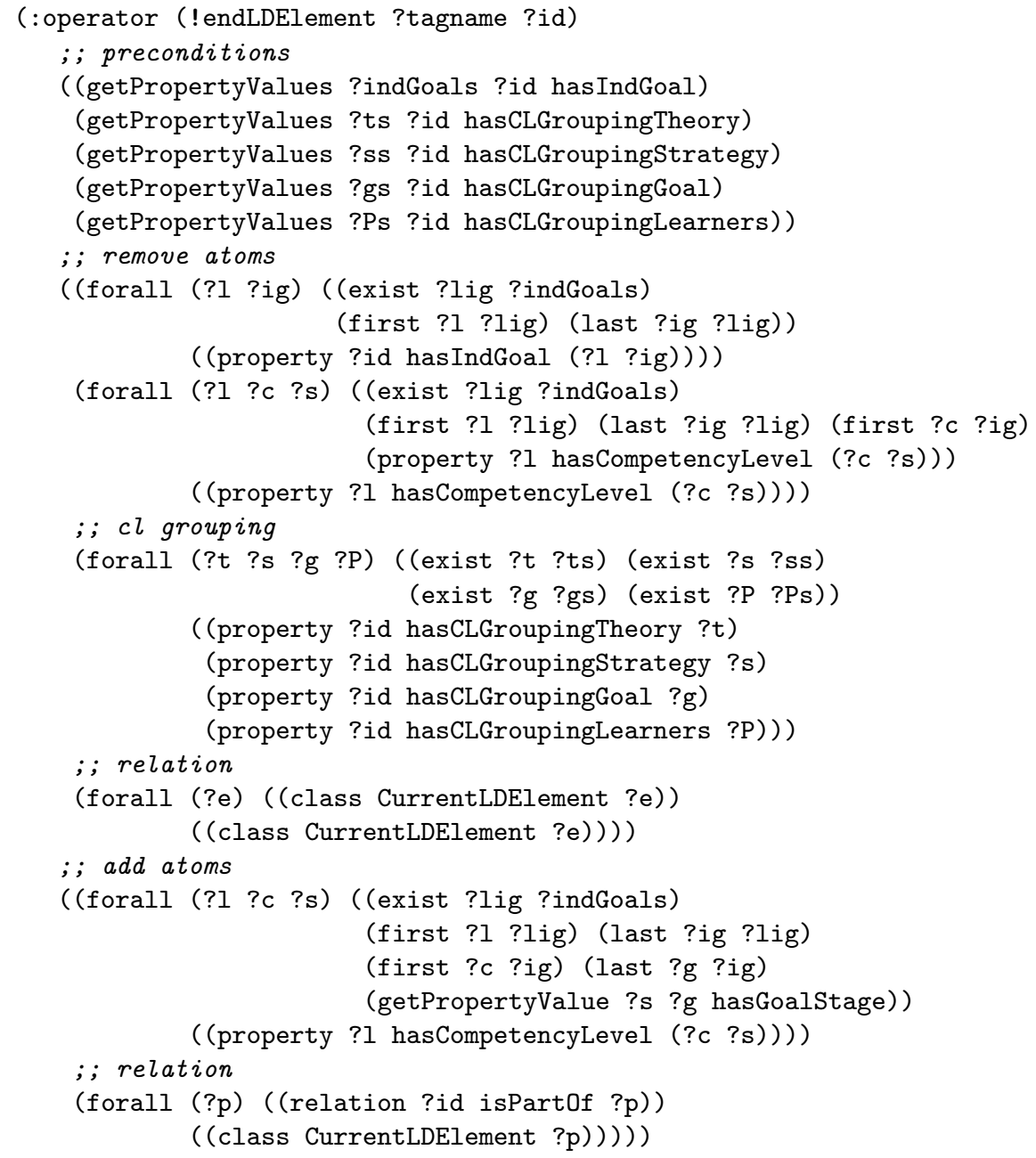

Figura 3.17: Operador !endLDElement para elementos de roteiros colaborativos 
Exemplo 3.9. Seja a lista de tarefas

$\mathrm{T}=(($ !startLDElement learning-activity ((identifier la123f342))

((Session) la123f342 ((c1 s1k2) (c1 s1k1)) ((I1 I2) (I3 I4))))

(!endLDElement learning-activity la123f342))

no estado $S=\{$ (currentLDElement as4e12d23), (property as4e12d23 hasFundCompetency ?c0) $\}$. $\mathrm{O}$ resultado $S_{1}$ de aplicar a primeira tarefa de acordo com a função $\gamma$ de transição de estados é

$\gamma(S, T[1])=\{$ (currentLDElement la123f342), (class Session la123f342),

(relation la123f342 isPartOf rp4e12d23), (property la123f342 hasGoal (c1 s1k1)),

(property la123f342 hasGoal (c1 s1k2)), (property la123f342 hasCompetency c1),

(property la123f342 hasFundCompetency c0), (property la123f342 hasParticipant I1),

(property la123f342 hasParticipant I2), (property la123f342 hasParticipant I3),

(property la123f342 hasParticipant 14)\}.

No estado $S_{1}$ o elemento de roteiro la123f342 é parte de um elemento as4e12d23. O elemento la123f342 é de classificação sessão (Session) com objetivo educacionais (c1 s1k1) e (c1 s1k2) a ser atingido pelos participantes I1, I2, I3 e 14 .

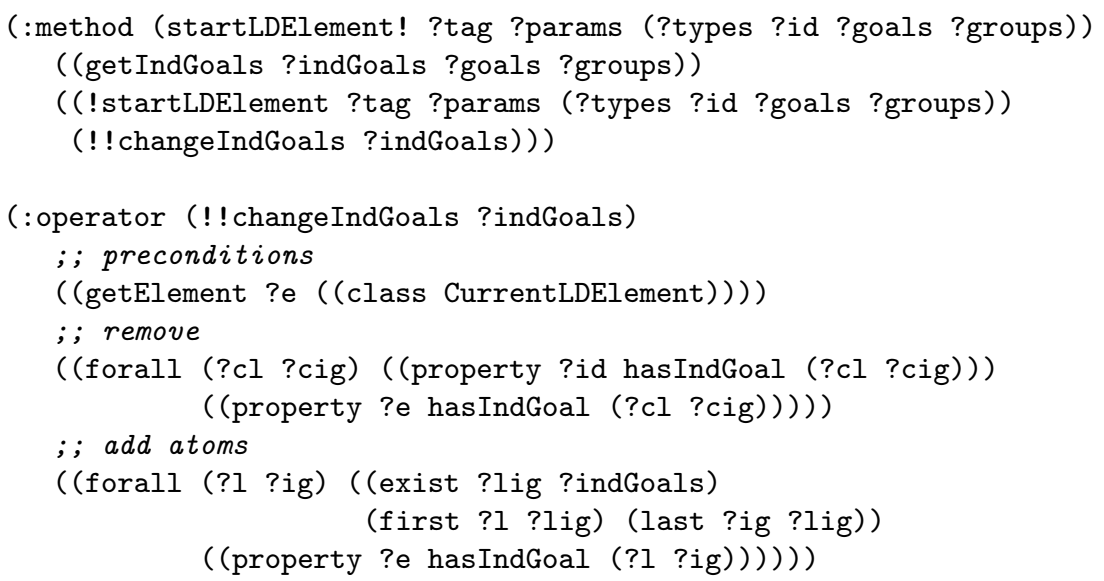

Figura 3.18: Tarefa de criação de um elemento de roteiros que atualiza os níveis de competência

Para definir mudanças nos níveis de competência ao término de execução de um elemento de roteiro, a tarefa startLDElement! mostrada na Figura 3.18 utiliza o operador !!changelndGoals (linha 4) para alterar a informação dos objetivos individuais no elemento corrente ?e (linha 8). 
Exemplo 3.10. Seja a lista de tarefas

$\mathrm{T}=(($ !startLDElement learning-activity ((identifier la123f342))

$$
\text { ((Session) la123f342 ((c1 s1k2) (c1 s1k1)) ((I1 I2) (I3 |4)))) }
$$

(!!changelndGoals ((I1 (c1 s1k0s1k2)) (I2 (c1 s0k0s1k2)) (I3 (c1 s1k1s1k1)) (14 ( s0k0s1k1))))

(!endLDElement learning-activity la123f342))

no estado corrente do mundo $S=\{$ (property I1 hasCompetencyLevel (c1 s1k0)), (property I3 hasCompetencyLevel (c1 s1k1))\}. O resultado $\mathrm{S}_{2}$ de aplicar as tarefas $\mathrm{T}[1]$ e $\mathrm{T}[2]$ de acordo com a função $\gamma$ de transição de estados é

$S_{2}=\{$ (currentLDElement la123f342), (class Session la123f342),

(property la123f342 hasCompetency c1),

(property la123f342 hasGoal (c1 s1k1)), (property la123f342 hasGoal (c1 s1k2)),

(property la123f342 hasParticipant I1), (property la123f342 hasParticipant I2),

(property la123f342 hasParticipant 13), (property la123f342 hasParticipant 14),

(property 11 hasCompetencyLevel (c1 s1k0)), (property 13 hasCompetencyLevel ( $c 1 s 1 k 1)$ ),

(property la123f342 hasIndGoal (I1 (c1 s1k0s1k2))),

(property la123f342 hasIndGoal (I2 (c1 s0k0s1k2))),

(property la123f342 hasIndGoal (I3 (c1 s1k1s1k1))),

(property la123f342 hasIndGoal (14 ( s0k0s1k1)))\}.

Logo, o estado $S_{3}=\gamma\left(S_{2}, T[3]\right)$ representa o término da construção do elemento la123f342, no qual os estudantes I1, I2, I3 e I4 alcançam os níveis de competência inicial-crescimento (s1k1) e inicial-aperfeiçoamento (s1k2) na competência cognitiva $\mathrm{c} 1$.

$S_{3}=\{$ (class Session la123f342), (property la123f342 hasCompetency c1)

(property la123f342 hasGoal (c1 s1k1)), (property la123f342 hasGoal (c1 s1k2)),

(property la123f342 hasParticipant I1), (property la123f342 hasParticipant I2),

(property la123f342 hasParticipant 13), (property la123f342 hasParticipant 14),

(property 11 hasCompetencyLevel (c1 s1k2)), (property 12 hasCompetencyLevel (c1 s1k2)),

(property 13 hasCompetencyLevel (c1 s1k1)), (property 14 hasCompetencyLevel (c1 s1k1))\}.

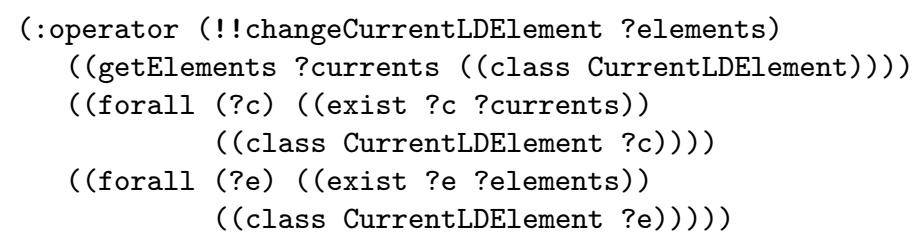

Figura 3.19: Operador !!changeCurrentLDElement que altera o elemento corrente de planejamento 


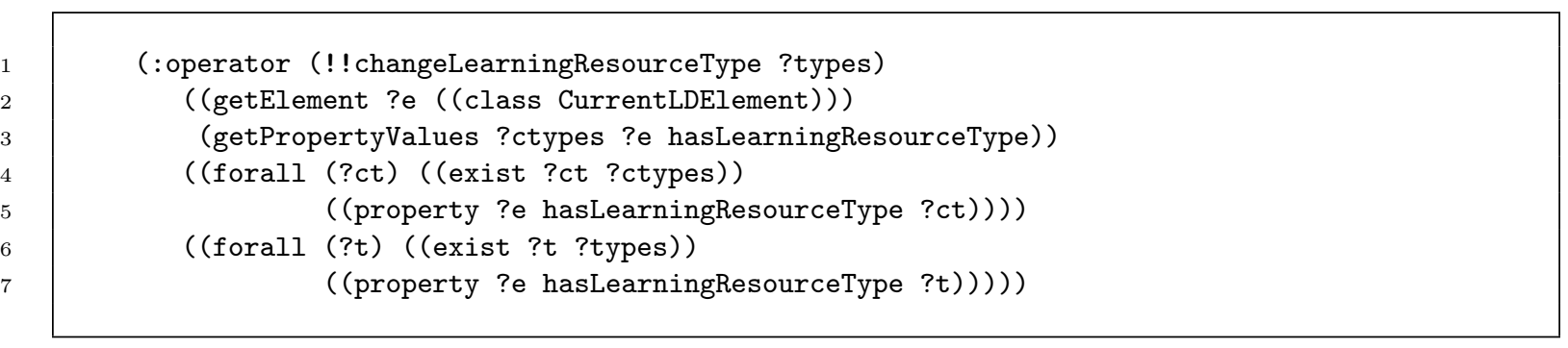

Figura 3.20: Operador utilizado para alterar o tipo de recurso instrucional

O operador !!changeCurrentLDElement mostrado na Figura 3.19 é utilizado para alterar a informação dos objetivos individuais no elemento de roteiro que está sendo objeto do processo de planejamento instrucional.

A Figura 3.20 mostra o operadores !!changeLearningResourceType utilizado para efetuar a alteração da informação do tipo de recurso instrucional a ser apresentado. Enquanto, a Figura 3.21 mostra o operador !!changeFundCompetency utilizado para efetuar a alteração da informação da competência fundamental no elemento de roteiro corrente ?e.

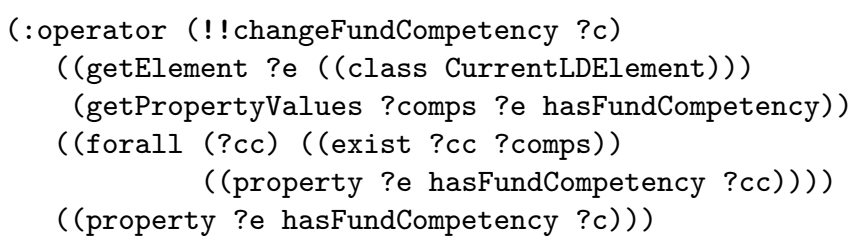

Figura 3.21: Operador utilizado para alterar a competência fundamental

Os operadores !!changeCLGrouping mostrados na Figura 3.22 efetua mudanças na informação de agrupamento do elemento de roteiro colaborativo corrente ?e (linhas 2, 14, 26, 45). O operador emprega a estrutura de formação de grupos definida pelo termo de chamada GetCLGrouping. Assim, se a estrutura é vazia (primeiro operador, linhas 1-11) ou independente (segundo operador, linhas 13-23) é efetuada a remoção das informações relativas ao agrupamento. O terceiro operador (linhas 25-38) adiciona as informações do agrupamento usando a estrutura (?t ?sgPs) (linhas 27-30). O quarto operador (linhas 40-57) efetua a substituição das informações de agrupamento usando informações extraídas do elemento de roteiro com identificador ?id (linhas 41-44). 
(:operator (!) changeCLGrouping ())

((getElement ?e ((class CurrentLDElement)))

(getPropertyValues ?ts ?e hasCLGroupingTheory)

(getPropertyValues ?ss ?e hasCLGroupingStrategy)

(getPropertyValues ?gs ?e hasCLGroupingGoal)

(getPropertyValues ?Ps ?e hasCLGroupingLearners))

((forall (?t ?s ?g ?P) ((exist ?t ?ts) (exist ?s ?ss)

(exist ?g ?gs) (exist ?P ?Ps))

((property ?e hasCLGroupingTheory ?t) (property ?e hasCLGroupingStrategy ?s) ())

(property ?e hasCLGroupingGoal ?g) (property ?e hasCLGroupingLearners ?P))))

(:operator (!!changeCLGrouping (independent ?sgPs))

((getElement ?e ((class CurrentLDElement)))

(getPropertyValues ?ts ?e hasCLGroupingTheory)

(getPropertyValues ?ss ?e hasCLGroupingStrategy)

(getPropertyValues ?gs ?e hasCLGroupingGoal)

(getPropertyValues ?Ps ?e hasCLGroupingLearners))

((forall (?t ?s ?g ?P) ((exist ?t ?ts) (exist ?s ?ss)

(exist ?g ?gs) (exist ?P ?Ps))

((property ?e hasCLGroupingTheory ?t) (property ?e hasCLGroupingStrategy ?s) ())

(property ?e hasCLGroupingGoal ?g) (property ?e hasCLGroupingLearners ?P))))

(:operator (!! changeCLGrouping (?t ?sgPs))

((getElement ?e ((class CurrentLDElement)))

(getPropertyValues ?cts ?e hasCLGroupingTheory)

(getPropertyValues ?css ?e hasCLGroupingStrategy)

(getPropertyValues ?cgs ?e hasCLGroupingGoal)

(getPropertyValues ?cPs ?e hasCLGroupingLearners))

((forall (?ct ?cs ?cg ?cP) ((exist ?ct ?cts) (exist ?cs ?css)

(exist ?cg ?cgs) (exist ?cP ?cPs))

((property ?e hasCLGroupingTheory ?ct) (property ?e hasCLGroupingStrategy ?cs)

(property ?e hasCLGroupingGoal ?cg) (property ?e hasCLGroupingLearners ?cP)))

((forall (?s ?g ?P) ((exist ?sgP ?sgPs) (first ?s ?sgP)

(rest ?gP ?sgP) (first ?g ?gP) (last ?P ?gP))

((property ?e hasCLGroupingTheory ?t) (property ?e hasCLGroupingStrategy ?s)

(property ?e hasCLGroupingGoal (?s ?g)) (property ?e hasCLGroupingLearners (?s ?P))))) )

(:operator (!! changeCLGrouping ?id)

( (getPropertyValues ?ts ?id hasCLGroupingTheory)

(getPropertyValues ?ss ?id hasCLGroupingStrategy)

(getPropertyValues ?gs ?id hasCLGroupingGoal)

(getPropertyValues ?Ps ?id hasCLGroupingLearners)

(getElement ?e ((class CurrentLDElement)))

(getPropertyValues ?cts ?e hasCLGroupingTheory)

(getPropertyValues ?css ?e hasCLGroupingStrategy)

(getPropertyValues ?cgs ?e hasCLGroupingGoal)

(getPropertyValues ?cPs ?e hasCLGroupingLearners))

((forall (?ct ?cs ?cg ?cP) ((exist ?ct ?cts) (exist ?cs ?css)

(exist ?cg ?cgs) (exist ?cP ?cPs))

((property ?e hasCLGroupingTheory ?ct) (property ?e hasCLGroupingStrategy ?cs)

(property ?e hasCLGroupingGoal ?cg) (property ?e hasCLGroupingLearners ?cP))) )

((forall (?t ?s ?g ?P) ((exist ?t ?ts) (exist ?s ?ss)

(exist ?g ?gs) (exist ?P ?Ps))

((property ?e hasCLGroupingTheory ?t) (property ?e hasCLGroupingStrategy ?s)

(property ?e hasCLGroupingGoal ?g) (property ?e hasCLGroupingLearners ?P)))))

Figura 3.22: Operador !!changeCLGrouping que altera a informação de agrupamento 
Exemplo 3.11. Seja a lista de tarefas

$\mathrm{T}=(($ ! changeCLGrouping (peer-tutoring ((learning-by-teaching (c1 s1k2) (I1 I2)) (learning-by-being-taugh (c1 s1k1) (|3 |4)))))

(!startLDElement role-part ((identifier rpf3a2)) ((GroupActivity) rpf3a2 ((c1 s1k2) (c1 s1k1)) ((I1 I2) (I3 I4))))

(!!changeLearningResourceType (exercise))

(!endLDElement learning-activity rp13ae24))

no estado corrente do mundo $S=\{\}$, o resultado $S_{3}=\gamma(\gamma(\gamma(\mathrm{S}, T[1]), T[2]), T[3])$ de aplicar as tarefas T[1], T[2] e T[3] de acordo com a função $\gamma$ de transição de estados é

$S_{3}=\{$ (currentLDElement rpf3a2), (class GroupActivity rpf3a2),

(property rpf3a2 hasCompetency c1), (property rpf3a2 hasLearningResourceType exercise),

(property rpf3a2 hasGoal (c1 s1k1)), (property rp13ae24 hasGoal (c1 s1k2)),

(property rpf3a2 hasParticipant I1), (property rp13ae24 hasParticipant I2),

(property rpf3a2 hasParticipant 13), (property rp13ae24 hasParticipant 14),

(property rpf3a2 hasIndGoal (I1 (c1 s1k0s1k2))),

(property rpf3a2 hasIndGoal (I2 (c1 s0k0s1k2))),

(property rpf3a2 hasIndGoal (I3 (c1 s1k1s1k1))),

(property rpf3a2 hasIndGoal (14 (c1 s0k0s1k1))),

(property rpf3a2 hasCLGroupingTheory peer-tutoring),

(property rpf3a2 hasCLGroupingStrategy learning-by-teaching),

(property rpf3a2 hasCLGroupingGoal (learning-by-teaching (c1 s1k2))),

(property rpf3a2 hasCLGroupingLearners (learning-by-teaching (I1 I2))),

(property rpf3a2 hasCLGroupingStrategy learning-by-being-taugh),

(property rpf3a2 hasCLGroupingGoal (learning-by-being-taugh (c1 s1k2))),

(property rpf3a2 hasCLGroupingLearners (learning-by-being-taugh (I3 I4)))\}.

No estado $S_{3}$, o átomo (property rpf3a2 hasLearningResourceType exercise) é adicionado pela ação $T[3]=($ !!changeLearningResourceType (exercise)) e os átomos das propriedades hasCLGroupingTheory, hasCLGroupingStrategy, hasCLGroupingGoal e hasCLGroupingLearners são adicionadas pela ação $T[1]=($ !!changeCLGrouping (peer-tutoring ((learning-by-teaching (c1 s1k2) (I1 I2)) (learning-by-being-taugh (c1 s1k1) (I3 14))))). 
Tarefas básicas e operadores de planejamento utilizados na fase de configuração

As tarefas básicas e os operadores de planejamento apresentados a seguir representam interações instrucionais a serem efetuadas na fase de configuração dos roteiros.

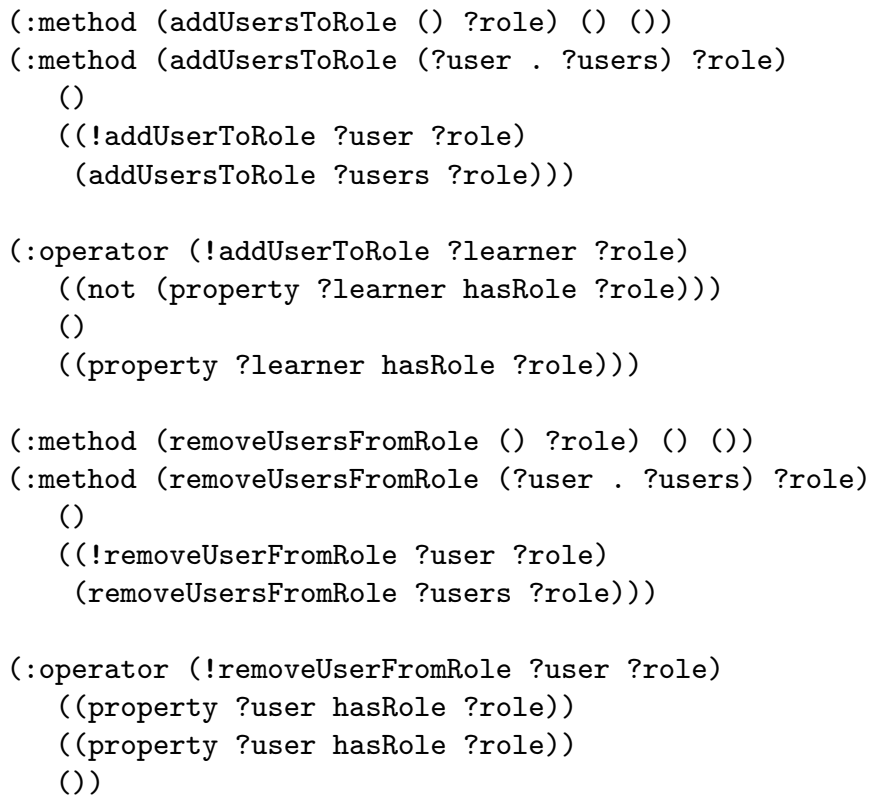

Figura 3.23: Tarefas básicas e operadores utilizados na adição e remoção de papéis

A tarefa básica addUsersToRole (linhas 1-5) e o operador !addUserToRole (linhas 7-10) mostrados na Figura 3.23 são utilizados para definir a atribuição de um papel ?role ao conjunto participantes ?users ou participante ?user. A atribuição de um papel é representada mediante o átomo lógico (property ?user hasRole ?role). A tarefa básica removeUsersFromRole (linhas 12-16) e o operador !removeUserFromRole são utilizados para definir a remoção de um papel ?role em um conjunto de participantes ?users ou participante ?user.

Exemplo 3.12. Sejam o estado corrente do mundo $S=\{\}$ e a lista de tarefas $\mathrm{T}=$ ((!addUserToRole I1 tutor) (!addUserToRole I2 tutee) (!removeUserFromRole I1 tutor)).

O resultado de executar a primeira e segunda tarefa de acordo à função $\gamma$ de transição de estados é $S_{2}=\gamma(\gamma(S, T[1]), T[2])=\{$ (property $\mathrm{I} 1$ hasRole tutor), (property $\mathrm{I} 2$ hasRole tutee) $\}$ devido a que a tarefa (!addUserToRole I1 tutor) adiciona o átomo (property I1 hasRole tutor), enquanto a tarefa (!addUserToRole 12 tutee) adiciona o átomo (property 12 hasRole tutee).

A tarefa básica addUsersToGroup (linhas 1-5) e o operador !addUserToGroup (linhas 7-10) mostrados na Figura 3.23 são utilizados para definir a adição de um participante ?user ou conjunto de participantes ?users ao grupo ?group. A tarefa básica removeUsersFromGroup (linhas 12-16) e o operador !removeUserFromGroup são utilizados para definir a remoção de um participante ?user ou conjunto de participantes ?users de um grupo ?group. 


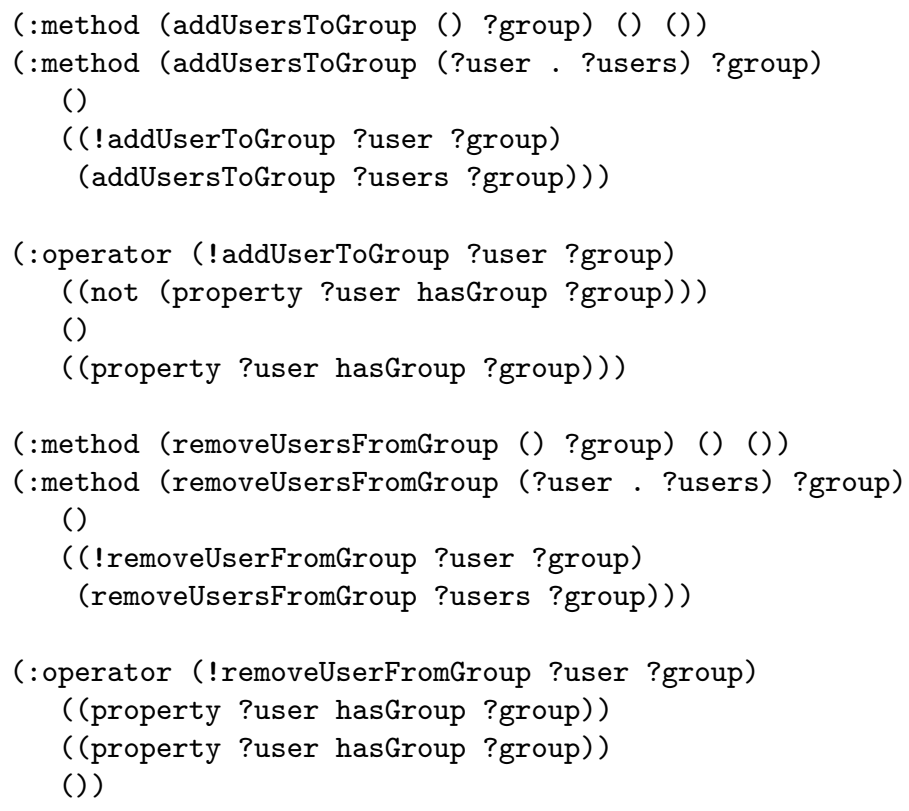

Figura 3.24: Tarefas básicas e operadores utilizado na adição e remoção de um grupo

Exemplo 3.13. Seja o estado $S=\{$ (property $\mid 1$ hasGroup g1) (property $\mid 2$ hasGroup g2) $\}$ e a lista

$$
\mathrm{T}=((\text { !removeUserFromGroup I1 g1) (!addUserToGroup I2 g1) (!addUserToGroup I3 g1)) }
$$

O resultado de aplicar a tarefa $T[1]$ de acordo à função $\gamma$ de transição de estados é $S_{1}=$ $\gamma(S, T[1])=\{$ (property 12 hasGroup g2) $\}$ devido à remoção do átomo (property 11 hasGroup g1). O estado depois de efetuar as tarefas $T[2]$ e $T[3]$ é $S_{3}=\gamma\left(\gamma\left(S_{1}, T[2]\right), T[3]\right)=\{($ property 12 hasGroup g2) (property 12 hasGroup g1) (property 13 hasGroup g1)\} devido à adição do átomo (property 12 hasGroup g1) na tarefa (!addUserToGroup I2 g1) e a adição do átomo (property I3 hasGroup g1) na tarefa (!addUserToGroup $13 \mathrm{~g} 1$ ). 
Tarefas básicas e operadores de planejamento utilizados na fase de instanciação

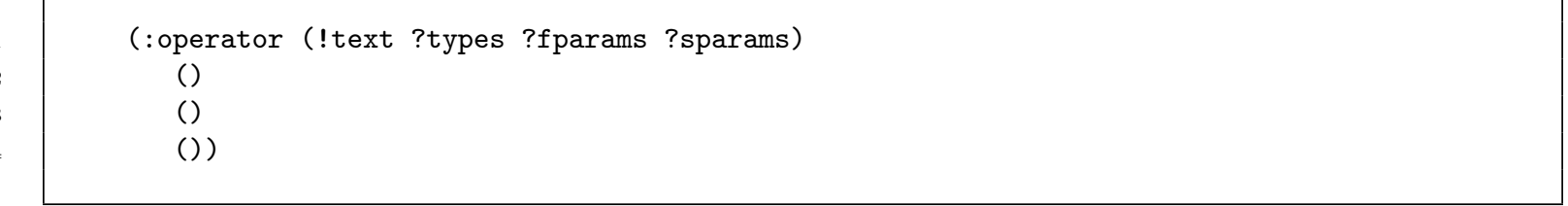

Figura 3.25: Inserção de um texto

O operador !text mostrado na Figura 3.25 define a interação instrucional de inserção de um texto no roteiro. Os textos nos roteiros colaborativos são utilizados como apoio ao entendimento da estrutura e dos objetivos educacionais. Assim, o parâmetro ?type define a estrutura à qual pertence o texto, o parâmetro ?fparams definem parâmetros principais do texto, e ?sparams definem parâmetros opcionais do texto. A tarefa createLDTitle mostrada na Figura 3.26 efetua a criação de um elemento < title> que contém a descrição do elemento IMS-LD.

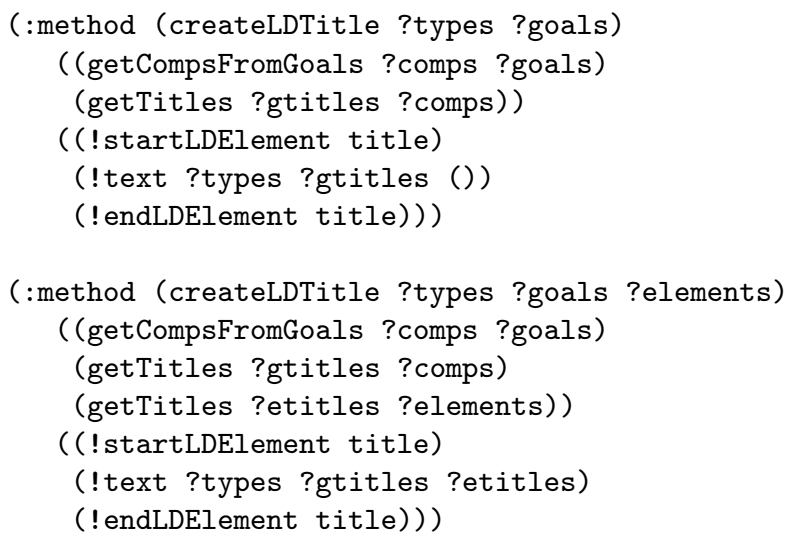

Figura 3.26: Tarefa básica de criação de um rótulo titulo com o nome do elemento IMS-LD

A obtenção do texto a ser inserido no roteiro emprega o esquema de valores da Figura 3.27 pelo qual uma ação (!text $\left.\left(t_{0} t_{1} \ldots t_{n}\right)\left(f_{0} f_{1} \ldots f_{m_{1}}\right)\left(s_{0} s_{1} \ldots s_{m_{2}}\right)\right)$ efetua a substituição de $\{f 0\}$, $\{\mathrm{f} 1\} \ldots\left\{\mathrm{fm}_{1}\right\},\{\mathrm{s} 0\},\{\mathrm{s} 1\} \ldots\left\{\mathrm{sm}_{2}\right\}$ pelos termos $\mathrm{f}_{0}, \mathrm{f}_{1}, \ldots \mathrm{f}_{m_{1}}, \mathrm{~s}_{0}, \mathrm{~s}_{1}, \ldots, \mathrm{s}_{m_{2}}$ na variável $\mathrm{t}_{0} \cdot \mathrm{t}_{1} \ldots \mathrm{t}_{n}$.

AnchoredInst.Phase = 'Anchored instrucion phase for $\{f 0\}$ '

LearningByBeingTaught.Strategy = 'Learning by being taught strategy for $\{f 0\}$ '

...

Figura 3.27: Esquema de valores empregados na geração de textos 
Exemplo 3.14. A ação $T=(($ !text (Anchoredlnst Phase) ('explain derivate') ())) efetua a inserção do texto "Anchored instrucion phase for explain derivate" no roteiro colaborativo devido a que o parâmetro $\{\mathrm{f} 0\}$ é substituído por 'explain derivate' no valor Anchoredlnst.Phase.

O operador !insertElement mostrados na Figura 3.28 efetua mudanças nos registro histórico dos estudantes ?learners mediante a adição dos átomos lógicos (property ?! hasAlreadySeen ?e) e (property ?e hasBeenSeen ?I) (linhas 5-6) que representam a inserção de um elemento ?e no roteiro colaborativo para cada um dos estudantes ?! definidos na lista ?learners.

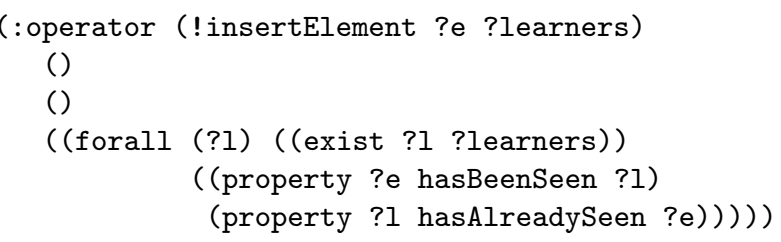

Figura 3.28: Inserção de um elemento de domínio a ser ensinado

O operador !insertResource mostrado na Figura 3.29 define a inserção de um recurso instrucional mediante a definição de um elemento $<$ resource $>$ com identificador ?r e atributos ?attributes. O operador efetua a adição do átomo lógico (insertedln ?r ?u) (linha 5) que representa a inserção do recurso ?r na unidade de aprendizagem ?u.

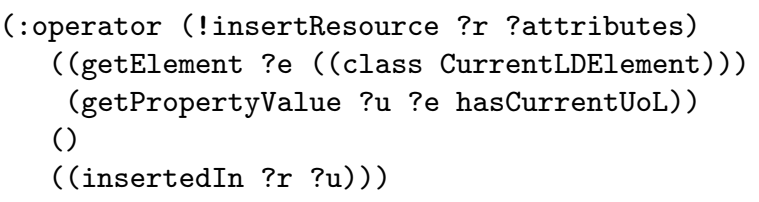

Figura 3.29: Inserção de recurso instrucional

O operador !insertResourceOnce é empregado na tarefa básica insertResourceOnce mostrada na Figura 3.30 para efetuar a inserção de um único recurso instrucional por unidade de aprendizagem. A tarefa efetua a inserção de um recurso definindo os atributos tipo de conteúdo ?type (linha 5) e endereço destino ?href (linha 7) representado na especificação IMS-LD como:

$$
\text { <resource identifier="id" type="type" href="href"/> }
$$

O operador !!addlnWorldStateAsAlreadySeen mostrado na Figura 3.31 efetua mudanças nos registros históricos do modelo de estudante mediante a inserção dos átomos lógicos (property ? hasAlreadySeen ?e) e (property ?e hasBeenSeen ?l), os quais definem que os elementos ?elements foram visualizados pelos participantes ?learners (linhas 4-7). 


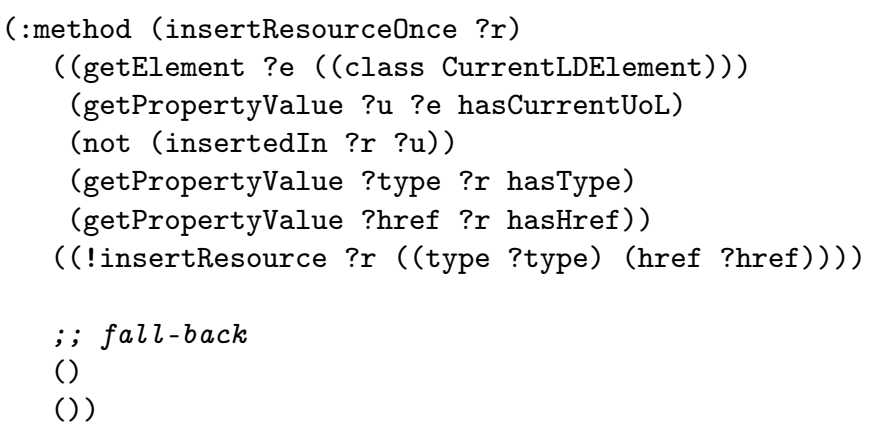

Figura 3.30: Inserção de um único recurso instrucional por unidade de aprendizagem

Figura 3.31: Alteração do registro histórico mediante a inserção de elementos de domínio

A tarefa básica createLDItem mostrada na Figura 3.32 efetua a definição de um elemento $<$ item $>$ que efetua a inserção do recurso instrucional ?r (linhas 6,15 ) associado ao elemento ?e do domínio a ser ensinado. O segundo método (linhas 9-16) é uma variante do primeiro que efetua mudanças nos registros históricos dos estudantes ?learners mediante o operador !insertElement (linhas 14).

As tarefas básicas createLDInstructltem (linhas 1-8) e createLDLearningltem (linhas 10-17) mostradas na Figura 3.33 são variantes da tarefa createLDItem empregadas na definição de eventos IL. Diferente da tarefa createLDItem, as tarefas createLDInstructltem e createLDLearningltem efetuam a inclusão de metadados de classificação Instructional e Learning (linhas 4-5, 13-14). 


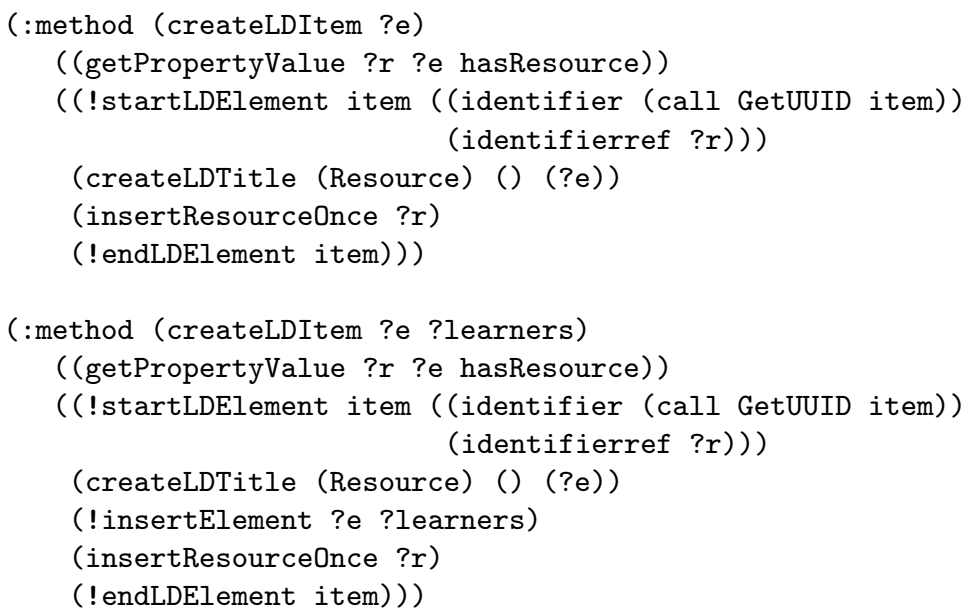

Figura 3.32: Tarefa básica de criação do elemento <item>

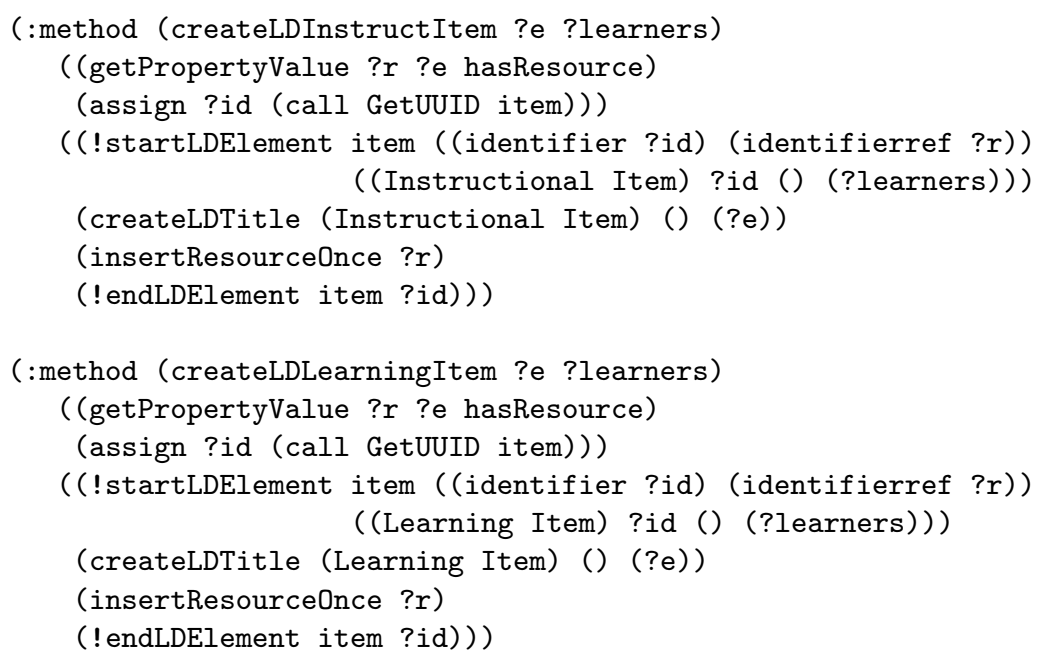

Figura 3.33: Tarefa básica de criação do elemento <item $>$ em eventos $I L$ 


\subsubsection{Representação das estratégias de planejamento instrucional como tarefas e métodos hierárquicos}

As estratégias de planejamento instrucional são representadas no domínio de planejamento como um conjunto de tarefas e métodos hierárquicos, mediante: (1) o mapeamento das tarefas de planejamento instrucional em tarefas hierárquicas; (2) a definição de interações instrucionais nos métodos hierárquicos; (3) a representação de regras de planejamento instrucional como precondições lógicas e condições relativas; (4) a definição de tarefas opcionais e críticas; e (5) a definição de métodos de decomposição distributiva. No capítulo seguinte usaremos esses conceitos para efetuar a representação das estratégias de planejamento instrucional como tarefas e métodos hierárquicos.

\section{Mapeamento das tarefas de planejamento instrucional em tarefas hierárquicas}

Seja a n-upla $\left\langle V^{\prime}, C^{\prime}, P^{\prime}, F^{\prime}, T^{\prime}, N^{\prime}, M^{\prime}\right\rangle$ o vocabulário da linguagem JSHOP2ip, no qual: $V^{\prime}$ é um conjunto infinito de símbolos de variável, $C^{\prime}$ é um conjunto finito de símbolos de constante, $\mathrm{P}^{\prime}$ é um conjunto finito de símbolos de predicado, F' é um conjunto finito de símbolos de função, T' é um conjunto finito de símbolos de tarefa composta, N' é um conjunto finito de símbolos de tarefa primitiva e M' é um conjunto infinito de símbolo de nome.

Definição 3.11. Uma tarefa de planejamento instrucional $t$ na linguagem JSHOP2ip é representada mediante a estrutura $\left(f_{1}(s)\left(f_{2}\left(g_{1}\right) \ldots f_{2}\left(g_{n}\right)\right)\left(\left(f_{3}\left(l_{1}\right) \ldots f_{3}\left(l_{m_{1}}\right)\right) \ldots\left(f_{3}\left(l_{1}\right) \ldots f_{3}\left(l_{m_{n}}\right)\right)\right)\right)$, na qual:

- $f_{1}: S \rightarrow \mathrm{T}^{\prime}$ é a função de mapeamento que associa cada nome de tarefa de planejamento instrucional $s \in S$ com um símbolo de tarefa $\mathrm{t} \in \mathrm{T}^{\prime}$;

- $f_{2}: G \rightarrow \mathrm{M}^{\prime} \times \mathrm{M}^{\prime}$ é a função de mapeamento que associa cada objetivo educacional, como um par de símbolos de nome $\left(\mathrm{m}_{i} \mathrm{~m}_{j}\right) \in \mathrm{M}^{\prime} \times \mathrm{M}^{\prime}$; e

- $f_{3}: L \rightarrow \mathrm{M}^{\prime}$ é a função de mapeamento que associa cada identificador de estudante $l \in L$ com um símbolo de nome $\mathrm{m} \in \mathrm{M}^{\prime}$.

Exemplo 3.15. A tarefa de planejamento instrucional $t$ de criação de um roteiro colaborativo "Jigsaw" na que são definidos os objetivos educacionais "compreensão do laço for no nível autônomo e restruturação" e "entendimento do laço While no nível explicativo e aperfeiçoamento" definidos para os estudantes learner1, learner2, learner3 e learner4 é representada na linguagem JSHOP2ip, como:

(createLDJigsaw ((comp1 s4k3) (comp2 s2k2)) ((I1 I2) (I3 I4))).

A representação é efetuada mediante a definição das funções:

- $f_{1}$ ("criação do roteiro colaborativo jigsaw") = createLDJigsawScript;

- $f_{2}$ ("compreensão do laço for no nível autônomo e restruturação") = (comp1 s4k3);

- $f_{2}$ ("entendimento do laço while no nível explicativo e aperfeiçoamento") = (comp2 s2k2);

- $f_{3}\left(\right.$ "learner1") $=\mathrm{I} 1 ; f_{3}\left(\right.$ "learner2") $=\mathrm{I} 2 ; f_{3}\left(\right.$ "learner3") $=13$; e $f_{3}$ ("learner4") = 4 . 
Definição de interações instrucionais nos métodos hierárquicos

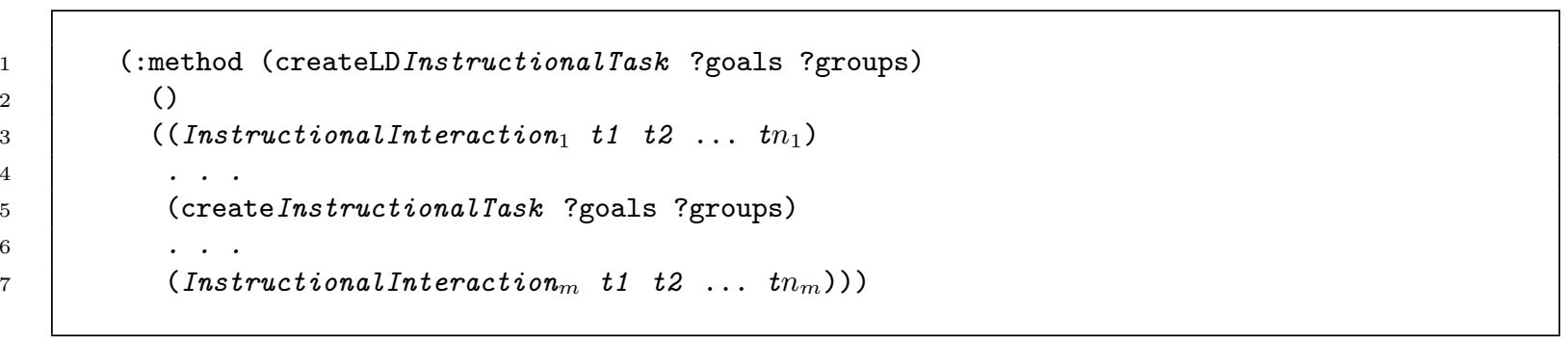

Figura 3.34: Esquema de definição de interações instrucionais nos método hierárquicos

Para efetuar a definição de interações instrucionais nos métodos hierárquicos que representam as estratégias de planejamento instrucional empregamos o esquema mostrado na Figura 3.34. Dessa maneira, cada uma das tarefas de planejamento instrucional createLD/nstructiona/Task contém um conjunto de interações instrucionais Instructionallnteraction ${ }_{i}$ a serem efetuadas antes (linhas 3-4) e depois (linhas 6-7) da tarefa createlnstructionalTask (linha 6). As interações instrucionais são tarefas básicas e operadores de planejamento apresentadas na Subseção 3.3.4.

Exemplo 3.16. Um exemplo de definição de interações instrucionais no método hierárquico é mostrado na Figura 3.35. Na figura, as interações instrucionais associadas à tarefa createLDPracticeSessions são !startLDElement (linha 3), startLDElement! (linhas 4-6), createLDTitle (linha 7) e !endLDElement (linhas 9-10). A tarefa createPracticeSession (linhas 12-16) é definida como o conjunto de subtarefas createLDPracticeWithExerciseSessions (linhas 14-16).

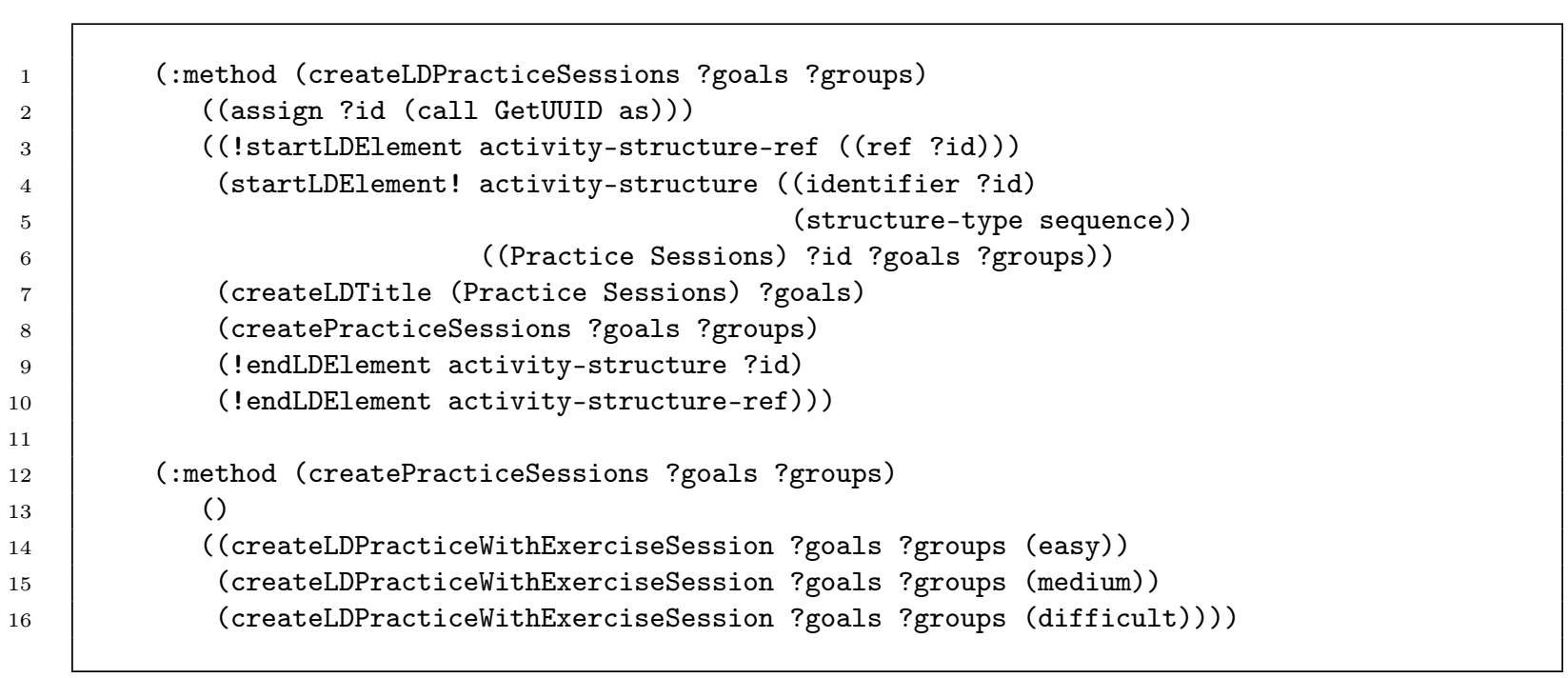

Figura 3.35: Definição de interações instrucionais associadas à tarefa createLDPracticeSessions 


\section{Representação de regras de planejamento instrucional}

As regras de planejamento instrucional são representadas como precondições lógicas e condições relativas nos métodos hierárquicos utilizando os axiomas e termos de chamada definidos anteriormente (Subseções 3.3.1, 3.3.2 e 3.3.3).

Exemplo 3.17. As regras de planejamento instrucional associadas ao método hierárquico mostrado na Figura 3.36 representam as precondições lógicas:

- a avaliação do tipo de elemento de conhecimento associado à competência ?c dos objetivos educacionais ?goals deve ser Auxiliar (linhas 3-4);

- a avaliação do valor da propriedade dificuldade (hasDifficult) do elemento de conhecimento associado à competência ?c deve ser difícil ou muito difícil (linhas 5-7); e

- a avaliação dos elementos de roteiros colaborativos do qual o elemento corrente ?e é parte não deve ser um roteiro Pyramid Script, Pyramid (linhas 8-10).

E as regras de planejamento instrucional que representam as condições relativas são:

- a avaliação do número de participantes com experiência meia ou baixa na aprendizagem colaborativa (hasCLExperience) deve ser maior à metade de participantes para incrementar o nível de aplicabilidade do método em três unidades (linhas 12-16);

- a avaliação da existência da atitude interdependência positiva (positive-interdependence) ou uma variante na unidade de aprendizagem ?u (linhas 18-22); e

- a avaliação da existência da habilidade discussão (discussion) ou uma variante na unidade de aprendizagem ?u (linhas 23-27). 


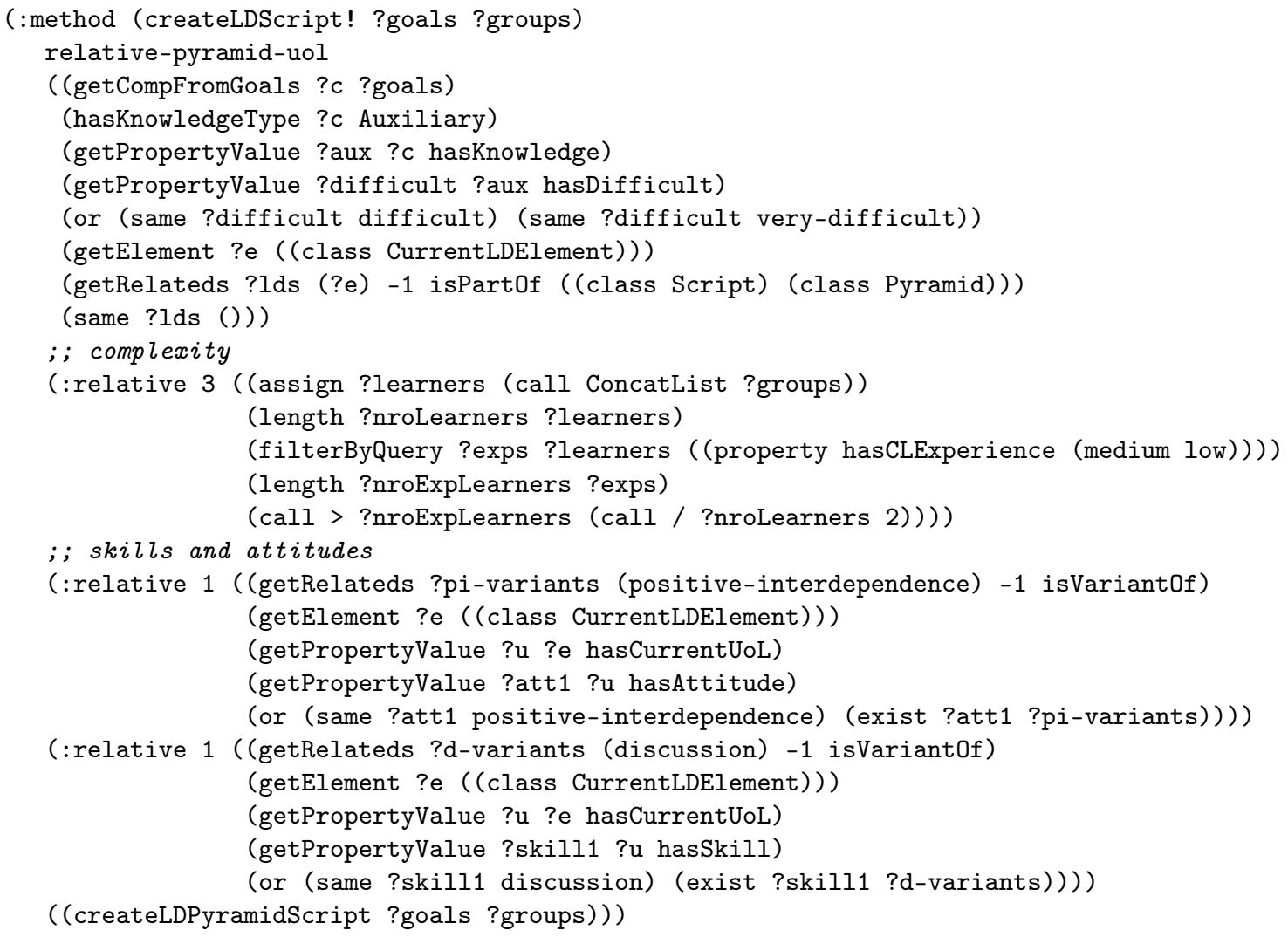

Figura 3.36: Exemplo de representação de regras de planejamento instrucional 
Definição de tarefas opcionais e críticas

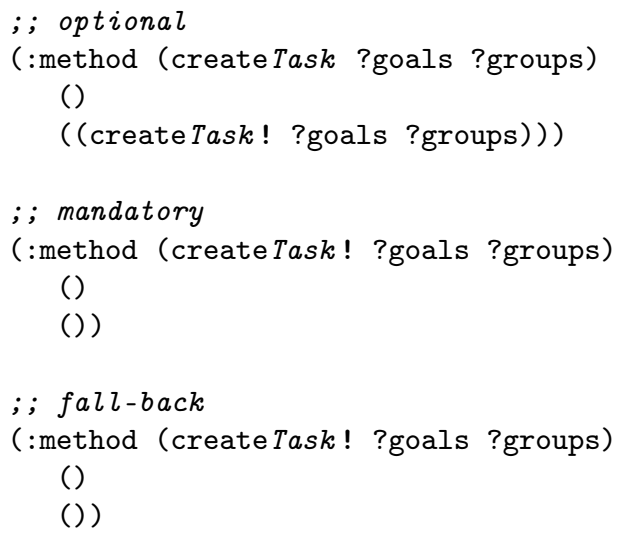

Figura 3.37: Esquema de representação de tarefas opcionais e críticas

As estratégias de planejamento instrucional apresentam a definição de tarefas opcionais e críticas. As tarefas de planejamento opcional são tarefas que sempre podem ser atingidas sem efetuar backtracking no caso de falha. Enquanto, as tarefas críticas definidas com o sufixo ! efetuam backtracking no caso de falha. Assim, em nossa representação de estratégias de planejamento instrucional empregamos o esquema mostrado na Figura 3.37 para efetuar a definição de uma tarefa opcional e crítica.

A Figura 3.38 mostra como exemplo a definição das tarefas de planejamento instrucional opcional e crítica relativas à estratégia de criação de uma descrição do evento IL "Show Solution". A tarefa crítica (linhas 7-13) efetua a busca de descrições explicação (Explanation) e receber explicação (ReceivingExplanation), enquanto a tarefa opcional no método fall-back (linhas 16-22) efetua construção de descrições no caso de falha da tarefa crítica. A construção das descrições é efetuada usando termos de chamada (call BuildElement ... ) (linhas 17-20).

\section{Definição de métodos de decomposição distributiva}

$\mathrm{Na}$ representação de estratégias de planejamento instrucional, algumas tarefas de planejamento instrucional são decompostas em um número idêntico de subtarefas de planejamento instrucional. Por exemplo, o método de decomposição distributiva mostrada na Figura 3.39 decompõe à tarefa distributeLearningObject em um conjunto de tarefas createLDLearningObject (linha 4) uma tarefa por cada objetivo ?goal e estudantes ?group (linha 2). 


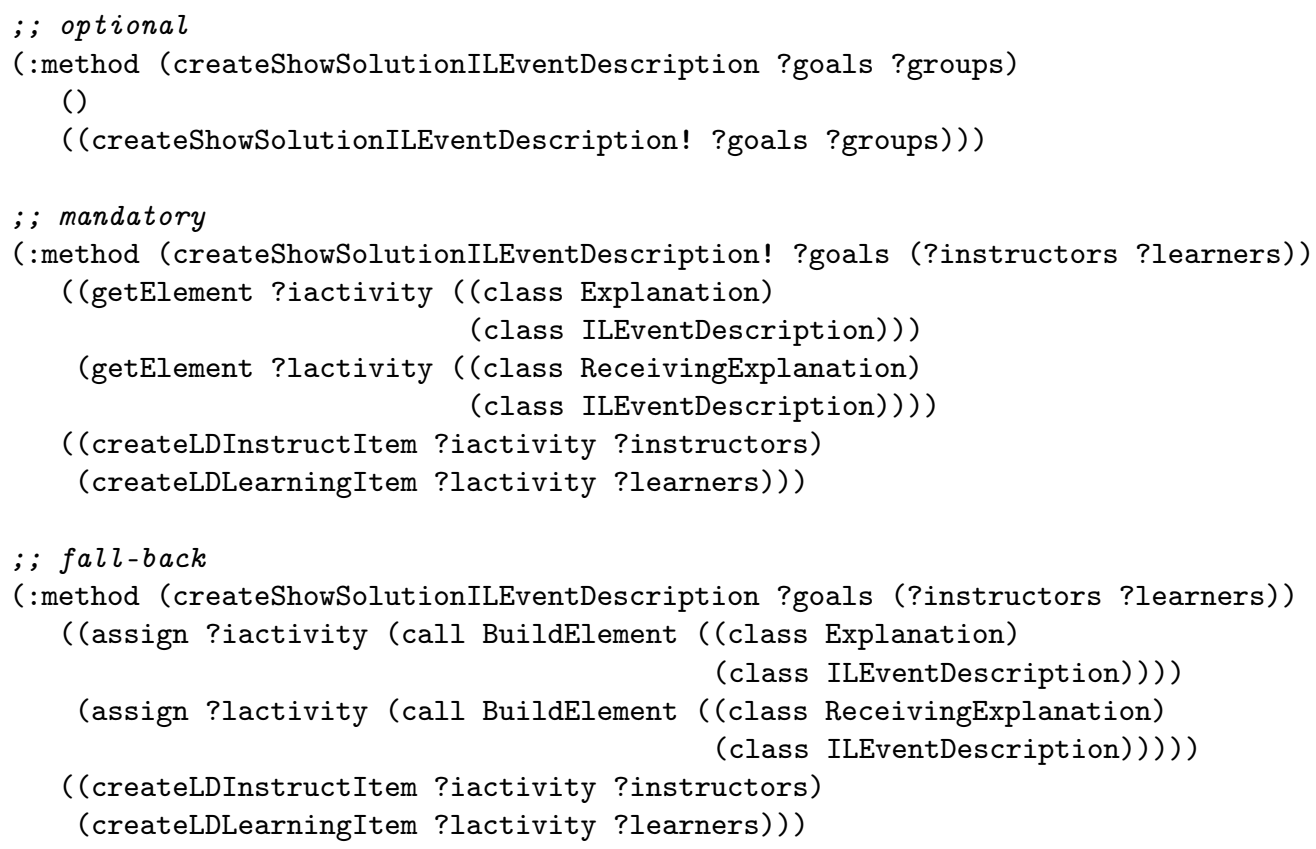

Figura 3.38: Tarefas opcionais e críticas associadas à estratégia de criação da descrição do evento IL

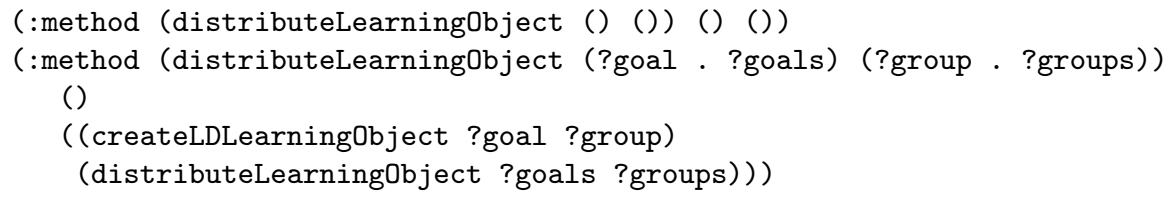

Figura 3.39: Método de decomposição distributiva da tarefa createLDLearningObject 


\subsection{Componente de conversão}

Uma vez o plano de solução seja obtido pelo planejador hierárquico, o componente de conversão efetua a tradução do plano em arquivos de manifesto "imsmanifest.xml" que representam roteiros colaborativos na especificação IMS-LD. Logo, os arquivos de manifesto serão empacotados em um pacote ZIP com todos os recursos instrucionais necessários.

A seguir descrevemos as funções de conversão dos operadores de planejamento em elementos XML da especificação IMS-LD e apresentamos o algoritmo de geração de roteiros colaborativos.

\subsubsection{Função de conversão dos operadores de planejamento}

Seja $\mathrm{p}=\left(h_{1} h_{2} \ldots h_{n}\right)$ o plano de solução obtido pelo planejador, no que cada ação $h_{i}$ é uma instância dos operadores !startLDElement, !endLDElement, ! insertResource e !text. Definimos "convert $\left(h_{i}\right)$ " como a função que efetua:

- A conversão da ação

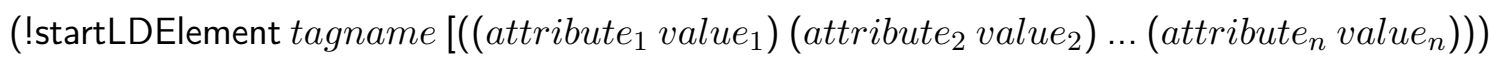

na etiqueta de abertura

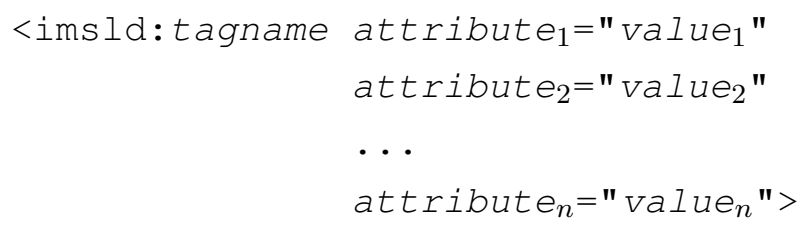

- A conversão da ação (!endLDElement tagname [id]) na etiqueta de fechamento

$</$ imsld:tagname $>$

- A conversão de cada ação (!insertResource id ((type type) (href href))) na etiqueta

<resource identifier="id" type="type" identifier-ref="href"/> 
Exemplo 3.18. As ações definidas no plano $\mathrm{P}$ mediante a função convert $\left(h_{i}\right)$ definem a geração de elementos XML da especificação IMS-LD mostrada na Figura 3.40.

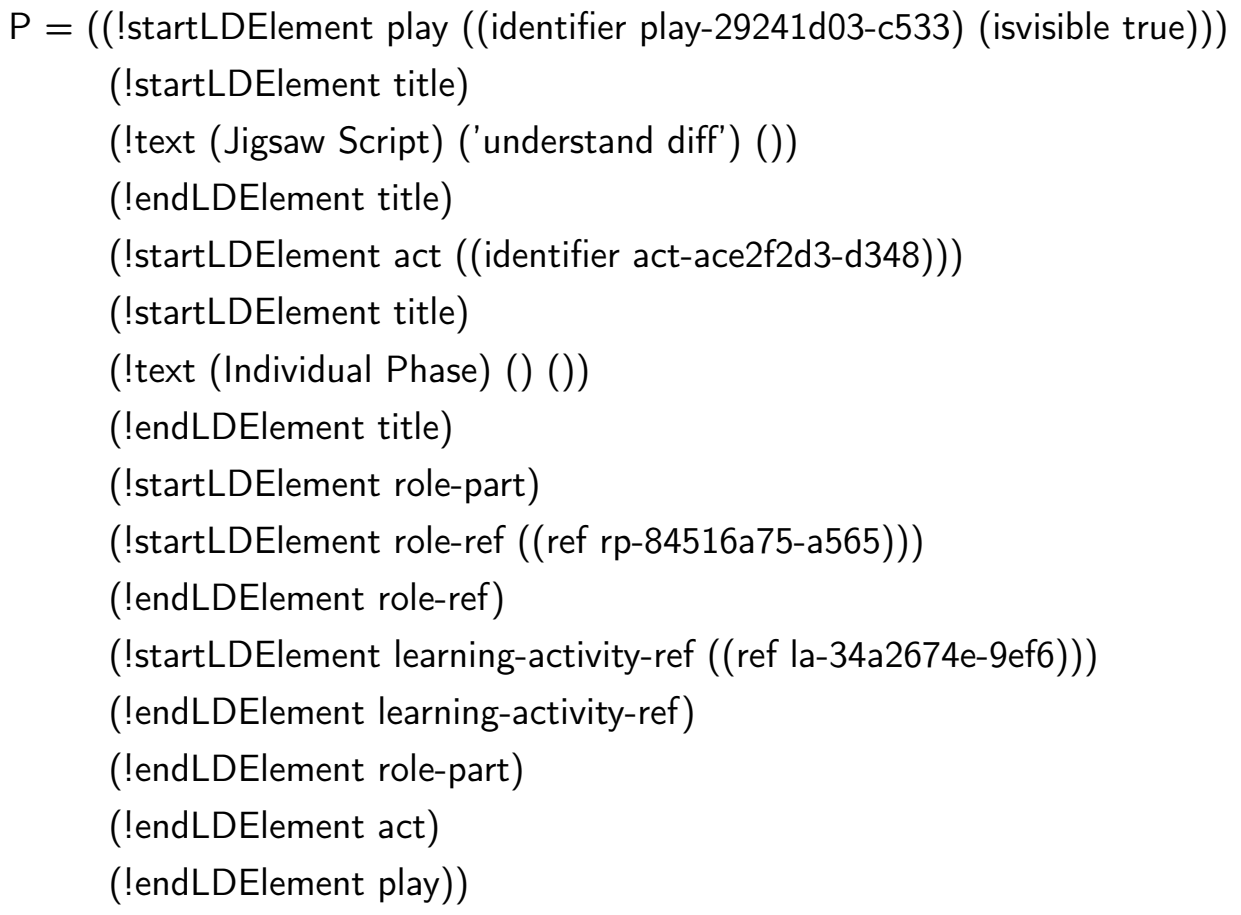

Figura 3.40: Exemplo de elementos XML obtidos usando o plano $P$ e a função convert $\left(\mathrm{h}_{i}\right)$

\subsubsection{Algoritmo de geração de roteiros colaborativos}

O algoritmo de geração de roteiros colaborativos mostrado na Figura 3.41 utiliza o plano de ações $\mathrm{P}$ e a estrutura de roteiro mostrada na Figura 3.42 para obter uma lista result de roteiros colaborativos descritos na especificação IMS-LD.

O algoritmo emprega a função de conversão de operadores de planejamento "convert(h)" para definir etiquetas de abertura e fechamento de elementos XML (linhas 6-10). A posição da inserção dos elementos obtidos no esquema de roteiro é efetuada utilizando a função "xmldoc(node[n])" (linhas 12-19, 25) que obtém um nó XML na posição $n$ da estrutura mostrada na Figura 3.42. 
Entrada: $\mathrm{P}=\left(h_{1} h_{2} \ldots h_{n}\right)$ é um plano de ações e $x m l d o c$ é um esquema de roteiros Saída: result $=\langle\rangle$ é a lista de roteiros colaborativos na especificação IMS-LD

\section{1 início}

$\mathbf{2} \mid$ queue $\leftarrow\langle\rangle$;

$3 \quad x m l d o c \leftarrow$ novo esquema de roteiro;

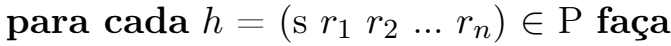

se $\mathrm{s}=$ "!endLDElement" então

element $\leftarrow$ convert $(h)$;

repita

$h^{\prime}=\left(\mathrm{s}^{\prime} r_{1}^{\prime} r_{2}^{\prime} \ldots r_{n}^{\prime}\right) \leftarrow$ tirar último elemento da lista queue;

element $\leftarrow$ convert $\left(h^{\prime}\right)+$ element;

até $r_{1}=r_{1}^{\prime}$;

selecione $r_{1}$ faça

caso leaner

$x m l d o c($ node $[2]) \leftarrow x m l d o c($ node $[2])+$ element

caso learning-activity ou support-activity ou activity-structure

$x m l d o c($ node $[3]) \leftarrow x m l d o c($ node $[3])+$ element

caso environment

$\mid x m l d o c($ node $[4]) \leftarrow x m l d o c($ node $[4])+$ element

caso learning-design

$x m l d o c($ node[1] $\leftarrow$ xmldoc $($ node $[1])+$ element

adicionar xmldoc à lista result;

$x m l d o c \leftarrow$ novo esquema de roteiro;

fim

fim

senão se $\mathrm{s}=$ "! insertResource" então

$\mid x m l d o c($ node $[5]) \leftarrow x m l d o c($ node $[5])+\operatorname{convert}(h) ;$

senão

| adicionar $h$ à lista queue;

fim

fim

30 fim

Figura 3.41: Algoritmo de geração de roteiros colaborativos 
No caso de que um operador de planejamento seja de fechamento do elemento <learningdesign > (linhas 18-21) é efetuada a adição do roteiro na lista result (linhas 20).

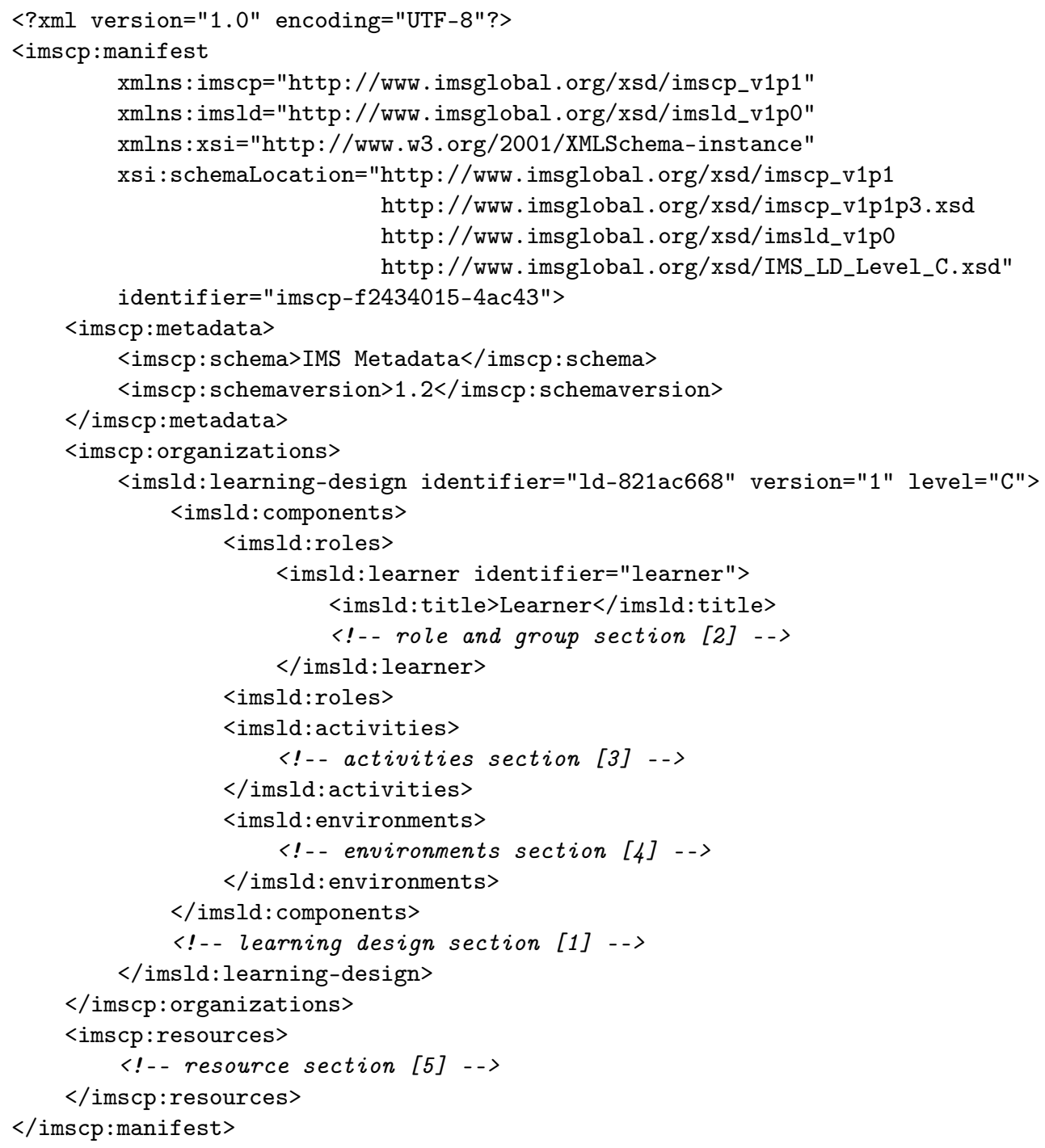

Figura 3.42: Estrutura de roteiro colaborativo na especificação IMS-LD 


\section{Capítulo 4}

\section{Modelo pedagógico: Estratégias de planejamento instru- cional}

Este capítulo apresenta a modelagem das estratégias de planejamento instrucional como tarefas e métodos hierárquicos. A modelagem emprega as definições apresentadas no Capítulo 4. Assim, as estratégias de planejamento instrucional que definem a criação de elementos básicos de roteiros são apresentadas na Seção 4.1. As estratégias que definem a criação de elementos de microrroteiro e macrorroteiros colaborativos são descritas nas Seções 4.2 e 4.3. Finalmente, na Seção 4.4 apresentamos a descrição das estratégias de criação da unidades de aprendizagem.

\subsection{Elementos básicos de roteiros colaborativos}

Nesta seção efetuamos a descrição das estratégias de planejamento instrucional empregadas na criação do serviço de conferência, objeto de aprendizagem, ambiente de apoio à aprendizagem e grupo de estudantes.

\subsubsection{Serviço de conferência}

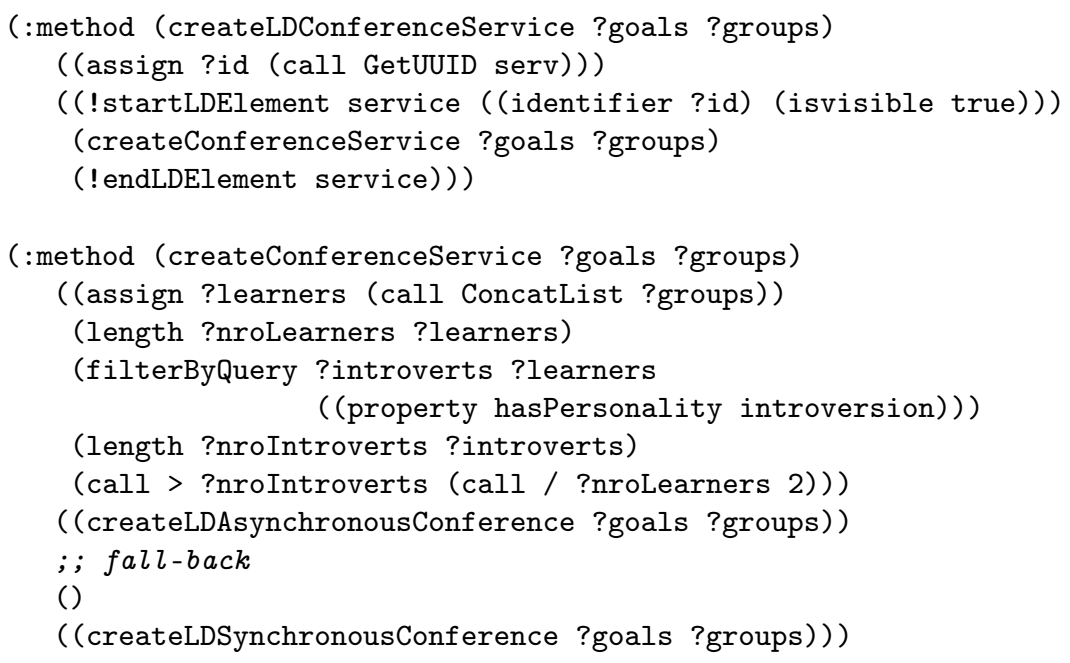

Figura 4.1: Representação da estratégia de criação de um serviço de conferência 
A Figura 4.1 mostra a representação da estratégia de criação de um serviço de conferência, definida como um elemento $<$ service $>$ (linhas 3, 5). A tarefa createConferenceService (linhas 7-17) avalia os registros de preferência dos estudantes (linhas 8-13), de modo que se a maioria dos estudantes são introvertidos é efetuada a criação de uma conferência assíncrona mediante à tarefa createLDAsynchronousConference (linha 14). Caso contrario é efetuada a criação de uma conferência síncrona mediante à tarefa createLDSynchronousConference (linha 17).

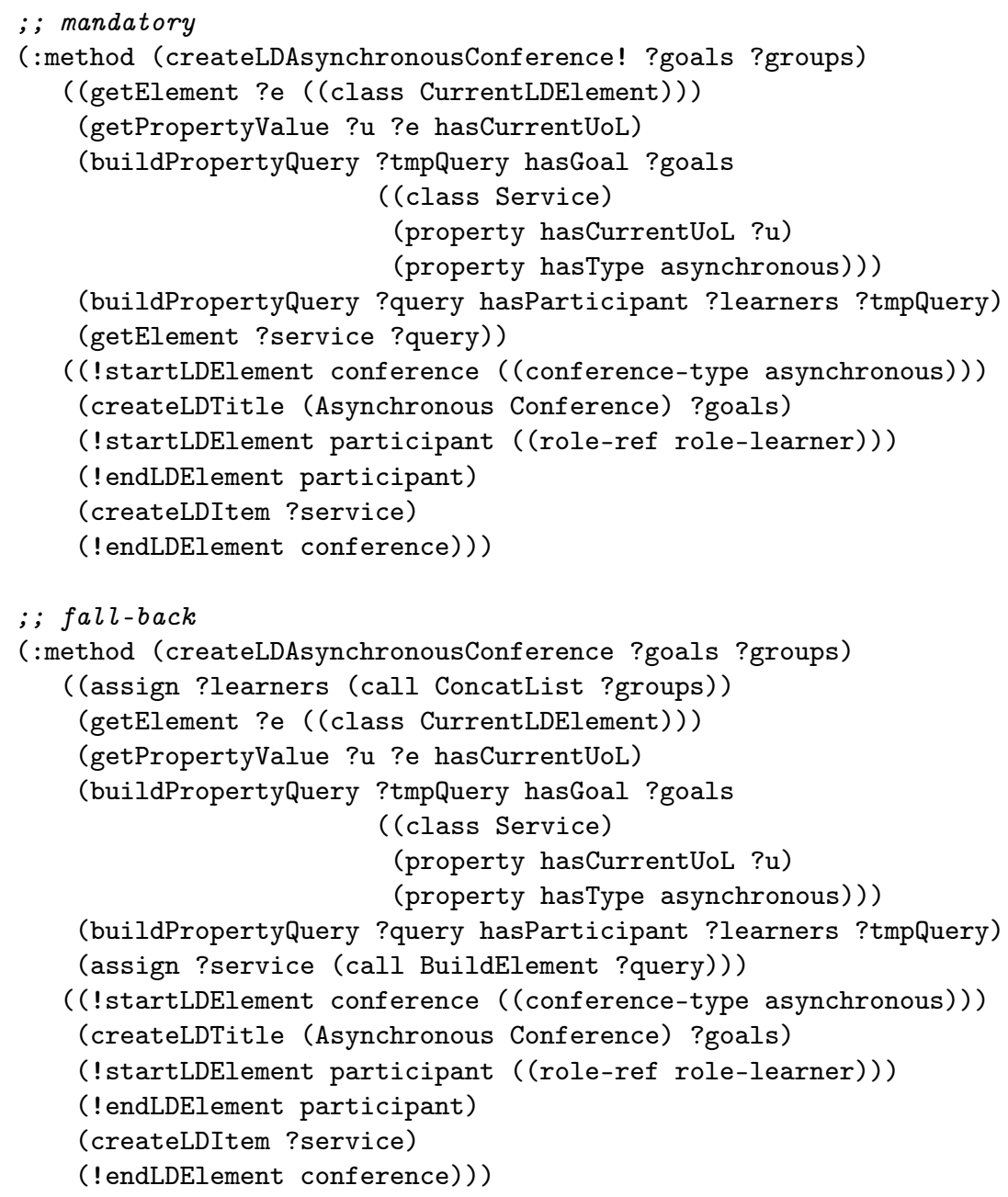

Figura 4.2: Representação da estratégia de criação de um serviço de conferência assíncrona

A Figura 4.2 mostra a estratégia de criação de uma conferência assíncrona que define elementos < conference $>$ (linhas 11, 16, 29, 34). O método mandatory (linhas 2-16) efetua a busca de um serviço de apoio à aprendizagem (Service) de tipo assíncrono (asynchronous) (linhas 610). Enquanto, o método fall-back (linhas 19-34) efetua a construção de um serviço de apoio à aprendizagem mediante o termo de chamada (call BuildElement ?query) (linha 28). 


\subsubsection{Objeto de aprendizagem}

A estratégia de criação de um objeto de aprendizagem é representada mediante as tarefas e métodos hierárquicos mostrados na Figura 4.3. O método fall-back (linhas 12-27) efetua a definição do elemento <learning-object> (linhas 14,18) e mediante à tarefa createLearningObject (linha 17) efetua inserção de um elemento de conhecimento ?aux (linha 22) relativo à competência cognitiva ?c utilizando a tarefa createLDItem (linha 26).

Enquanto, o método mandatory (linhas 2-9) não efetua a definição de nenhum elemento de roteiro alterando unicamente o registro histórico do modelo de estudante utilizando a tarefa !!addInWorldStateAsAlreadySeen (linha 9). O método não efetua a criação de nenhum elemento devido a que um elemento de conhecimento relativo à competência ?c foi inserido anteriormente no ambiente de apoio à aprendizagem corrente ?e (linhas 3-7).

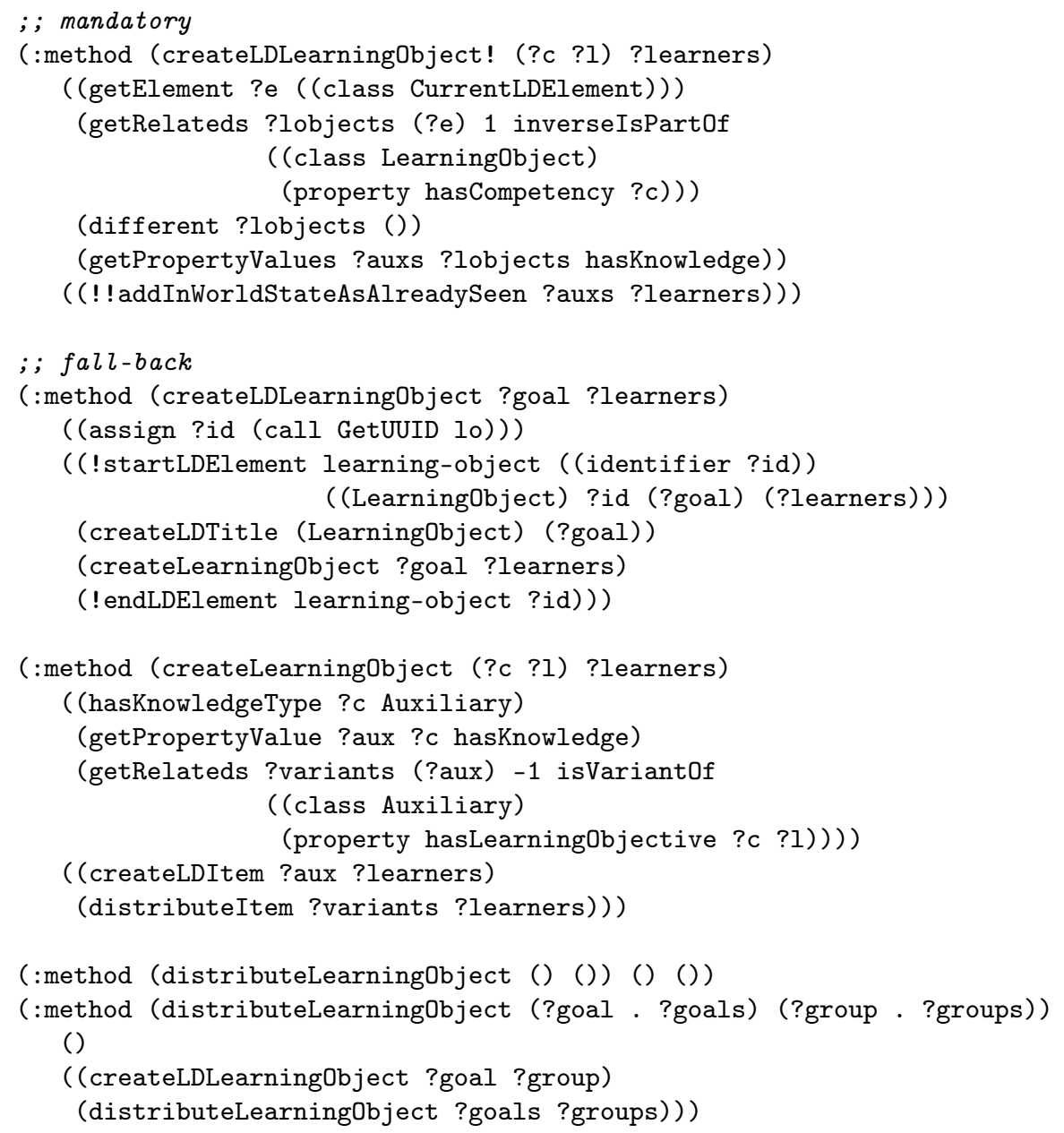

Figura 4.3: Representação da estratégia de criação de um objeto de aprendizagem

Finalmente, o método de decomposição distributiva distributeLearningObject (linhas 29-33) efetua a criação consecutiva de um conjunto de objeto de aprendizagem por cada objetivo educacional ?goals (linhas 32-33). 


\subsubsection{Ambiente de apoio à aprendizagem}

A estratégia de criação de um ambiente de apoio à aprendizagem é representada mediante o conjunto de tarefas e métodos hierárquicos mostrados na Figura 4.4 que efetuam a definição de um elemento <environment> (linha 4,8). A tarefa createEnvironment (linha 7) define o ambiente de apoio à aprendizagem como um conjunto de objetos de aprendizagem definidos pela tarefa distributeLearningObject (linhas 13) e um serviço de conferência definido pela tarefa createLDConferenceService (linha 14).

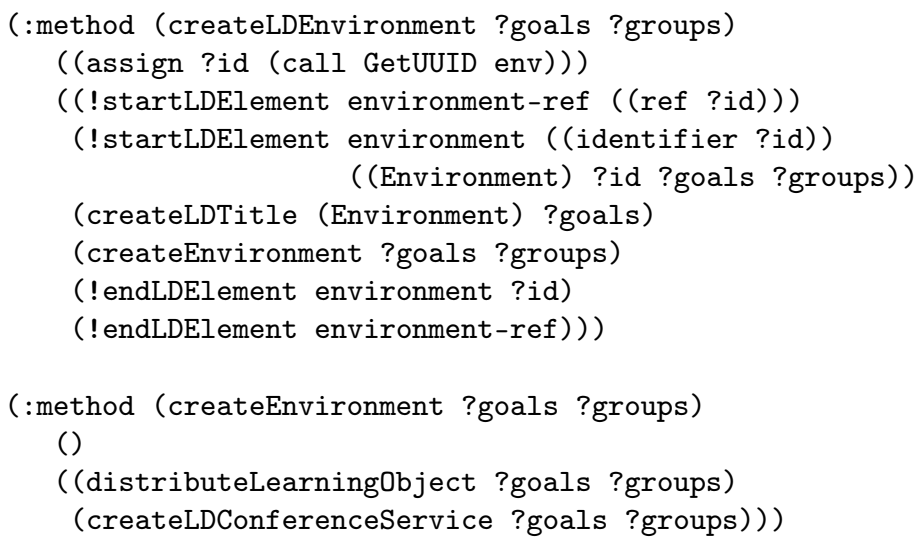

Figura 4.4: Representação da estratégia de criação de um ambiente de apoio à aprendizagem

\subsubsection{Grupo de estudantes}

As tarefas e métodos hierárquicos mostrados na Figura 4.5 representam a estratégia de criação de um grupo de estudantes no que a tarefa createLDGroup efetua a definição de elementos $<$ role-ref $>$ (linhas 12-13, 19,25).

O método mandatory (linhas 2-13) efetua a busca de um grupo de estudantes definido na unidade de aprendizagem corrente ?u (linha 5) para todos os membros do grupo ?group (linhas 3,6,10-11). Enquanto, o método fall-back (linhas 16-25) efetua a criação de um novo grupo de estudantes mediante a definição do elemento <learner> (linhas 20,24). No método fall-back, a tarefa addUsersToGroup (linhas 29) define a formação do grupo, e a tarefa createLDInformation (linha 30) define a inclusão de recursos instrucionais utilizando perfis de estudantes. 


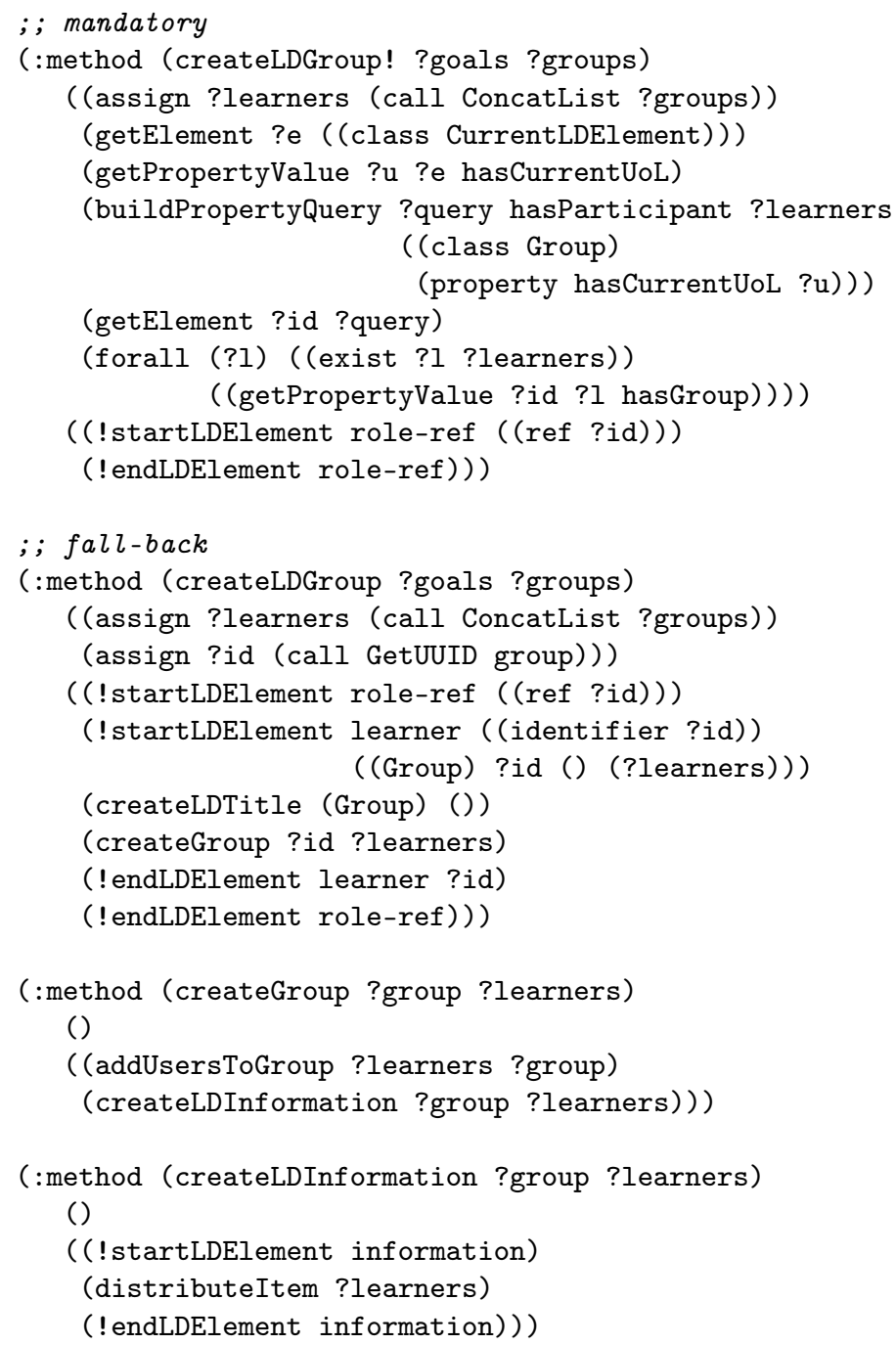

Figura 4.5: Representação da estratégia de criação de um grupo de estudantes 


\subsection{Microrroteiros: Cenários colaborativos}

As tarefas e métodos hierárquicos definidos a seguir representam estratégias de planejamento instrucional que definem a criação dos elementos de microrroteiros colaborativos: eventos IL, fluxo de interações cíclicas e direcionadas, padrões de interação, papéis dos estudantes, estratégias de aprendizagem, fases e cenários colaborativos. As estratégias são apresentadas como esquemas de roteiros que definem a abstração de um conjunto de estratégias. Os termos em itálico nos esquemas são substituídos por termos constante para representar uma estratégia específica, assim, utilizando esses esquemas na Subseção 6.2.1 apresentamos exemplos da modelagem.

\subsubsection{Eventos IL}

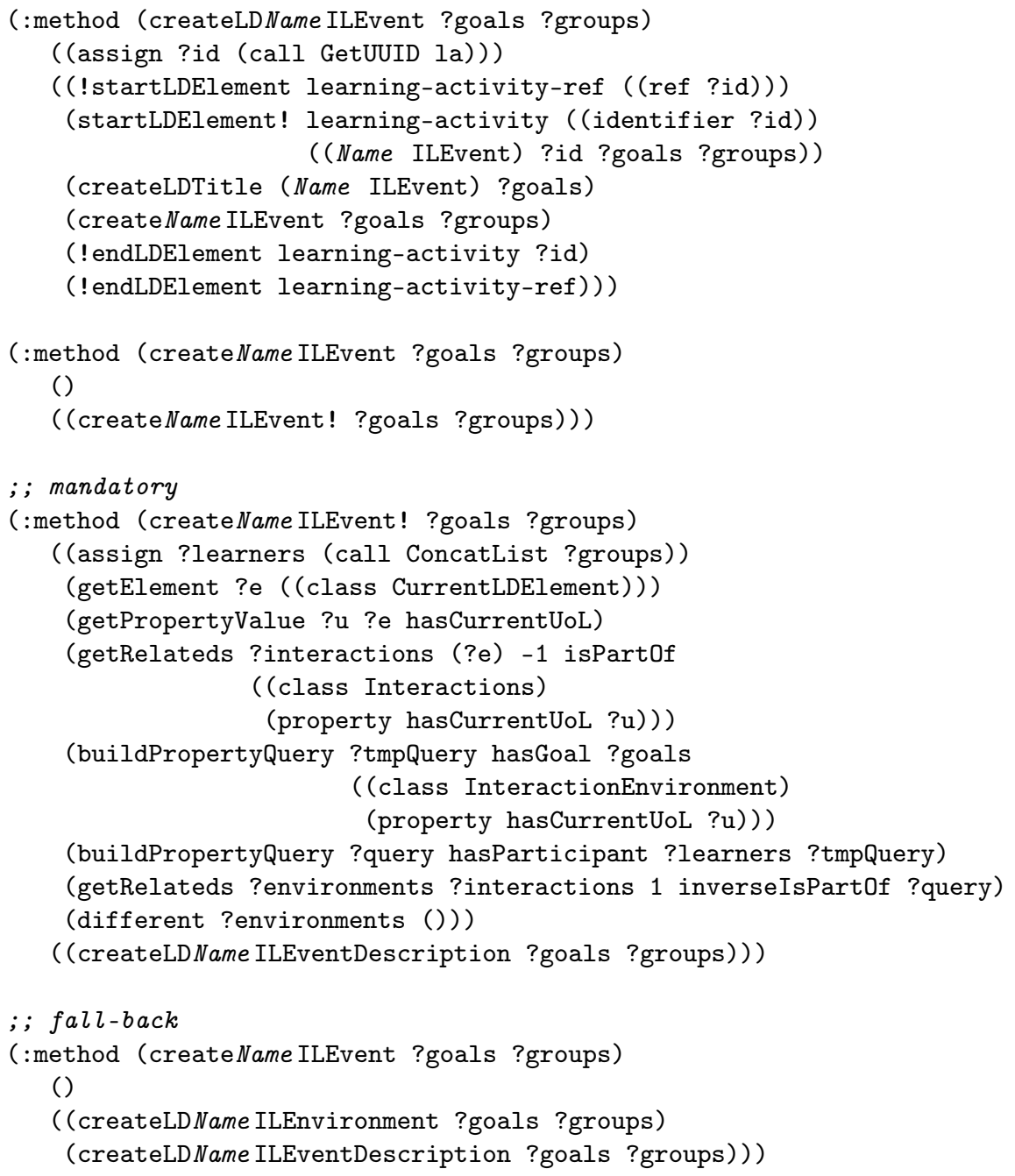

Figura 4.6: Esquema de representação de estratégias de criação de eventos $I L$

As estratégias de criação de eventos IL são representadas usando o esquema da Figura 4.6 que efetua a definição de elementos <learning-activity> (linhas 4,8). No esquema, os benefícios educacionais são definidos pela tarefa startLDElement! (linha 4), as ações a serem efetuadas pelos 
participantes são definidas pela tarefa createLD NamelLEventDescription (linha 35) e os objetos de aprendizagem com serviços a serem empregados durante a execução das ações são definidos pela tarefa createLD NameILEnvironment (linha 35).

Se o resultado da busca de ambientes de apoio à aprendizagem no padrão de interação corrente (linhas 20-22, 27) com objetivos educacionais ?goals e participantes ?learners (linhas 23, 26) é diferente de vazio (linha 28), então o método mandatory (linhas 16-29) de criação do evento é definida como ações pela tarefa createLDNamelLEventDescription (linha 29).

\section{Ações nos eventos IL}

As estratégias de criação de ações nos eventos IL são representadas mediante o esquema da Figura 4.7 que efetua a definição do elemento < activity-description > (linha 3,6). O método mandatory (linhas 13-19) efetua a seleção de ações definidas no modelo de domínio. Enquanto, o método fall-back (linhas 22-28) efetua a criação de ações a serem editadas.

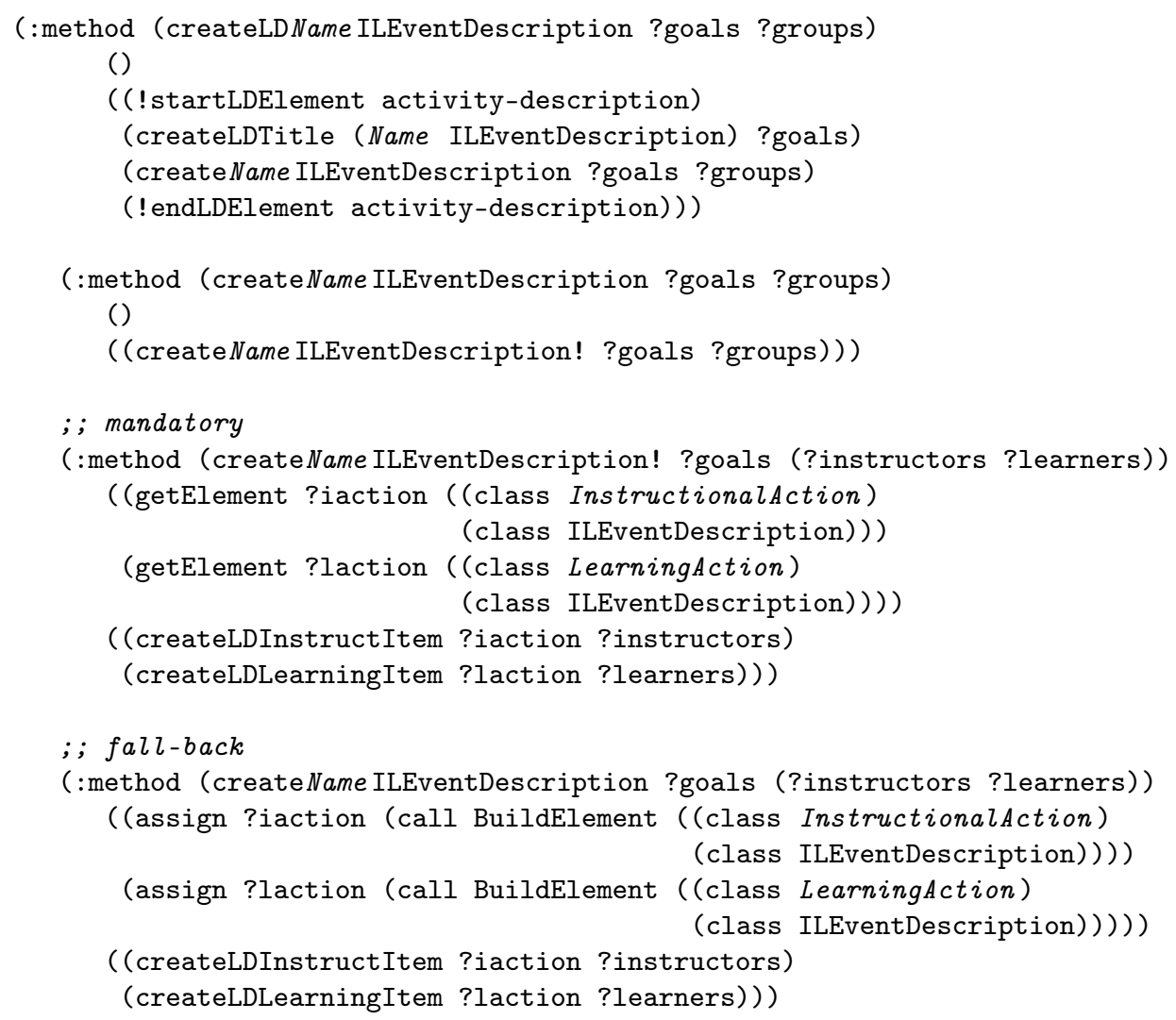

Figura 4.7: Esquema de representação das estratégias de criação de ações associadas aos eventos IL

O evento instrucional é associado à ação InstrucionalAction (linhas 14, 23) mediante a tarefa createLDInstructltem (linhas 18, 27). Enquanto, o evento de aprendizagem é associado à ação LearningAction (linhas 16, 25) mediante a tarefa createLDLearningltem (linhas 19, 28). 
Ambiente de apoio à aprendizagem associados aos eventos IL

A estratégia de criação de ambiente de apoio à aprendizagem associado aos eventos IL é definida mediante o esquema da Figura 4.8 que efetuam a definição de elementos <environment $>$ (linha 4,8) (linha 8).

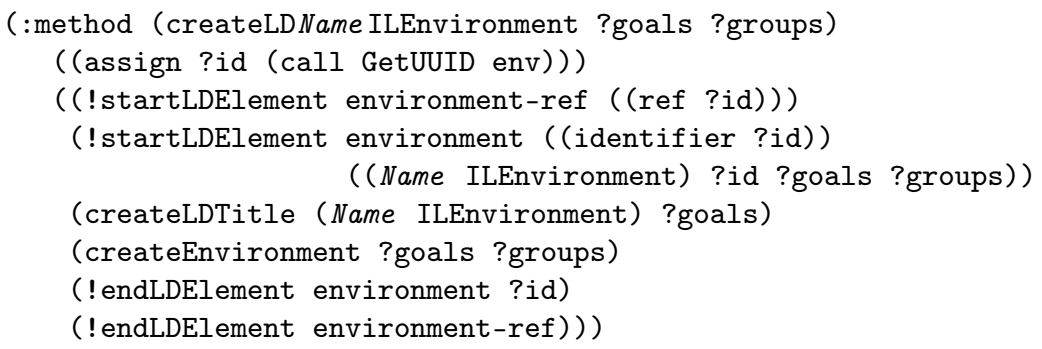

Figura 4.8: Esquema de representação das estratégias de criação de ambiente de apoio à aprendizagem

\subsubsection{Fluxo de interações direcionadas e cíclicas}

As estratégias de criação de um fluxo de interações direcionadas e cíclicas são representadas mediante o esquema da Figura 4.9, no que o fluxo de interações são definidos como elementos $<$ activity-structure $>$ (linha 4,9).

A criação de um fluxo de interações consiste na definição de eventos IL $E N a m e_{1}, \ldots, E N a m e_{n}$

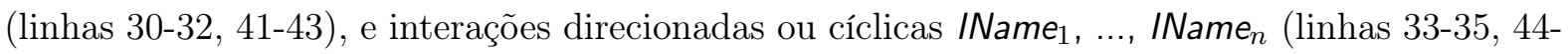
46). O tipo de relação entre os eventos IL e outras interações é definida na tarefa startLDElement! (linha 4-5) mediante o atributo "structure-type" que define se a relação é cíclica (selection) ou direcionada (sequence) (linha 5).

Os ambientes de apoio à aprendizagem associado ao fluxo de interações direcionadas e cíclicas são definidas pela tarefa createLDNamelnteractionEnvironment (linha 40). A criação do ambiente está sujeita ao método mandatory (linhas 17-33) que evita sua construção, se já existe um ambiente definido por outro fluxo de interação superior no que é definido o fluxo de interação (linhas 19-29). 


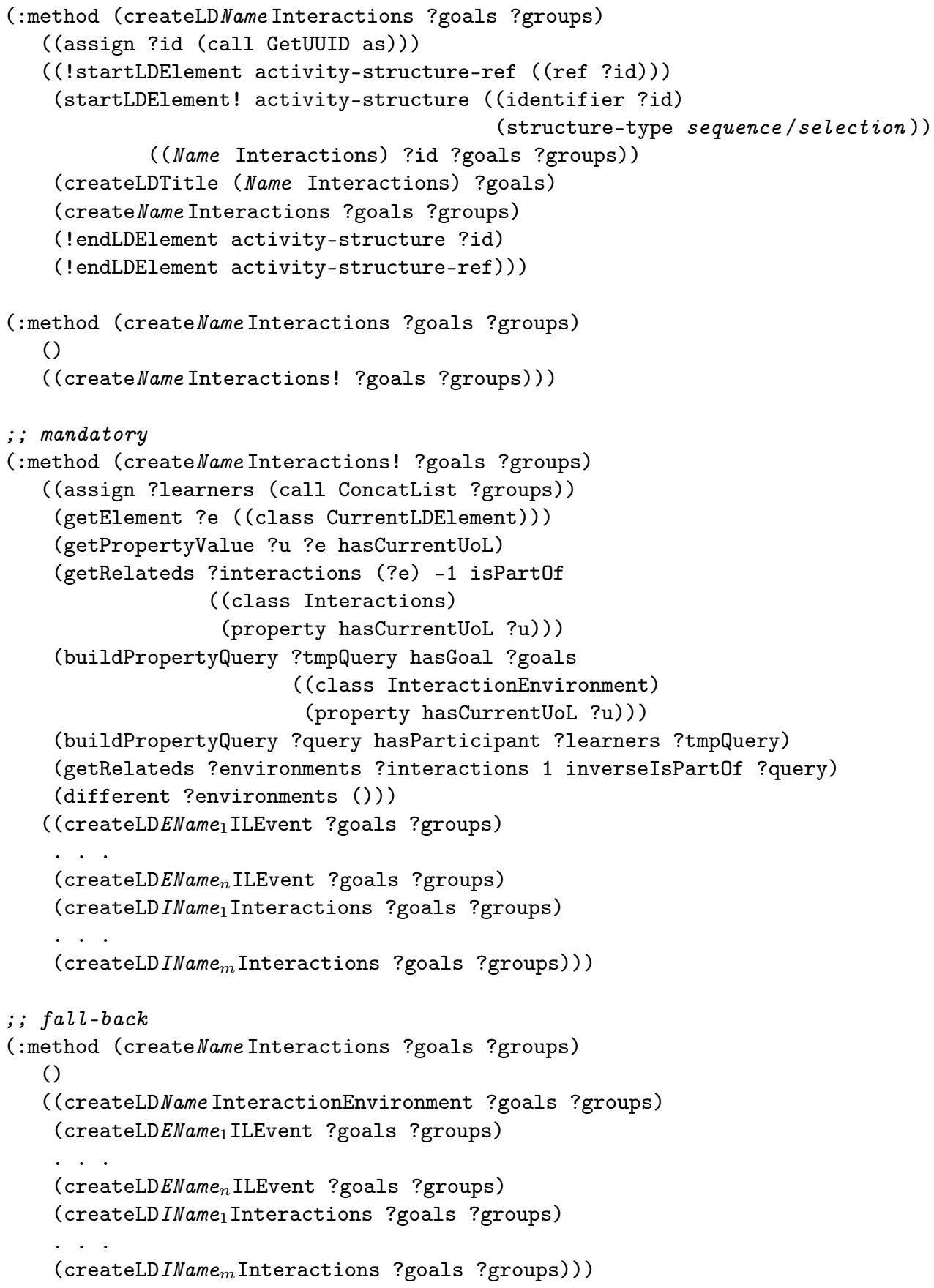

Figura 4.9: Esquema de representação da estratégia de criação de um fluxo de interações 


\subsubsection{Padrões de interação}

A Figura 4.10 mostra o esquema de tarefas e métodos hierárquicos utilizados para representar a estratégia de criação dos padrões de interação mediante a definição de elementos < activitystructure $>$ (linha 8,13). A tarefa createNamelnteractions é definida mediante uma sequência de eventos IL ou fluxos de interações direcionadas e cíclicas (linhas 20-23). Além de eventos IL e fluxos de interações direcionadas e cíclicas, a tarefa define a criação de um ambiente de apoio à aprendizagem com os objetos de aprendizagem e serviços necessários (linha 19).

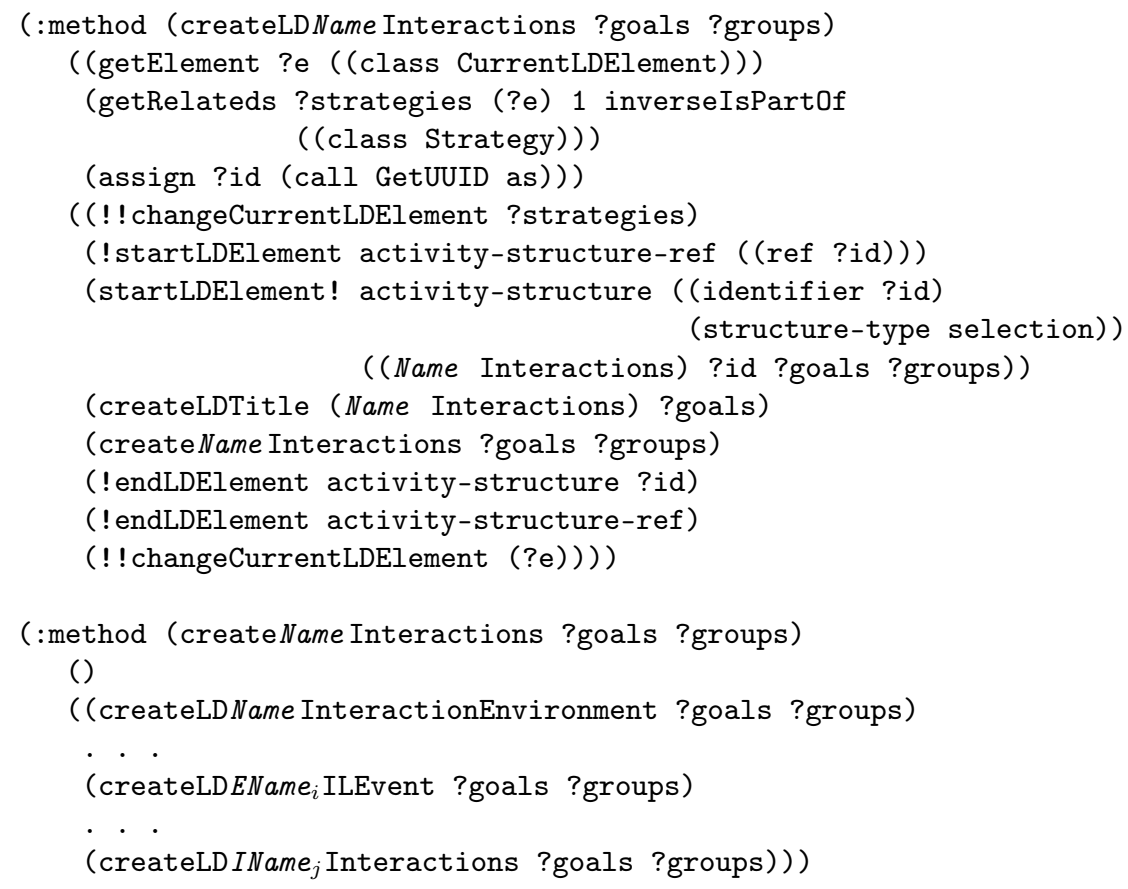

Figura 4.10: Esquema de representação da estratégia de criação de padrões de interação

O padrão de interação é definido como parte de estratégias de aprendizagem de um cenário, para isso, empregamos a tarefa !!changeCurrentLDElement (linhas 6,15) que é efetuada antes e depois da construção da estrutura de atividades (linhas 8,13).

\subsubsection{Papéis dos estudantes}

A Figura 4.11 mostra o esquema de tarefas e métodos hierárquicos empregados para representar a estratégia de criação dos papéis dos estudantes definidos como elementos < role-ref $>$ (linhas 17, 18, 24, 30). O método mandatory (linhas 6-18) efetua a busca de um papel previamente definido na unidade de aprendizagem corrente para todos os estudantes. Enquanto, o método fall-back (linhas 21-30) efetua a construção de um novo papel mediante a definição do elemento $<$ learner $>$ (linhas 25, 29). 


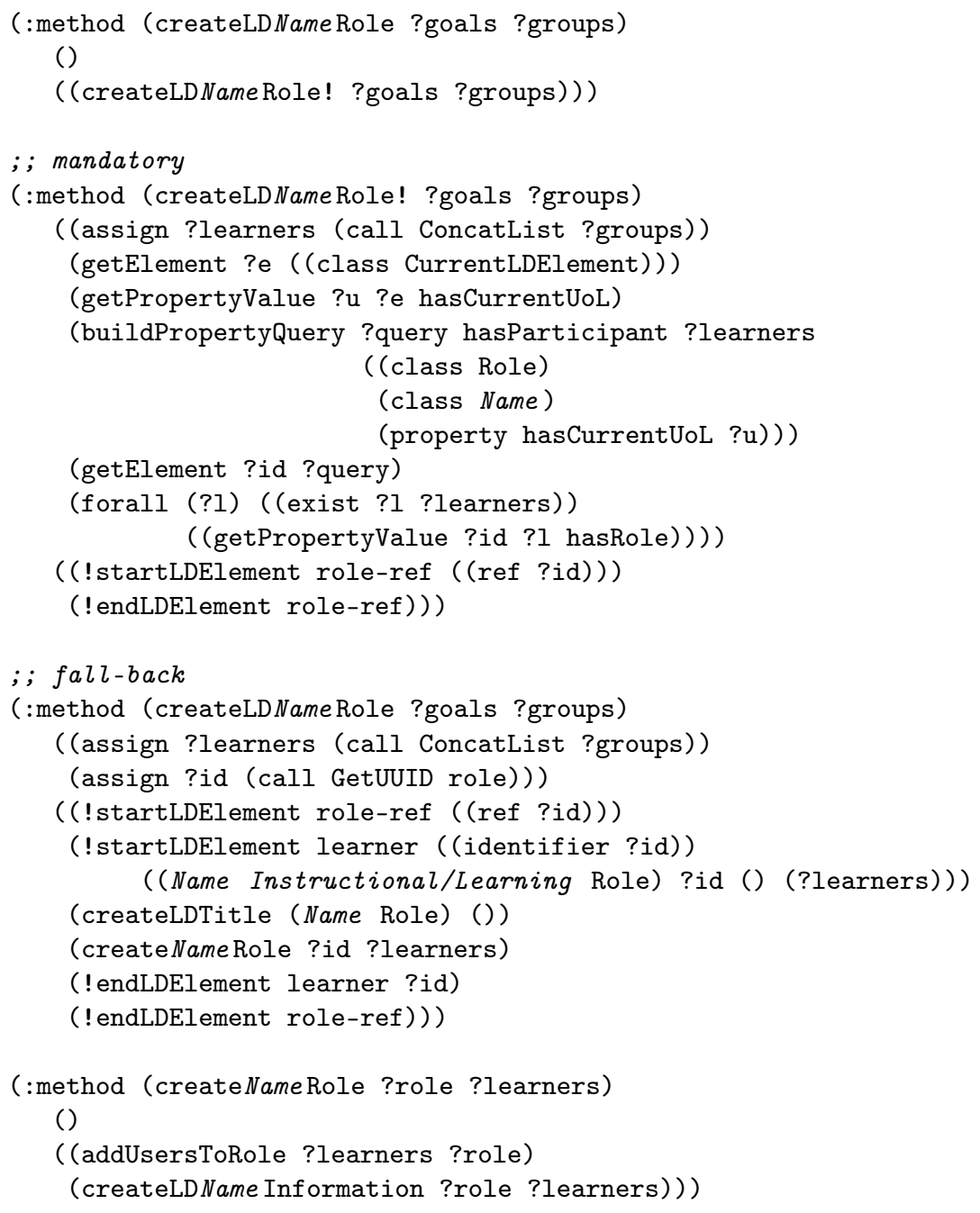

Figura 4.11: Esquema de representação das estratégia de criação de papéis

A definição do papel instrucional (Instructional) ou de aprendizagem (Learning) é efetuada no metadado da tarefa !startLDElement (linha 26). A tarefa createNameRole (linha 28) efetua a atribuição do papel ao conjunto de estudantes mediante a tarefa addUsersToRole (linha 34). A definição de informações é efetuada mediante a tarefa createLDNamelnformation (linha 35).

\subsubsection{Estratégias de aprendizagem}

O esquema mostrado na Figura 4.12 é utilizado para representar a criação de estratégias de aprendizagem definidas como elementos $<$ role-ref $>$ (linhas 3,7). Assim, o método createNameStrategy (linhas 9-12) efetua a criação da estratégia de aprendizagem como: a construção de um papel do estudante mediante a tarefa createLDRNameRole (linha 11), e a construção do padrão de interação mediante a tarefa createLDRNamelnteractions (linha 12). 


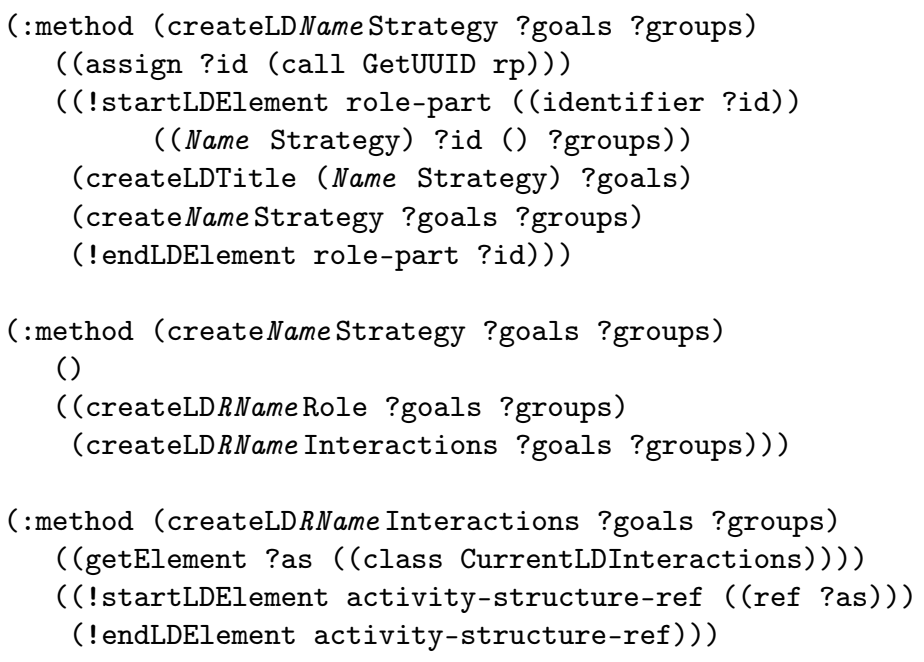

Figura 4.12: Esquema de representação das estratégias de criação de estratégias de aprendizagem

\subsubsection{Fases nos cenários colaborativos}

O esquema de tarefas e métodos hierárquicos mostrado na Figura 4.13 é utilizado para representar a criação das fases nos cenários colaborativos, as quais são definidas como elementos $<$ act $>$ (linha 4,10).

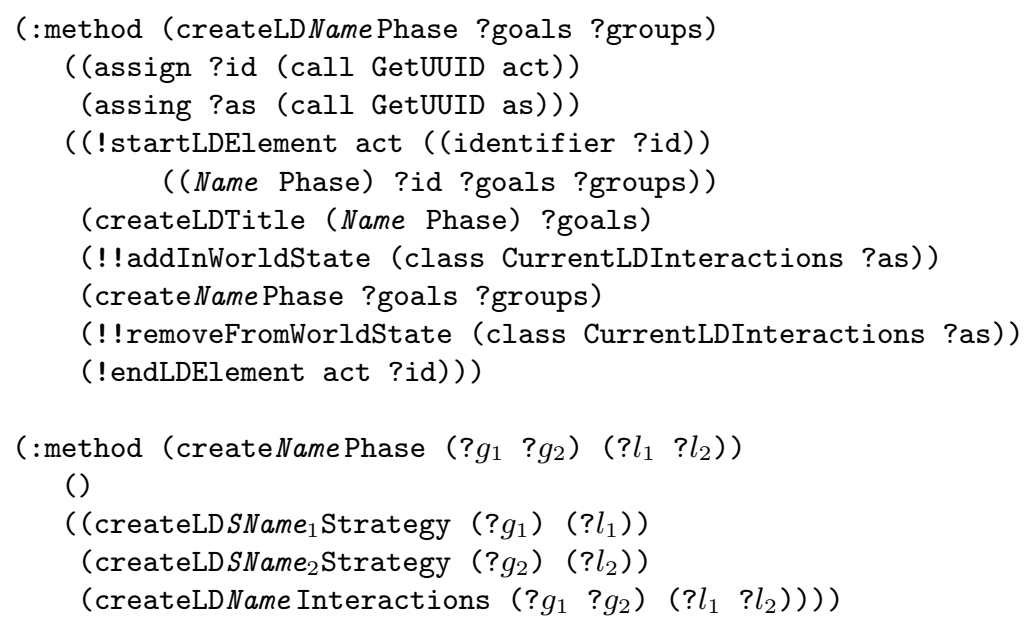

Figura 4.13: Esquema de representação das estratégias de criação de fases nos cenários colaborativos

O método createNamePhase (linhas 12-16) consiste na definição de estratégias $S N_{a m e}$ e SName $_{2}$ (linhas 14-15) mediante tarefas createSName ${ }_{1}$ Strategy e a definição de um padrão de interação mediante a tarefa createLDNamelnteractions (linha 16). O uso da tarefa !!addlnWorldState (linhas 7,9) efetua a definição de ?as como o identificador do padrão de interação associado às estratégias. 


\subsubsection{Cenários colaborativos}

O esquema de tarefas e métodos hierárquicos mostrados na Figura 4.14 é utilizado para representar as estratégias de criação de cenários colaborativos, os quais são definidos como elementos < play $>$ (linhas 8,12, 33,38). O método fall-back (linhas 6-12) efetua a criação do cenário colaborativo no caso de que as competências dos objetivos educacionais sejam relativas a elementos de conhecimento de tipo auxiliar. Enquanto, o método fall-back (linhas 15-38) efetua a criação do cenário colaborativo no caso de que a competência ?c dos objetivos seja relativa a um elementos de conhecimento de tipo fundamental.

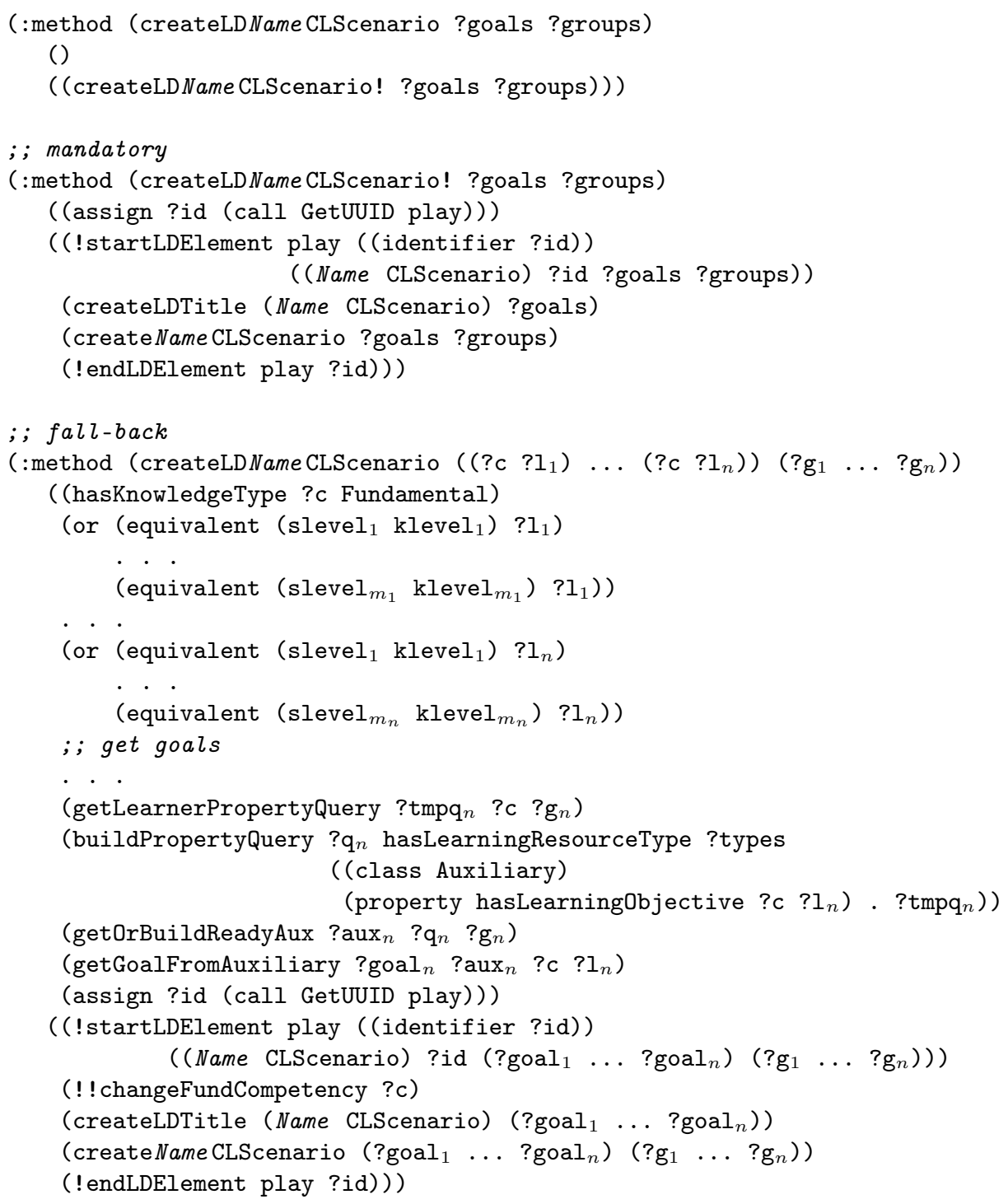

Figura 4.14: Esquema de representação das estratégias de criação de cenários colaborativos 
O método fall-back efetua a busca ou criação de elementos de conhecimento de tipo auxiliar ?aux 1 ... ? aux $_{n}$ (linhas 24-30) que satisfazem as características individuais dos grupos de estudantes $? \mathrm{~g}_{1} . . \mathrm{?g}_{n}$ (linha 26), tipos de recurso instrucional ?types (linhas 27) e objetivos de aprendizagem (linha 29). Efetuada a obtenção dos elementos de tipo auxiliar é efetuada a obtenção dos objetivos educacionais goal ${ }_{1} \ldots$ ? goal $_{n}$ mediante o axioma getGoalFromAuxiliary (linha 31), efetuando a definição das fases na tarefa createNameCLScenario.

Antes de efetuar a definição das fases no cenário utilizamos o operador !!changeFundCompetency (linha 35) para alterar o valor da competência fundamental no elemento de roteiro corrente. Outra característica dos métodos de decomposição das tarefas createLDNameCLScenario e createNameCLScenario são as restrições de níveis de competência definidas mediante axiomas equivalent que avaliam os níveis de competência definidos nos objetivos.

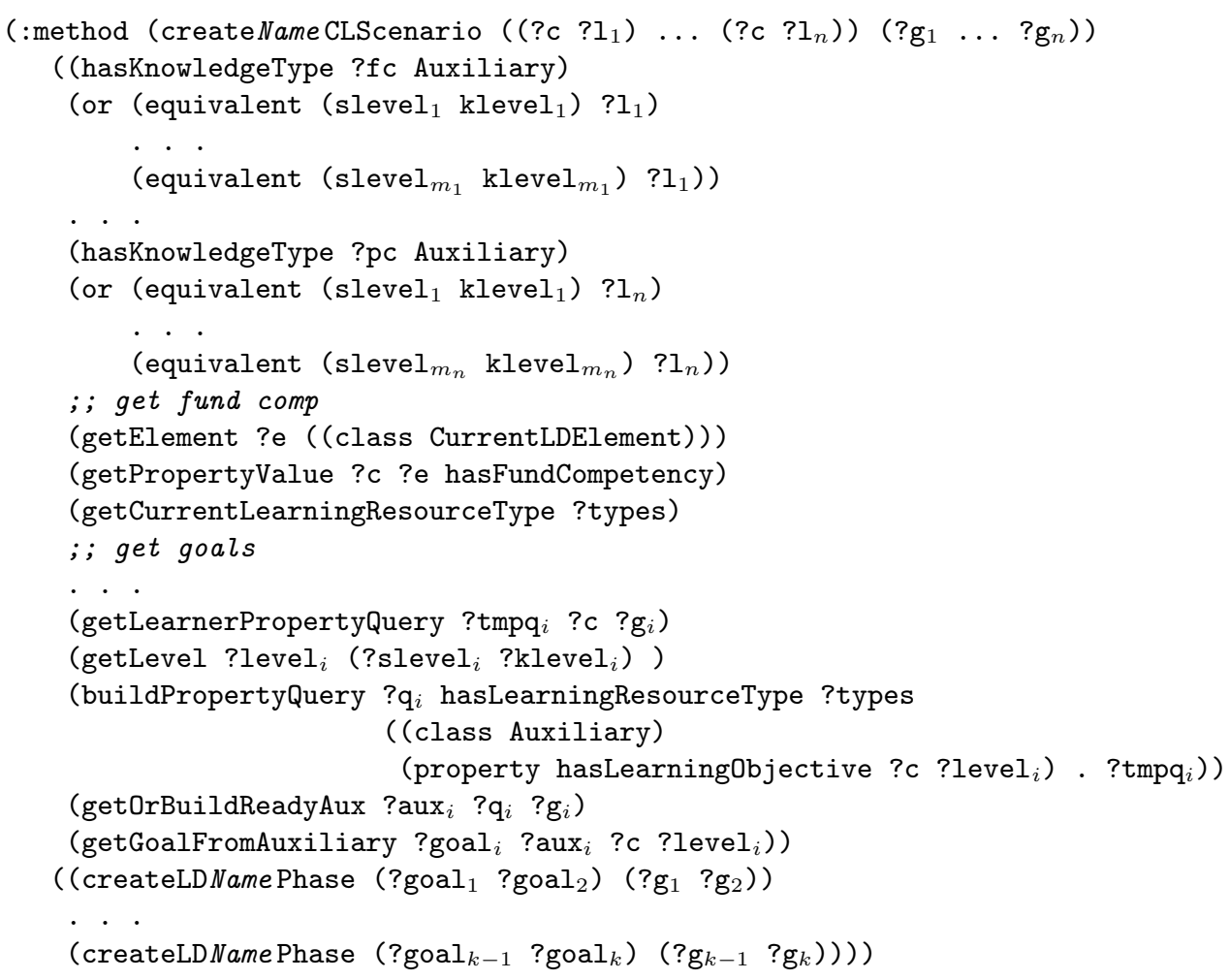

Figura 4.15: Esquema de representação dos métodos associados à tarefa createNameCLScenario

Os métodos hierárquicos associados à tarefa createNameCLScenario utilizam o esquema da Figura 4.15 para definir as fases do cenário colaborativo como um conjunto de tarefas createLD NamePhase (linhas 24-26), detalhada na subseção 4.2.6. Os objetivos educacionais ?goal 1 ... ? goal $_{k}$ nessas tarefas são obtidos mediante o uso dos axiomas getLearnerPropertyQuery (linha 17), buildPropertyQuery (linhas 19-21), getOrBuildReadyAux (linha 22), e getGoalFromAuxiliary (linhas 23). 


\subsection{Macrorroteiros: CLFPs}

As tarefas e métodos hierárquicos apresentados a seguir representam as estratégias de planejamento instrucional que definem a criação dos elementos de macrorroteiros: sessões de aprendizagem, atividades de grupo, fases e roteiros. As estratégias são apresentadas como esquemas de roteiros que definem a abstração de um conjunto de estratégias. Os termos em itálico nos esquemas são substituídos por termos constante para representar uma estratégia específica, assim, utilizando esses esquemas na Subseção 6.2.2 apresentamos exemplos da modelagem.

\subsubsection{Sessões de aprendizagem}

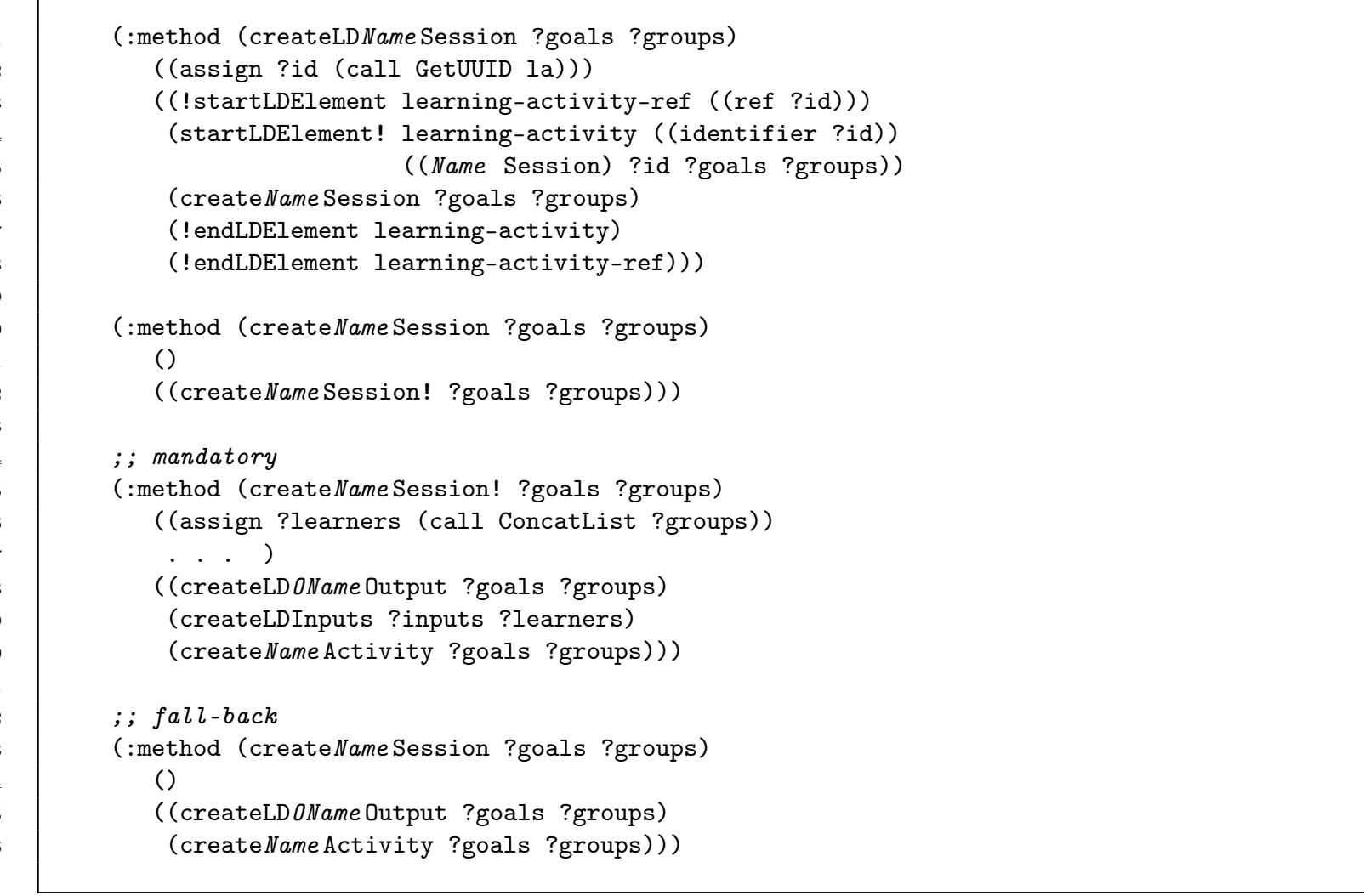

Figura 4.16: Esquema de representação das estratégias de criação de sessões de aprendizagem

As estratégias de criação de sessões de aprendizagem são representados usando o esquema de tarefas e métodos hierárquicos apresentados na Figura 4.16. O esquema efetua a definição de elementos <learning-activity $>$ (linhas 4,7 ), no qual: a atividade de aprendizagem a ser efetuada pelos participantes é definida pela tarefa createNameActivity (linhas 20,26), os recursos de saída são definidos pela tarefa createLDONameOutput (linhas 18,25$)$ e os recursos de entrada são definidos pela tarefa createLDInputs (linha 19). 


\section{Recursos de entrada}

A Figura 4.17 mostra a representação da estratégia de criação de recursos de entrada em sessões de aprendizagem definidas como elementos < prerequisites $>$ (linhas 5, 7), na que os recursos de entrada são definidos como a distribuição dos elementos de entrada ?inputs para os participantes ?learners mediante a tarefa distributeltem (linha 11).

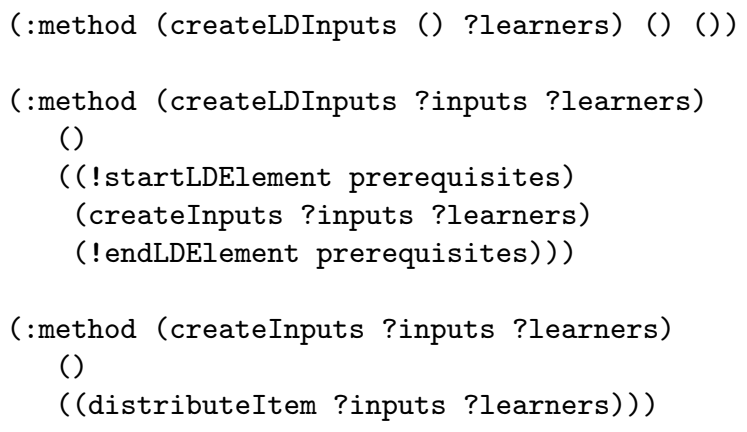

Figura 4.17: Representação da estratégia de criação de recursos de entrada em sessões

\section{Recursos de saída}

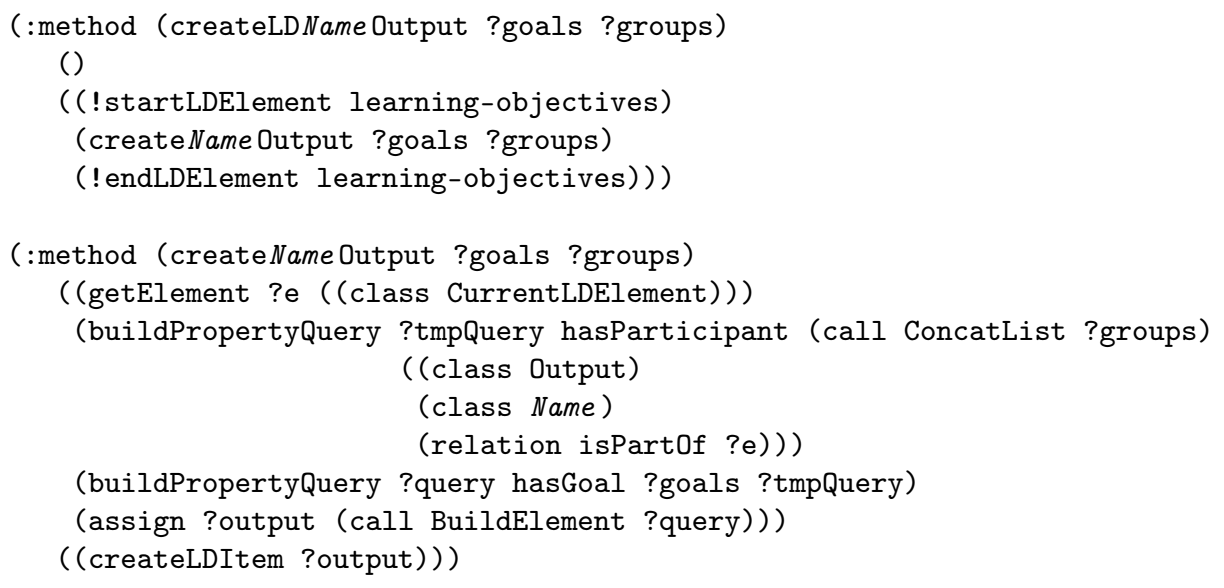

Figura 4.18: Esquema de representação das estratégias de criação de recursos de saída em sessões

As estratégias de criação de recursos de saída nas sessões de aprendizagem são definidas mediante o esquema da Figura 4.18 que definem a criação de elementos <learning-objectives> (linhas 3,5). A estratégia consiste na criação de um novo elemento no modelo de domínio a ser ensinado mediante o termo de chamada (call BuildElement ...) (linha 14). O elemento de saída Output (linha 10) é definido para um conjunto de participantes ?groups (linha 9) como parte do elemento corrente ?e (linha 12). 


\section{Atividades}

A tarefa createNameActivity mostrada na Figura 4.19 é empregada para definir as estratégias de criação de atividades a serem efetuadas em sessões. As atividades são definidas como: um ambiente de apoio à aprendizagem mediante a tarefa createLDNameEnvironment (linha 3); e uma descrição da sessão mediante a tarefa createLDNameSessionDescription (linha 4).

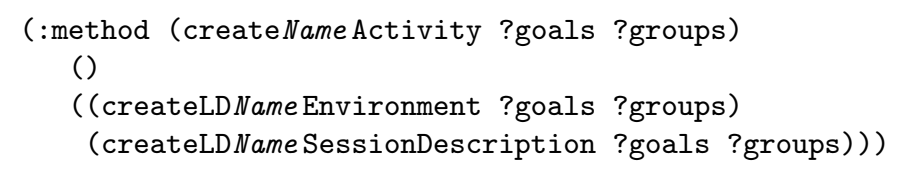

Figura 4.19: Esquema de representação de estratégias de criação das atividades em sessões

O esquema de tarefas e métodos hierárquicos apresentados na Figura 4.20 possibilitam a definição de estratégias de criação de descrições em sessões de aprendizagem como elementos $<$ activity-description > (linha 3-6). O método mandatory (linhas 13-16) efetua a seleção de descrição de atividades apropriadas no modelo de domínio. Enquanto, o método fall-back (linhas 19-22) efetua a construção de descrições das atividades no caso de que não existam no modelo de domínio a ser ensinado.

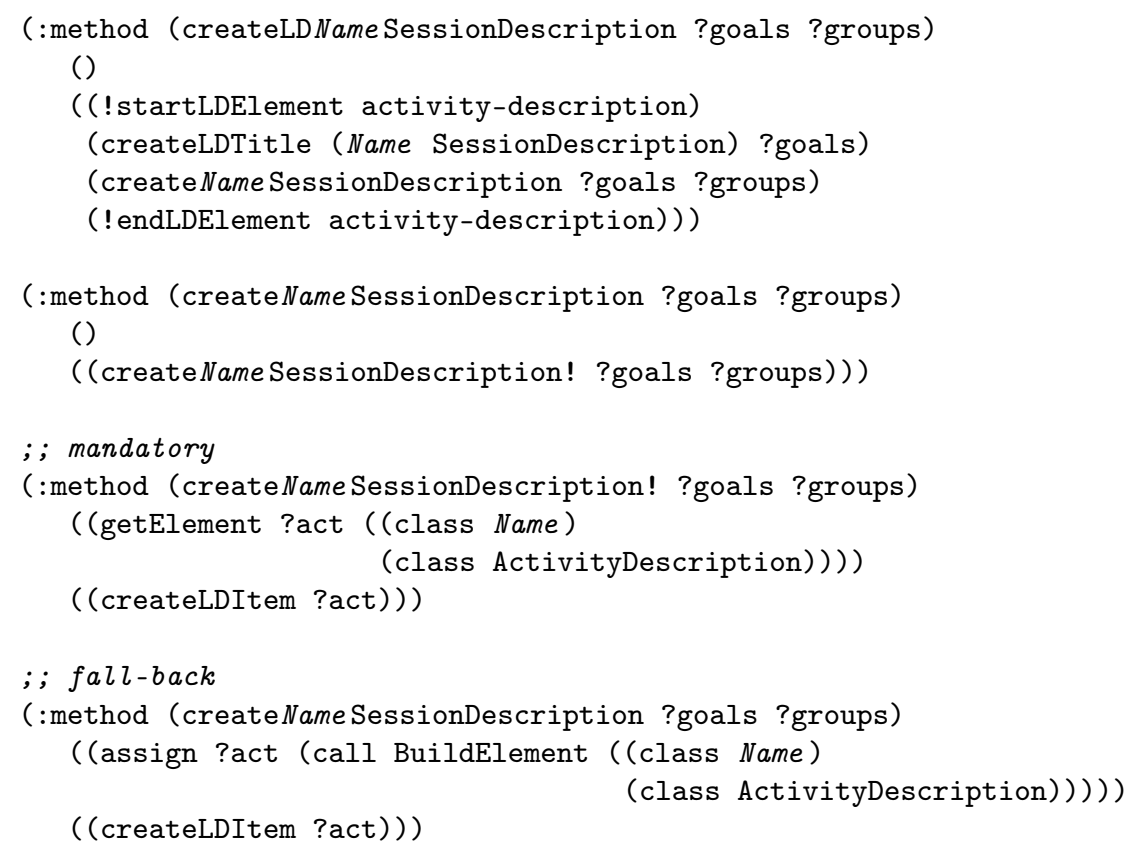

Figura 4.20: Esquema de representação de estratégias de criação de descrições de sessões 


\subsubsection{Atividades de grupo}

As tarefas e métodos hierárquicos apresentados na Figura 4.21 possibilitam a representação de estratégias de criação de atividades de grupo como elementos $<$ role-part $>$ (linhas 3-7).

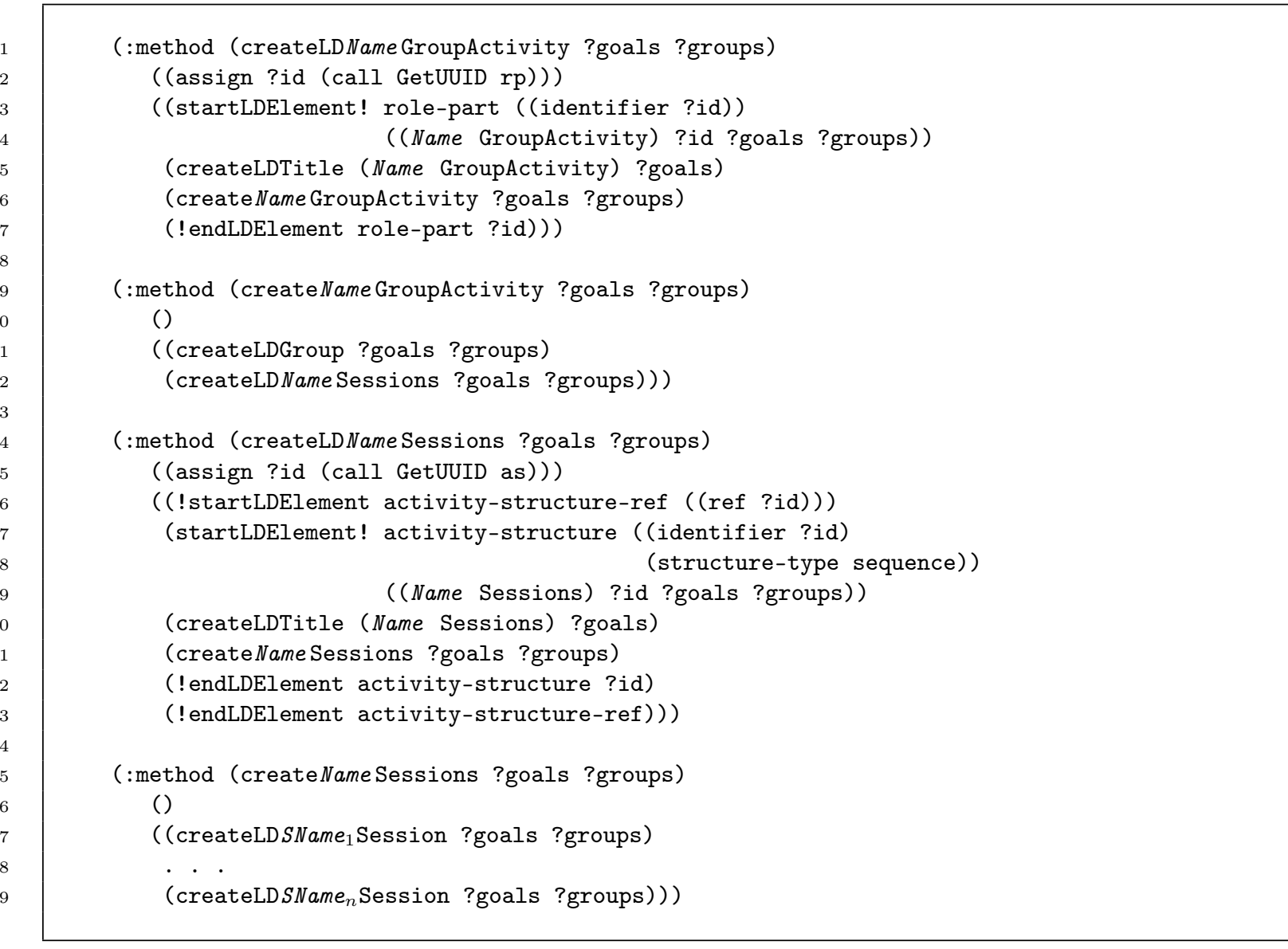

Figura 4.21: Esquema de representação de estratégias de criação de atividades de grupo

A estratégia define a atividade de grupo como a associação de uma lista de sessões com um grupo de estudantes mediante as tarefas createLDGroup e createLD NameSessions (linhas 11-12). A lista de sessões definida mediante a tarefa createLDNameSessions consiste em uma sequência de tarefas createLDSName ${ }_{1}$ Session ... createLDSName ${ }_{n}$ Session (linhas 27-29).

\subsubsection{Fases}

$\mathrm{Na}$ modelagem de estratégias de criação de fases não foi possível definir um esquema de representação comum devido a que cada uma efetua a formação de grupos usando diferentes informações do estado corrente. A Figura 4.22 mostra a representação da estratégia de criação da fase aprendizagem de papéis (Role) pertencente ao macrorroteiro simulação (Simulation). A estratégia define a fase como um conjunto de atividades de grupos definidos mediante as tarefas distributeRoleGroupActivityByComps (linhas 16-32) e distributeRoleGroupActivityByCLGroups (linhas 34-40). 


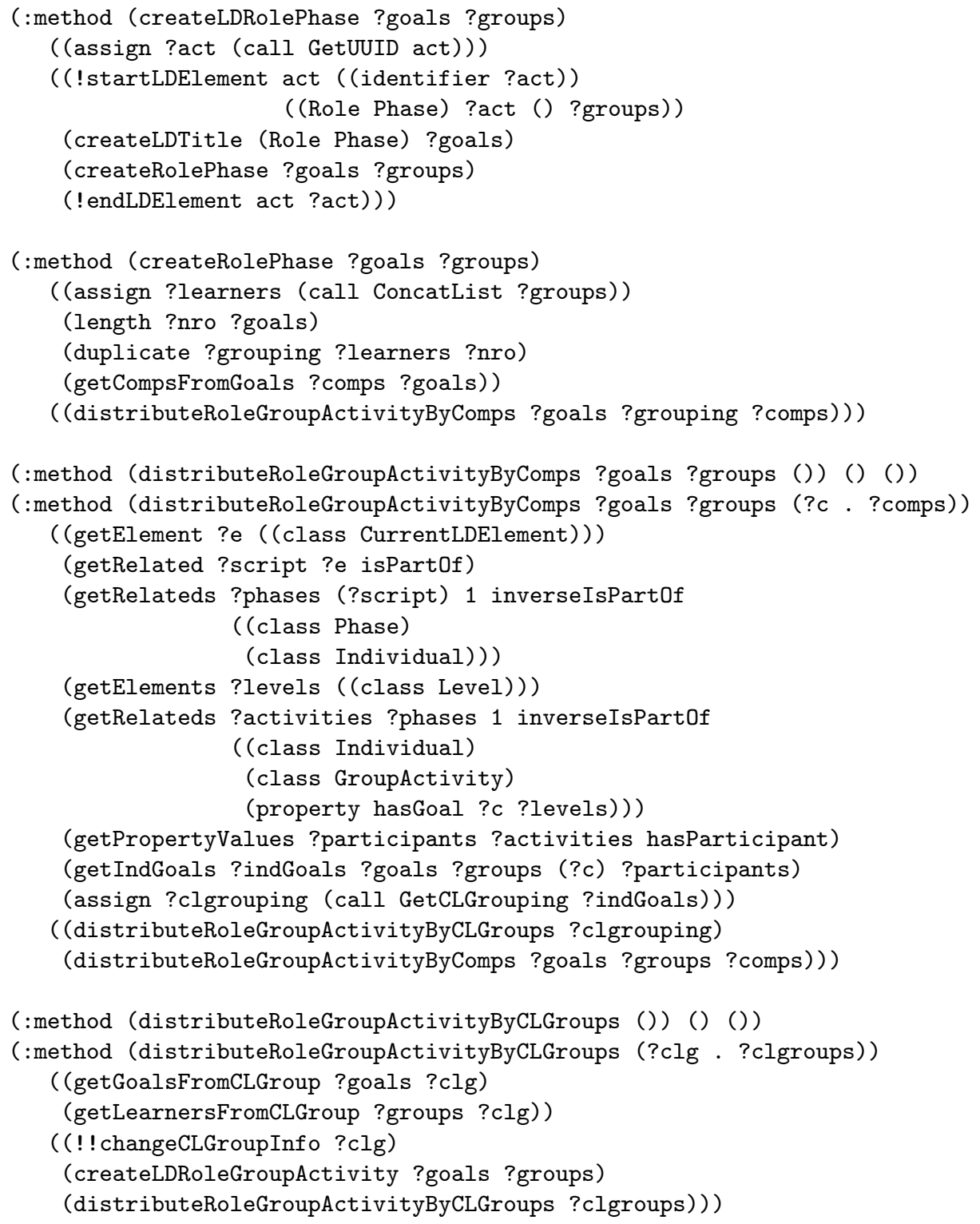

Figura 4.22: Representação da fase aprendizagem de papéis (Role) 
A formação de grupos é definida pelo termo de chamada GetCLGrouping (linha 30) que obtém o agrupamento ?clgrouping a partir de participantes que tenham atingido objetivos educacionais relativos à competência ?c nas atividades de grupo da fase individual (linhas 18-28). O conjunto de competências e estudantes com a qual deve ser efetuada a formação de grupos são obtidos com os axiomas getCompsFromGoals (linha 13) e duplicate (linha 12) no método createRolePhase (linhas 9-14).

\subsubsection{Macrorroteiros colaborativos}

O esquema de tarefas e método hierárquicos mostrado na Figura 4.23 é utilizado para representar as estratégias de criação dos macrorroteiros colaborativos definidos como elementos $<$ play $>$ (linhas 8, 13, 30, 35). O método fall-back (linhas 16-35) efetua a criação do macrorroteiro no caso de que a competência ?c dos objetivos educacionais ?fgoals seja uma competência de tipo fundamental (linhas 17-18). Enquanto, o método mandatory (linhas 6-13) é utilizado no caso de uma competência de tipo auxiliar.

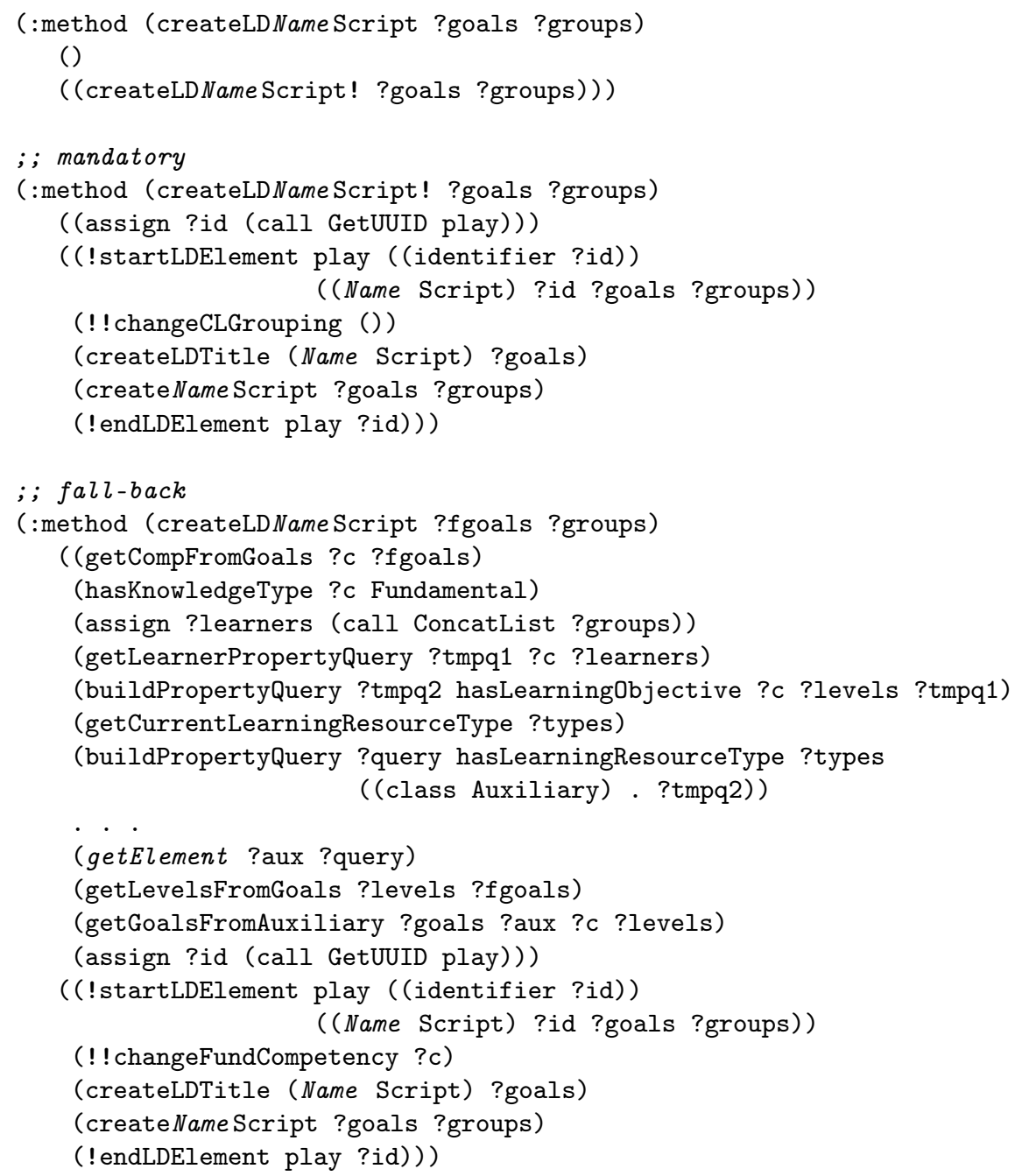

Figura 4.23: Esquema de representação das estratégias de criação de criação de macrorroteiros 
O método fall-back efetua a busca ou criação de um elemento de conhecimento ?aux de tipo auxiliar (linhas 19-26) mediante o axioma getElements ou getOrBuildReadyAux (linha 26) que satisfazem as condições ?query, condições de propriedades definidas pelas características individuais dos estudantes mediante o axioma getLearnerPropertyQuery (linhas 19-20), os objetivos educacionais (linhas 21), tipos de recurso instrucional ?types (linhas 22-24) e outras condições dependente do macrorroteiro.

Mediante os axiomas getLevelsFromGoals e getGoalFromAuxiliary (linhas 27-28) obtemos os objetivos ?goals a ser utilizado na tarefa createNameScript (linha 34). Antes de efetuar a tarefa createNameScript utilizamos o operador !!changeFundCompetency (linha 32) para alterar a competência fundamental dos elementos de roteiros a serem definidos.

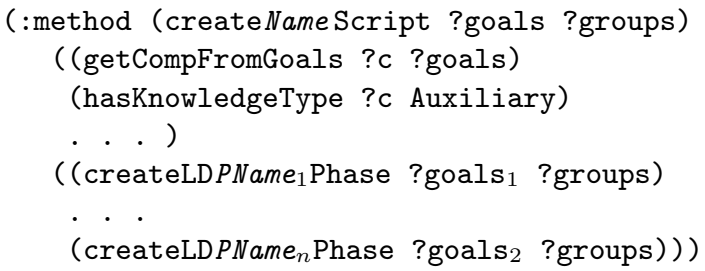

Figura 4.24: Esquema de representação dos métodos associados à tarefa createNameScript

A Figura 4.24 mostra o esquema dos métodos associados à tarefa createNameScript que efetuar a criação das fases $P N_{a m e} \ldots P N a m e_{n}$ do roteiro mediante as tarefas createLDPName ${ }_{1}$ Phase ... createLDPName ${ }_{n}$ Phase (linhas 13-43).

\subsubsection{Integração de macrorroteiros e microrroteiros}

No presente trabalho, a integração de macrorroteiros e microrroteiros utiliza a abordagem proposta por Villasclaras-Fernández et al. (2009) (Figura 4.25), de maneira que: os macrorroteiros são utilizados para definir o sequenciamento das atividades e a formação de grupos; enquanto, os microroteiros são utilizados para definir o fluxo de interação e o conjunto de ações individuais dos estudantes. Assim, a integração do microrroteiro é efetuada na definição das atividades e configuração de papéis do macrorroteiro.

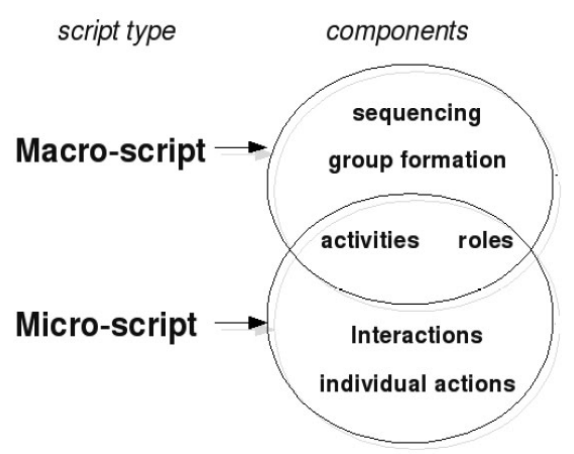

Figura 4.25: Integração de macrorroteiros e microrroteiros (Villasclaras-Fernández et al., 2009) 


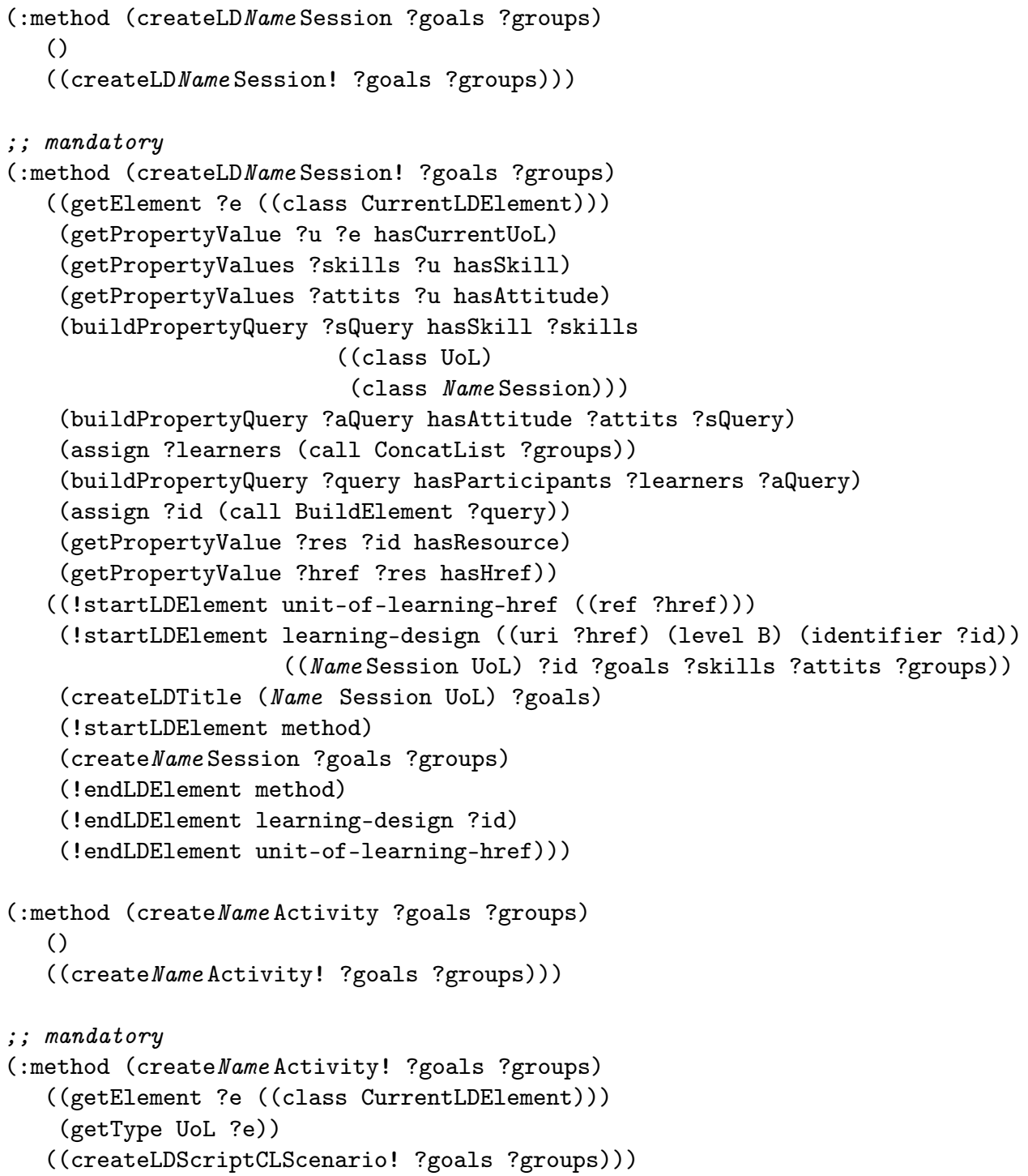

Figura 4.26: Tarefas e métodos hierárquicos que definem a integração de macro e microrroteiros 
Baseados na definição de objetivos educacionais e informações de agrupamento nos elementos de roteiros, a integração de micro e macrorroteiros é efetuada na modelagem de estratégias de criação de sessões de aprendizagem mediante a definição das tarefas e métodos hierárquicos mostrados na Figura 4.26.

O método mandatory da tarefa createLDNameSession! (linhas 6-28) efetua a definição da sessão de aprendizagem como um elemento <learning-design > (linhas 21, 27). Logo, a integração é efetuada mediante o método mandatory da tarefa createNameActivity! (linhas 35-38), no que a integração é definida na tarefa createLDScriptCLScenario! (linha 38).

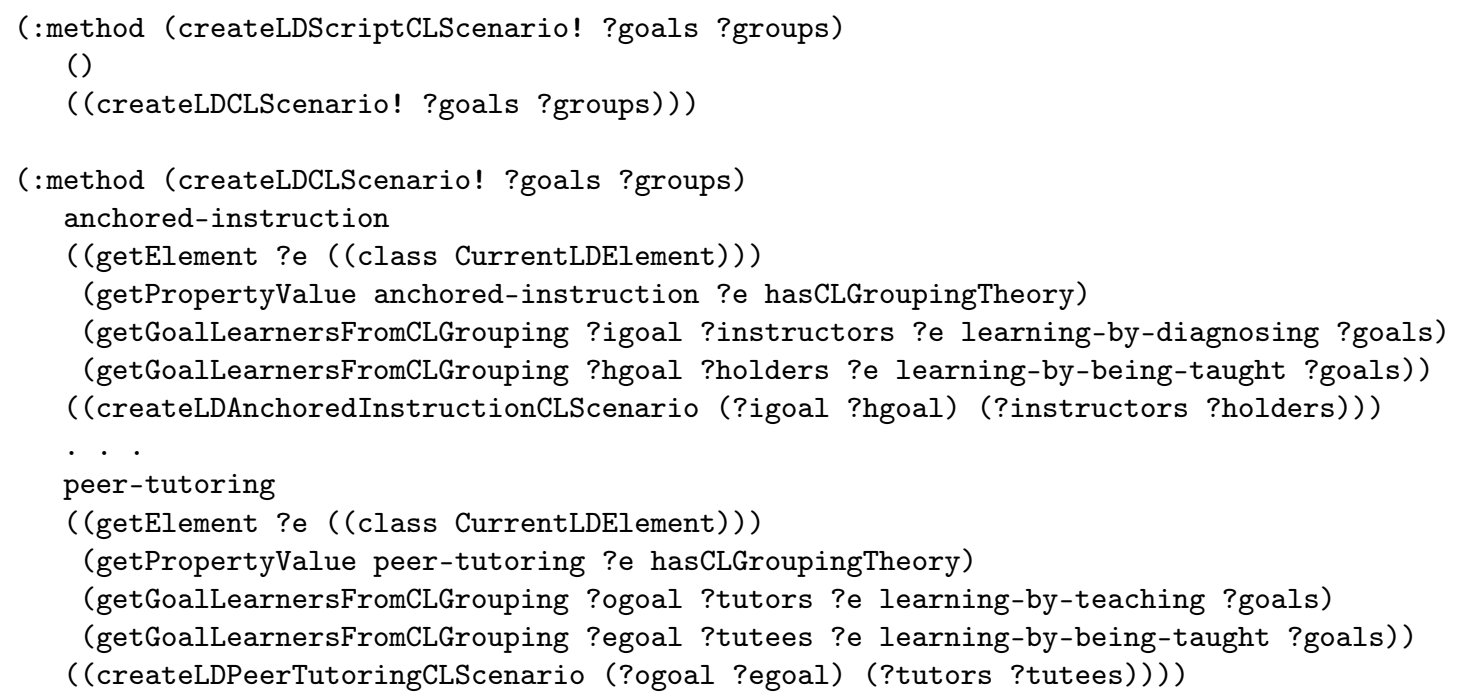

Figura 4.27: Métodos associados à tarefa createJigsawScript

A tarefa de integração createLDScriptCLScenario! mostrada na Figura 4.27 efetua a seleção do microrroteiro definido como sessão colaborativa de aprendizagem mediante os axiomas getPropertyValue (linhas 8,15) e getGoalLearnersFromCLGrouping (linhas 9-10, 16-17) que utilizam as informações de agrupamento definida no elemento de roteiro corrente ?e (linhas 7,14). O axioma getPropertyValue avalia o valor corrente da teoria de aprendizagem, enquanto o axioma getGoalLearnersFromCLGrouping obtém objetivos educacionais e participantes. Por exemplo, no método peer-tutoring (linhas 14-18) obtemos os objetivos ?ogoal, ?egoal e participantes ?tutors, ?tutees relativos à estratégias learning-by-teaching e learning-by-being-taught do elemento corrente.

\subsubsection{Combinação dos padrões de macrorroteiro}

De acordo com as relações de aperfeiçoamento definidas na estrutura de classificação de padrões de roteiros colaborativos (Subseção 3.3.1), um padrão de macrorroteiro pode ser aperfeiçoado por um outro padrão de macrorroteiro. Isto quer dizer que dois padrões de macrorroteiro podem ser: combinados efetuando a substituição de uma sessão com um outro padrão com o que apresenta uma relação de aperfeiçoar. A Figura 4.28 exemplifica a combinação dos padrões de fluxo de aprendizagem colaborativa, na qual a sessão de especialização no padrão Jigsaw é aperfeiçoada com o padrão Pyramid. 


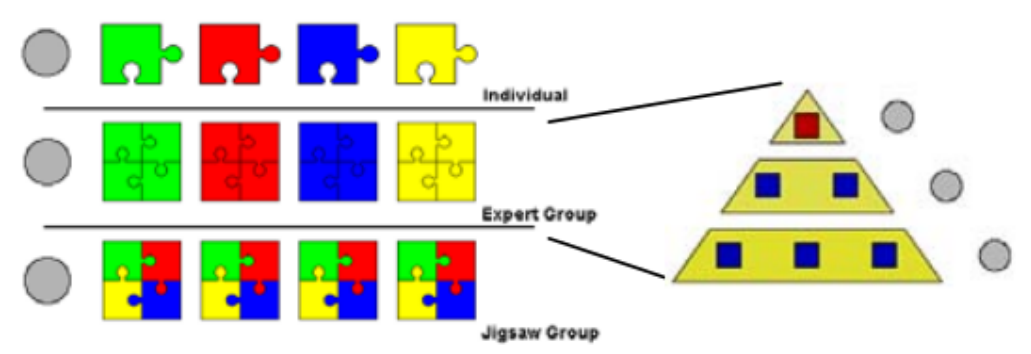

Figura 4.28: Exemplificação da combinação dos macrorroteiro Jigsaw e Pyramid

Ao igual que na integração de macrorroteiros e microrroteiros, a combinação dos padrões de macrorroteiros é definida na modelagem de estratégias de criação de sessões de aprendizagem. Assim, a Figura 4.30 mostra que a combinação é definida no método mandatory (6-8) de decomposição da tarefa createLDScriptCLScenario! (linhas 1-3) mediante a tarefa createLDScript! (linha 8), enquanto a integração é definida no método fall-back (linhas 11-13).

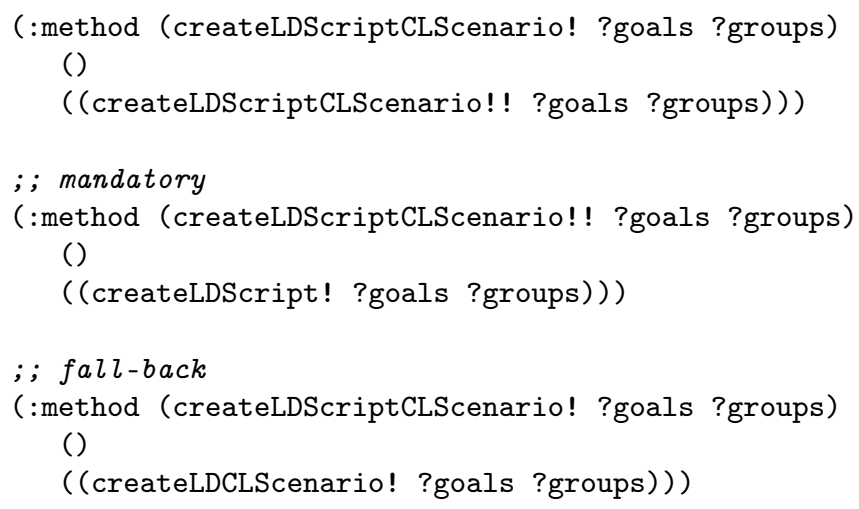

Figura 4.29: Método de cominação associados à tarefa createLDScriptCLScenario!

A tarefa createLDScript! é associada a diferentes métodos hierárquicos que definem a seleção do macrorroteiro adequado a ser combinado. Os métodos associado a tarefa são representado mediante o esquema da Figura 4.30, no que:

- a condição lógica que evita que um padrão de roteiro seja combinado com ele mesmo (linhas 3-8) é definido como pré-condições lógicas; e

- as condições de complexidade (linhas 10-15), habilidades e atitudes (linhas 17-23) do roteiro são definidas como condições relativas (:relative). 


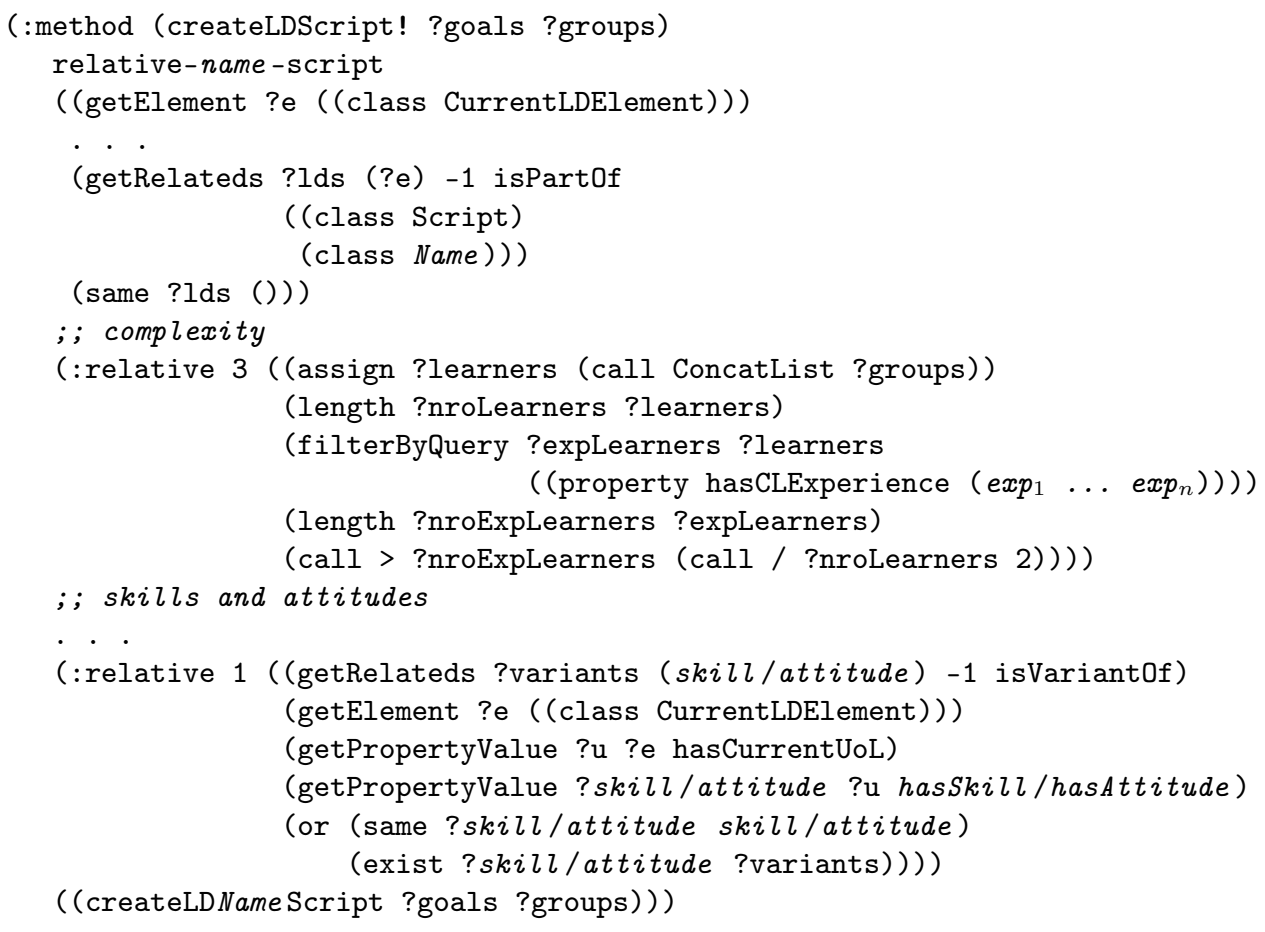

Figura 4.30: Esquema dos métodos associados à tarefa createLDScriptCLScenario!

\subsection{Unidades de aprendizagem}

As estratégias de criação de unidades de aprendizagem são representadas usando o esquema de tarefas e métodos hierárquicos mostrado na Figura 4.31. O esquema efetua a definição de elementos <learning-design > (linhas 11-17), no qual: cada competência ?c definida nos objetivos ?goals define um roteiro colaborativo mediante a tarefa createLDNameScript (linha 32). No método de decomposição da tarefa createNameUoL (linhas 19-22), o axioma getCompsFromGoals e sortBy obtém em forma ordenada as competências cognitivas. Os axiomas filterGoalsByComp e filterGroupsByComp (linhas 30-31) efetuam a filtragem dos objetivos educacionais.

Neste trabalho, a única estratégia modelada usando o esquema da Figura 4.31 é a criação da unidade de aprendizagem Fundamental, definida mediante a substituição do termo itálico Name. 


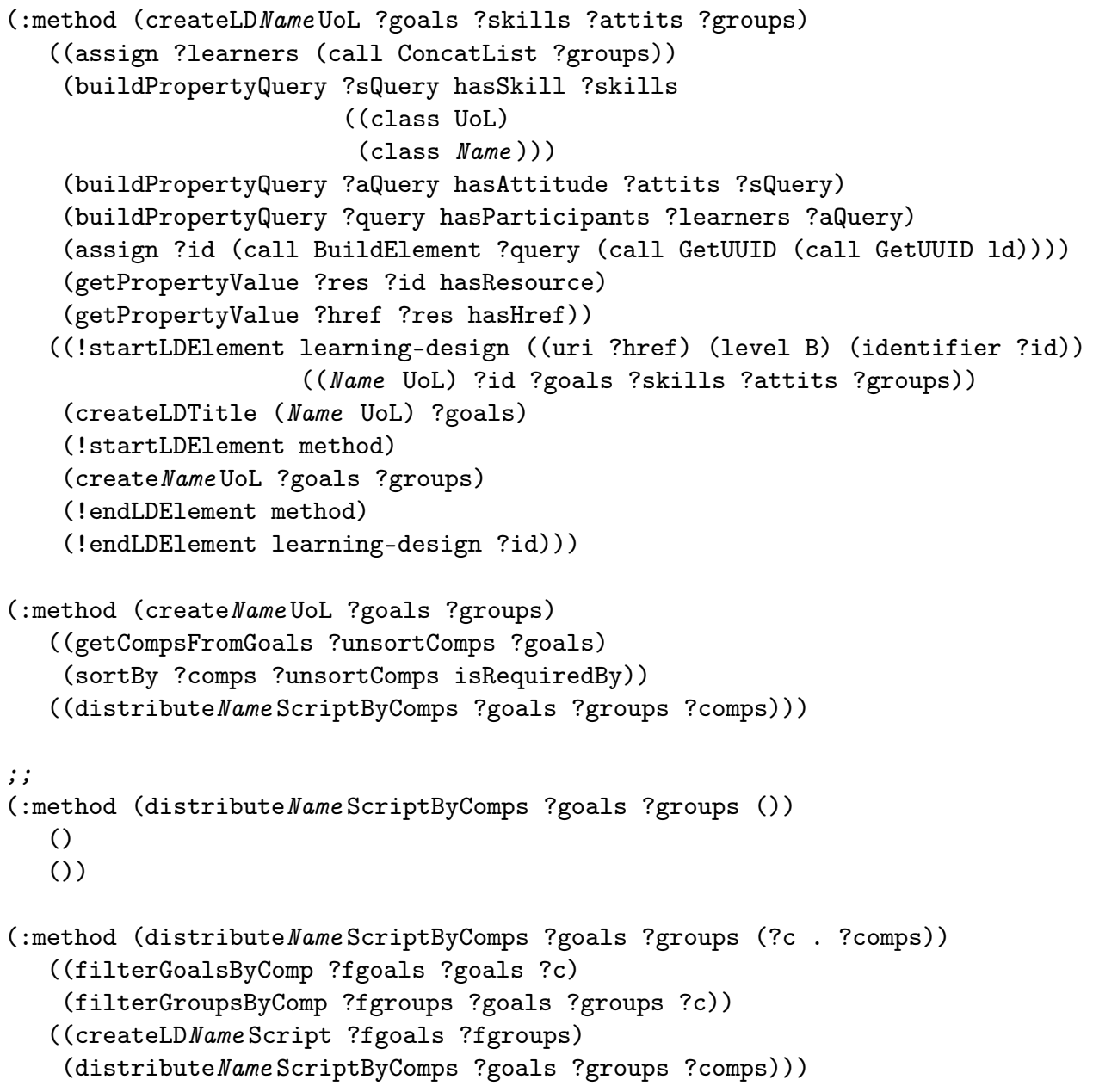

Figura 4.31: Esquema de representação da estratégia de criação de unidades de aprendizagem 


\section{Capítulo 5}

\section{Implementação}

Neste capítulo descrevemos os aspetos técnicos e as características principais do gerador de cursos colaborativos e da ferramenta de autoria das unidades de aprendizagem desenvolvidas na forma de protótipos para avaliar a modelagem proposta. A Seção 5.1 descreve as caraterísticas da implementação do gerador de cursos colaborativos. A Seção 5.2 descreve as caraterísticas da ferramenta ADL de autoria das unidades de aprendizagem.

\subsection{Implementação do gerador de cursos colaborativos}

O gerador de cursos colaborativos é um software educativo que efetua a geração de unidades de aprendizagem adaptadas às características individuais dos estudantes. A geração acontece a solicitude de um projetista instrucional quem define os objetivos educacionais e participantes da unidade. Neste trabalho, a unidade de aprendizagem obtida consiste em um pacote ZIP que contém: um conjunto de roteiros colaborativos, definidos na especificação IMS-LD; e todos os recursos instrucionais necessários.

Uma vez obtido o planejador dependente de domínio, usando o processo de compilação apresentado na Subseção 2.4.3 e a modelagem do domínio de planejamento apresentada nos Capítulos 3 e 4, o gerador de cursos consiste apenas de um pequeno número de classes principais apresentadas no diagrama UML da Figura 5.1.

A classe LDElement representa a unidade de aprendizagem obtida pelo sistema de planejamento como um elemento de roteiro colaborativo que apresenta:

- um atributo type que define se o elemento de roteiro é uma etiqueta de abertura ou fechamento, atribuição ou remoção de um papel, adição ou remoção de um grupo, inserção de texto ou recurso;

- um atributo tag que define o nome da etiqueta;

- um atributo parameters que define a lista de atributos no marcador XML;

- um atributo children que define a lista de elementos que são parte do elemento; e

- um atributo metadata que define informações de classificação, objetivos educacionais e participantes conforme foi descrito na Subseção 4.3.4. Além disso, o atributo metadada contém outras informações a serem definidas pelo gerador de curso como tarefas públicas, termos de busca, etc. 


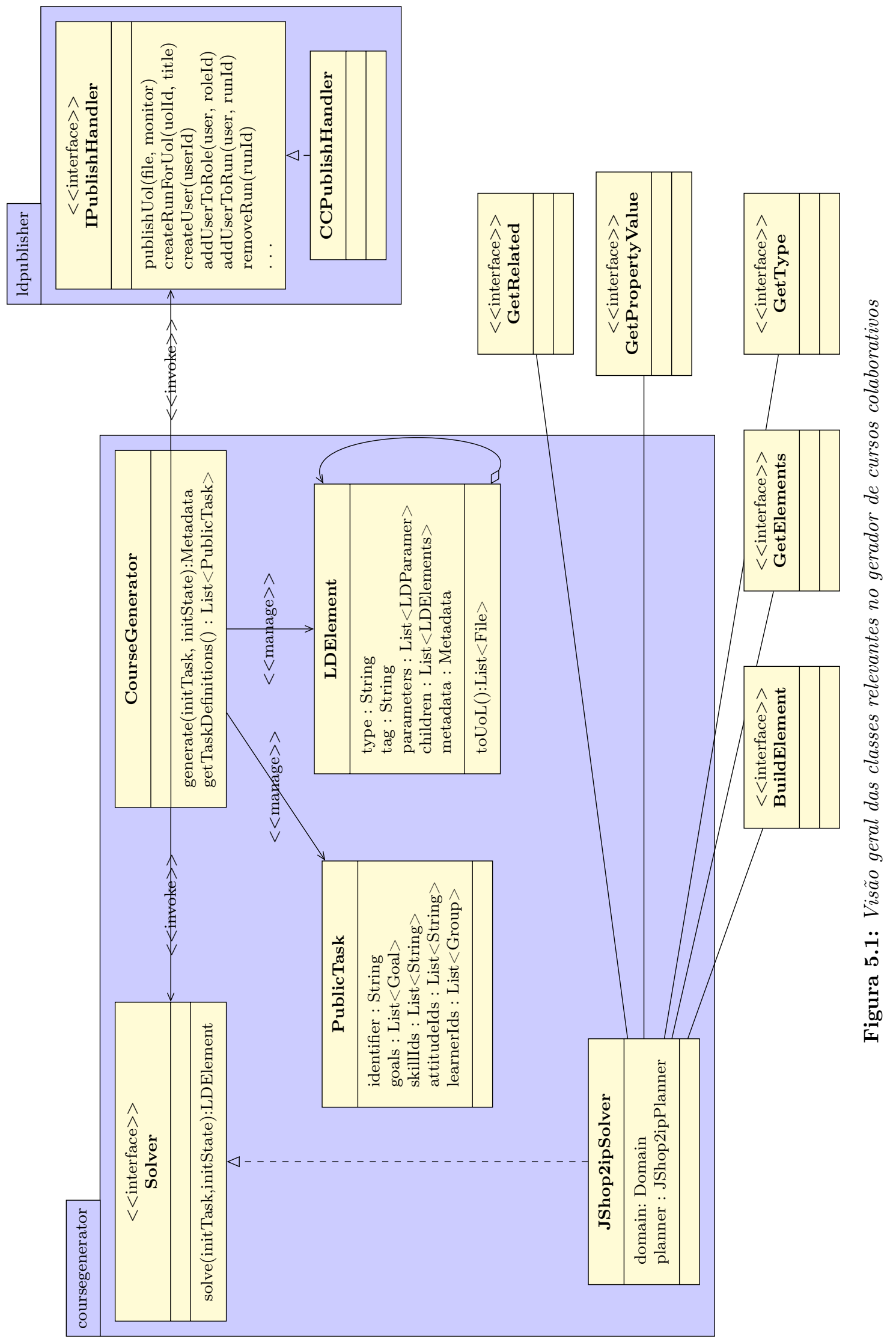


As classes encarregadas de efetuar o processo de planejamento instrucional são abstraias na interface Solver, interface que apresenta o método solve para dar solução ao problema de planejamento instrucional (definido na Seção 3.2). Assim, em nosso gerador de cursos a classe JShop2ipSolver encapsula o algoritmo de planejamento JSHOP2ip (detalhado na Subseção 2.4.3) no atributo planner e o domínio de planejamento (definido na Seção 3.3) no atributo domain.

A interface IPublishHandler apresentam métodos que possibilitam publicar as unidades de aprendizagem obtidas em um AVA. Assim, como métodos que manipulam a atribuição e remoção de usuários nos papéis e grupos. A classe CCPublishHandler implementa a interface para definir a integração do gerador de cursos com o software CopperCore (Vogten e Martens, 2004).

Finalmente, os métodos da classe CourseGenerator são empregados pelos projetista instrucional e outras ferramentas de autoria para efetuar a geração do curso mediante requisições de tipo GET e POST que empregam os métodos getTaskDefinitions e generate.

\subsubsection{Processo de geração de cursos}

O processo de geração de cursos mostrado no diagrama de sequência da Figura 5.2.

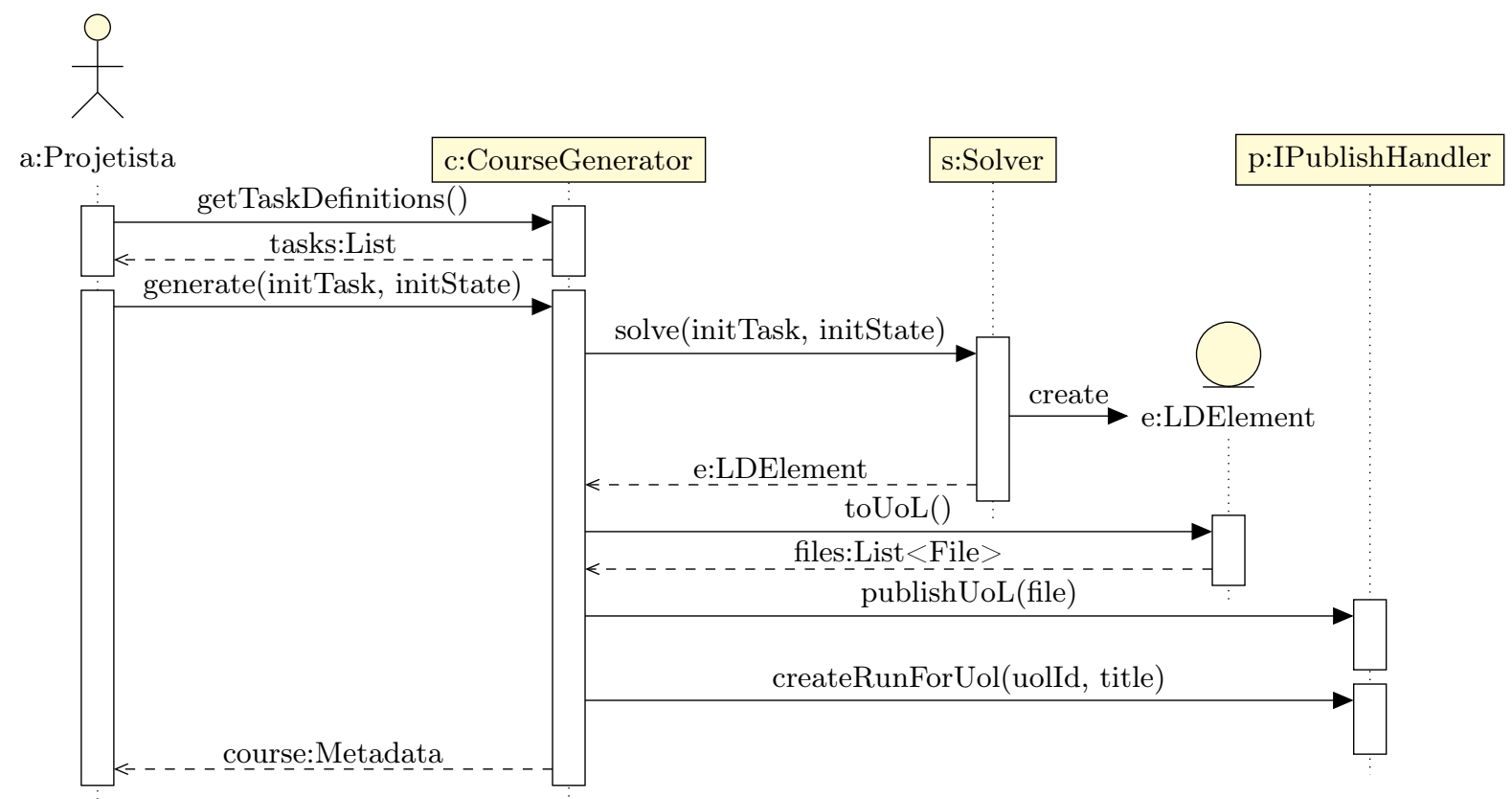

Figura 5.2: Diagrama de sequência que ilustra a geração do curso

O processo consiste primeiro na obtenção de um lista de tarefas públicas mediante o método getTaskDefinitions. A Figura 5.3 contém um exemplo da lista de tarefas públicas que são devolvidas pelo método. A informação é apresentada como uma lista de elementos $<$ task $>$ que apresentam: um identificador de tarefa $<$ identifier $>$, um conjunto de objetivos $<$ goals $>$, uma lista de habilidades independentes $<$ skills $>$, uma lista de atitudes $<$ attitudes $>$ e um conjunto de estudantes $<$ learners $>$. Os atributos compId e level em cada objetivo < goal $>$ são um identificador de competência e um nível de competência. 


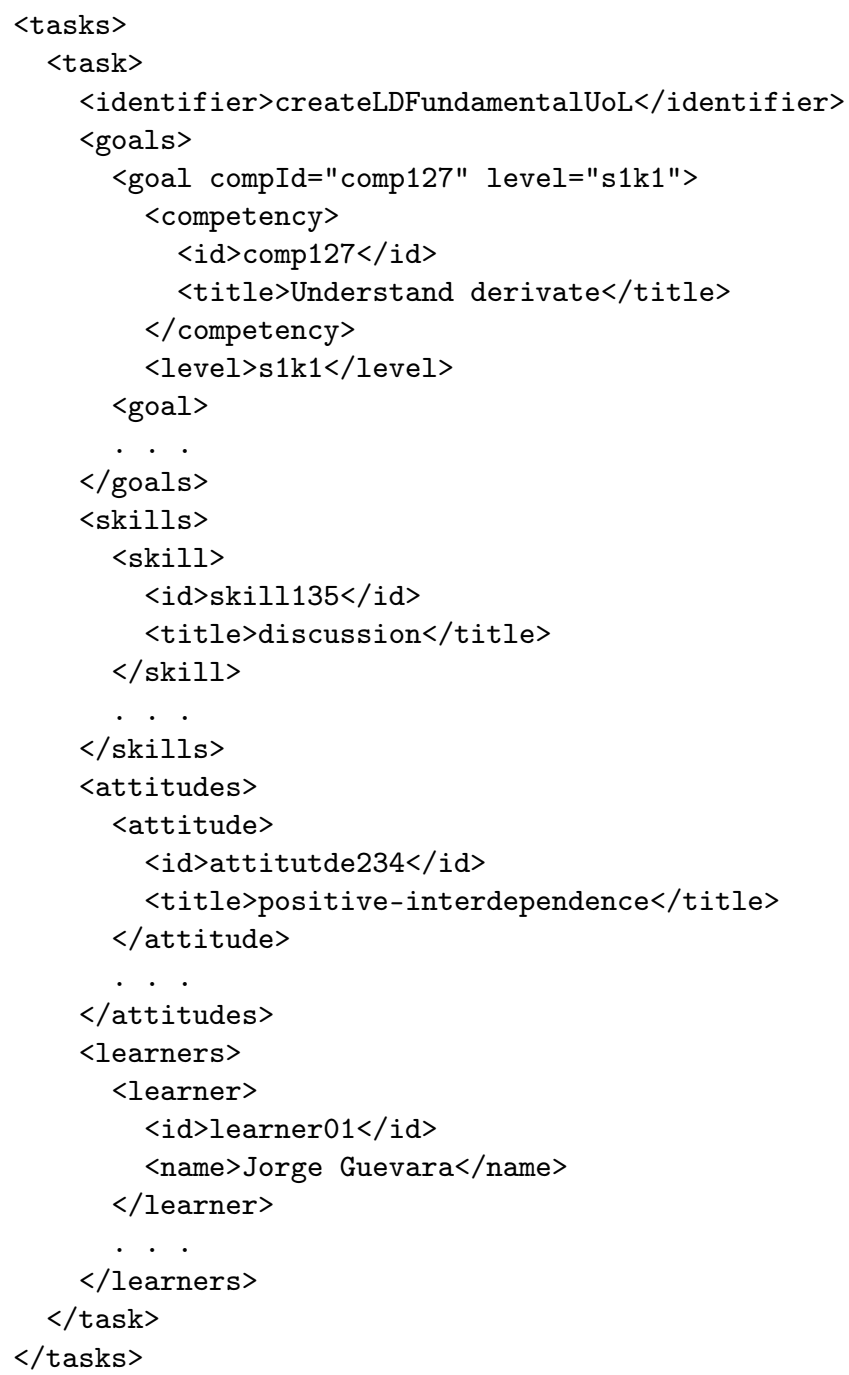

Figura 5.3: Exemplo de descrição do conjunto de tarefas públicas 
A lista de tarefas públicas <tasks $>$ é utilizada pelo projetista instrucional ou outra ferramenta para definir o estado inicial initState e a tarefa pública inicial initTask como a requisição:

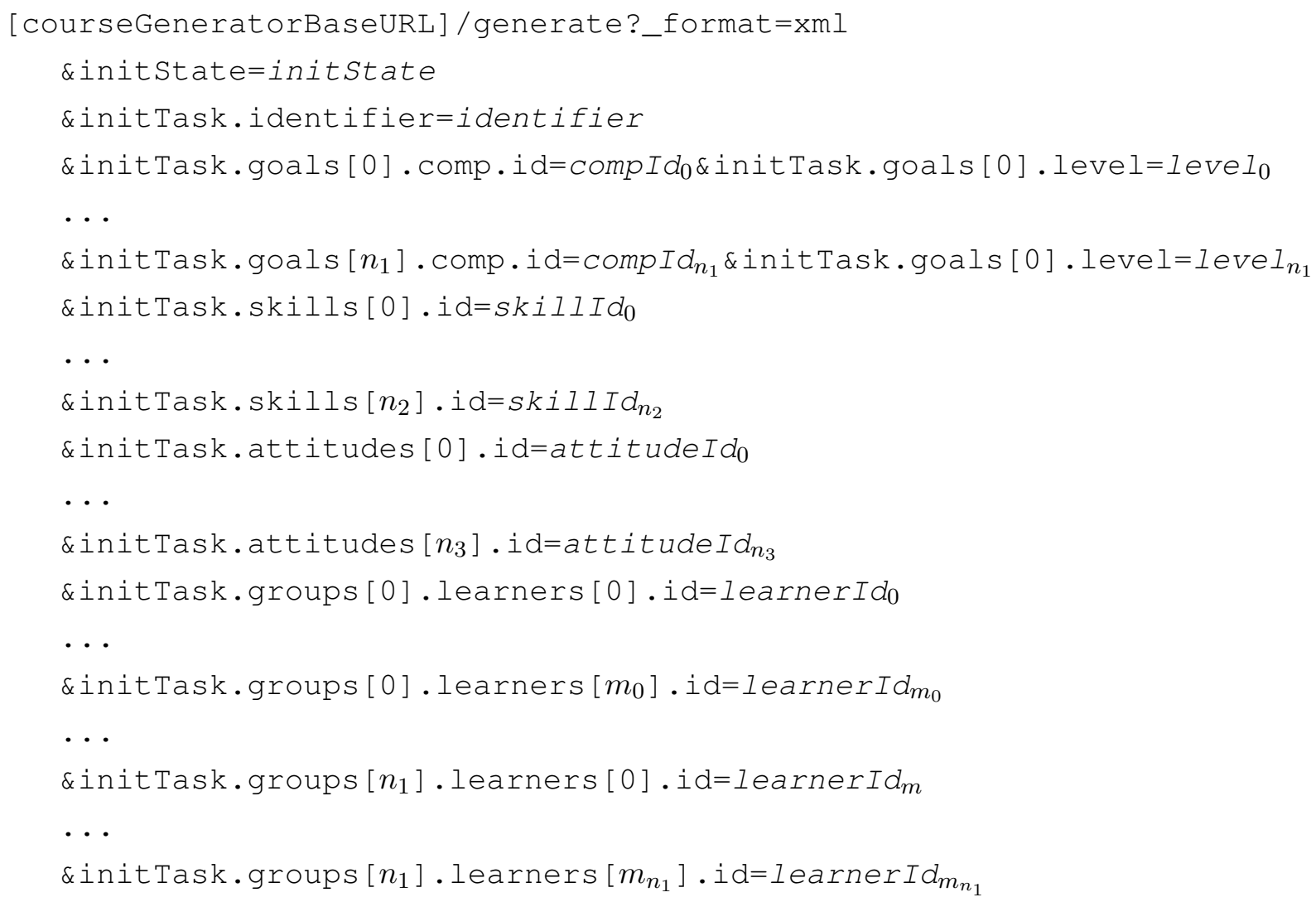

Onde:

- identifier é um identificador de tarefa de planejamento instrucional pública (detalhados na Subseção 3.2.2);

- compId ${ }_{0} \ldots$ compIdn $_{1}$ são identificadores de competência cognitiva e level $_{n_{1}} \ldots$ level $_{n_{1}}$ são níveis de competência que definem objetivos educacionais goal $l_{0} \ldots$ goal $_{n_{1}}$ (detalhados na Subseção 3.2.1);

- skillId $_{0} \ldots$ skillId $_{n_{2}}$ são identificadores de habilidades independentes;

- attitudeId $_{0} \ldots$ attitudeId $_{n_{3}}$ são identificadores de atitudes; e

- learnerId $d_{0} \ldots$ learnerId $d_{m_{0}}, \ldots$, learnerId $d_{m} \ldots$ learnerId $d_{m_{n_{1}}}$ são identificadores de estudantes que definem os grupos de participantes que irão atingir os objetivos goal $l_{0} \ldots$ goal $_{n_{1}}$.

Então, o processo de geração continua efetuando o método generate da classe CourseGenerator que efetua a criação da unidade de aprendizagem e (da classe LDElement) mediante o método solve. Logo, o método toUoL no objeto e da classe LDElement é empregado para obter uma lista de arquivos files das unidades da aprendizagem descritas na especificação IMS-LD usando o algoritmo de geração de roteiros colaborativos detalhado na Seção 3.4. 
Os métodos publishUoL e createRunForUoL são utilizados durante o processo de geração para publicar e criar ambientes de execução das unidades de aprendizagem usando a lista de arquivos files. Assim, o metadado course devolvido ao final do processo contém informações das URIs das unidades de aprendizagem e suas instancias de execução. A Figura 5.4 apresenta um exemplo do metadado course obtido usando o gerador de cursos colaborativos.

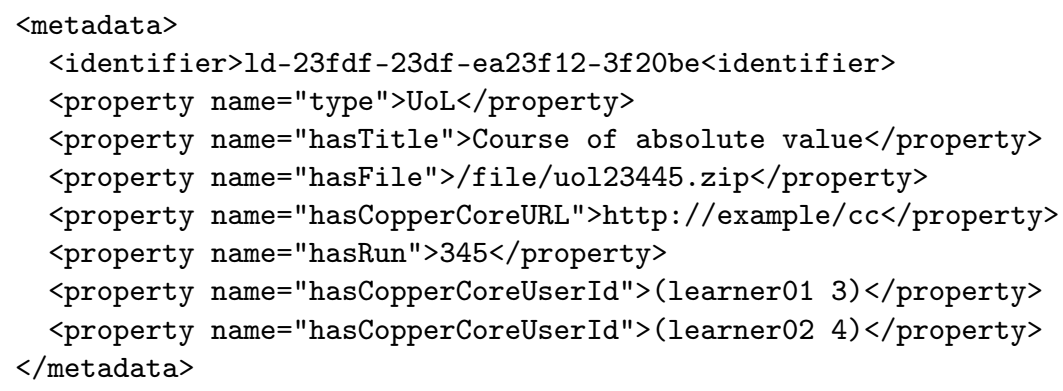

Figura 5.4: Exemplo do metadado de um curso

\subsubsection{Mediador de consultas}

O componente mediador mostrado na Figura 5.5 é utilizadas pelo domínio de planejamento no atributo domain da classe JShop2ipSolver para dar solução aos termos de chamada que efetuam consultas nos modelos de domínio a ser ensinado e de estudantes. Assim, o mediador implementa as interfaces BuildElements, GetElements, GetType, GetPropertyValue e GetRelated.

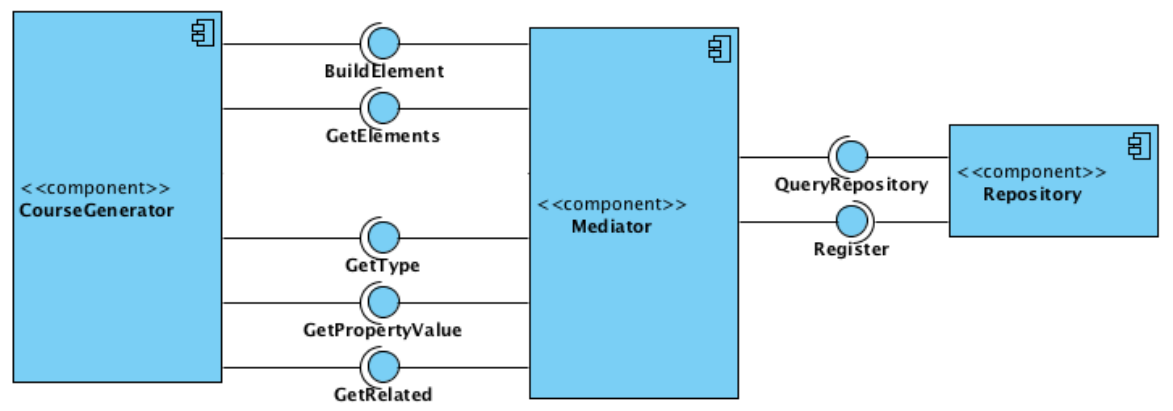

Figura 5.5: Visão geral do mediador dos modelos de dominio a ser ensinado e de estudante

As interfaces QueryRepository e Register no mediador são Serviços Web baseados em RESTful (Fielding , 2000) que efetuam consultas nos repositórios externos. Os repositórios são registrados mediante a interface Register, na qual são registrados o nome e a localização URL base do repositório. A interface QueryRepository possibilita ao mediador efetuar consultas nos repositórios mediante requisições de tipo GET ou POST na URL base do repositório definido como

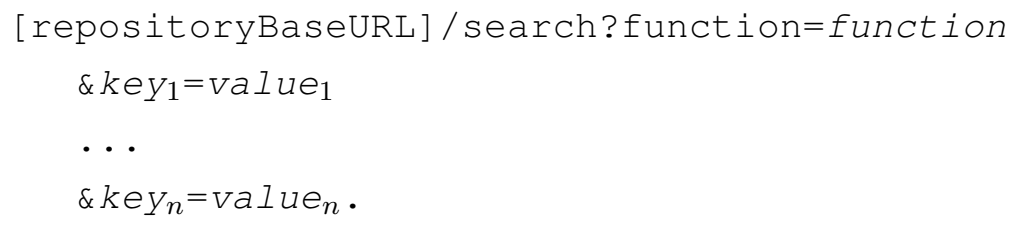


Se o termo da chamada é (call BuildElement ?query [?id [?n]]) ou (call GetElement ?query) então o valor de function é BuildElement ou GetElement; e os valores key $y_{i}=$ value $_{i}$ são:

- types $[\mathrm{i}]=t$ para cada termo (class $t$ ) da lista ?query;

- properties $[\mathrm{i}]$. name $=n$ e properties[i].value $=v$ para cada termo (property $n v$ ) da lista ?query;

- relations $[\mathrm{i}] \cdot$ name $=n$ e relations $[\mathrm{i}]$. value $=v$ para cada termo (relation $n v$ ) da lista ?query;

- id=id para o termo constante ?id; e

- $\mathrm{nro}=n$ para o termo constante ?n.

Exemplo 5.1. O termo de chamada

(assign ?result (call GetElements ((class Auxiliary)

(property hasLearningResourceType (exercise diagram))

(property hasLearningObjective (c1 s1k2))))

é representado no repositório com URL base http://repository.com mediante a requisição:

http://repository.com/search?function=GetElements

\&class [0] =Auxiliary

\&property [0] . name=has LearningResourceType

\&property [0] .value [0] = (exercise\%20diagram)

\&property [1] . name=has Learningobjective

\&property $[1] \cdot$ value $[0]=(\mathrm{c} 1 \% 20 \mathrm{~s} 1 \mathrm{k} 2)$

Se o termo da chamada é (call GetType ?element), (call GetPropertyValue ?element ?n [?dest]) ou (call GetRelated ?element ?n) então o valor de function é GetType, GetPropertyValue ou GetRelated; e os valores $k e y_{i}=$ value $_{i}$ são:

- element $[\mathrm{i}]=e$ para cada termo e da lista ?element;

- name $=n$ para o termo constante ?n; e

- dest $=d$ para cada termo d da lista ?dest.

Exemplo 5.2. A função (call GetPropertyValue aux1 hasLearningObjective comp1) é representado no repositório com URL base http://repository.com mediante a requisição:

http://repository.com/search?function=GetPropertyValue

\&elements $[0]=\operatorname{aux} 1$

\&name=hasLearningobjective\&dest $[0]=$ comp 1 


\subsubsection{Integração do gerador de cursos com CopperCore}

O Coppercore (Vogten et al., 2006) é uma aplicação de código aberto em Java desenvolvida pela Universidade Aberta da Holanda que possibilita executar unidades de aprendizagem descritas na especificação IMS-LD. Assim, CopperCore é nosso motor de execução dos roteiros colaborativos obtidos pelo gerador de curso.

A classe CCPublishHandler (Figura 5.1) implementa a classe IPublishHandler para definir a integração do gerador do curso com o sistema CopperCore. O método publishUoL nesta classe é encarregado de publicar e as unidades de aprendizagem obtidas pelo gerador de curso, unidades definidas como pacotes ZIPs (files) que contém arquivos de manifesto "imsmanifest.xml" e todos os recursos necessários.

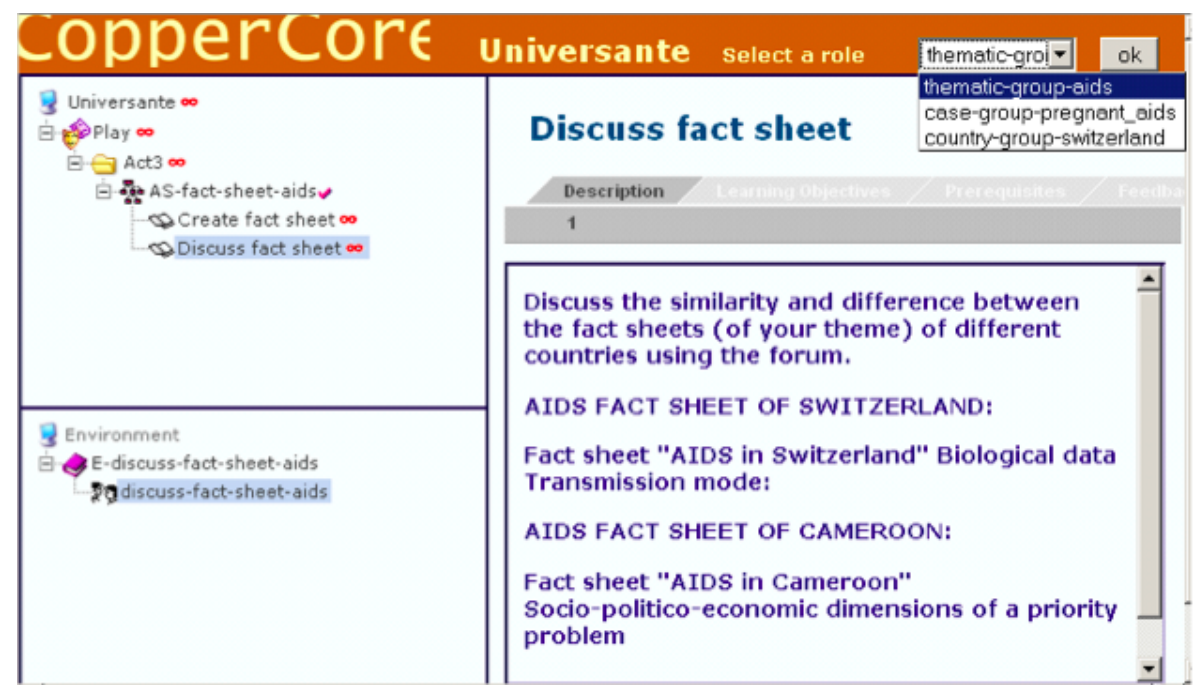

Figura 5.6: Ambiente de execução da unidade de aprendizagem de CopperCore

Finalmente, o método createRunForUoL é encarregado de criar ambientes de execução das unidades de aprendizagem usando a atribuição de papéis e grupos definidas na unidade de aprendizagem. A Figura 5.6 apresenta a interface de um ambiente de execução da unidade de aprendizagem no sistema CopperCore.

\subsection{Modelo conceitual da ferramenta de autoria}

Nesta seção, descrevemos as principais características e funções da ferramenta de autoria das unidades de aprendizagem denominada ALD (Automated Learning Design), ferramenta que emprega os Serviços Web baseados em RESTful fornecidos pelo gerador do cursos colaborativos (serviços detalhados na Seção 5.1). Além de possibilitar a autoria de unidades de aprendizagem, a ferramenta possibilita a edição dos modelos de estudante e de domínio a ser ensinado. 


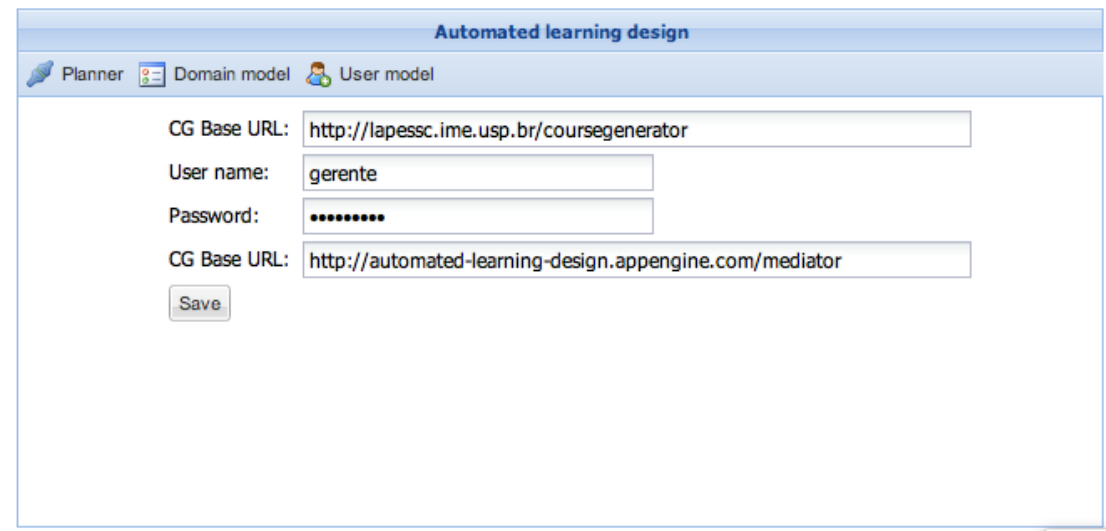

Figura 5.7: Tela inicial da ferramenta de autoria $A L D$

A Figura 5.7 mostra a tela inicial da ferramenta de autoria de roteiros. Na tela, o formulário permite ao projetista instrucional definir a URL base, usuário e senha do gerador de cursos colaborativos. A tela também apresenta um formulário que utiliza a interface Register do gerador de cursos colaborativos para registrar a URL base do repositório externo para ser usado no mediador de consultas apresentado na Subseção 5.1.2. A barra de menu superior na figura apresenta as opções de: edição do modelos de domínio a ser ensinado (Domain model), edição modelo de estudante (User model) e gerenciamento de cursos (Planner).

\subsubsection{Edição do modelo de estudante}

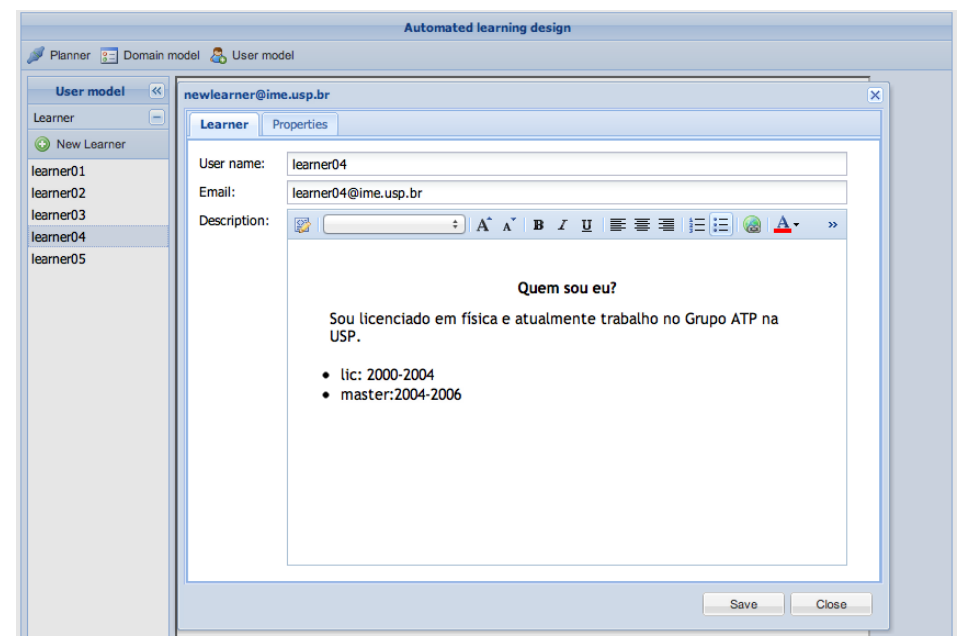

Figura 5.8: Tela de edição do modelo de estudante

A tela de edição do modelo de estudante mostrada na Figura 5.8 possibilita a edição das informações de cada um dos estudantes. A figura mostra o formulário de edição das informações do estudante como nome do usuário, e-mail e descrição.

A Figura 5.9 mostra o formulário de edição do modelo de estudante, as propriedades nível de competência (hasCompetencyLevel), histórico (hasAlreadySeen), personalidade (hasPersonality), experiência (hasCLExperience), etc. 


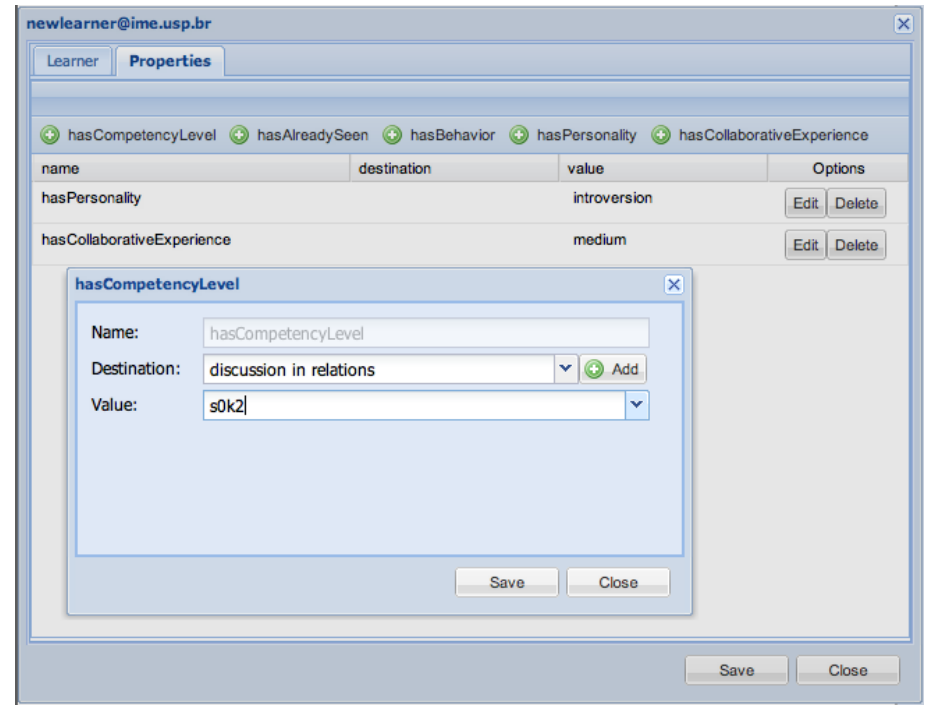

Figura 5.9: Tela de edição de propriedades do modelo de estudante

\subsubsection{Edição do modelo do domínio a ser ensinado}

A tela mostrada na Figura 5.10 consiste em um menu da esquerda divido em quatro blocos que possibilitam a edição dos elementos de conhecimento fundamental (Fundamental), elementos de conhecimento auxiliar (Auxiliary), habilidades (Skill) e atitudes (Attitudes).

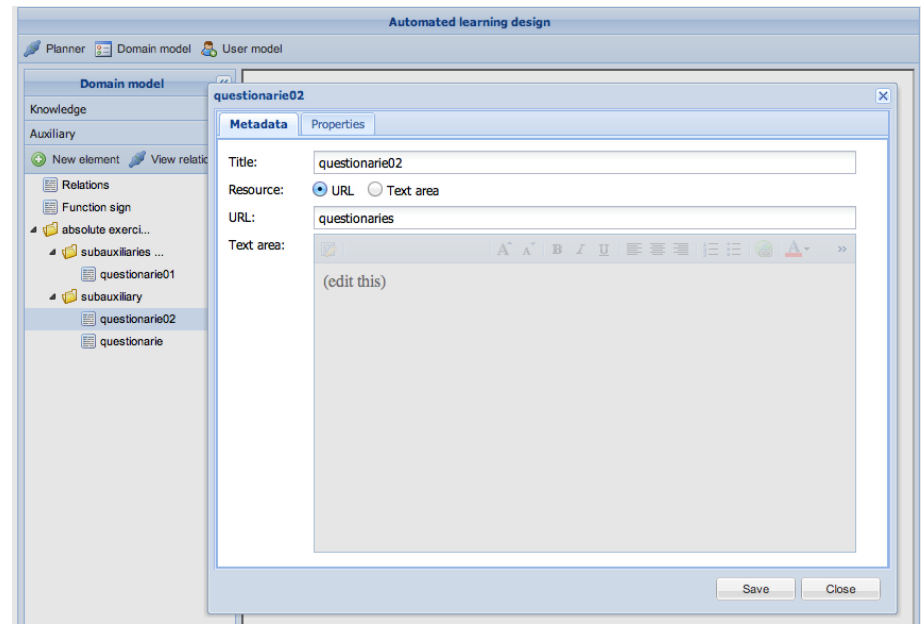

Figura 5.10: Tela de edição do modelo de domínio a ser ensinado

As relações entre os elementos do domínio a ser ensinado são definidas usando a tela mostrada na Figura 5.11. A tela é acessada usando o botão visualizar relações (View relations). 


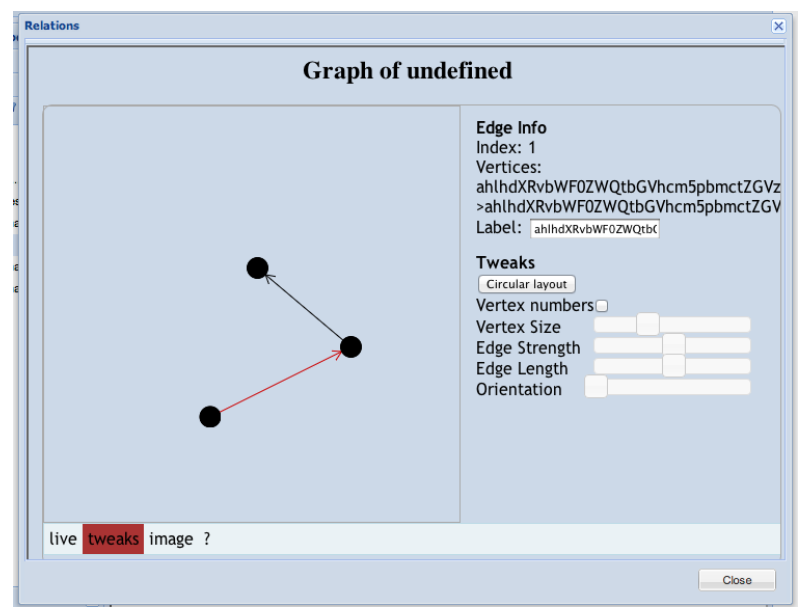

Figura 5.11: Tela de edição das relações do modelo de domínio a ser ensinado

\subsubsection{Gerenciamento de cursos}

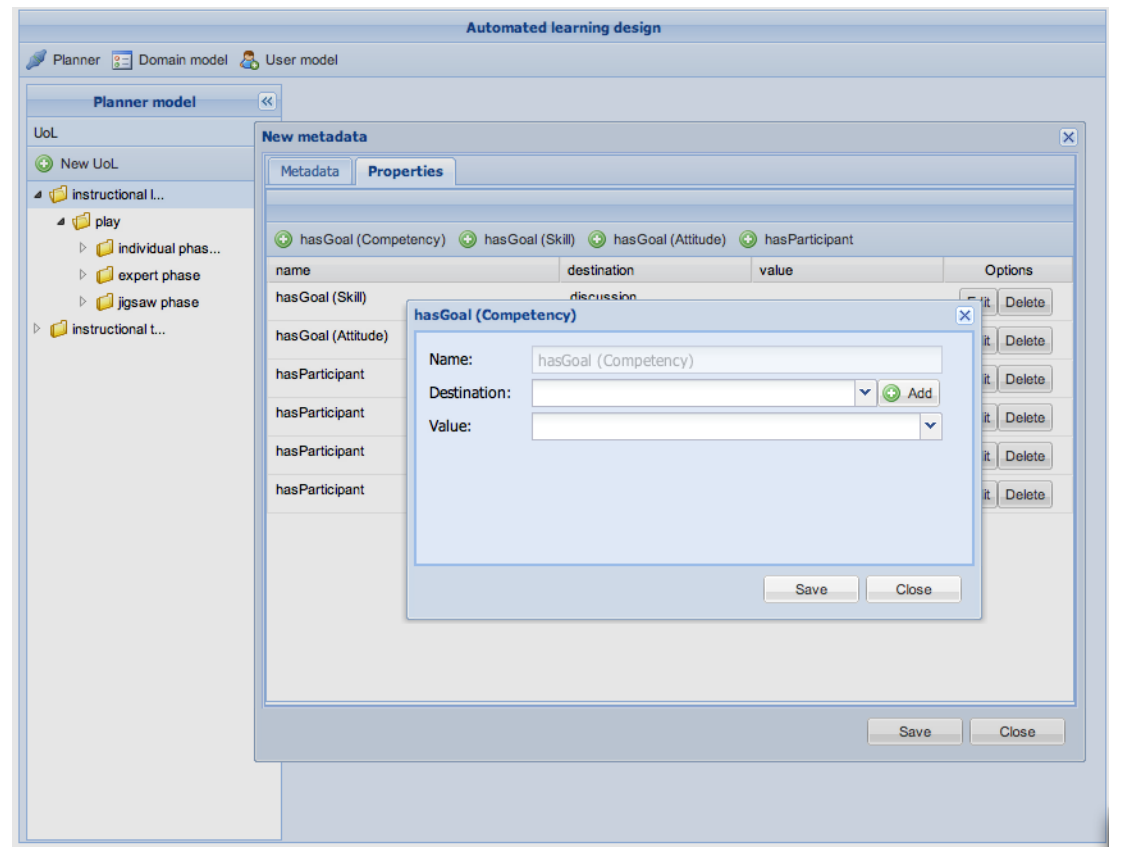

Figura 5.12: Tela inicial do gerenciamento de cursos

A tela de gerenciamento de cursos mostrada na Figura 5.12 apresenta a lista de unidades de aprendizagem obtidas pelo gerador no menu da esquerda. Uma unidade de aprendizagem é gerada usando o processo de geração apresentado na Subseção 5.1.1. A Figura 5.12 apresenta o formulário pelo qual são definidos o estado inicial e a tarefa inicial pública. 


\section{Capítulo 6}

\section{Avaliações}

Este capítulo descreve as avaliações efetuadas no protótipo de gerador de cursos colaborativos. Na Seção 6.1 é apresentada a avaliação de desempenho efetuada sob o gerador de cursos colaborativos. Para uma avaliação da modelagem proposta na Seção 6.2 apresentamo exemplos da modelagem de estrategias de planejamento instrucional. Finalmente, na Seção 6.3 apresentamos a avaliação da saída do planejador no modelo proposto.

\subsection{Avaliação de desempenho}

Se o gerador de cursos colaborativos deve ser utilizado em situações de aprendizagem real, o processo de planejamento instrucional automatizado deve ser efetuado em tempo hábil. Nesta seção descrevemos os resultados dos testes efetuados que avaliam o desempenho do planejador sob diferentes condições.

Para minimizar a influência da latência causada pela rede em aplicações Web, os repositórios com informações dos modelos de domínio a ser ensinado e de estudante, os componentes do gerador de curso e os testes são executados no mesmo computador, um computador PC padrão com processador Intel de $2.4 \mathrm{GHz}$ com $4 \mathrm{~GB}$ de memória RAM.

Como os testes são desenvolvidos para medir o desempenho do planejador, as influências de outros componentes como o mediador e o componente de conversão são minimizadas. Os modelos de estudante e de domínio a ser ensinado são substituídos por um modelo que retorna valores aleatórios para cada consulta.

Os testes foram efetuados empregando a tarefa pública createLDFundamentaUoL, tarefa de maior nível de abstração que envolve outras tarefas públicas como subtarefas de menor nível. Os testes da tarefa pública foram executados empregando 2, 4, 8, 16 e 32 objetivos educacionais com 32, 64, 128 e 256 estudantes. Cada tarefa de geração foi repetida 10 vezes sendo calculada a média do tempo.

\begin{tabular}{|c|r|r|r|r|r|}
\hline Estudantes/objetivos & $\mathbf{2}$ & $\mathbf{4}$ & $\mathbf{8}$ & $\mathbf{1 6}$ & $\mathbf{3 2}$ \\
\hline \hline 32 & 12,17 & 12,25 & 14,46 & 15,13 & 16,79 \\
\hline 64 & 17,23 & 27,23 & 35,37 & 37,23 & 47,98 \\
\hline 128 & 81,51 & 94,85 & 108,81 & 135,36 & 139,21 \\
\hline 256 & 154,83 & 297,45 & 328,31 & 371,20 & 417,60 \\
\hline
\end{tabular}

Tabela 6.1: Tempo em segundos empregado na geração da tarefa createLDFundamentaUoL 


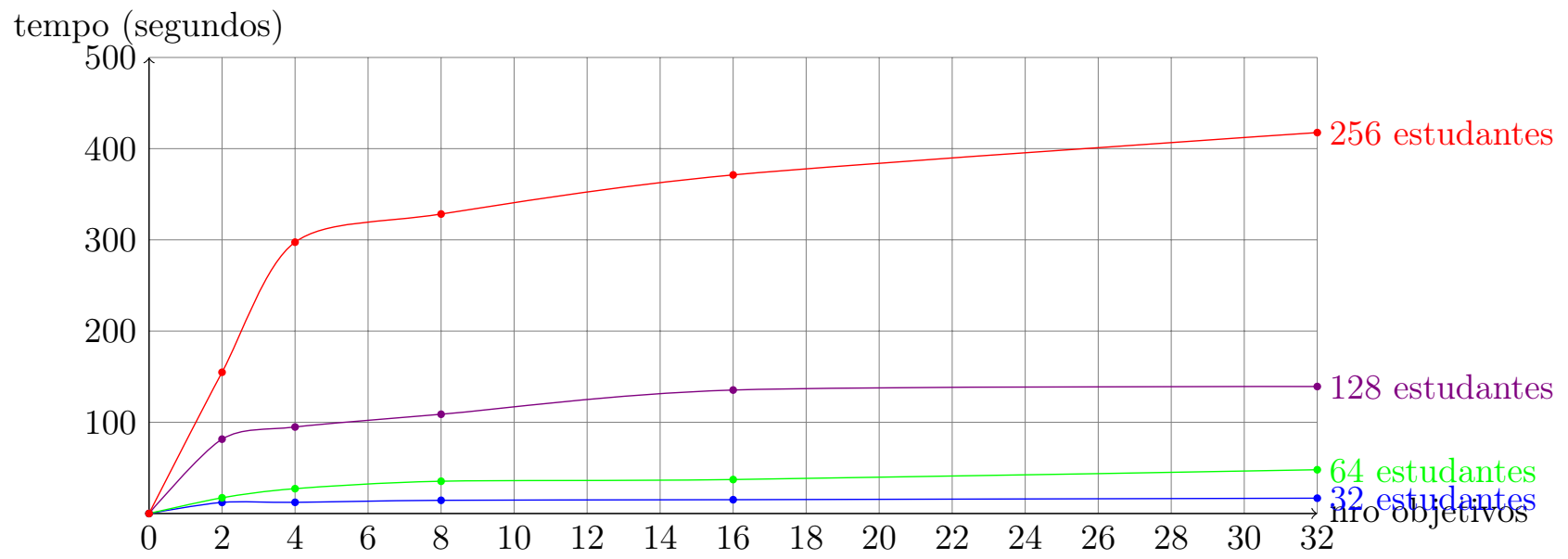

Figura 6.1: Gráfico do número de objetivos e tempo necessário para a geração de cursos

A Tabela 6.1 e a Figura 6.1 fornece detalhes do tempo (em segundo) de geração dos cursos usando a tarefa createLDFundamentaUoL. Na tabela, o tempo necessário para gerar um curso com 32 estudantes e 2 objetivos educacionais é de 12,17 segundos, enquanto o tempo necessário para gerar um curso com 32 objetivos educacionais e 256 estudantes é de 10,12.

\begin{tabular}{|c|r|r|r|r|r|}
\hline Estudantes/objetivos & $\mathbf{2}$ & $\mathbf{4}$ & $\mathbf{8}$ & $\mathbf{1 6}$ & $\mathbf{3 2}$ \\
\hline \hline 32 & 3.528 & 7.240 & 14.654 & 28.486 & 56.234 \\
\hline 64 & 4.237 & 8.756 & 16.458 & 33.126 & 67.128 \\
\hline 128 & 5.348 & 10.248 & 20.456 & 41.245 & 80.436 \\
\hline 256 & 7.796 & 14.567 & 29.678 & 61.234 & 131.146 \\
\hline
\end{tabular}

Tabela 6.2: Tamanho do plano gerado pela tarefa createLDFundamentaUoL

A Tabela 6.2 e a Figura 6.2 mostra as médias no tamanho do plano de solução obtido pelo gerador. Na tabela, um curso gerado para 2 objetivos educacionais e 32 é em média de 3528 operadores que representam 352 elementos <learning-activity $>$ e 650 recursos instrucionais. Se cada elemento <learning-activity > tem uma média de tempo de aprendizagem de dois minutos, a conclusão deste curso levaria entre 11 e 12 horas.

Os resultados mostrados nos testes demostram que o processo de planejamento instrucional automatizado no gerador de cursos colaborativos é rápido minimizando os fatores externos. $\mathrm{O}$ desempenho em casos de uso real depende do componente mediador (tempo de resposta dos repositórios externos) e a latência da rede, como consequência, o tempo meio para gerar um curso com 02 objetivos e 32 estudantes requere 4:30 minutos ao invés de 10.324 segundos.

Para sistemas Web, as experiências conduzidas por Bhatti et al. (2000) mostram que a taxa de espera de mais de 11 segundos é inaceitável. No entanto, o tamanho do plano solução e a quantidade de elementos de roteiros obtidos justifica a espera devido a que em média são gerados mais de 150 elementos em menos de um segundo. 
tamanho (nro ações)

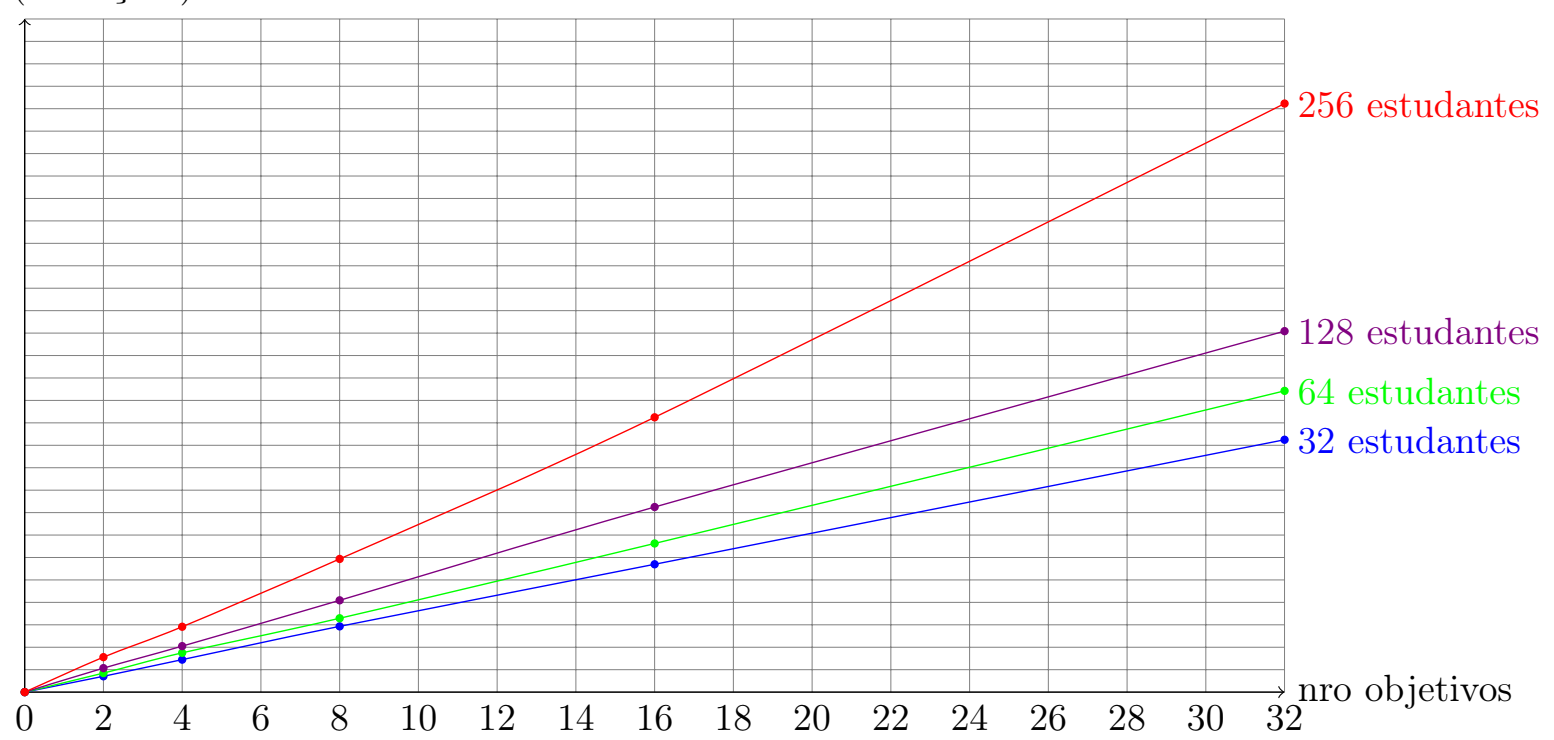

Figura 6.2: Gráfico do número de objetivos e tamanho do plano para a geração de cursos

\subsection{Avaliação da modelagem de estratégias}

Nesta seção, a avaliação da modelagem de estratégias de planejamento instrucional proposta nesta dissertação é efetuada utilizando os esquemas de roteiros apresentados no Capítulo 4. A validação da modelagem é efetuada mediante a modelagem de estratégias extraídas dos padrões de roteiros "peer tutoring" e "jigsaw".

\subsubsection{Exemplo de microrroteiro: Peer tutoring}

O padrão de roteiro Peer tutoring é definido como o fluxo de eventos IL mostrado na Figura 6.3, no qual estudantes com papel tutor e estudantes com papel aprendiz obtêm benefícios a partir de suas interações. Nos eventos IL, os tutores terão de obter mais conhecimento, a fim de ensinar e organizar seus conhecimentos de forma compreensível. Enquanto, os aprendizes irão adquirir seu conhecimento do ensino dos tutores.

A seguir apresentamos a modelagem de algumas estratégias de planejamento instrucional extraídas do padrão Peer tutoring. Neste trabalho usando 6 padrões de microrroteiros também foram modeladas: 12 estratégias de eventos IL, 16 estratégias de interações cíclicas e direcionadas, 6 estratégias de padrões de interação de microrroteiros, 6 estratégias de fases dos cenários colaborativos, 9 estratégias de definição de estratégias de aprendizagem, 10 estratégias de papéis colaborativos e 6 estratégias de cenários colaborativos detalhadas no website

$$
\text { http://www.ime.usp.br/ geiser/dissertacao/microrroteiros/ }
$$

\section{Cenário colaborativo: Peer tutoring}

Utilizando o esquema da Figura 4.14, a Figura 6.4 mostra a estratégia de criação do cenário colaborativo Peer tutoring no que o método fall-back (linha 16-41) apresenta a restrição de níveis de competência (any tuning) para o nível ?ol (linha 18) e restrição (any accretion) para 


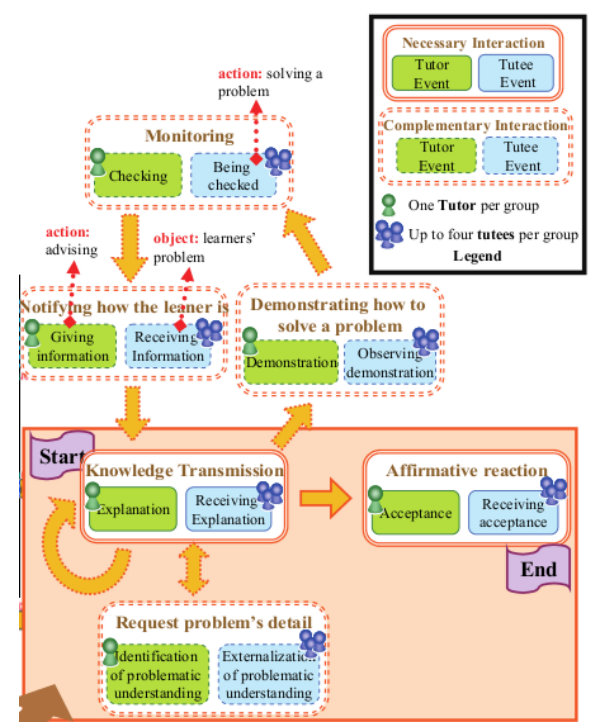

Figura 6.3: Representação gráfica do microrroteiro Peer-Tutoring (Isotani, 2009)

o nível ?el (linha 19). Logo, os elementos de conhecimento de tipo auxiliar ?oaux e ?eaux são obtidos empregando o axiomas getOrBuildReadyAux (linhas 26, 32). Finalmente, os objetivos educacionais ?ogoal e ?egoal são obtidos usando o axioma getGoalFromAuxiliary (linha 27, 33).

Utilizando o esquema da Figura 4.15, os métodos associados à tarefa createPeerTutoringCLScenario são mostrados na Figura 6.5. O método apresentado na figura não efetua a busca de elemento de conhecimento auxiliar nem objetivos educacionais relativos aos elementos, devido a que todos os elementos auxiliares necessários foram definidos nas competências ?oc e ?ec.

\section{Fase no cenário colaborativo: Peer tutoring}

Utilizando o esquema de representação mostrado na Figura 4.13, a Figura 6.6 apresenta a representação da estratégia de criação de fases para o cenário colaborativo Peer tutoring, na que são definidas as estratégias de aprendizagem por ensino (LearningByTeaching) (linha 14) e de sendo ensinado (LearningByBeingTaught) (linha 15).

\section{Estratégia de aprendizagem: Aprendizagem por ensino}

Utilizando o esquema de representação da Figura 4.12, a Figura 6.7 mostra a representação das tarefas e métodos empregados para representar a criação da estratégia de aprendizagem por ensino (LearningByTeaching). A estratégia de aprendizagem é definida como a construção de um papel de estudante PeerTutor mediante a tarefa createLDPeerTutorRole (linha 11) e de um padrão de interação mediante a tarefa createLDPeerTutorInteractions (linha 12).

\section{Papel dos estudantes: Peer tutor}

Utilizando o esquema de representação da Figura 4.11, a Figura 6.8 mostra a representação da estratégia de criação do papel Peer-tutor, papel de tipo instrucional Instructional (linha 26) definido no método fall-back (linhas 21-30). 


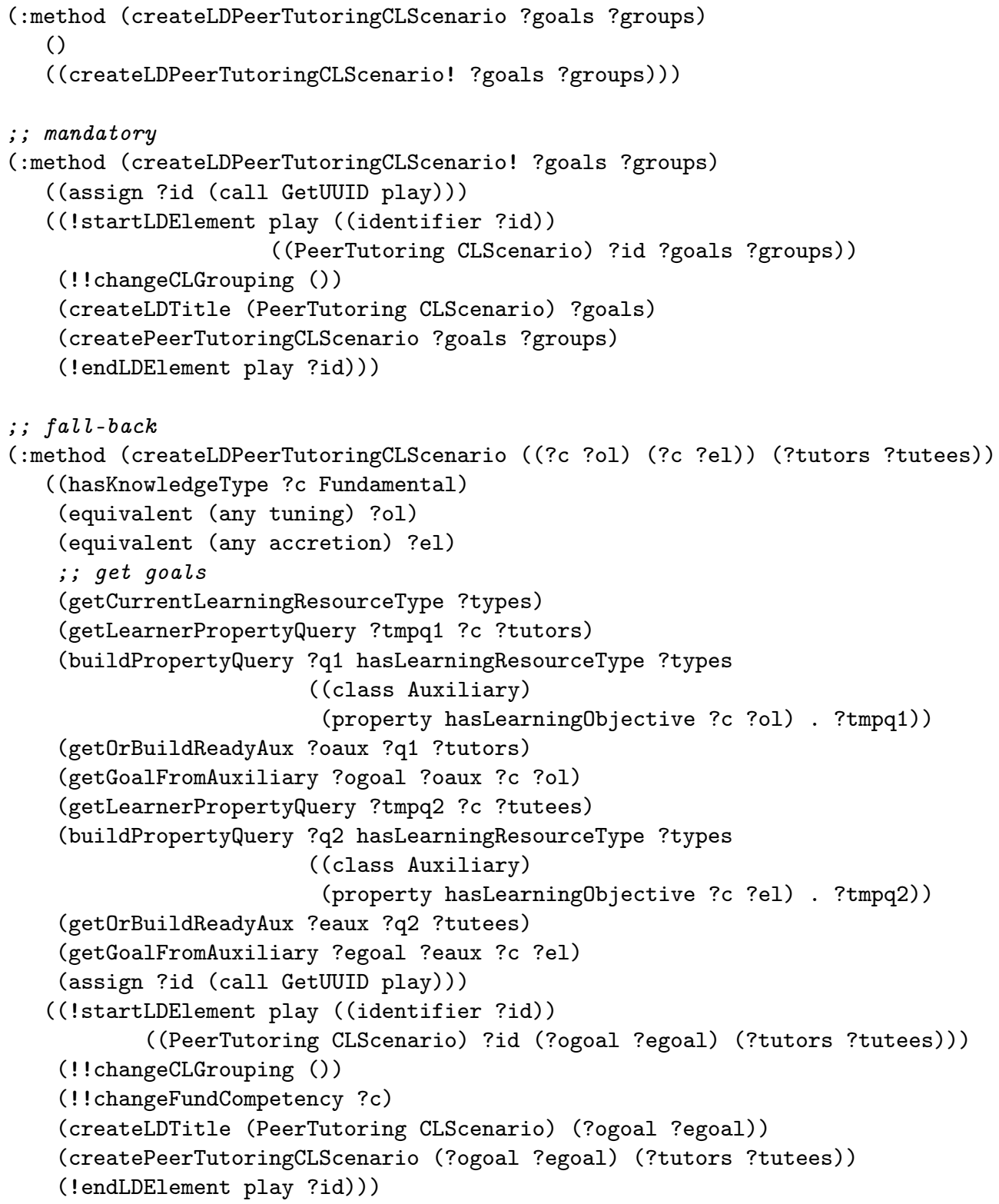

Figura 6.4: Representação da estratégia de criação do cenário colaborativo Peer Tutoring

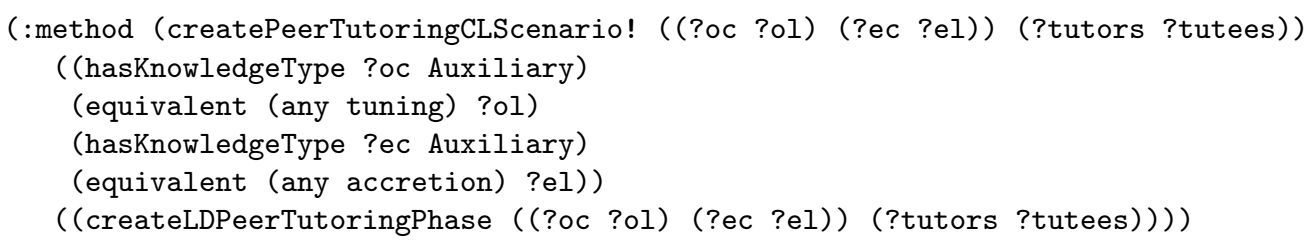

Figura 6.5: Representação dos métodos associados à tarefa createPeerTutoringCLScenario 


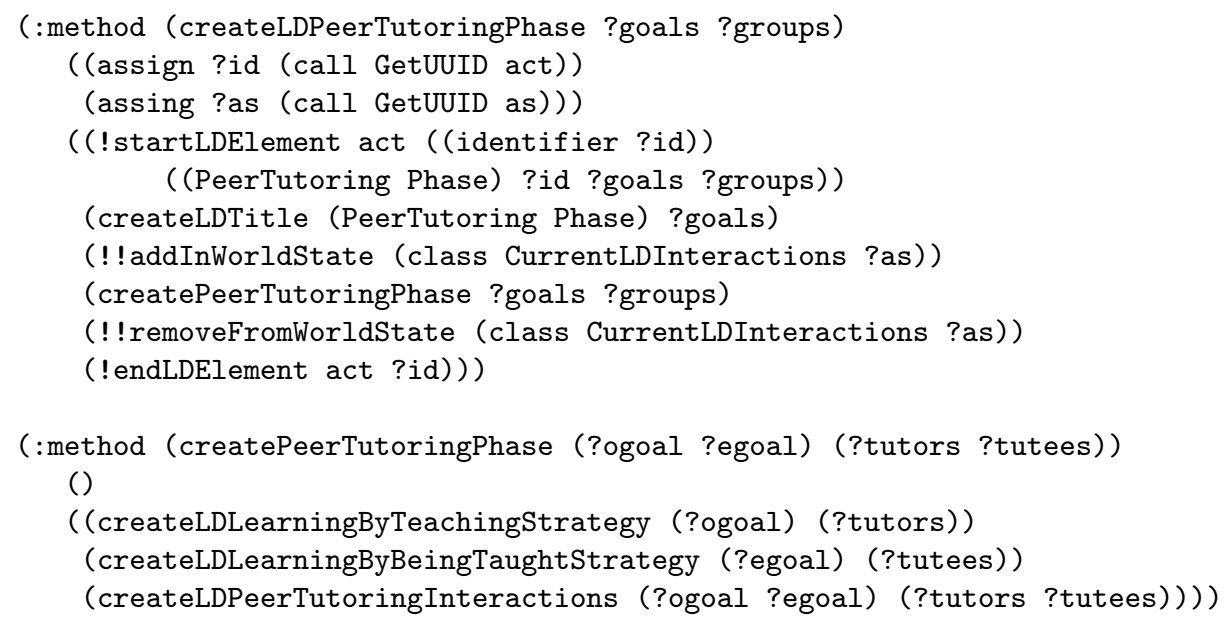

Figura 6.6: Esquema de representação da estratégia de criação da fase Peer tutoring

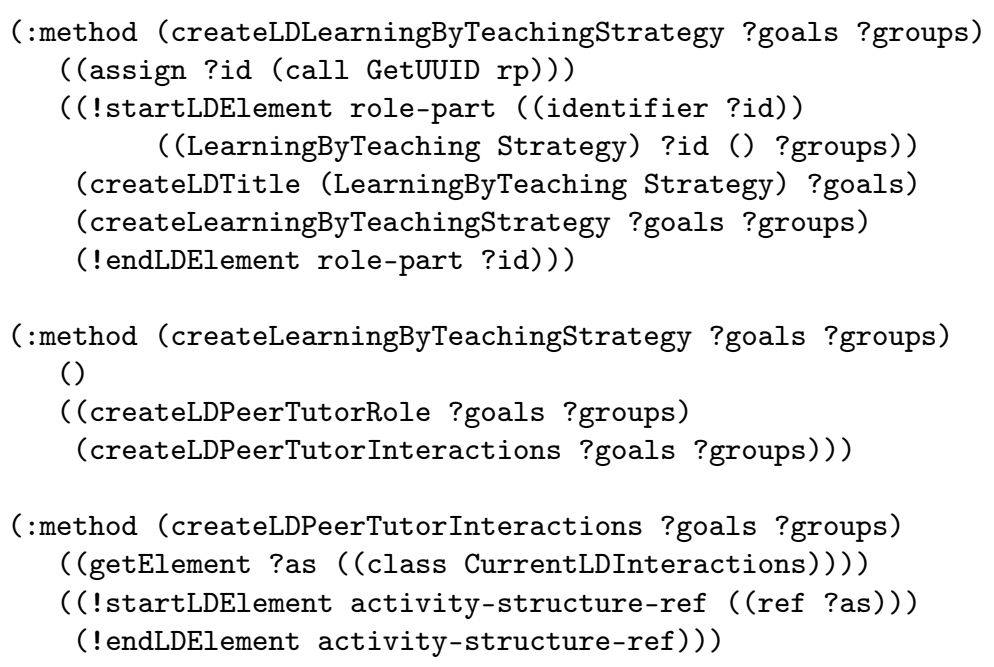

Figura 6.7: Representação da estratégia de criação da estratégia aprendizagem por ensino 


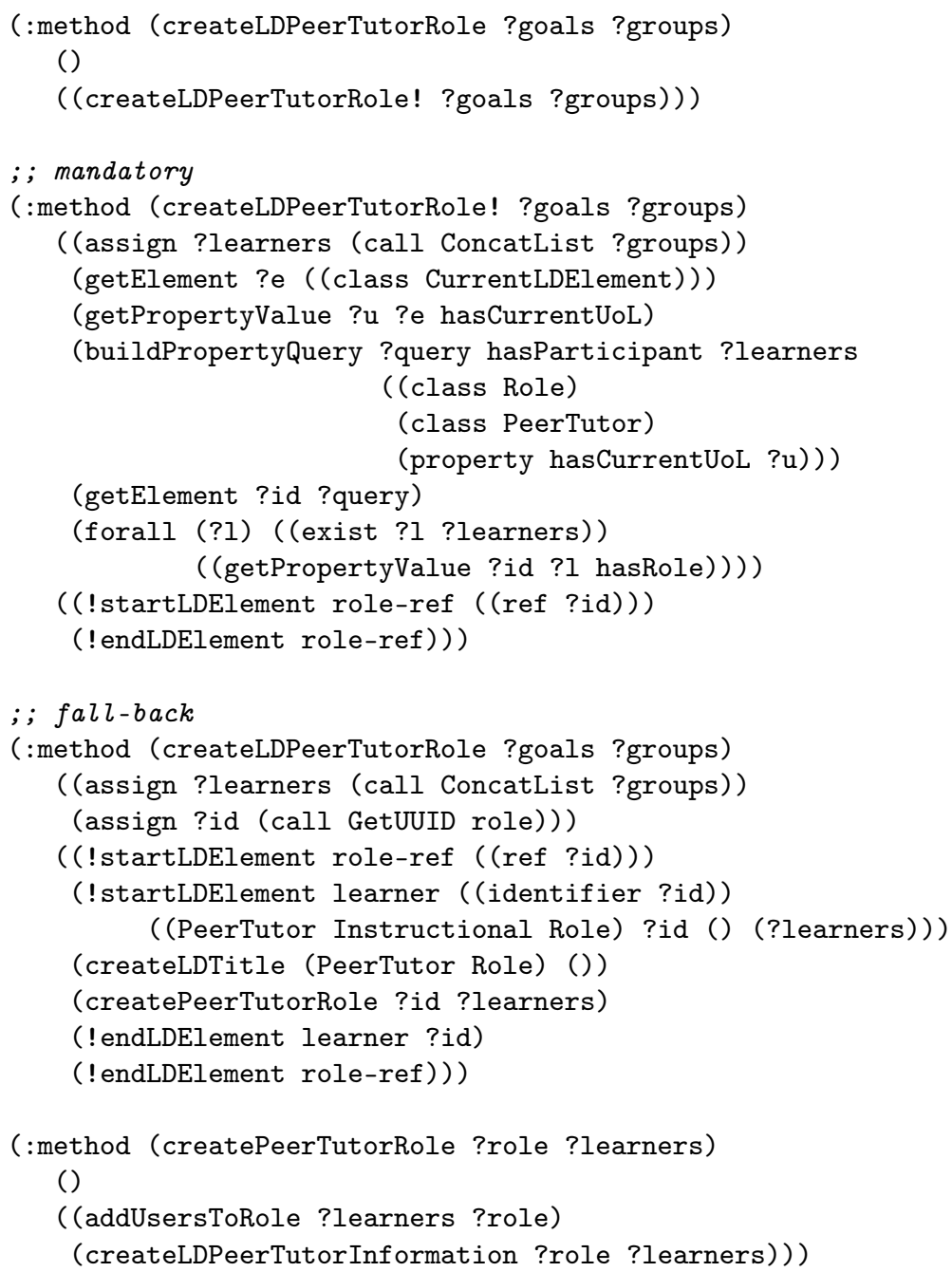

Figura 6.8: Representação da estratégia de criação do papel Peer tutor 


\section{Padrão de interação: Peer tutoring}

Utilizando o esquema de representação da Figura 4.10, a Figura 6.9 mostra a representação da estratégia de criação do padrão de interação Peer tutoring. A tarefa é definida como fluxos de interações direcionadas e cíclicas: transmissão de conhecimento e requisitar detalhes sobre o problema, KnowlTransmissionReqProblemDetail (linha 20); e meta-reconhecimento do progresso de aprendizagem, MetarecognizeProgress (linha 21).

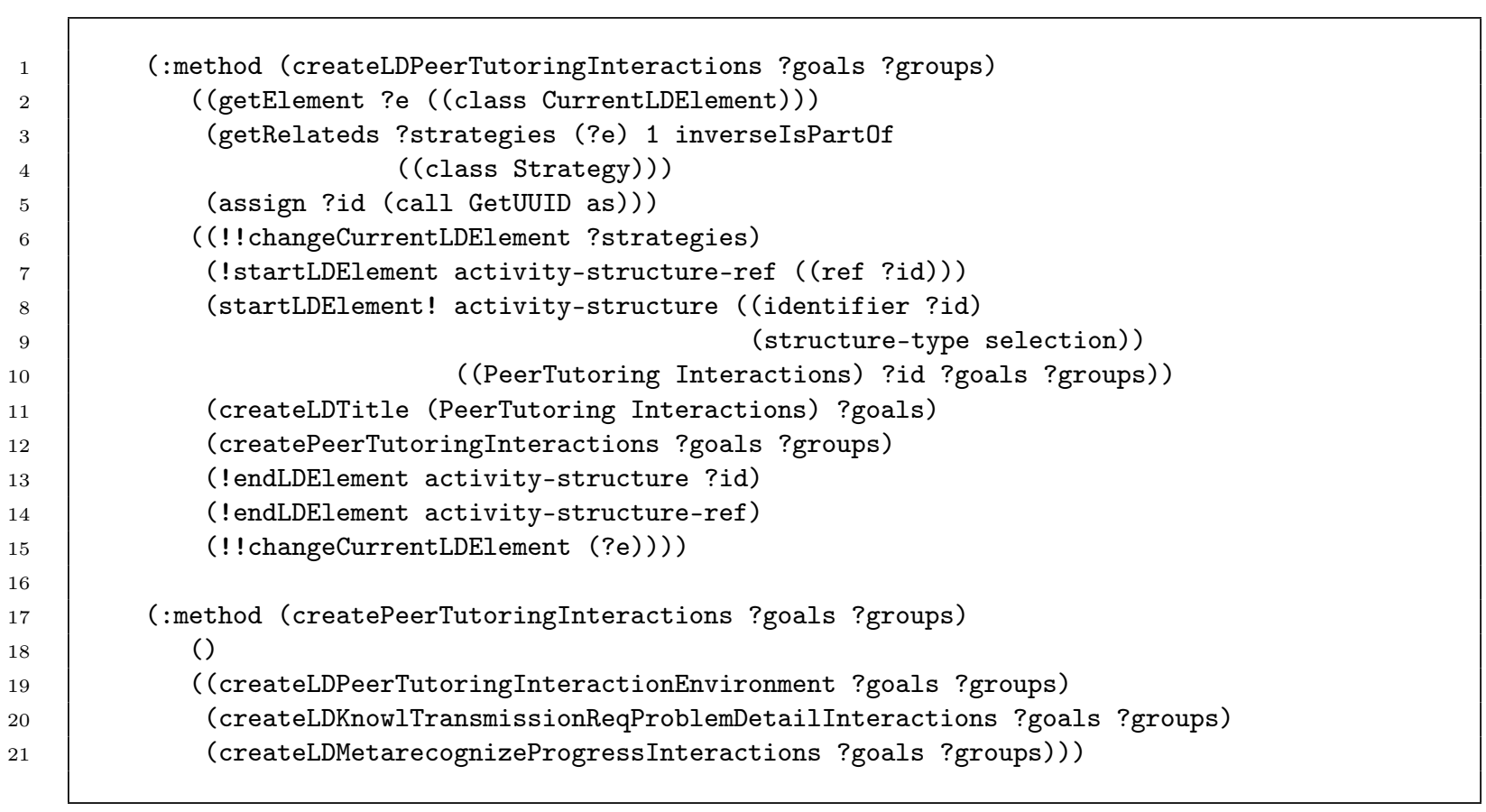

Figura 6.9: Representação da estratégia de criação do padrão de interação Peer tutoring

\section{Fluxo de interações direcionadas: meta-reconhecimento do progresso}

Utilizando o esquema de representação da Figura 4.9, a estratégia de criação de um fluxo de interação de meta-reconhecimento do progresso de aprendizagem (MetarecognizeProgress) é mostrada na Figura 6.10. A tarefa de criação do fluxo de interações direcionadas e cíclicas do meta-reconhecimento é conformado pelos eventos IL: demostrar como resolver um problema, DemonHowSolveProblem (linhas 30, 37); monitorar, Monitoring (linhas 31, 39); e notificar estado corrente de estudante, NotifyHowLearnerls (linhas 32, 40). 
(:method (createLDMetarecognizeProgressInteractions ?goals ?groups)

((assign ?id (call GetUUID as)))

((!startLDElement activity-structure-ref ((ref ?id)))

(startLDElement! activity-structure ((identifier ?id)

(structure-type sequence))

((MetarecognizeProgress Interactions) ?id ?goals ?groups))

(createLDTitle (MetarecognizeProgress Interactions) ?goals)

(createMetarecognizeProgressInteractions ?goals ?groups)

(!endLDElement activity-structure ?id)

(!endLDElement activity-structure-ref)))

(:method (createMetarecognizeProgressInteractions ?goals ?groups)

()

((createMetarecognizeProgressInteractions! ?goals ?groups)))

; ; mandatory

(:method (createMetarecognizeProgressInteractions! ?goals ?groups)

((assign ?learners (call ConcatList ?groups))

(getElement ?e ((class CurrentLDElement)))

(getPropertyValue ?u ?e hasCurrentUoL)

(getRelateds ?interactions (?e) -1 isPart0f

( (class Interactions)

(property hasCurrentUoL ?u)))

(buildPropertyQuery ?tmpQuery hasGoal ?goals

((class InteractionEnvironment)

(property hasCurrentUoL ?u)))

(buildPropertyQuery ?query hasParticipant ?learners ?tmpQuery)

(getRelateds ?environments ?interactions 1 inverseIsPartOf ?query)

(different ?environments ()) )

((createLDDemonHowSolveProblemILEvent ?goals ?groups)

(createLDMonitoringILEvent ?goals ?groups)

(createLDNotifyHowLearnerIsILEvent ?goals ?groups)))

; ; fall-back

(:method (createMetarecognizeProgressInteractions ?goals ?groups)

()

((createLDMetarecognizeProgressInteractionEnvironment ?goals ?groups)

(createLDDemonHowSolveProblemILEvent ?goals ?groups)

(createLDMonitoringILEvent ?goals ?groups)

(createLDNotifyHowLearnerIsILEvent ?goals ?groups)))

Figura 6.10: Representação da estratégia de criação do fluxo de interações meta-reconhecimento 


\section{Evento IL: Monitorar}

Utilizando os esquemas de representação das Figuras 4.6, 4.7 e 4.8; a estratégia de criação do evento IL Monitoring é definida mediante as tarefa e métodos hierárquicos mostrados nas Figuras $6.11,6.12$ e 6.13 .

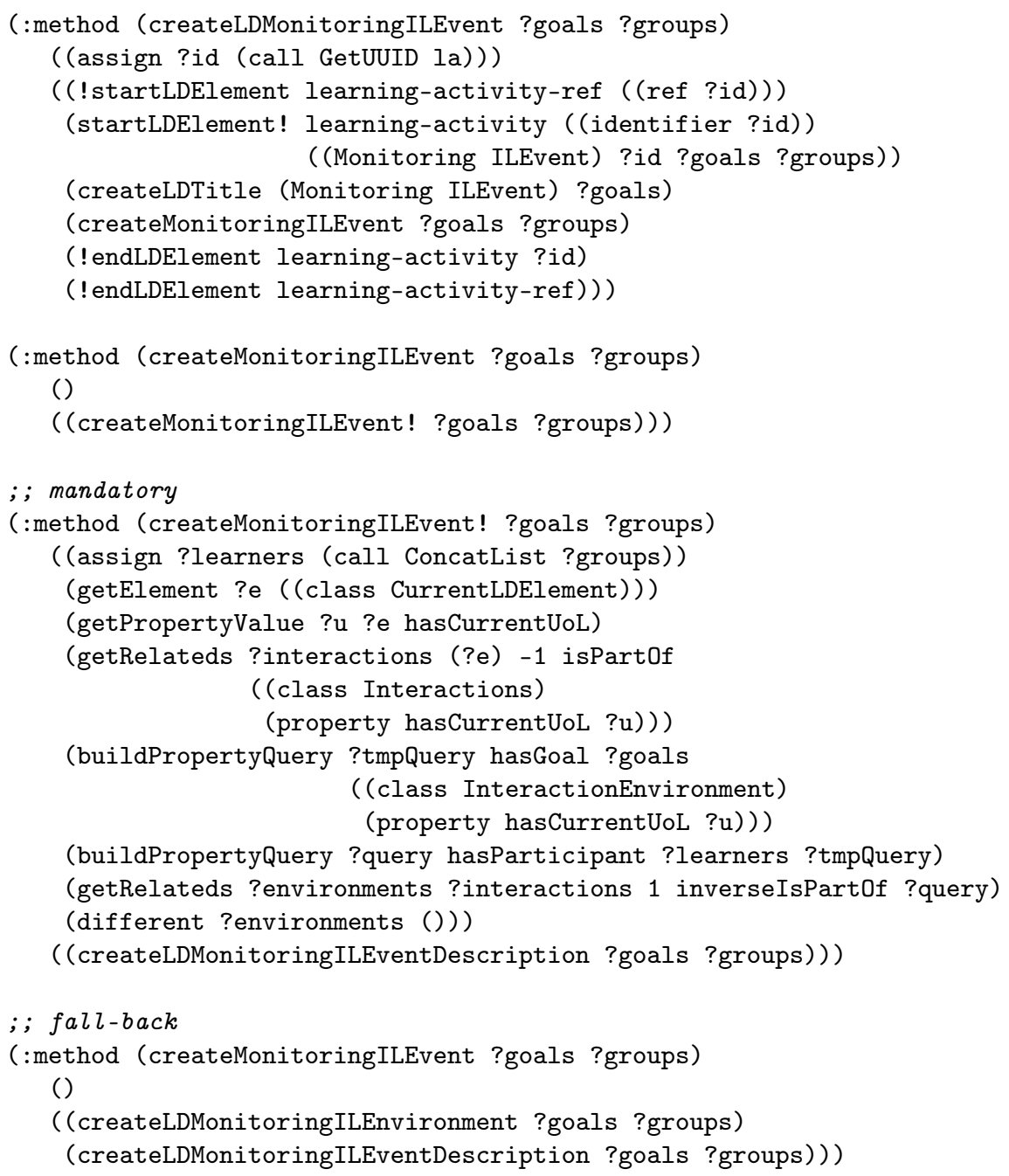

Figura 6.11: Representação da estratégia de criação do evento IL Monitorar (Monitoring)

A Figura 6.12 mostra a representação da estratégia de criação de ações associadas ao evento IL Monitorar (Monitoring), no qual: as ações associadas aos eventos instrucional e de aprendizagem são a verificação (Checking) e sendo objeto de verificação (BeingChecked). Enquanto, a Figura 6.13 mostra a representação da estratégia de criação do ambiente de apoio à aprendizagem associado ao evento IL Monitorar (Monitoring). 


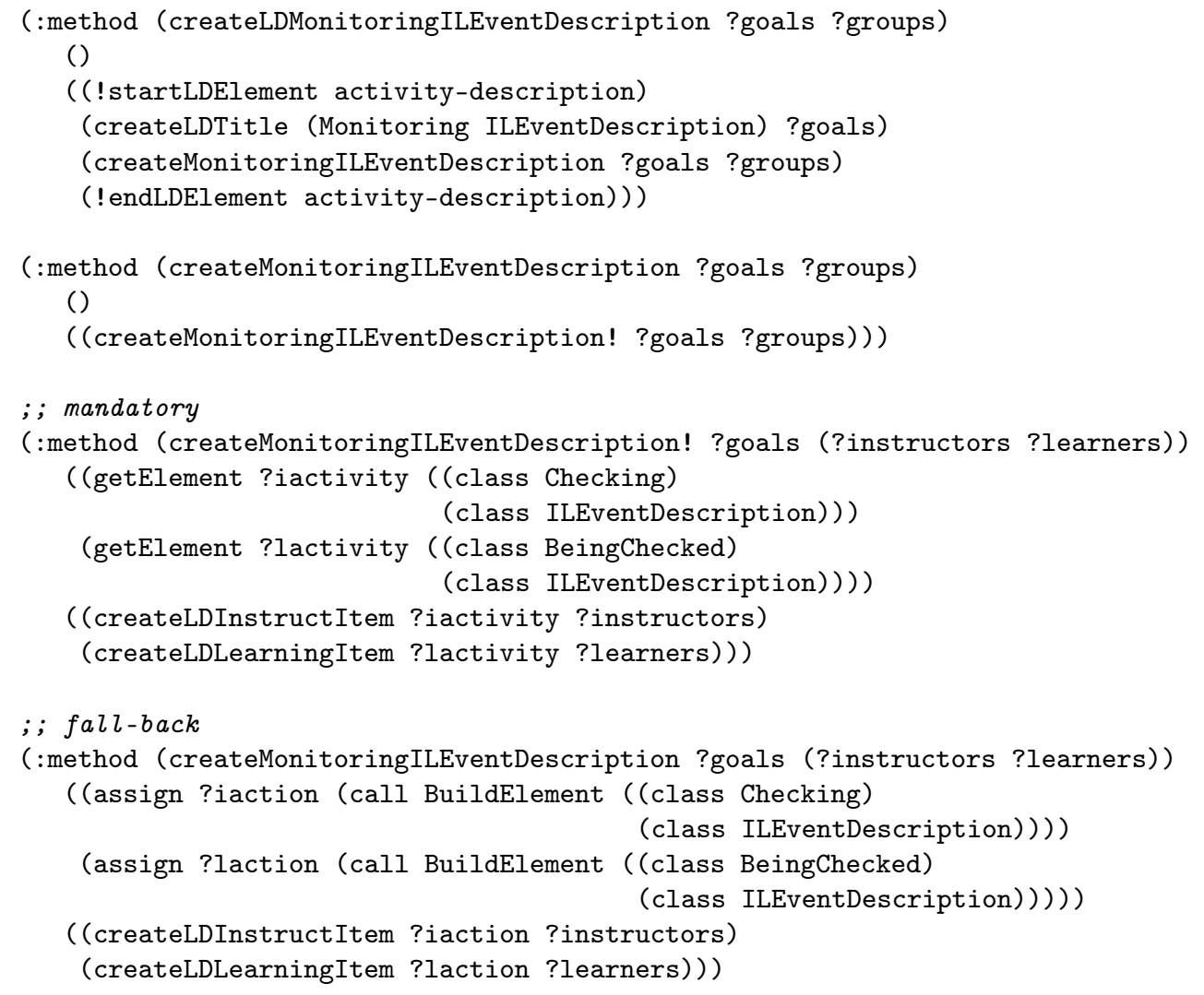

Figura 6.12: Representação da estratégia de criação de ações associadas ao evento IL Monitorar

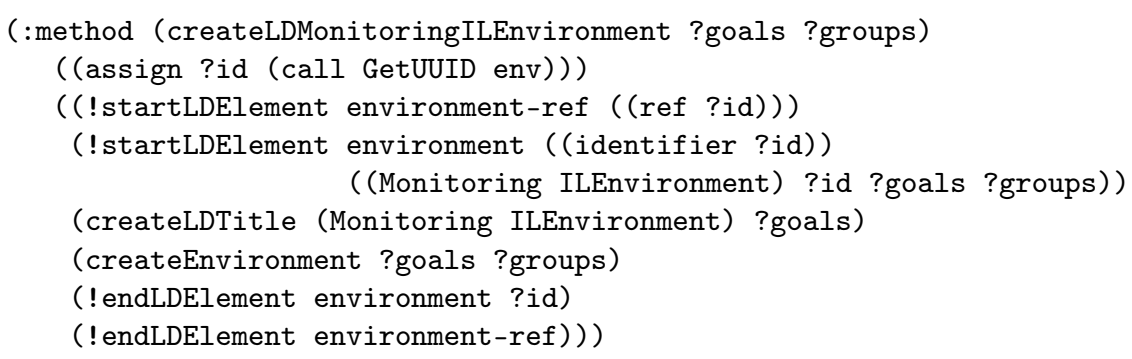

Figura 6.13: Representação da estratégia de criação do ambiente no evento IL Monitorar 


\subsubsection{Exemplo de macrorroteiro: Jigsaw}

O padrão de roteiro Jigsaw é definido como o diagrama mostrado na Figura 6.14, no qual os estudantes são enfrentados à resolução de um problema complexo que pode ser dividido em subproblemas. O fluxo de sessões de aprendizagem definidas pelo padrão possibilitam: promover a interdependência positiva, promover a responsabilidade individual e fomentar a discussão.

O fluxo de sessões de aprendizagem é estruturado em: uma fase individual na que cada estudante trabalha individualmente em um dos subproblemas; uma fase de especialização na que cada grupo de estudantes estudam um mesmo subproblema; e uma fase Jigsaw na que são reunidos todos os estudantes para contribuir com a resolução do problema principal.

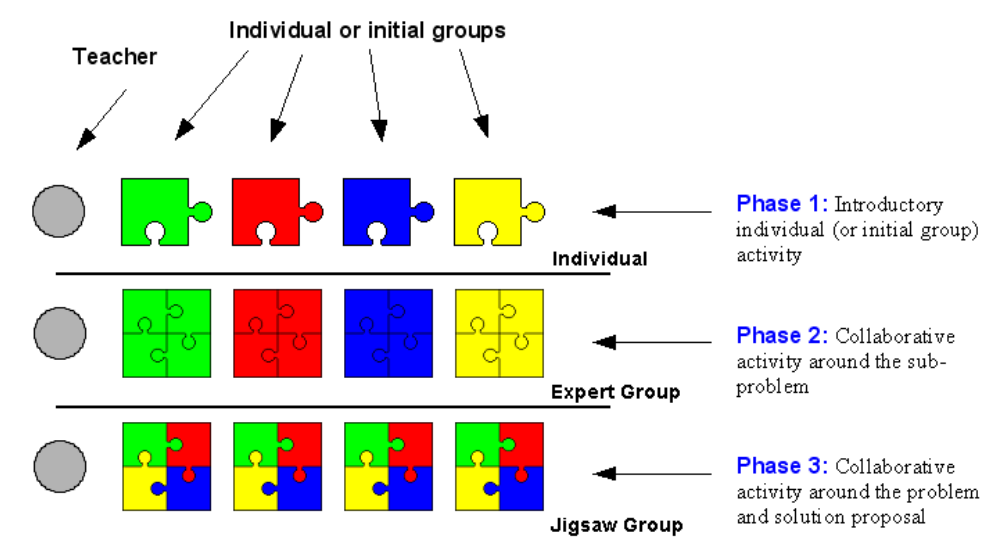

Figura 6.14: Diagrama do macrorroteiro Jigsaw

A seguir apresentamos a modelagem de algumas estratégias de planejamento instrucional extraídas do padrão Jigsaw. Neste trabalho usando 3 padrões de macrorroteiros foram modeladas: 4 estratégias de sessões de aprendizagem, 8 estratégias de atividades de grupo, 8 estratégias de atividades de grupo, 10 estratégias de fases, 3 estratégias de macrorroteiros detalhadas no website

$$
\text { http://www.ime.usp.br/ geiser/dissertacao/macrorroteiros/ }
$$

\section{Macrorroteiro: Jigsaw}

Utilizando o esquema de representação da Figura 4.23, a Figura 6.15 mostra a representação da estratégia de criação do macrorroteiro Jigsaw, no que o método fall-back (linhas 16-42) efetua a seleção de um elemento auxiliar ?aux (linhas 19-28) composto de mais de um elemento auxiliar ?subauxs (linhas 29-32). O número de participantes do roteiro ?nroLearners deve ser duas vezes maior ao número de sub-elementos ?nroSubAuxs (linhas 33-34) para que durante a fase de especialização exista como mínimo dois participantes estudando juntos cada um dos sub-elementos. 


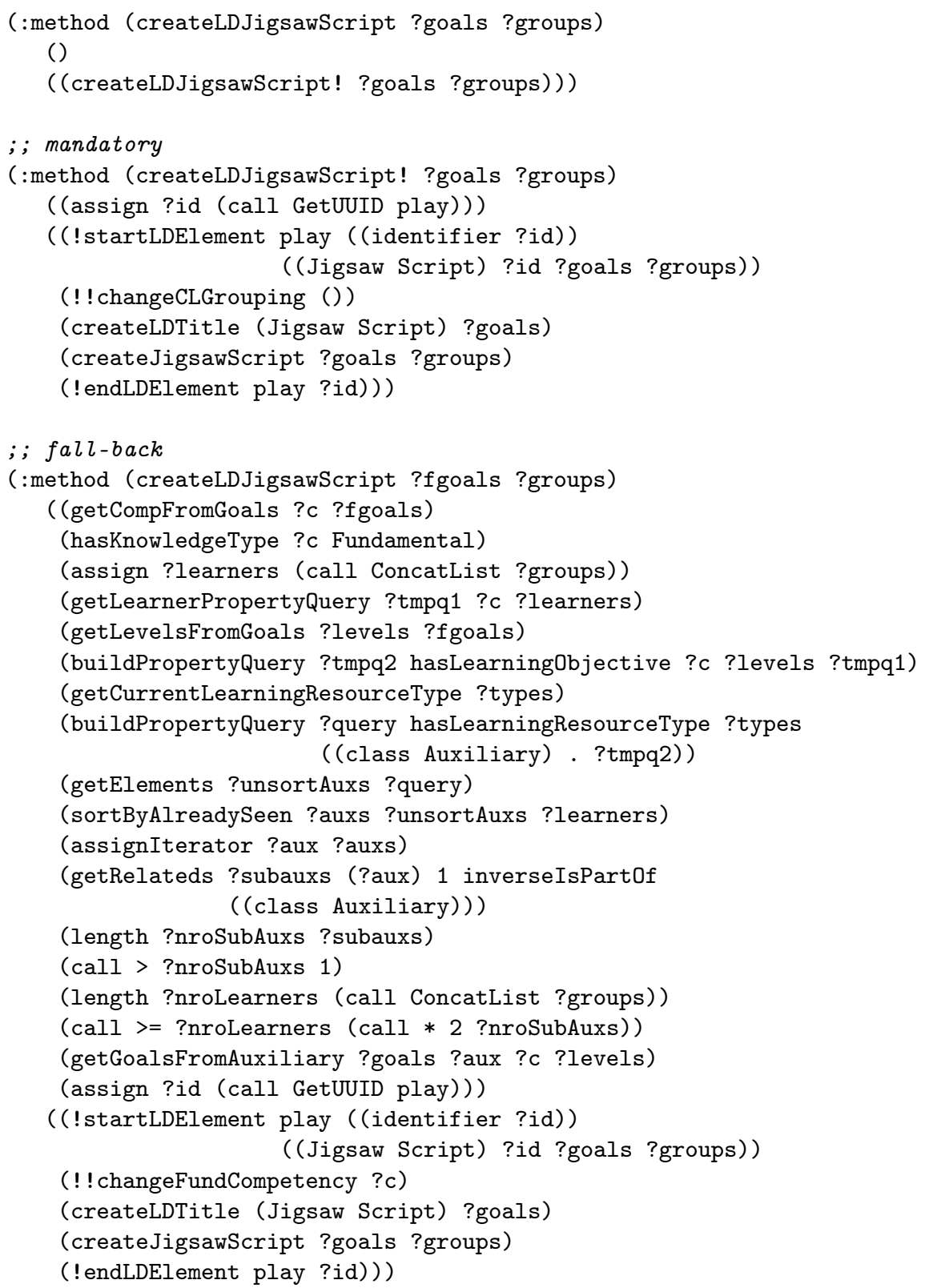

Figura 6.15: Representação da estratégia de criação do macrorroteiro Jigsaw 
Utilizando o esquema de representação da Figura 4.24, a Figura 6.16 mostra o método associados à tarefa createJigsawScript que define a criação das fases Individual, Expert e Jigsaw (linhas 15-17). No método, os objetivos ?subGoals são obtidos mediante o axioma getGoalsFromAuxiliaries (linha 14) usando os subelementos auxiliares ?subauxs (linhas 4-6).

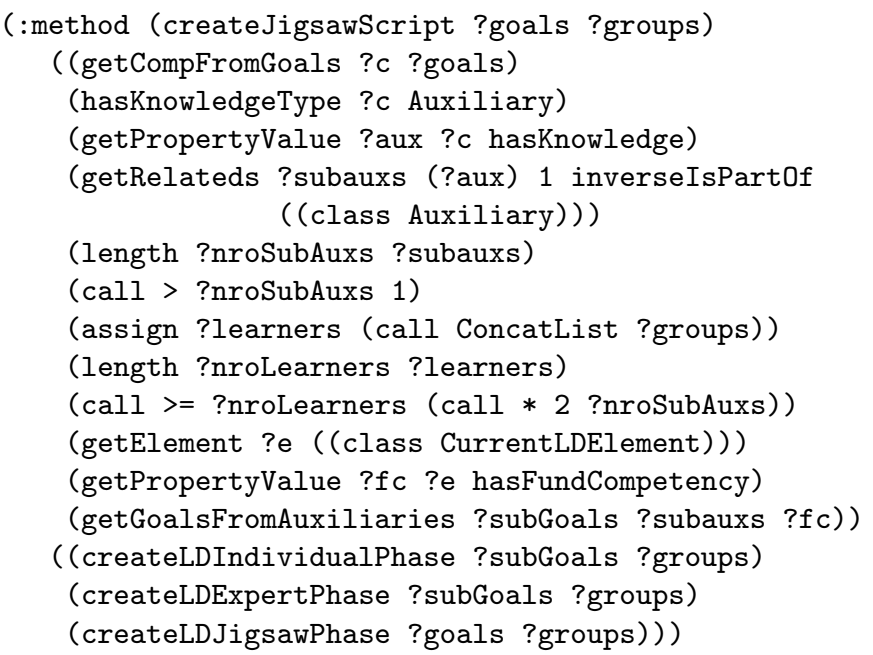

Figura 6.16: Métodos associados à tarefa createJigsawScript

\section{Fase: Jigsaw}

A Figura 6.17 mostra a representação da estratégia de criação da fase Jigsaw pertencente ao macrorroteiro Jigsaw. A formação de grupos não é definida devido a que todos os participantes na fase serão reunidos para contribuir na resolução do problema.

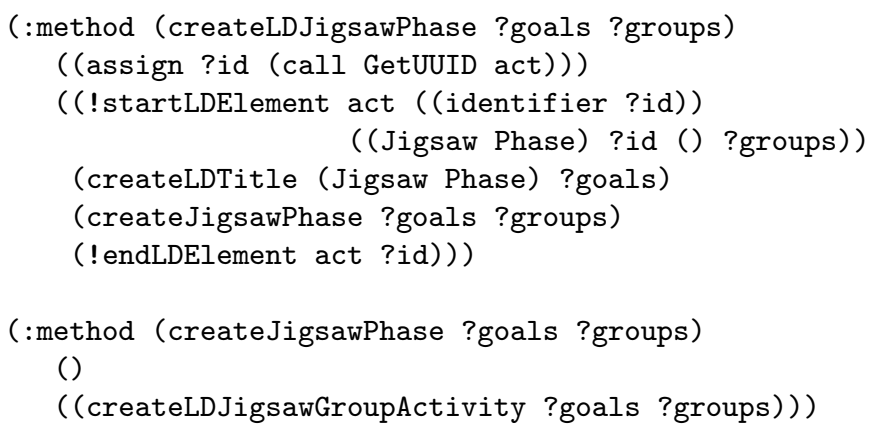

Figura 6.17: Representação da fase Jigsaw 


\section{Atividade de grupo: Jigsaw}

Utilizando o esquema de representação da Figura 4.21, a Figura 6.18 mostra a representação da estratégia de criação da atividade de grupo Jigsaw. A estratégia define a atividade de grupo como: um conjunto de sessões de discussão definidas pelo método de decomposição distributiva associado à tarefa distributeDiscussionSession (linha 34) e uma sessão de conclusão definida pela tarefa createLDJigsawSession (linha 35).

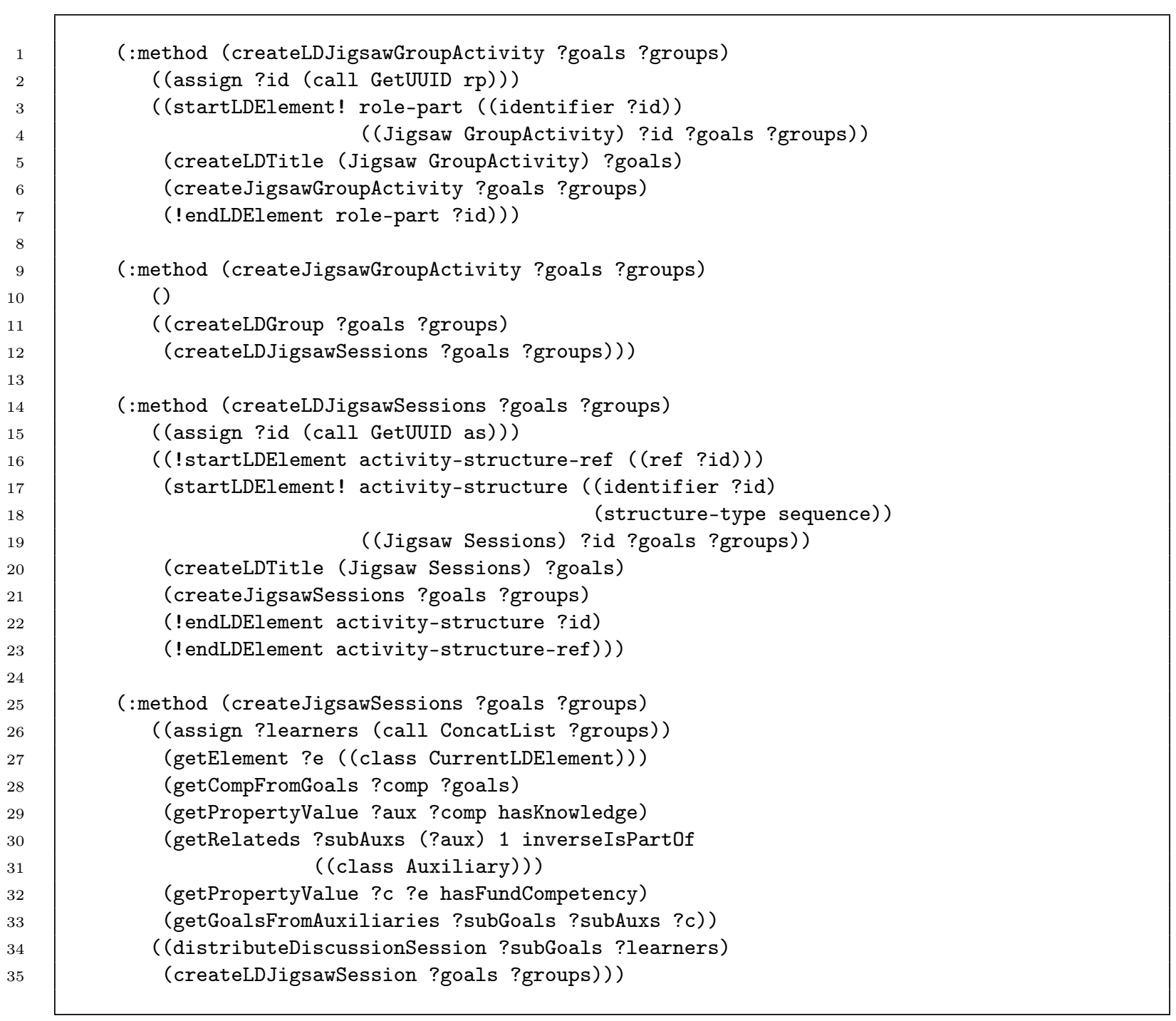

Figura 6.18: Representação da estratégia de criação da atividades de grupo Jigsaw

\section{Sessão de aprendizagem: Discussão}

Utilizando os esquemas de representação das Figuras 4.16, 4.18, 4.19 e 4.20 ; a estratégia de criação da sessão de aprendizagem discussão (Discussion) é definida mediante as tarefas e métodos hierárquicos mostrados nas Figuras 6.19, 6.20, 6.21 e 6.22 . 


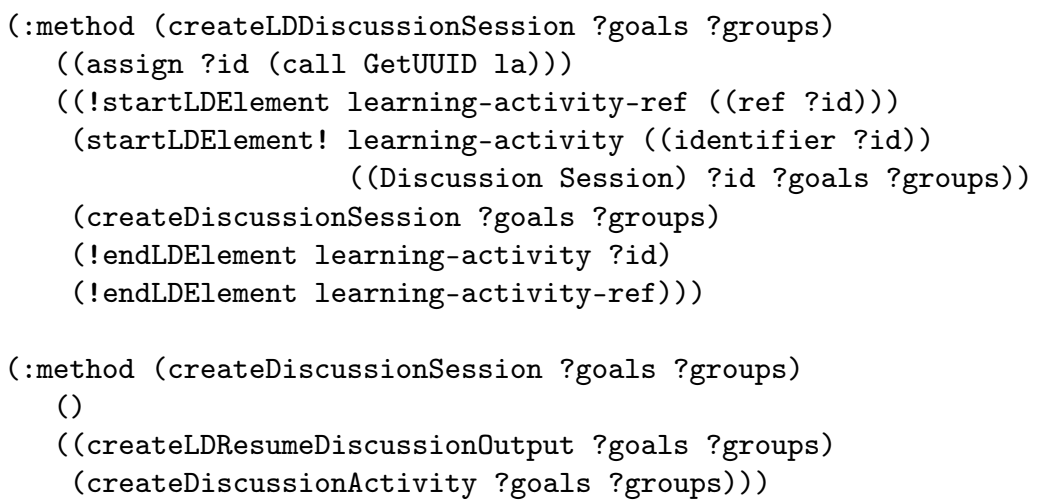

Figura 6.19: Representação da estratégia de criação da sessão de aprendizagem discussão

A Figura 6.19 mostra a representação da estratégia de criação da sessão de aprendizagem discussão, na que a tarefa createExpertSession consiste de: um resumo da discussão como recurso de saída definida pela tarefa createLDResumeDiscussionOutput (linha 12); e um atividade de aprendizagem definida pela tarefa createDiscussionActivity (linha 13). A estratégia de criação do resumo da discussão (ResumeDiscussion) é mostrada na Figura 6.20.

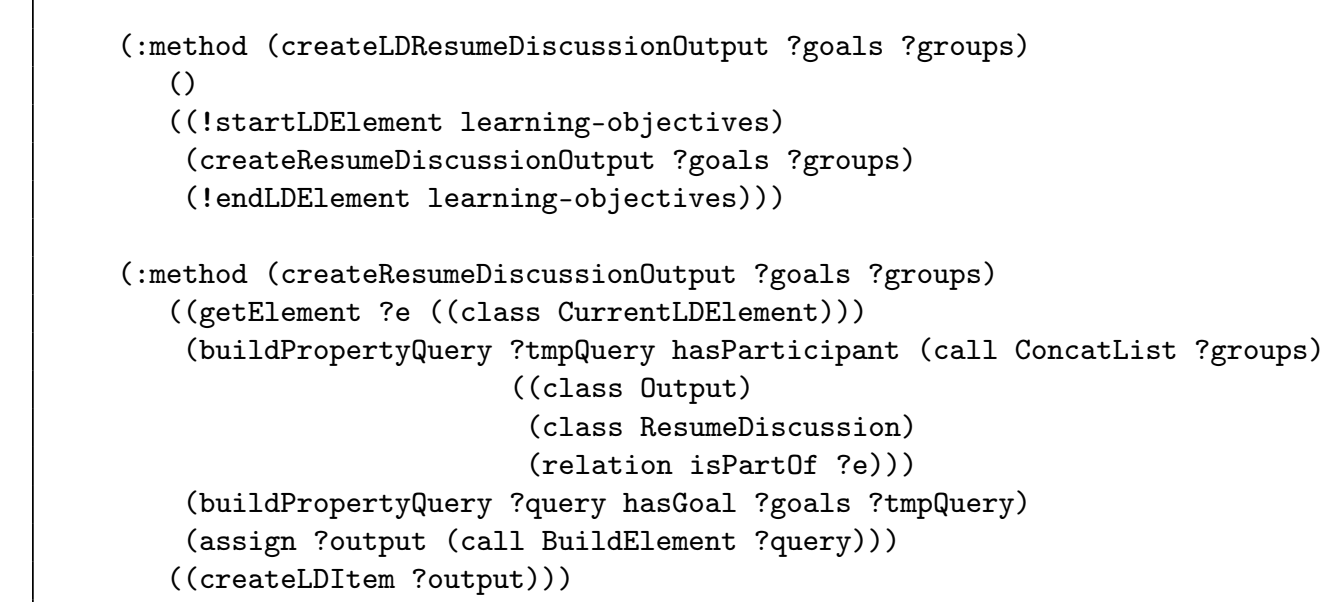

Figura 6.20: Representação da estratégia de criação de resumos de discussão

A Figura 6.21 mostra a estratégia de criação da atividade a ser efetuada na sessão de aprendizagem discussão definida como um ambiente de apoio à aprendizagem e uma descrição da sessão de aprendizagem no método fall-back (linhas 12-16). Enquanto, o método mandatory (linhas 6-9) define a atividade como um roteiro definido mediante à tarefa createLDScriptCLScenario!. A estratégia de criação da descrição de sessão discussão é mostrada na Figura 6.22. 


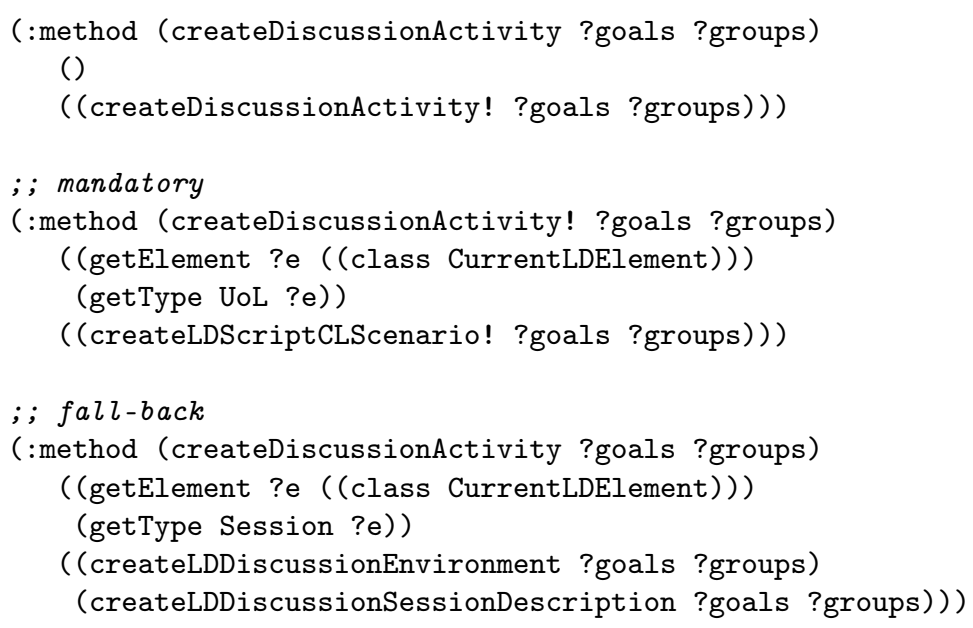

Figura 6.21: Esquema de representação de estratégias de criação das atividades em sessões

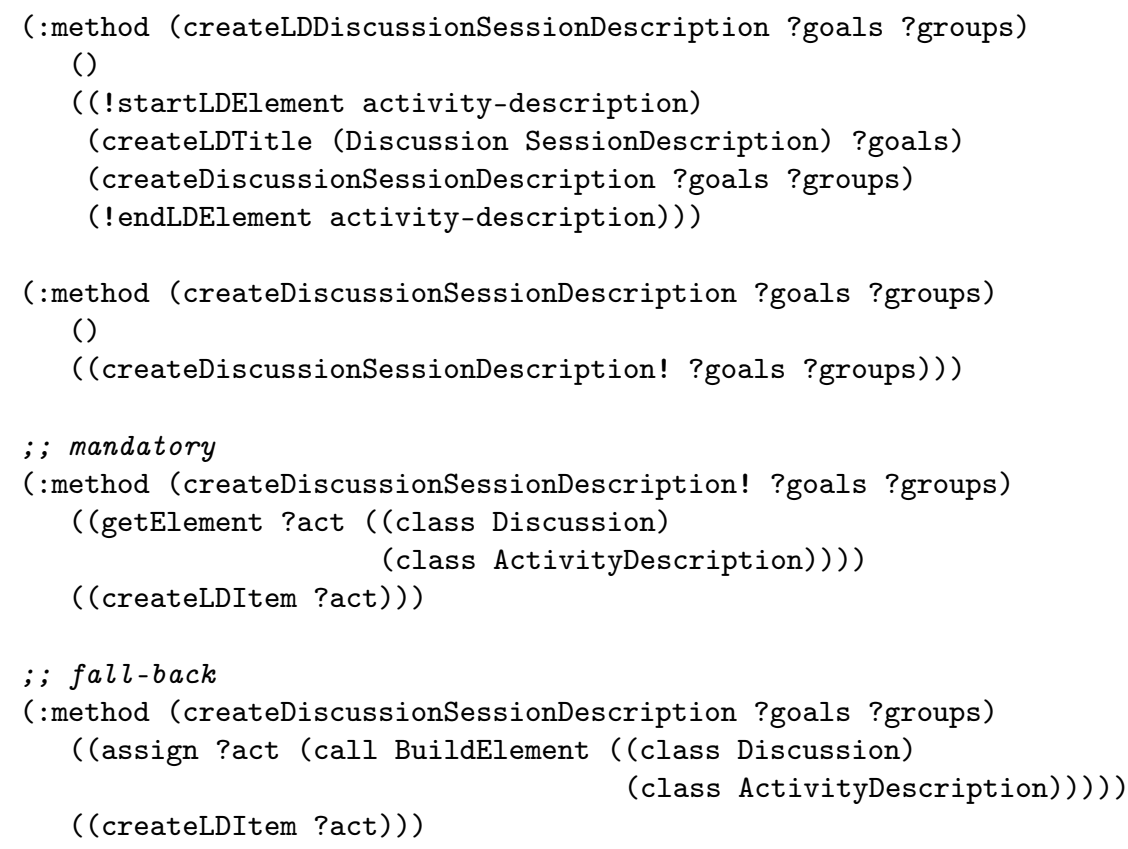

Figura 6.22: Representação da estratégia de criação da descrição na sessão discussão 
Combinação dos padrões de macrorroteiro com Jigsaw

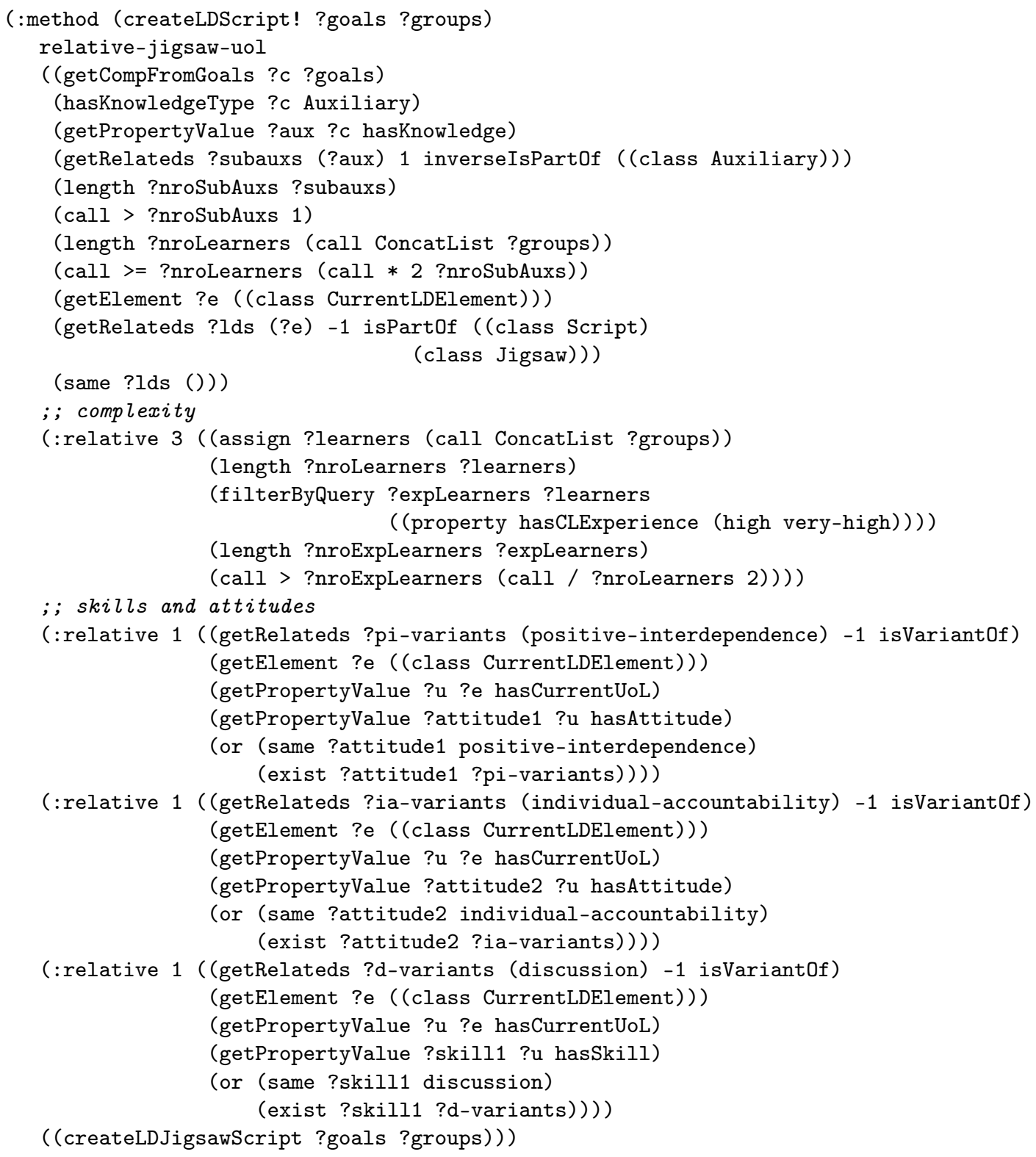

Figura 6.23: Método de combinação do padrão Jigsaw

Utilizando o esquema da Figura 4.30, o método associado à tarefa createLDScript! que definem a combinação dos padrões de macrorroteiros com o padrão Jigsaw é mostrado na Figura 6.23. No método, a condição lógica é definida como o número de estudantes ?nroLearners deve ser maior do que o dobro de sub-elementos auxiliares ?nroSubAuxs do elemento ?aux (linhas 3-10). A condição de complexidade é definida como maior preferência, se os estudantes têm um nível alto de experiência (linhas 16-21). As condições de habilidades e atitudes são independência positiva (linhas 23-28), responsabilidade individual (linhas 29-34) e discussão (linhas 35-40). 


\subsection{Avaliação da saída do planejador}

A avaliação da saída do planejador no modelo proposto foi efetuada mediante a geração de uma unidade de aprendizagem correspondente ao tópico "Métodos de validade", pertencente ao módulo "Lógica básica" extraída do currículo de Ciências de Computação (Cassel et al., 2008).
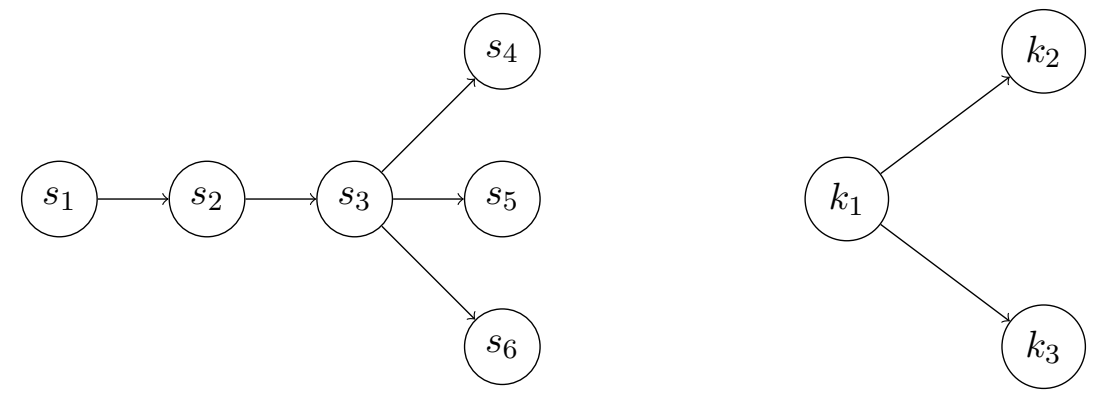

Figura 6.24: Habilidades (esquerda) e elementos de conhecimento de tipo fundamental (direita)

No exemplo, devido ao gerador de cursos ser independente do domínio a ser ensinado, utilizamos a ferramenta ALD para definir as estruturas de habilidades e de elementos de conhecimento de tipo fundamental mostrados na Figura 6.24 (com relações de pré-requisito identificadas mediante linhas sólidas), na qual: $s_{1}, s_{2}, s_{3}, s_{4}, s_{5}$ e $s_{6}$ são as habilidades "conhecimento", "compreensão", "aplicação", "análise", "síntese" e "avaliação"; e $k_{1}, k_{2}$ e $k_{3}$ são os elementos de conhecimento de tipo fundamental "método da tabela de verdade", "método da árvore semântica" e "método da negação ou absurdo".

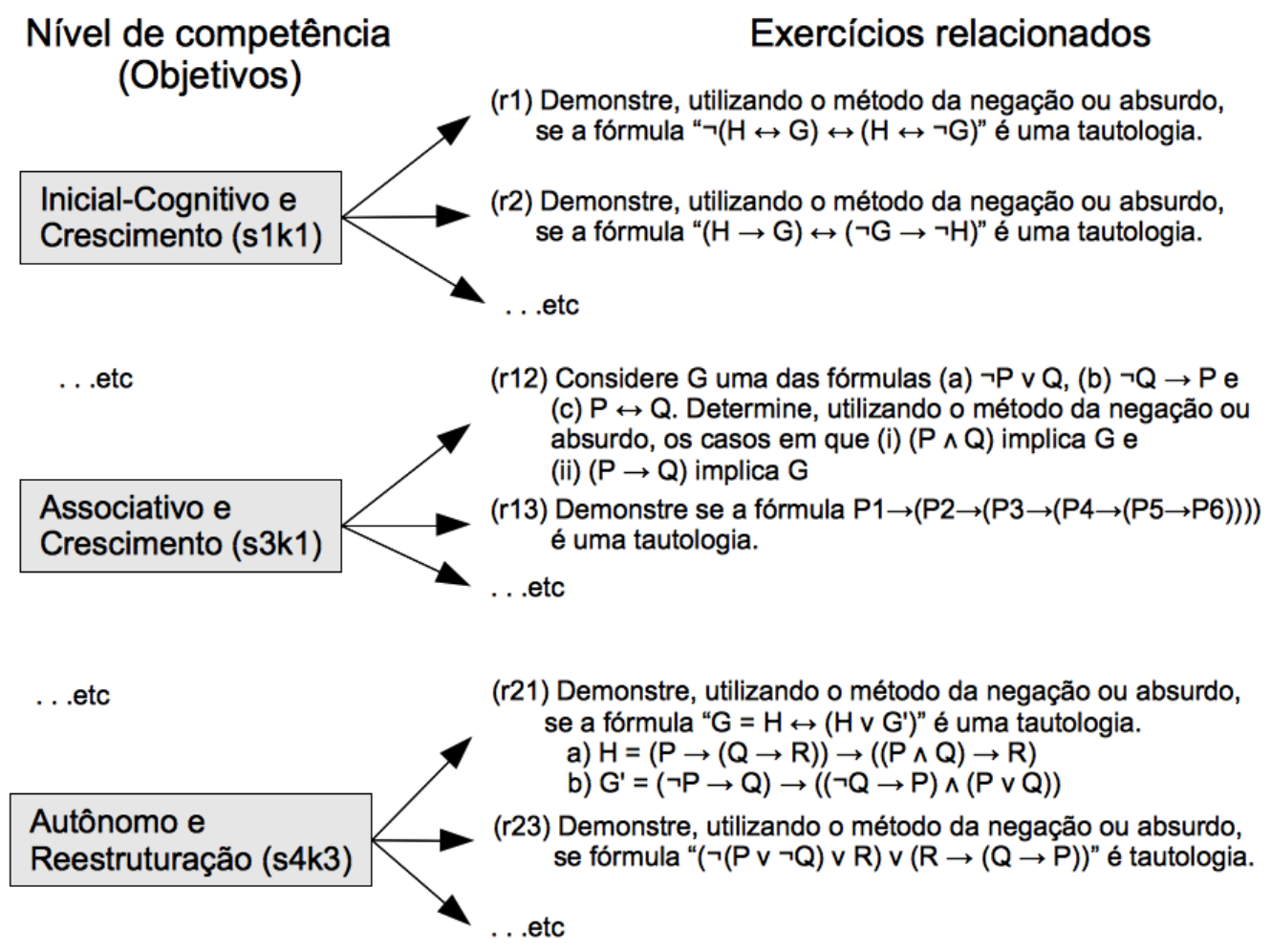

Figura 6.25: Relações entre competência e exercícios usados na validação da saída do planejador 
Empregando as habilidades e os conhecimentos fundamentais apresentados acima, na ferramenta ALD são definidas as competências cognitivas $c_{1}, c_{2}$ e $c_{3}$ como "aplicar $\left(s_{3}\right)$ o método da tabela verdade $\left(k_{1}\right)$ ", "aplicar $\left(s_{3}\right)$ o método da árvore semântica $\left(k_{2}\right)$ " e "aplicar $\left(s_{3}\right)$ o método da negação ou absurdo $\left(k_{3}\right)$ ". Logo, efetuamos a definição dos elementos de conhecimento de tipo auxiliar e efetuamos a relação com as competências usando as propriedades de pré-requisitos (hasPrerequisite) e de objetivos de aprendizagem (hasLearningObjective). Em nosso exemplo, 34 exercícios foram criados e relacionados com os diferentes níveis de competências referentes à competência "aplicar o método da negação ou absurdo" $\left(c_{3}\right)$, como é mostrada na Figura 6.25 na qual as relações são objetivos de aprendizagem.

Finalmente, devido ao gerador de cursos ser independente da informação dos estudantes, o projetista instrucional usando a ferramenta ALD define o modelo de estudante mediante a informação da Tabela 6.3 como registros de competências, históricos e preferências.

\begin{tabular}{|c|r|r|r|r|r|r|r|}
\hline & \multicolumn{2}{|c|}{ competências } & \multicolumn{2}{c|}{ históricos } & \multicolumn{2}{|c|}{ preferências } \\
\hline \hline identificador & $c_{1}$ & $c_{2}$ & $c_{3}$ & $r_{1}$ & $r_{2}$ & personalidade & experiência \\
\hline \hline estudante1 & $\mathrm{s} 1 \mathrm{k} 2$ & $\mathrm{~s} 0 \mathrm{k} 3$ & $\mathrm{~s} 4 \mathrm{k} 2$ & sim & não & introversion & high \\
\hline estudante2 & $\mathrm{s} 2 \mathrm{k} 3$ & $\mathrm{~s} 2 \mathrm{k} 2$ & $\mathrm{~s} 4 \mathrm{k} 2$ & $\mathrm{sim}$ & não & extraversion & high \\
\hline estudante3 & $\mathrm{s} 2 \mathrm{k} 2$ & $\mathrm{~s} 2 \mathrm{k} 2$ & $\mathrm{~s} 3 \mathrm{k} 2$ & $\mathrm{sim}$ & sim & ambiversion & medium \\
\hline estudante4 & $\mathrm{s} 1 \mathrm{k} 2$ & $\mathrm{~s} 2 \mathrm{k} 2$ & $\mathrm{~s} 3 \mathrm{k} 2$ & $\mathrm{sim}$ & $\mathrm{sim}$ & extraversion & medium \\
\hline estudante5 & $\mathrm{s} 2 \mathrm{k} 2$ & $\mathrm{~s} 0 \mathrm{k} 3$ & $\mathrm{~s} 3 \mathrm{k} 1$ & não & não & introversion & medium \\
\hline estudante6 & $\mathrm{s} 2 \mathrm{k} 3$ & $\mathrm{~s} 1 \mathrm{k} 2$ & $\mathrm{~s} 3 \mathrm{k} 1$ & não & não & introversion & medium \\
\hline estudante7 & $\mathrm{s} 2 \mathrm{k} 3$ & $\mathrm{~s} 1 \mathrm{k} 2$ & $\mathrm{~s} 3 \mathrm{k} 0$ & não & sim & extraversion & low \\
\hline estudante8 & $\mathrm{s} 1 \mathrm{k} 2$ & $\mathrm{~s} 0 \mathrm{k} 3$ & $\mathrm{~s} 3 \mathrm{k} 0$ & não & sim & ambiversion & low \\
\hline
\end{tabular}

Tabela 6.3: Informação do modelo de estudante usada na validação da saída do planejador

Na validação da saída do planejador, a tarefa de planejamento instrucional inicial "criação de uma unidade de aprendizagem para o tópico métodos de validade" definida para os estudantes "estudante1, estudante2, ... e estudante8" é representada como:

\section{$t_{0}=\left(\right.$ createLDFundamentalUoL $\left(\left(c_{1} s 4 \mathrm{k} 3\right)\left(c_{2} \mathrm{~s} 4 \mathrm{k} 3\right)\left(c_{3} \mathrm{~s} 4 \mathrm{k} 3\right)\right)()$ (positive-interdependence) \\ ((estudante1 estudante2 estudante3 estudante4 ... estudante8) \\ (estudante1 estudante2 estudante3 estudante4 ... estudante8) \\ (estudante1 estudante2 estudante3 estudante4 ... estudante8)))}

Usando o domínio a ser ensinado, o modelo de estudante e a tarefa inicial definidas acima apresentamos a seguir partes do resultado obtido no planejamento instrucional em ACSC, os quais são: um plano de seções para um objetivo educacional; um plano de sessões práticas para uma seção prática; um plano de sessões definidas pelo macrorroteiro "jigsaw" para uma sessão de prática; e um plano de interações definidas pelo microrroteiro "distributed cognition" para uma sessão do macrorroteiro. 


\subsubsection{Plano de seções para um objetivo educacional}

A Tabela 6.4 mostra o plano de seções a ser obtido para o objetivo educacional "aplicar o método da negação ou absurdo no nível autônomo e restruturação" ( $c_{3}$ s4k3). O plano consiste das seções "introdução", "desenvolvimento", "prática" e "mostrar as relações" definidas pelo cenário pedagógico "descobrir como aplicar o método da negação ou absurdo".

\section{Tópico: "Métodos de validade"}

Objetivos educacionais:

- Aplicar o método da tabela verdade no nível autônomo e restruturação ( $\left.c_{1} \mathrm{~s} 4 \mathrm{k} 3\right)$.

- Aplicar o método da árvore semântica no nível autônomo e restruturação ( $\left.c_{2} \mathrm{~s} 4 \mathrm{k} 3\right)$.

- Aplicar o método da negação ou absurdo no nível autônomo e restruturação ( $c_{3}$ s4k3).

Modelo de estudante, estado corrente (nível de competência para $c_{3}$ ):

- Autônomo e aperfeiçoamento (s4k2) - estudante1, estudante2.

- Associativo e aperfeiçoamento (s3k2) - estudante3, estudante4.

- Associativo e crescimento (s3k1) - estudante5, estudante6.

- Associativo e sem conhecimento (s3k0) - estudante7, estudante8.

Resultado, plano de seções:

- Ensaio para aplicar o método da tabela verdade (play $\left.y_{1}\right)$.

- Ensaio para aplicar o método da árvore semântica (play $)$.

- Descobrir como aplicar o método da negação ou absurdo (plays).

- Introdução para aplicar o método da negação ou absurdo $\left(a c t_{1}\right)$.

- Desenvolvimento para aplicar o método da negação ou absurdo $\left(a c t_{2}\right)$.

- Prática para aplicar o método da negação ou absurdo $\left(\right.$ act $\left._{3}\right)$.

- Mostrar as relações para aplicar o método da negação ou absurdo $\left(a c t_{4}\right)$.

Tabela 6.4: Resultado esperado das seções a serem obtidas para um objetivo educacional

Empregando o gerador de cursos e a tarefa inicial $t_{0}$, o processo de planejamento hierárquico mostrado na Figura 6.26 obtém o plano de seções $\mathrm{P}$ apresentado a seguir mediante:

(1) o sequenciamento dos objetivos educacionais mediante a decomposição distributiva da tarefa createFundamentalUoL; e

(2) a seleção do cenário pedagógico descoberta (discover) mediante a decomposição da tarefa createFundamentalScript. 


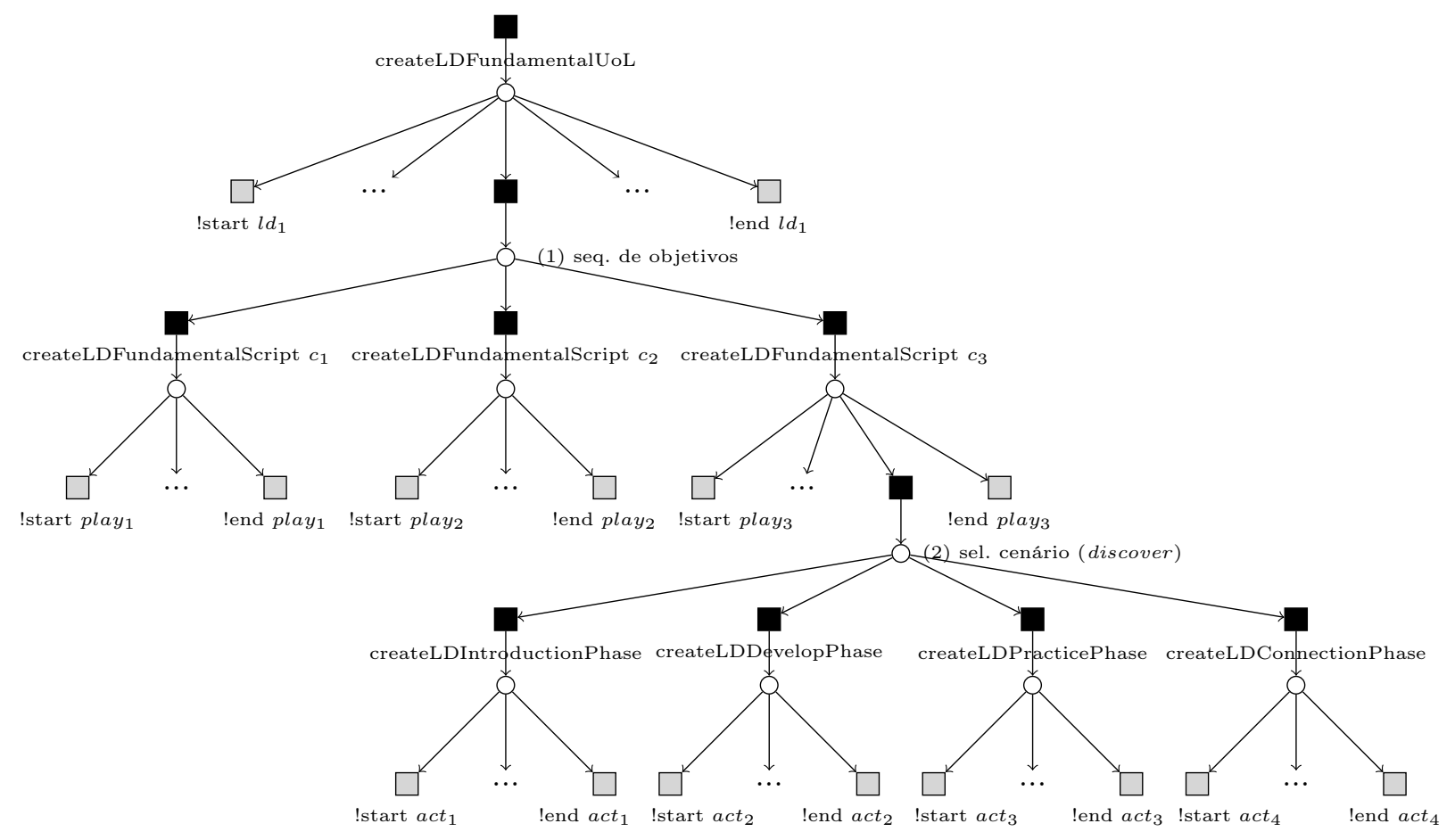

Figura 6.26: Processo de planejamento hierárquico usado para obter o plano de seções

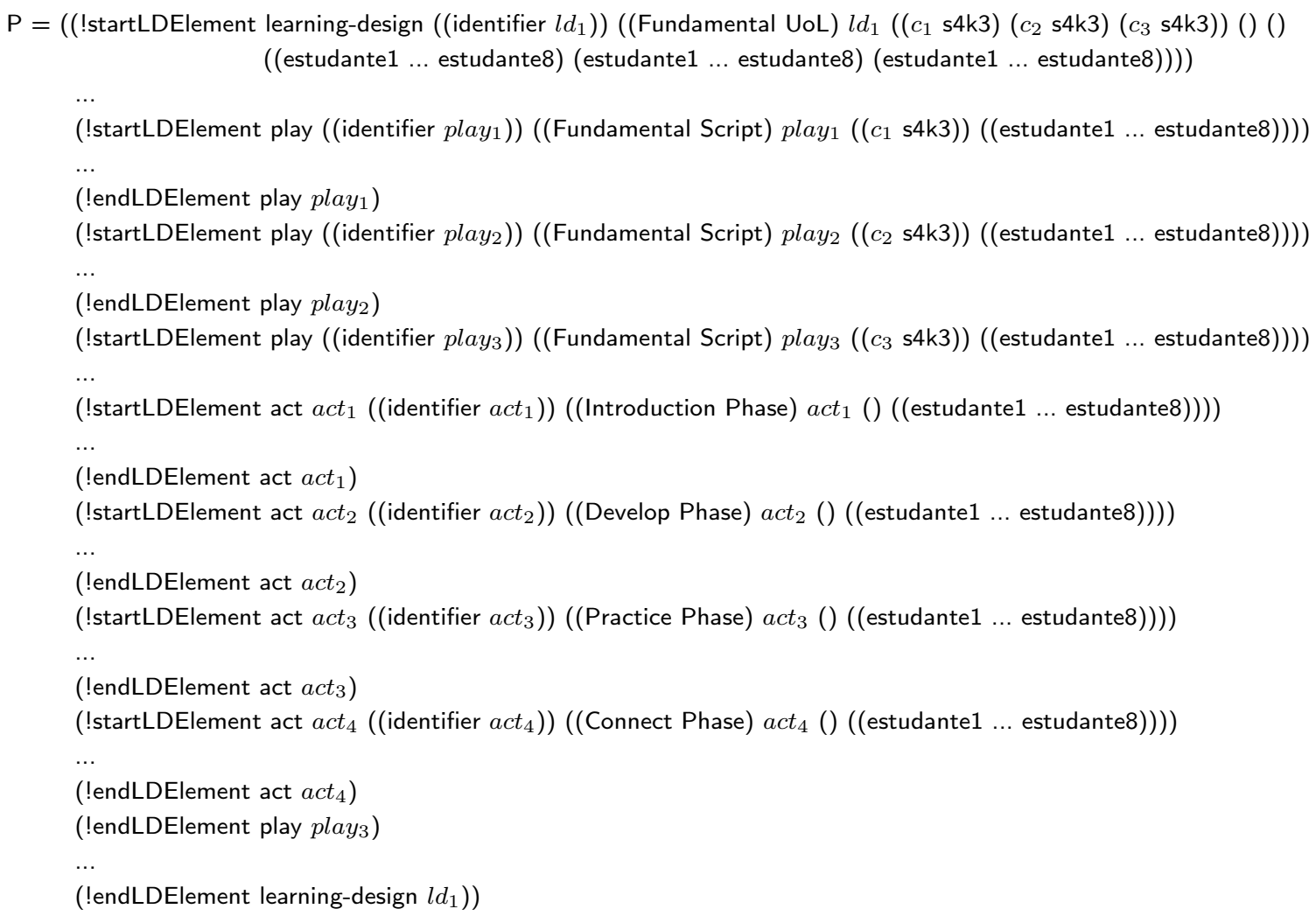

A Figura 6.27 mostra a interface de usuário no sistema CopperCore apresentando o plano de seções $\mathrm{P}$, obtido pelo gerador de cursos colaborativos. A interface mostra as seções do cenário "descobrir como aplicar o método da negação ou absurdo". 


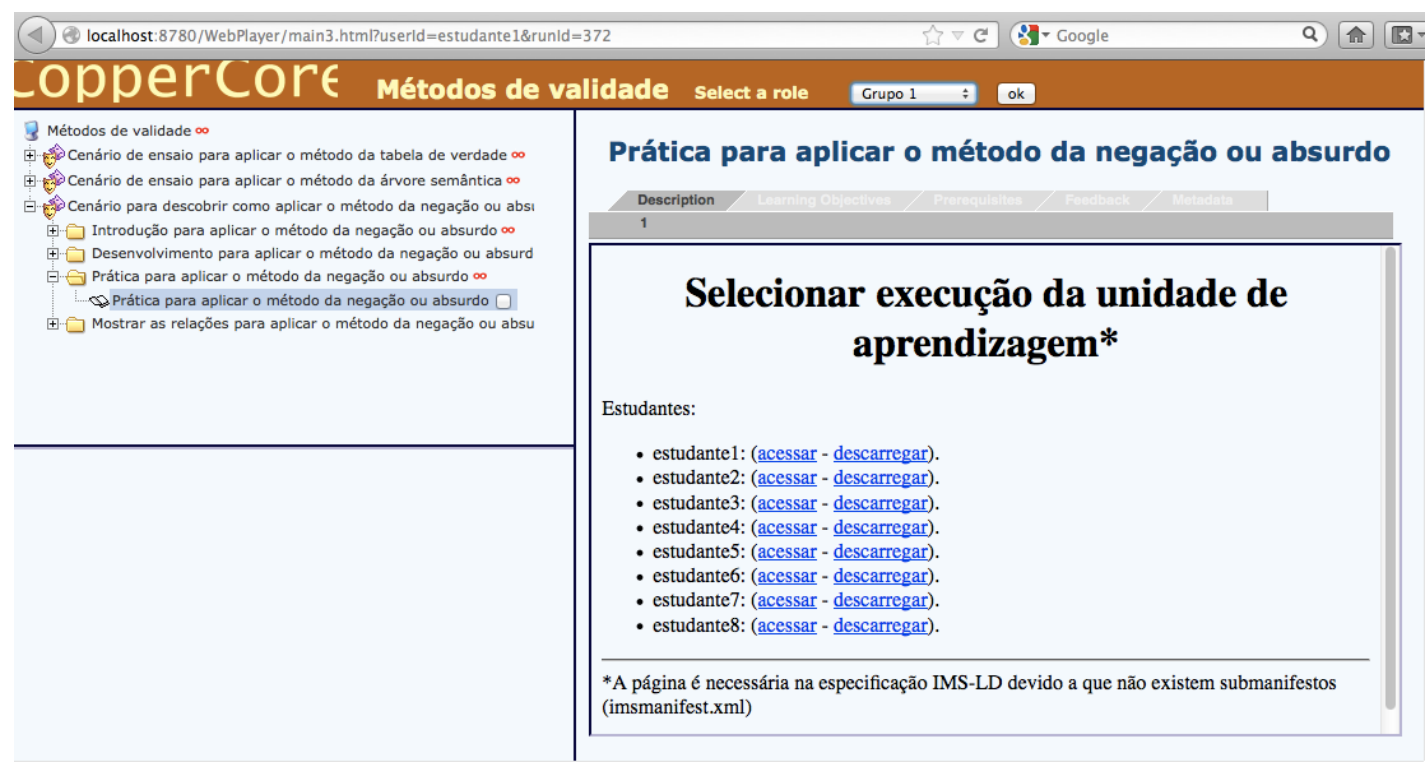

Figura 6.27: Interface de usuário no CopperCore do plano de seções para um objetivo educacional

\subsubsection{Plano de sessões práticas para uma seção prática}

A Tabela 6.6 mostra o plano de sessões a ser obtido para a seção "prática para aplicar o método da negação ou absurdo" ( $\left.a_{c} t_{3}\right)$. O plano consiste de sete sessões com diferentes níveis de competência definidas em três fases. O plano de sessões esperado consiste de:

- Uma fase 01 definida como uma sessão $s_{1}$ formada pelo Grupo1 (estudante1 e estudante2) usando a teoria "distributed cognition", uma sessão $s_{2}$ formada pelo Grupo2 (estudante3 e estudante4) usando a teoria "distributed cognition" e uma sessão $s_{3}$ formada pelo Grupo3 (estudante 5, ... e estudante8) usando a teoria "peer tutoring".

- Uma fase 02 definida como uma sessão $s_{4}$ formada pelo Grupo4 (estudante1, estudante2, estudante3 e estudante4) usando a teoria "distributed cognition", uma sessão $s_{5}$ formada pelo Grupo5 (estudante5 e estudante6) usando a teoria "distributed cognition" e uma sessão $s_{6}$ formada pelo Grupo6 (estudante7 e estudante8) não associado a nenhuma teoria.

- Uma fase 03 definida como uma sessão $s_{7}$ formada pelo Grupo7 (estudante1, estudante2, ... e estudante8) usando a teoria "distributed cognition". 
Seção: "Prática para aplicar o método da negação ou absurdo"

Objetivo educacional:

- Aplicar o método da negação ou absurdo no nível autônomo e restruturação ( $c_{3}$ s4k3).

Modelo de estudante (nível de competência para $c_{3}$ ):

- Autônomo e aperfeiçoamento (s4k2) - estudante1, estudante2.

- Associativo e aperfeiçoamento (s3k2) - estudante3, estudante4.

- Associativo e crescimento (s3k1) - estudante5, estudante6.

- Associativo e sem conhecimento (s3k0) - estudante7, estudante8.

Resultado, plano de sessões:

- Fase $01\left(\right.$ act $\left._{5}\right)$ :

- Praticar $c_{3}$ com um exercício do nível s4k3 $\left(s_{1}\right)$ - estudante1, estudante2.

- Praticar $c_{3}$ com um exercício do nível s4k2 $\left(s_{2}\right)$ - estudante3, estudante4.

- Praticar $c_{3}$ com um exercício do nível s3k1 e s3k2 $\left(s_{3}\right)$ - estudante5, estudante6, estudante7, estudante8.

- Fase $02\left(\right.$ act $\left._{6}\right)$ :

- Praticar $c_{3}$ com um exercício do nível s4k3 $\left(s_{4}\right)$ - estudante1, estudante2, estudante3, estudante4.

- Praticar $c_{3}$ com um exercício do nível s3k3 $\left(s_{5}\right)$ - estudante5, estudante6.

- Praticar $c_{3}$ com um exercício do nível s4k3 (s6) - estudante7, estudante8.

- Fase $03\left(\right.$ act $\left._{7}\right)$ :

- Praticar $c_{3}$ com um exercício do nível s4k3 $\left(s_{7}\right)$ - estudante1, estudante2, estudante3, estudante4, estudante5, estudante6, estudante7, estudante 8.

Tabela 6.5: Resultado esperado das sessões a serem obtidas para uma seção prática

Antes de efetuar a geração do plano sessões práticas para a seção prática, o gerador de cursos colaborativos obtém um plano de tarefas createLDPracticeSessions mediante a decomposição da tarefa createPracticePhase empregando o processo mostrado na Figura 6.28. O processo obtém as tarefas mediante a definição de atividade de grupo usando a decomposição da tarefa createLDPracticeGroupActivity e createPracticeGroupActivity que define um par de tarefas createLDGroup e createLDPracticeSessions. 


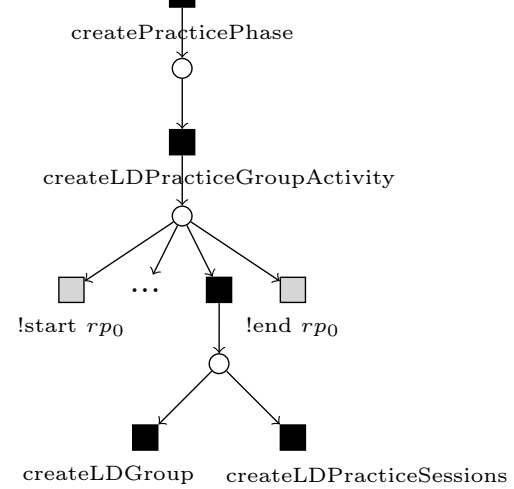

Figura 6.28: Processo de planejamento hierárquico usado para obter tarefas de criação de sessões

Empregando o gerador de cursos colaborativos e a tarefa createLDPracticeSessions, o plano de sessões práticas P para a seção "prática para aplicar o método da negação ou absurdo" (act $\left.{ }_{3}\right)$ é obtido mediante o processo de planejamento hierárquico mostrado na Figura 6.29. O processo de planejamento hierárquico consiste de:

(1) a criação de um roteiro mediante a decomposição da tarefa createPracticeSessions;

(2) a criação de fases práticas mediante a decomposição distributiva da tarefa createPracticeScript, decomposição distributiva efetuada até que todos os estudantes alcancem os objetivos educacionais; e

(3) a formação de grupos mediante a decomposição distributiva das tarefas createPracticePhase, nas quais definimos a criação de atividades em grupo utilizando a tarefa createLDPracticeGroupActivity. 


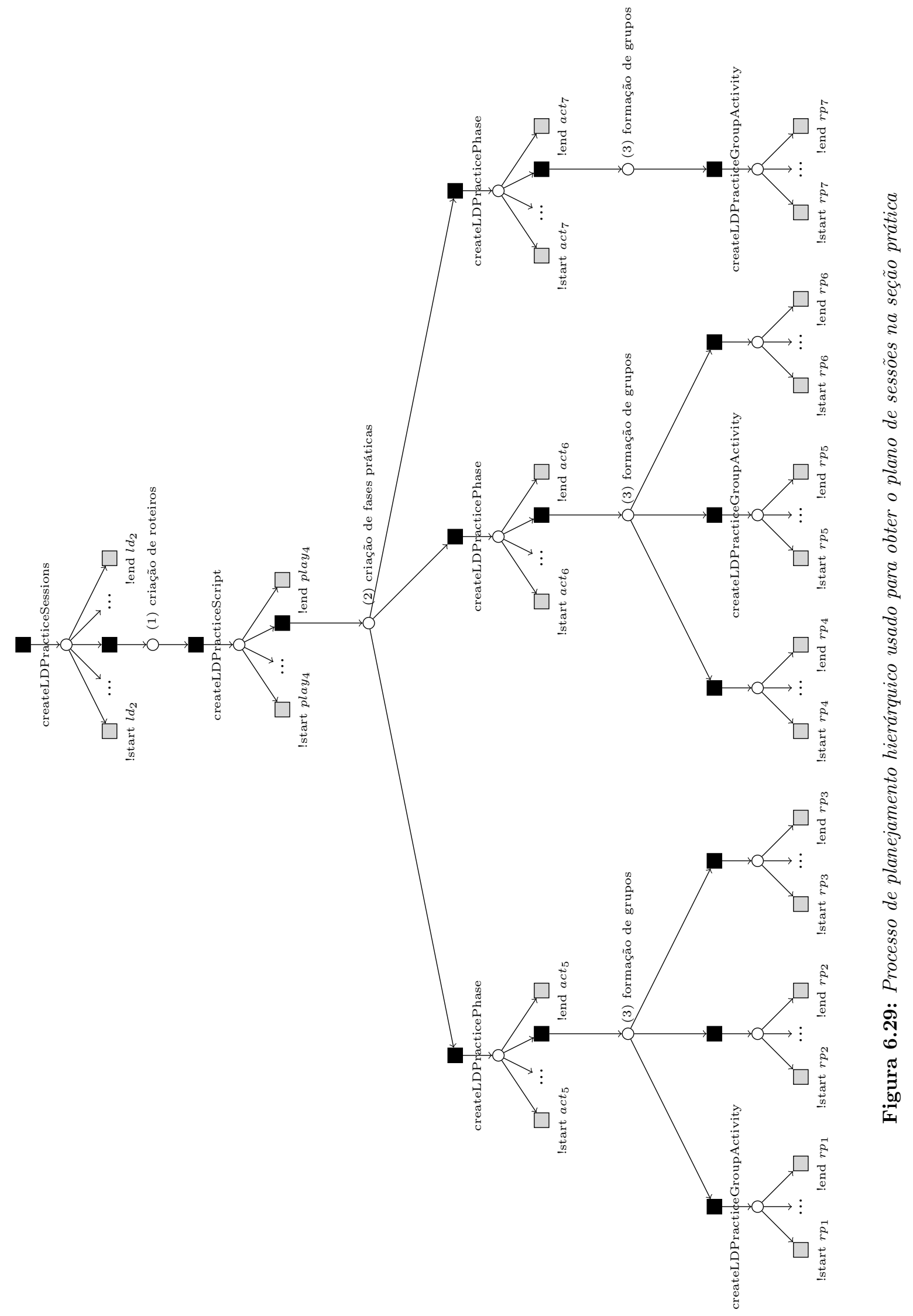


$\mathrm{P}=\left(\left(\right.\right.$ !startLDElement role-part $r p_{0}\left(\left(\right.\right.$ identifier $\left.\left.r p_{0}\right)\right)\left(\left(\right.\right.$ Practice GroupActivity) $\left.r p_{0}\left(\left(c_{3} \mathrm{~s} 4 \mathrm{k} 3\right)\right)\right)(($ estudante1 ... estudante8) $\left.))\right)$ $\cdots$ (!startLDElement learning-design ((identifier $\left.\left.l d_{2}\right)\right)\left(\left(\right.\right.$ PracticeSessions UoL) $l d_{2}\left(\left(c_{3} s 4 \mathrm{k} 3\right)\right)(($ estudante1 ... estudante8) $\left.))\right)$

A Tabela 6.6 mostra as interfaces de usuário no sistema CopperCore, apresentando o plano de sessões $\mathrm{P}$ obtido pelo gerador de cursos colaborativos. As imagens na tabela mostram as interfaces de cada uma das sessões práticas obtidas na seção "prática para aplicar o método da negação ou absurdo". 


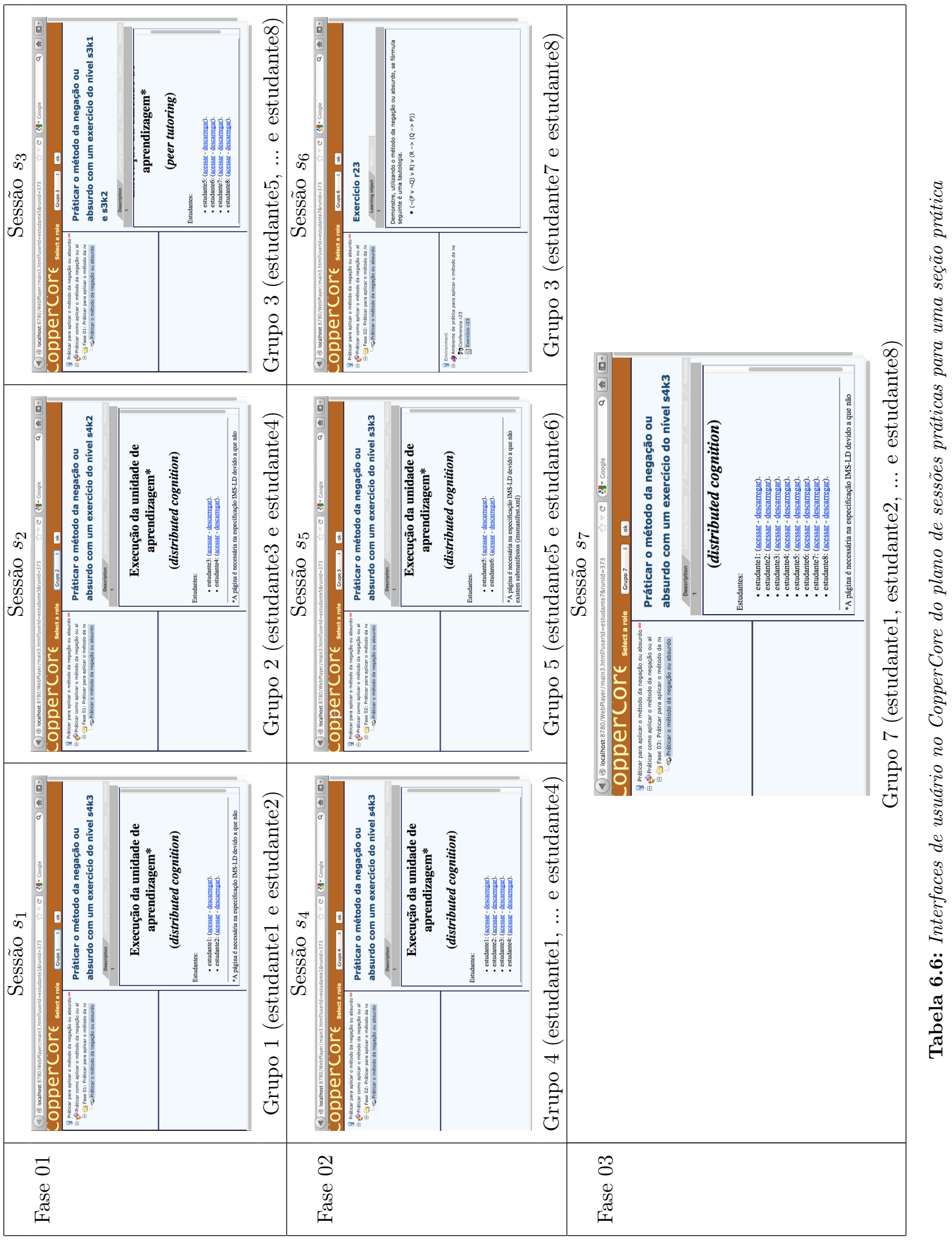




\subsubsection{Plano de sessões definidas pelo macrorroteiro jigsaw}

A Tabela 6.7 mostra o plano de sessões definidas pelo macrorroteiro jigsaw a ser obtido para a sessão "praticar o método da negação ou absurdo com um exercício do nível autônomo e restruturação" $\left(s_{7}\right)$. O plano de sessões esperado consiste de:

- Uma fase individual definida como: quatro sessões $s_{8}, s_{9}, s_{10}$ e $s_{11}$, na qual cada estudante estudante1, estudante2, estudante3 e estudante4 participam da sessão "demonstrar, se a fórmula $H$ é uma tautologia"; e quatro sessões $s_{12}, s_{13}, s_{14}$ e $s_{15}$, na qual cada estudante estudante5, estudante6, estudante7 e estudante8 participam da sessão "demonstrar, se a fórmula $G^{\prime}$ é uma tautologia".

- Uma fase de especialização definida como uma sessão $s_{16}$ formada pelo Grupo16 (estudante1, estudante2, estudante3, estudante4) com estudantes que participaram da sessão "demonstrar, se a fórmula $H$ é uma tautologia" na fase individual e uma sessão $s_{17}$ formada pelo Grupo17 (estudante5, estudante6, estudante7, estudante8) com estudantes que participaram da sessão "demonstrar, se a fórmula $G^{\prime}$ é uma tautologia" na fase individual.

- Uma fase jigsaw definida como uma sessão $s_{18}$ "discussão para demonstrar, se a fórmula $H$ é uma tautologia", uma sessão $s_{19}$ "discussão para demonstrar, se a fórmula $G^{\prime}$ é uma tautologia" e uma sessão $s_{20}$ para "demonstrar, se a fórmula $G$ é uma tautologia" formada pelo Grupo18 (estudante1, estudante2, ... e estudante8).

O gerador de cursos colaborativos obtém o plano de sessões definido pelo macrorroteiro jigsaw na sessão $s_{7}$ mediante o processo de planejamento hierárquico mostrado na Figura 6.30. Empregando a tarefa createLDPracticeSession, o processo de planejamento hierárquico para obter o plano $\mathrm{P}$, apresentado a seguir, consiste de:

(1) a seleção do elemento de conhecimento de tipo auxiliar adequado mediante a decomposição da tarefa createPracticeSession;

(2) a seleção do padrão de macrorroteiro mediante a decomposição da tarefa createLDScriptCLScenario!, tarefa de integração de macrorroteiros e microrroteiros que define a seleção como a tarefa createLD JigsawScript;

(3) a criação das fases individual, especialização e jigsaw mediante a decomposição da tarefa createJigsawScript;

(4) a formação de grupos mediante a decomposição distributiva das tarefas createlndividualPhase, createExpertPhase e createJigsawPhase, nas quais definimos a criação de atividades em grupo utilizando as tarefas createLDIndividualGroupActivity, createLDExpertGroupActivity e createLDJigsawGroupActivity. 
Objetivo educacional:

- Demonstre, utilizando o método da negação ou absurdo, se a fórmula " $G=H \leftrightarrow\left(H \vee G^{\prime}\right)$ " é uma tautologia ( $\left.c_{a} \mathrm{~s} 4 \mathrm{k} 3\right)$, onde:

$$
\begin{aligned}
& -H=(P \rightarrow(Q \rightarrow R)) \rightarrow((P \wedge Q) \rightarrow R),\left(c_{a 1}\right) . \\
& -G^{\prime}=(\neg P \rightarrow Q) \rightarrow((\neg Q \rightarrow P) \wedge(P \vee Q)),\left(c_{a 2}\right) .
\end{aligned}
$$

Modelo de estudante (nível de competência para $c_{a}$ ):

- Autônomo e restruturação (s4k3) - estudante1, estudante2, estudante3, estudante4, estudante7, estudante8.

- Associativo e restruturação (s3k3) - estudante5, estudante6.

Resultado, plano de sessões usando o macrorroteiro "Jigsaw":

- Fase individual:

- Demostrar, se a fórmula $H$ é uma tautologia $\left(s_{8}\right)$ - estudante1.

- Demostrar, se a fórmula $H$ é uma tautologia $\left(s_{9}\right)$ - estudante2.

- Demostrar, se a fórmula $H$ é uma tautologia $\left(s_{10}\right)$ - estudante3.

- Demostrar, se a fórmula $H$ é uma tautologia $\left(s_{11}\right)$ - estudante4.

- Demostrar, se a fórmula $G^{\prime}$ é uma tautologia $\left(s_{12}\right)$ - estudante5.

- Demostrar, se a fórmula $G^{\prime}$ é uma tautologia $\left(s_{13}\right)$ - estudante6.

- Demostrar, se a fórmula $G^{\prime}$ é uma tautologia $\left(s_{14}\right)$ - estudante7.

- Demostrar, se a fórmula $G^{\prime}$ é uma tautologia $\left(s_{15}\right)$ - estudante8.

- Fase de especialização:

- Demostrar, se a fórmula $H$ é uma tautologia $\left(s_{16}\right)$ - estudante1, estudante2, estudante3, estudante4.

- Demostrar, se a fórmula $G^{\prime}$ é uma tautologia $\left(s_{17}\right)$ - estudante5, estudante6, estudante7, estudante8.

- Fase jigsaw - estudante1, estudante2, ... e estudante 8:

- Discussão para demonstrar, se a fórmula $H$ é uma tautologia $\left(s_{18}\right)$.

- Discussão para demonstrar, se a fórmula $G^{\prime}$ é uma tautologia $\left(s_{19}\right)$.

- Demostrar se a fórmula $G$ é uma tautologia $\left(s_{20}\right)$.

Tabela 6.7: Resultado esperado das sessões definidas pelo macrorroteiro jigsaw em uma sessão prática 


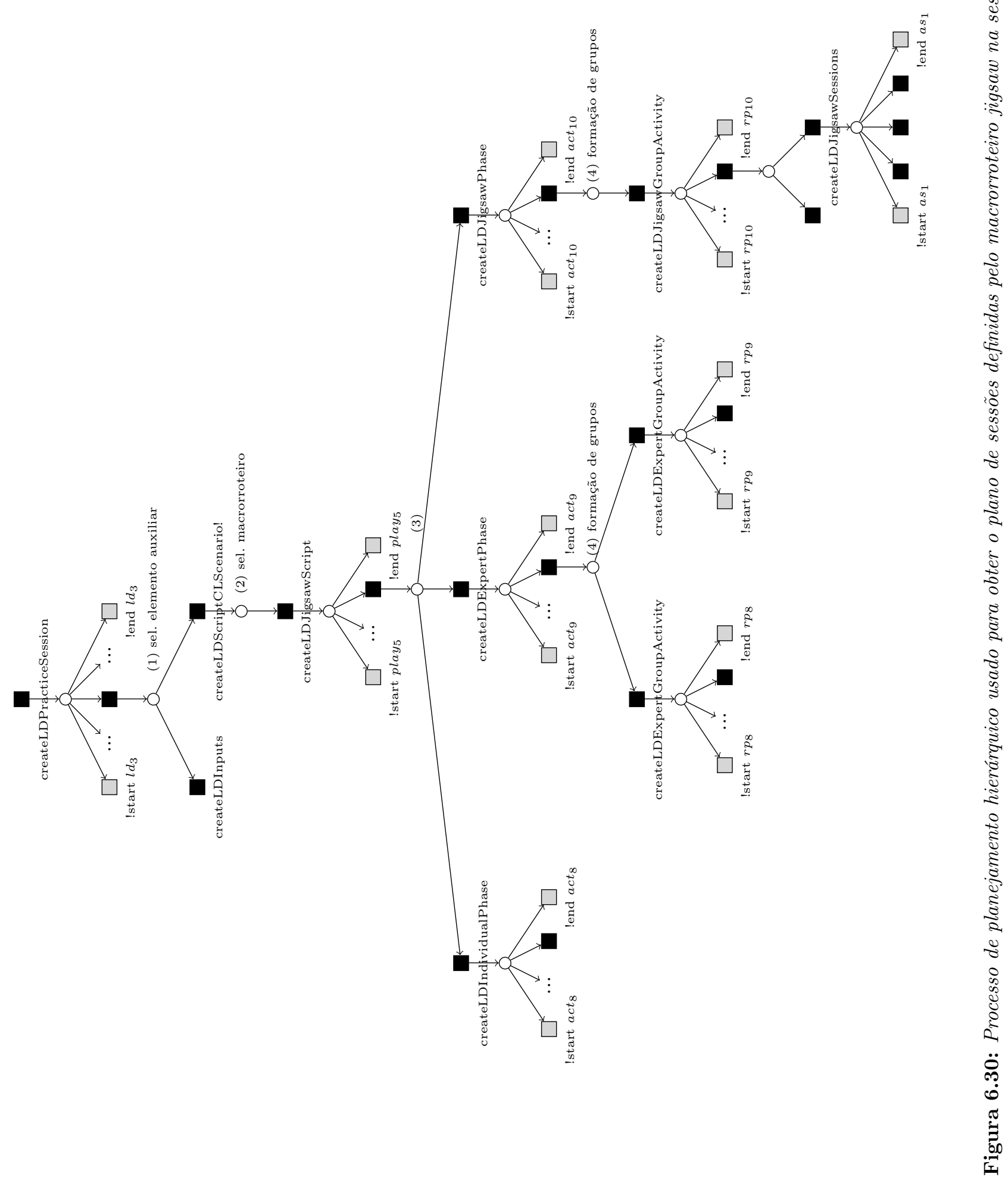


$\mathrm{P}=\left(\left(\right.\right.$ !startLDElement learning-design $\left(\left(\right.\right.$ identifier $\left.\left.l d_{3}\right)\right)\left(\left(\right.\right.$ PracticeSession UoL) $l d_{3}\left(\left(c_{3}\right.\right.$ s4k3)) ((estudante1 ... estudante8)))) (!startLDElement play ((identifier play $))$ ((Jigsaw Script) play $\left(\left(c_{a}\right.\right.$ s4k3)) ((estudante1 ... estudante8))))

A Tabela 6.8 mostra as interfaces de usuário no sistema CopperCore, apresentando o plano de sessões $\mathrm{P}$ definido pelo macrorroteiro jigsaw. As imagens na tabela mostram as interfaces de cada uma das sessões práticas obtidas pelo gerador de cursos colaborativos. 


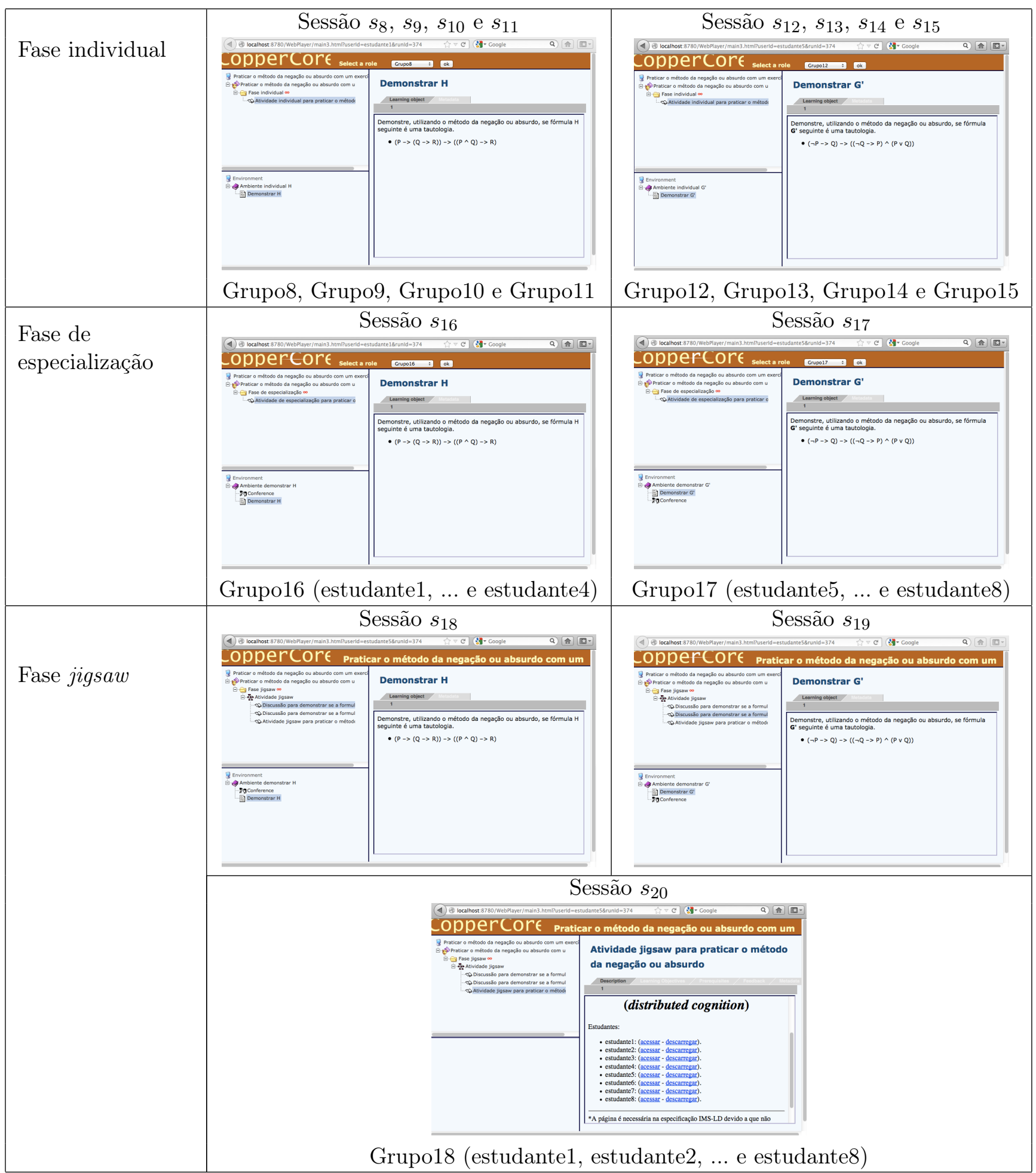

Tabela 6.8: Interfaces de usuário no CopperCore do plano de sessões definidas pelo macrorroteiro jigsaw 


\subsubsection{Plano de interações definidas pelo microrroteiro distributed cognition}

A Tabela 6.9 mostra o plano de interações definidas pelo microrroteiro distributed cognition a ser obtido na sessão "demostrar se a fórmula $G^{\prime}$ é uma tautologia" $\left(s_{20}\right)$ do macrorroteiro jigsaw. O plano de interações esperado consiste de:

- Duas interações cíclicas $a s_{3}$ e $a s_{4}$ definidas como um par de eventos IL "demonstrar como resolver o problema - instigar a troca de ideias" e um par de eventos IL "requisitar detalhes sobre o problema - instigar o pensar"; e

- Um evento IL "notificar o estado corrente do estudante" $\left(l a_{9}\right)$.

O gerador de cursos colaborativos obtém o plano das interações definidas pelo microrroteiro distributed cognition na sessão $s_{20}$ do macrorroteiro jigsaw mediante o processo de planejamento hierárquico mostrado na Figura 6.31. O processo de obtenção do plano P, consiste de:

(1) a seleção do elemento de conhecimento de tipo auxiliar adequado mediante a decomposição da tarefa createJigsawSession;

(2) a seleção do padrão de microroteiro distributed cognition mediante a decomposição da tarefa createLDScriptCLScenario!, tarefa de integração de macrorroteiros e microrroteiros que define a seleção do microrroteiro como a tarefa createLDDistCognitionCLScenario;

(3) a criação de fases mediante a decomposição da tarefa createDistCognitionPhase; e

(4) a criação de interações (direcionadas e cíclicas) e eventos IL mediante a decomposição da tarefa createDistCognitionInteractions, na qual definimos a criação das interações e eventos IL utilizando as tarefas createLDDemonstInstigDiscussionInteractions, createLDReqDetaillnstThinkingInteractions e createLDHowLearnerIsILEvent.

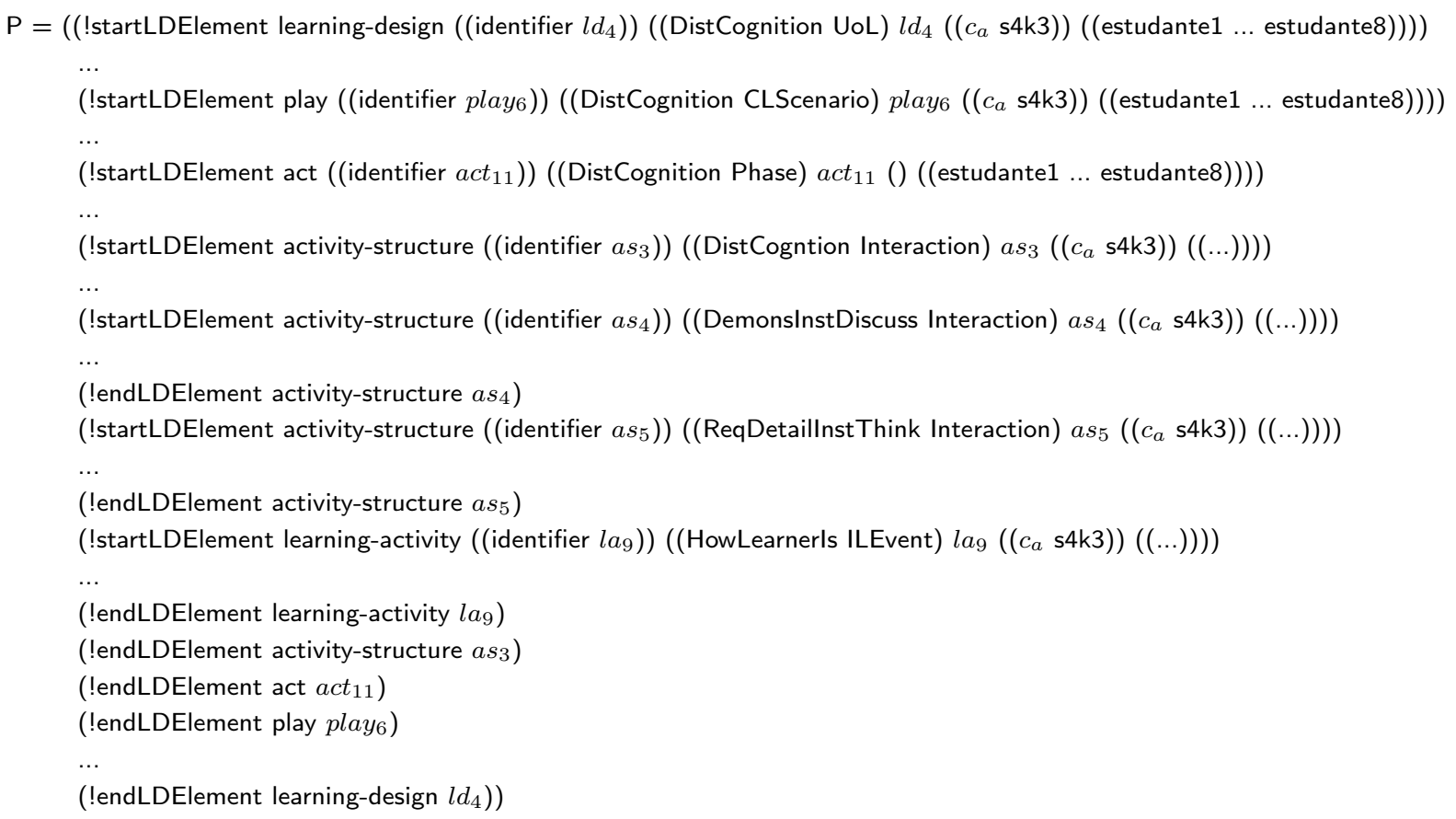


Sessão: Demostrar se a fórmula " $G=H \leftrightarrow\left(H \vee G^{\prime}\right)$ " é uma tautologia $\left(c_{a}\right.$ s4k3)

Objetivo educacional:

- Aperfeiçoamento continuo e gradual na demostração da fórmula $G$ e reestruturação do método de negação ou absurdo para considerar as relações entre os conhecimentos.

Modelo de estudante (nível de competência para $c_{a}$ ):

- Autônomo e restruturação (s4k3) - estudante1, estudante2, estudante3, estudante4, estudante7, estudante8.

- Associativo e restruturação (s3k3) - estudante5, estudante6.

- Participante pleno como instrutor: estudante1, estudante2, estudante3, estudante4.

- Participante pleno como aprendiz: estudante5, estudante6, estudante7, estudante8.

Resultado, plano de interações usando o microrroteiro "distributed cognition":

- Demonstrar como resolver o problema - Instigar a troca de ideias (interação cíclica, $a s_{3}$ )

- Demonstrar como resolver o problema (evento IL, $l a_{5}$ )

* Evento instrucional: Demonstrar.

* Evento de aprendizagem: Observar demonstração.

- Instigar a troca de ideias (evento IL, $l a_{6}$ )

* Evento instrucional: Requisição de opinião.

* Evento de aprendizagem: Exposição de opinião.

- Requisitar detalhes sobre o problema - Instigar o pensar (interação cíclica, $a s_{4}$ )

- Requisitar detalhes sobre o problema (evento IL, $l a_{7}$ )

* Evento instrucional: Requisição de pontos problemáticos.

* Evento de aprendizagem: Apresentação de pontos problemáticos.

- Instigar o pensar (evento IL, $l a_{8}$ )

* Evento instrucional: Argumentação.

* Evento de aprendizagem: Análise de argumentos.

- Notificar o estado corrente do estudante (evento IL, $l a_{9}$ )

- Evento instrucional: Dar informação.

- Evento de aprendizagem: Receber informação.

Tabela 6.9: Resultado esperado das interações definidas pelo microrroteiro distributed cognition 


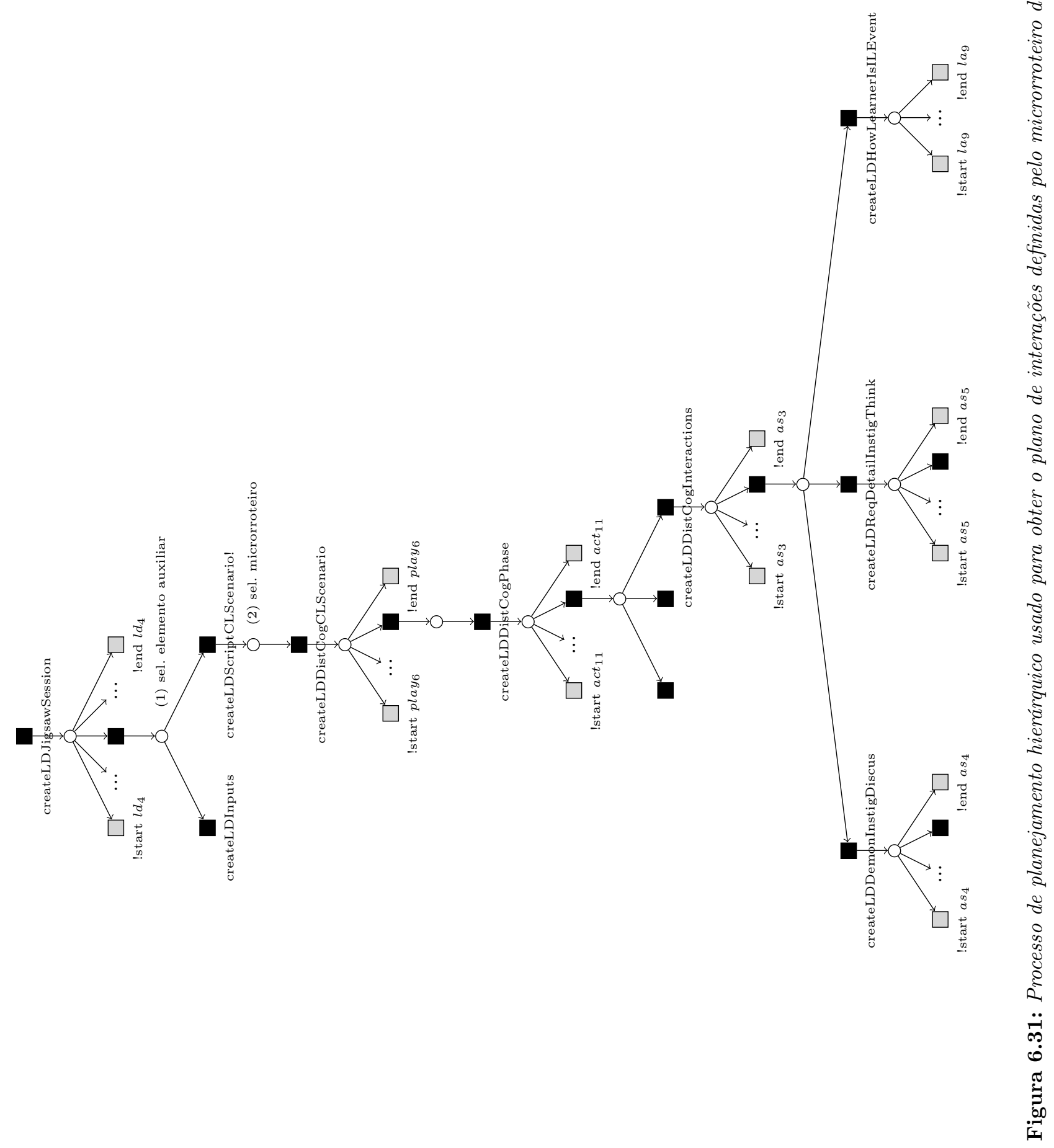


A Tabela 6.10 mostra as interfaces de usuário no sistema CopperCore, apresentando o plano de interações $\mathrm{P}$ obtido pelo gerador de cursos colaborativos definido pelo microrroteiro distributed cognition. As imagens na tabela mostram as interfaces para usuários com papéis de "participante pleno como instrutor" e "participante pleno como aprendiz".

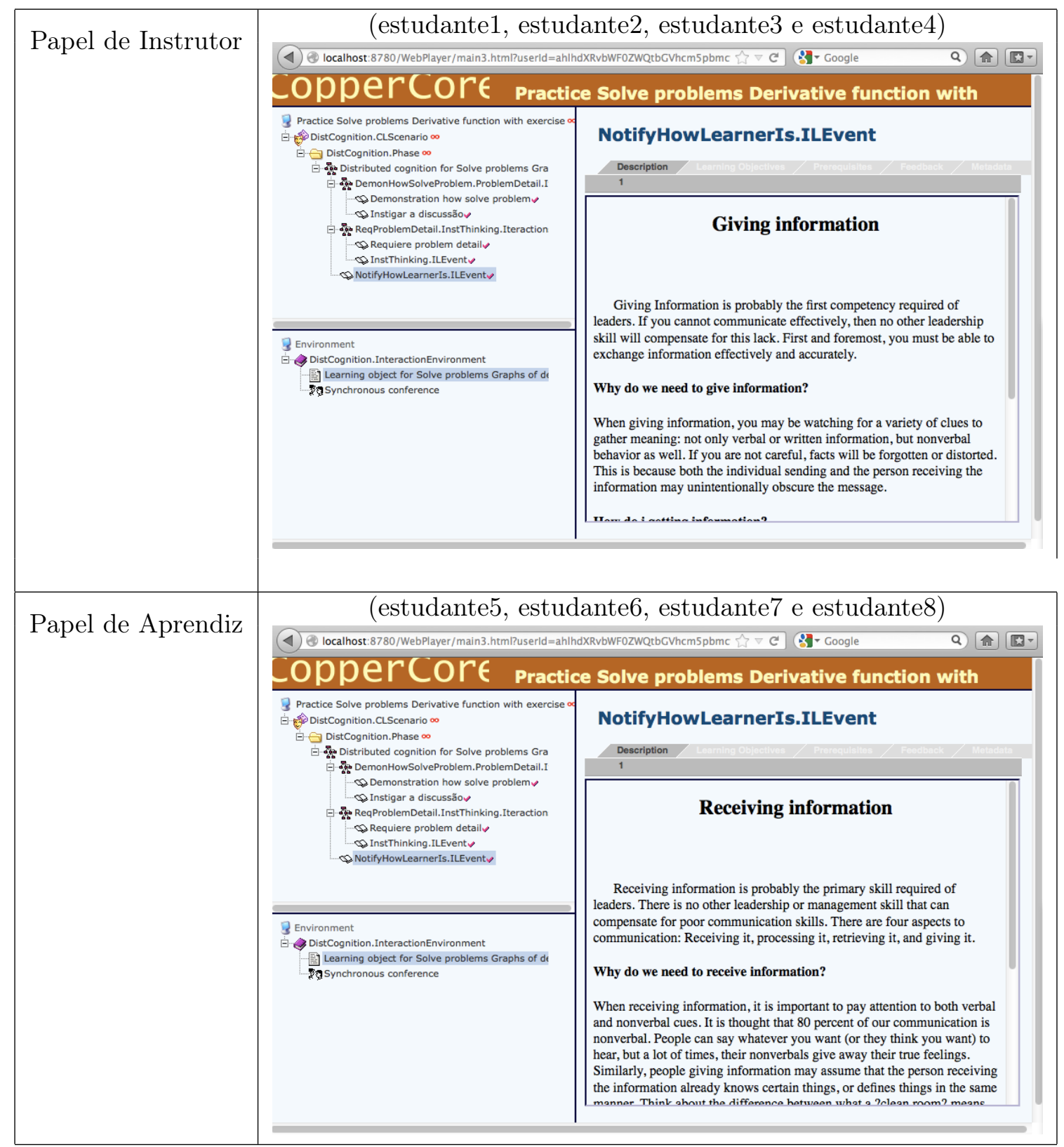

Tabela 6.10: Interfaces de usuário no CopperCore definidas pelo microrroteiro distributed cognition 


\section{Capítulo 7}

\section{Trabalhos relacionados}

Esta dissertação apresenta a modelagem do planejamento instrucional em ACSC como problema de planejamento hierárquico nos Capítulos 3 e 4, uma nova proposta em ACSC que possibilita o desenvolvimento de sistemas de tutores inteligentes como o gerador de curso colaborativos apresentado no Capítulo 5. A proposta se enfoca em facilitar a tarefa do projetista instrucional, fornecendo a geração automática de unidades de aprendizagem nas que são definidas roteiros colaborativos adaptados aos participantes, a tarefa é efetuada partir da definição de um estado inicial (definição dos modelos de domínio a ser ensinado e de estudante) e uma tarefa pública (definição dos objetivos educacionais e seleção de estudantes).

Nas seguintes seções abordaremos trabalhos relacionados revisados na literatura, discutiremos as diferenças e melhoras efetuadas em nosso trabalho. Os trabalhos relacionados são divididos em sistemas de tutores inteligentes (detalhados na Seção 7.1) e ferramentas de autoria das unidades de aprendizagem (detalhadas na Seção 7.2).

\subsection{Sistemas tutores inteligentes}

Desde o sistema proposto por Peachey e McCalla (1986) que propuseram a integração de técnicas de planejamento em IA e planejamento instrucional, têm-se desenvolvido vários sistemas tutores inteligentes que efetuam o planejamento instrucional de forma automatizada mediante a obtenção de planos de interações instrucionais adaptados a cada estudante.

Com o surgimento dos ambientes virtuais de aprendizagem, numerosas propostas de integração entre os sistemas tutores inteligentes e esses sistemas foram apresentados. Algumas propostas utilizam um etiquetado exaustivo de recursos instrucionais usando especificações IMS-MD e LOM, para a definição do modelo de domínio a ser ensinado. Algumas propostas usam planejamento hierárquico enquanto outras usam outras técnicas. No entanto, todas as propostas desenvolvidas ao longo destes 26 anos dependem dos seguintes supostos:

- O estado inicial do problema é baseado na informação extraída dos bancos de dados dos ambientes virtuais de aprendizagem. A informação do modelo de estudante em todos os casos é obtida dos registros de informação do estudante.

- Os objetivos educacionais são traduzidos como objetivos do problema de planejamento.

- As interações instrucionais do plano de solução são obtidos a partir de informações do modelo do domínio a ser ensinado, informação expressada nos metadados dos recursos. 


\subsubsection{O sistema GTE}

O sistema GTE (Generic Tutoring Environment) é um sistema de tutor inteligente que possibilita ao projetista instrucional a definição declarativa do modelo pedagógico como tarefas e métodos instrucionais (Van Marcke, 1998). Dessa maneira, GTE possibilita a representação das estratégias de planejamento instrucional de forma manual pelo projetista instrucional.

O algoritmo de planejamento em GTE é similar ao algoritmo de planejamento hierárquico no que o plano de ações é obtido mediante a decomposição sucessiva de tarefas usando as estruturas dos métodos até o nível de tarefas primitivas consistente de interações instrucionais. Van Marcke (1998) argumenta que o algoritmo proposto fornece uma grande flexibilidade comparada com os algoritmos de planejamento, pois ela avalia continuamente o estado de execução de cada tarefa. A desvantagem é que nenhuma análise do algoritmo existe (pelo menos não publicado) e sua complexidade é desconhecida.

A representação das estratégias instrucionais como um conjunto de tarefas e métodos no sistema GTE é avaliada em diferentes STIs como NOBIT (Cerri et al. , 1992), EPOS (Erol, 1990), TOSKA (Toska, 1991) e CAPRA (Fernández et al., 1988). No entanto, apesar da grande quantidade de estratégias instrucionais modeladas com GTE nestes sistemas, não existem estratégias que possam ser utilizadas no domínio de ACSC.

Neste trabalho de dissertação apresentamos a modelagem de estratégias extraídas do processo de planejamento instrucional usando padrões de roteiros no Capitulo 4 a serem utilizadas no domínio de ACSC.

\subsubsection{O sistema DCG}

Assim como GTE, o sistema DCG (Dynamic Courseware Generator) (Vassileva, 1998) é um dos STI mais antigos que utiliza tarefas e métodos de planejamento instrucional como representação do modelo pedagógico.

A modelagem do domínio a ser ensino em DCG efetua a classificação entre conceitos e recursos instrucionais, essa classificação é similar à efetuada em nossa modelagem proposta. As relações entre conceitos são definidas mediante estruturas de grafos AND/OR, na qual: os nós representam conceitos ou recursos, enquanto as arestas representam relações de pré-requisito, agregação, composição e semelhança. Logo, os nós recursos são relacionados aos nós conceitos mediante relaciones que definem a função pedagógica de cada recurso (por exemplo: questionário, exercícios e testes).

O processo de planejamento instrucional no sistema DCG é efetuado em duas fases. Na primeira fase, um plano de conteúdo é obtido mediante a seleção dos conceitos que irão ser abrangidos na unidade de aprendizagem. Assim, dado um estudante e um conceito objetivo, o plano de conteúdo é obtido no grafo de conceitos através das relações entre os conceitos conhecidos pelo estudante e o conceito objetivo. Na segunda fase, o plano de conteúdo define a sequência de apresentação dos recursos associados a cada um dos conceitos definidos pelo plano de conteúdo. 
Os planos de apresentação em DCG são obtidos mediante o uso de métodos de planejamento instrucional associados a cada um dos nós conceitos. Em nossa modelagem proposta de planejamento instrucional em ACSC, o plano de conteúdo é obtido usando as relações definidas entre elementos de conhecimento de tipo fundamental, enquanto o plano de apresentação consistente de elementos de conhecimento de tipo auxiliar são obtidos usando as diferentes estratégias apresentadas no Capítulo 4.

O sistema DCG é avaliado em um gerador de curso que efetua o sequenciamento de recursos instrucionais a serem utilizados em páginas de ensino dos conceitos (cada conceito apresenta mais de uma página). A geração de cada uma das páginas é efetuada em forma dinâmica a solicitude do estudante efetuando assim uma avaliação continua do nível de conhecimento possuído. Enquanto isso permite um planejamento instrucional mais adaptado, o estudante não é capaz de ver a estrutura da unidade de aprendizagem de forma completa, pois para avançar ao próximo conceito deveram ser geradas todas as páginas de ensino do conceito atual limitando a livre navegação.

O gerador de cursos colaborativos apresentado no Capítulo 5 efetua a geração da unidade de aprendizagem de forma completa antes de ser apresentada para os estudantes. Esse tipo de geração tem a vantagem de que a estrutura da unidade de aprendizagem é gerada de forma completa podendo ser navegar livremente através da mesma.

\subsubsection{O sistema PAIGOS}

O sistema PAIGOS (Ullrich, 2008) utiliza o algoritmo de planejamento JShop2 para efetuar a geração de planos baseada na descrição de estratégias pedagógicas como tarefa e métodos hierárquicos. Diferentemente dos sistemas DCG e GTE, em PAIGOS a modelagem do domínio a ser ensinado utiliza uma ontologia instrucional para efetuar a representação dos recursos instrucionais a serem sequenciados pelo planejador. Isso possibilita a reutilização das estratégias de planejamento instrucional em outros domínios sem efetuar mudanças no sistema.

Diferentemente de DCG, o plano de conteúdo é obtido como parte da unidade de aprendizagem, a qual consiste de uma sequência de seções com textos que descrevem o propósito de cada uma. Assim, os estudantes são fornecidos com informações que possam ajudá-los a entender o porque do planejamento e possibilitam a liberdade de escolha da atividade a serem realizadas.

Sete estratégias pedagógicas foram modeladas como tarefas e métodos hierárquicos baseadas em teorias de aprendizagem construtivistas e de planejamento instrucional com as quais foi avaliada a proposta em diferentes sistemas como LeActiveMath, MathCoach e TEAL.

O sistema PAIGOS apresenta o mesmo problema de GTE, ele não apresenta a modelagem de estratégias que possam ser utilizadas no domínio de ACSC. Assim, as estratégias apresentadas no Capítulo 4 serão utilizadas no domínio de ACSC para projetar roteiros colaborativos. 


\subsubsection{O sistema PASER}

O sistema PASER (Vrakas et al., 2007) é um STI que faz uso extensivo de metadados descritos nas especificações IMS-MD, IMS-RDCEO e IMS-LIP. Na modelagem do domínio a ser ensinado, os objetos de aprendizagem são descritos na especificação IMS-MD, enquanto os conceitos a serem ensinados são descritos como competências na especificação IMS-RDCEO; na modelagem de estudante são usadas as informações contidas nos perfis dos estudantes descritos na especificação IMS-LIP.

O sistema PASER diferentemente dos sistemas apresentados anteriormente efetua a conversão dos modelos de domínio a ser ensinado e de estudante em descrições de domínio e de problema de planejamento na linguagem PDDL. No processo de conversão um módulo denominado RDEVICE é responsável de efetuar a seleção de objetos de aprendizagem relevantes para um estudante baseado nos objetivos, preferências e conhecimentos possuídos pelo estudante, assim as descrições de domínio e de problema de planejamento é limitada unicamente a objetos relevantes.

Outra característica relevante em PASER similar à adotada em nossa proposta é que os planos de solução obtidos são convertidos em uma unidade de aprendizagem mediante um componente de conversão denominado CP-Producer que utiliza a especificação IMS-CP para descrever as sequências de conceitos e recursos instrucionais a serem usados pelos estudantes.

\subsubsection{O sistema ADAPTAPLAN}

O sistema ADAPTAPLAN (ADAPTAção baseada em aprendizagem, modelagem e PLANejamento de tarefas) (Garrido et al., 2008) efetua planejamento instrucional automatizado mediante sequências individualizadas de atividades descritas na especificação IMS-LD. O processo de planejamento diferente dos sistemas de planejamento apresentados anteriormente efetua a conversão do plano obtido em elementos da especificação IMS-LD (nível A).

As sequências de atividades obtidas para cada estudantes são generalizadas para todos os estudantes mediante a geração de restrições descrita na especificação IMS-LD (nível B). Embora a generalização das sequências de atividades possibilite a definição de atividades a serem efetuadas por um grupo de participantes, elas carecem de instruções prescritas de como deveriam ser efetuadas essas atividades (denominadas sessões de aprendizagem).

Em nosso modelo de planejamento instrucional apresentado nesta dissertação as instruções são definidas nos eventos IL na que são especificadas as ações a serem efetuadas mediante recursos instrucionais. 


\subsection{Ferramentas de autoria de autoria das unidades de aprendizagem}

A seguir apresentamos um resumo de ferramentas de autoria das unidades de aprendizagem encontradas na literatura.

\subsubsection{COOL MODES}

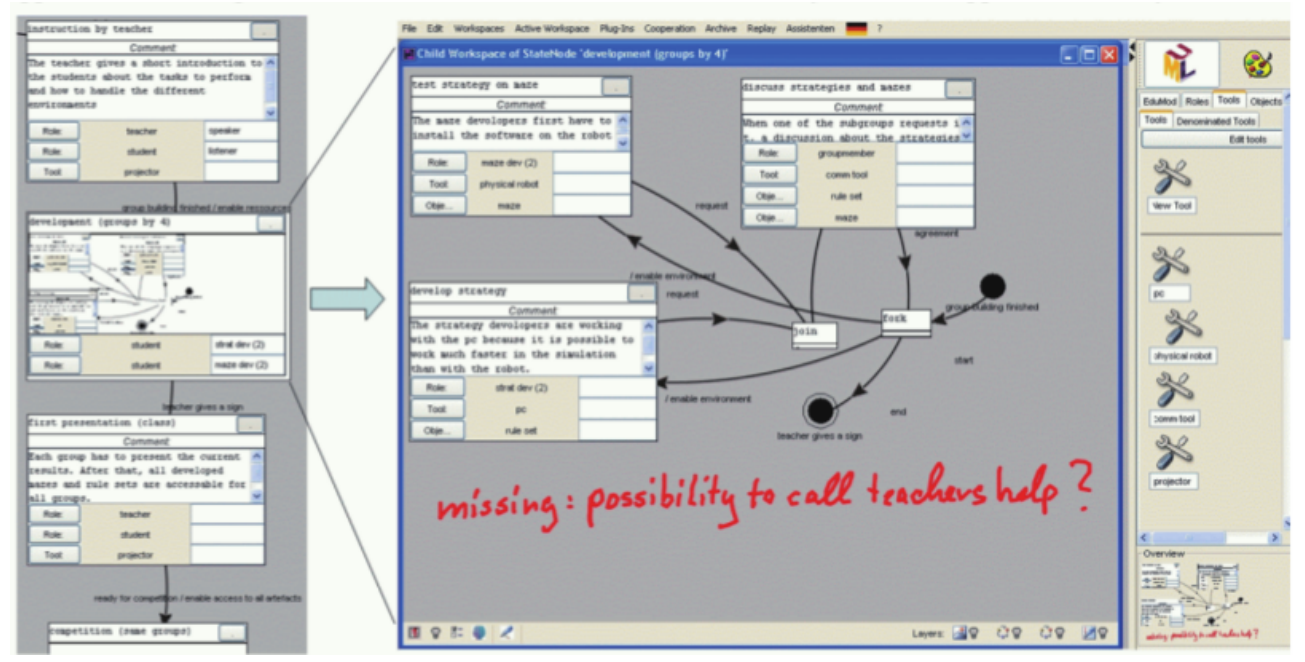

Figura 7.1: Interface gráfica de COOL MODES (Miao, 2005)

A ferramenta de autoria COOL MODES (COllaborative Open Learning MODEling System) desenvolvida pelo grupo COLLIDE da universidade de Duisburg-Essen possibilita o desenvolvimento de roteiros colaborativos mediante a definição de diagramas baseados em grafos (Miao, 2005; Pinkwart, 2003).

A Figura 7.1 mostra a interface gráfica de COOL MODES, a interface é dividida em um diagrama de fases no lado esquerdo e um diagrama de atividades no lado direito. Nos diagramas cada nó é uma fase ou atividade e cada seta é uma transição possível. Em cada um dos nós são definidos informações (definidas como recursos instrucionais) dos papéis, objetos de aprendizagem e serviços de apoio à aprendizagem a serem empregados durante a execução do roteiro colaborativo.

Nosso modelo proposto diferentemente de COOL MODES não precisa a definição de todas as fases, atividades, papeis e objetos de aprendizagem para o desenvolvimento de roteiros adaptados às características dos participantes.

\subsubsection{COLLAGE}

A ferramenta de projeto instrucional gráfica COLLAGE (COLlaborative LeArning desiGn Editor) (Hernández-Leo et al. , 2006) desenvolvida pelo grupo de pesquisas em Sistemas Cooperativos da universidade de Valladolid de Espanha possibilita a criação de roteiros colaborativos mediante o uso de padrões de roteiros. Em vez de definir um roteiro colaborativo de zero como em COOL MODES, o usuário utiliza um padrão como apoio ao desenvolvimento de roteiros específicos. 
A Figura 7.2 mostra a interface inicial de COLLAGE na qual o usuário define os objetivos pedagógicos a serem atingidos e a complexidade dos roteiro. Dessa maneira, o sistema identifica os padrões de interação que podem ser utilizados para atingir os objetivos pedagógicos. $\mathrm{Na}$ ferramenta, podem ser utilizados os padrões brainstorming, jigsaw, pyramid, simulation, think pair share e thinking aloud pair problem solving.

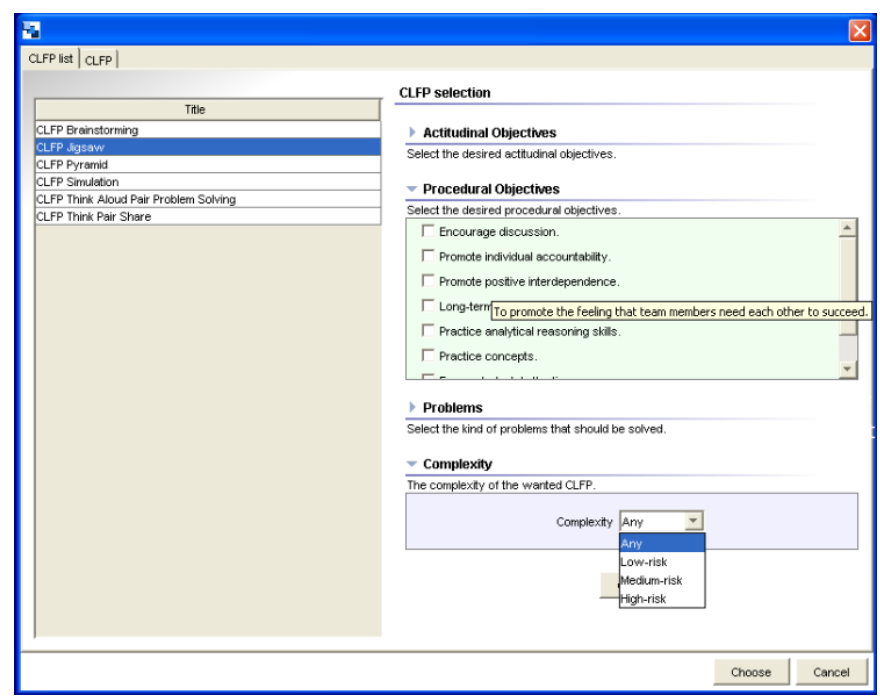

Figura 7.2: Interface gráfica de COLLAGE

Embora o processo de planejamento instrucional de roteiros colaborativos adaptado às características individuais seja mais simples em COLLAGE, o sistema não apresenta forma de seleção automática dos padrões a serem utilizados, nem como efetuar a combinação e concatenação deles. Nosso modelo de planejamento instrucional como problema de planejamento hierárquico apresenta solução a este problema ao definir a representação de regras de planejamento instrucional como precondições lógicas e condições relativas.

\subsubsection{CHOCOLATO}

O sistema CHOCOLATO (Concrete Helpful Ontology-aware COllaborative Learning Authoring TOol) é uma ferramenta de autoria que possibilita a formação, planejamento e análise de sessões colaborativas. O sistema efetua essas tarefas mediante o uso de ontologias que auxiliam tanto ao projetista instrucional a formação de grupos, a atribuição de papéis aos estudantes e o planejamento de interações a serem efetuadas nas sessões colaborativas (Isotani e Mizoguchi, 2007; Isotani et al., 2010b).

A interface principal de CHOCOLATO apresentada na Figura 7.3 mostra algumas das funcionalidades do sistema, onde é possível: (1) selecionar as estratégia de aprendizagem em função do objetivo grupal; (2) selecionar os tópicos, habilidades e conhecimento a ser ensinado; e (3) efetuar a formação de grupos e atribuição de papéis.

Nossa proposta de planejamento utiliza o algoritmo de formação de grupos proposto em CHOCOLATO, assim como a representação de cenários colaborativos para efetuar a modelagem de microrroteiros apresentada na Seção 4.2. 


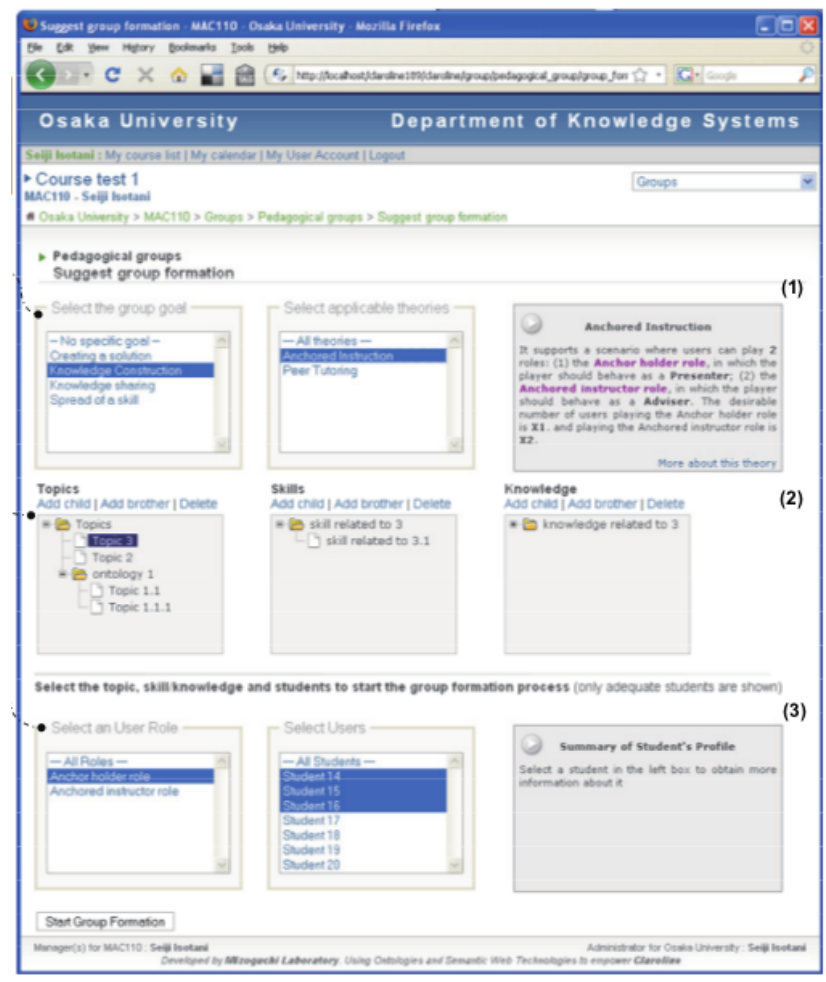

Figura 7.3: Interface principal de CHOCOLATO (Isotani et al., 2010b)

\subsection{Considerações finais}

Os STIs apresentados facilitam o processo de planejamento instrucional usando técnicas de planejamento em IA favorecendo um processo eficiente (que consome menos tempo) e efetivo (adaptado às necessidades de cada estudante). No entanto, os planos obtidos não possibilitam a definição de atividades a serem efetuadas em grupos, nem informação de como os estudantes deveriam interagir entre eles para atingir objetivos educacionais definidos pelo projetista.

As ferramentas de autoria possibilitam o desenvolvimento de unidades de aprendizagem, mas não fornecem um planejamento automatizado que possibilite reduzir o custo em tempo e esforço necessário para desenvolver roteiros colaborativos adaptados as características individuais dos estudantes. Assim, neste trabalho foi efetuado uma modelagem de planejamento instrucional nos Capitulo 3 e 4 que possibilita integrar as vantagens dos STI no desenvolvimento das unidades de aprendizagem usando padrões de roteiros colaborativos. 


\section{Capítulo 8}

\section{Conclusões e trabalhos futuros}

Esta dissertação apresentou a modelagem do planejamento instrucional em ACSC como um problema de planejamento hierárquico, uma abordagem que utiliza o processo de planejamento instrucional usando padrões de roteiros para representar estratégias de planejamento instrucional como tarefas e métodos hierárquicos. A modelagem proposta foi implementada no gerador do curso colaborativos que utiliza o sistema de planejamento hierárquico denominado JSHOP2ip.

Os esquemas de representação de estratégias de planejamento instrucional apresentados no modelo pedagógico (Capítulo 4) possibilitam a representação de novas estratégias. Utilizando esses esquemas foram modeladas para padrões de microrroteiros 12 estratégias de eventos IL, 16 estratégias de interações cíclicas e direcionadas, 6 estratégias de padrões de interação de microrroteiros, 6 estratégias de fases dos cenários colaborativos, 9 estratégias de definição de estratégias de aprendizagem, 10 estratégias de papéis colaborativos e 6 estratégias de cenários colaborativos. Empregando os esquemas também foram modeladas para padrões de macrorroteiros 4 estratégias de sessões de aprendizagem, 8 estratégias de atividades de grupo, 10 estratégias de fases e 3 estratégias de macrorroteiros.

O componente mediador no gerador de cursos possibilita efetuar consultas em repositórios externos mediante a tradução dos termos de chamada de consultas aos modelos de domínio a ser ensinado e de estudante em requisições de tipo GET e POST que devolvem o resultado no formato XML. O gerador pode abstrair detalhes das consultas e ser reutilizado em outro domínio empregando as mesmas estratégias de planejamento instrucional.

A avaliação efetuada neste trabalho mostra que a modelagem proposta no gerador de cursos é viável computacionalmente, devido a que em média são gerados mais de 150 elementos de roteiros em menos de um segundo. A avaliação também é efetuada na modelagem de estratégias de planejamento instrucional usando como exemplo o padrão de microrroteiro peer tutoring e o padrão de macrorroteiro jigsaw. Finalmente, a avaliação da saída do planejador no modelo proposto demostra viabilidade em situações reais. 


\subsection{Trabalhos futuros}

Nesta seção apresentamos os trabalhos que podem complementar o trabalho desenvolvido.

\section{- Generalização das estratégias de criação de fases nos macrorroteiro}

As estratégias de criação de fases nos macrorroteiros colaborativos não apresentam um esquema de representação comum. No entanto, todas as estratégias têm como objetivo efetuar a formação de grupos, assim explorando mais estratégias de criação de fases deve ser possível estabelecer um esquema de representação. Além disso, todas as estratégias de criação de fases, com exceção da criação da fase individual, empregam o termo de chamada (call CLGrouping ...), o que reforça a existência de um esquema de representação.

- Modelagem de estratégias de planejamento instrucional usando padrões do nível de recursos e do nível de papéis e mecanismos comuns

Os padrões de roteiros colaborativos são classificados em quatro tipos (nível do fluxo de aprendizagem colaborativa, nível de atividades, nível de recursos e nível de papéis e mecanismos comuns). Nesta dissertação efetuamos a modelagem de estratégias de planejamento instrucional que utilizam unicamente padrões do nível de fluxo de aprendizagem e do nível de atividade. Um estudo de padrões do nível de recursos e do nível de papéis e mecanismos comuns deve ser realizado para definir a modelagem de estratégias de planejamento instrucional empregando os princípios da modelagem apresentada no Capítulo 3.

\section{- Desenvolvimento de uma ferramenta de autoria de estratégias de planejamento instrucional}

Os esquemas de representação de estratégias de planejamento instrucional obtidos nesta dissertação fazem do modelo pedagógico um candidato ao desenvolvimento de uma ferramenta de autoria. A ferramenta de autoria de planejamento instrucional a ser desenvolvida usando esses esquemas de representação deve apresentar uma interface de usuário na qual deve ser possível gerenciar (criar, editar e apagar) as estratégias de planejamento instrucional mediante uma interface gráfica de usuário. Além disso, outra característica da ferramenta de autoria deve ser a possibilidade de representar estratégias de planejamento instrucional mais específicas dependentes do domínio a ser ensinado.

\section{- Melhorias no componente mediador}

O componente de mediador traduz as consultas efetuadas aos modelos de domínio a ser ensinado e de estudantes em métodos de requisição GET e POST que efetuam consultas em repositórios externos. No entanto, essas requisições não utilizam um padrão ou especificação de consultas. Uma proposta de trabalho futuro é efetuar melhorias no componente mediador a fim de dar suporte a consultas SQI (Simon et al. , 2005) para recuperar as informações de diferentes repositórios nas especificações IMS-MD e IMS-LIP.

Outra melhora poderia incluir a implementação de uma cache que deverá arquivar resultados de consultas prévias efetuadas aos repositórios externos. Isso deve minimizar a latência da rede e o tempo de reposta das consultas. 


\section{- Integração com ambientes virtuais de aprendizagem}

CopperCore não pode ser usado como um produto final para à execução de roteiros colaborativos porque ele não fornece interface de usuário, nem serviços de autorização e autenticação. Portanto, para a aplicação em casos reais de uso, um trabalho futuro é a integração do CopperCore em ambientes virtuais de aprendizagem como Moodle, Sakai etc.

Outra alternativa para a integração do gerador de cursos com ambientes virtuais de aprendizagem é desenvolver novos algoritmos de conversão do plano solução em formatos específicos de curso. Isto é, desenvolver novos métodos de conversão na classe LDELement e novas classes que implementam a interface IPublishHandler (detalhados no Capítulo 5).

No desenvolvimento de software educacional, a modelagem apresentada nesta dissertação pode ser utilizada para definir um componente que auxilie o projetista instrucional no desenvolvimento, adaptação e personalização de unidades de aprendizagem de maneira fácil, devido à independência do modelo pedagógico fornecida pelo componente Mediador nos axiomas de consultas aos modelos de estudante e de domínio a ser ensinado. Por exemplo, no desenvolvimento de ferramentas de autoria, os serviços Web que fornece o gerador de cursos podem ser usados para desenvolver um componente de apoio que forneça dicas de como definir os roteiros colaborativos.

\subsection{Produções ao longo do mestrado}

Ao longo do mestrado, produzimos o artigo intitulado "Uso da técnica de planejamento hierárquico no sequenciamento automático de atividades colaborativas" aceito no XXI Simpósio Brasileiro de Informática na Educação, em 2010. 


\section{Apêndice A}

\section{Planejamento clássico}

Em planejamento clássico, o plano de solução para atingir os objetivos é obtido da busca no espaço de estados das ações que devem ser adicionadas ao plano, para que depois da execução um estado meta seja alcançado. A fim de manter uma semântica bem definida na representação do estado corrente e ações, a técnica de planejamento clássico utiliza um modelo simplificado e restrito pelas seguintes suposições (Ghallab et al., 2004):

A0: $\Sigma$ é finito. O sistema de transição de estados tem um número finito de estados.

A1: $\Sigma$ é completamente observável. O sistema de planejamento sabe com exatidão qual é o estado atual do mundo.

A2: $\Sigma$ é determinístico. A ação efetuada no sistema de transição de estado leva a um único estado possível.

A3: $\Sigma$ é estático. No sistema de transição de estados, não existem eventos externos ao agente, o único que manipula o estado do mundo é o agente.

A4: Metas restritivas. Os objetivos são representados por um conjunto de estados meta.

A5: Planos sequenciais. O plano solução é uma sequência de ações a serem executadas na ordem indicada.

A6: Tempo implícito. A ação efetuada pelo sistema é executada uma por vez e não há informações sobre a duração.

A7: Planejamento offline. O plano de ações obtido pelo planejador é executado pelo agente sem realimentação sobre o processo de execução do plano, isto quer dizer que uma vez obtido o plano ele não muda durante o processo de execução.

Os planejadores que utilizam a técnica de planejamento clássico recebem como entrada a descrição do problema de planejamento formalizada como a n-upla $P=\left\langle D, s_{0}, G\right\rangle$, em que $D$ é a descrição do sistema de transição de estados $\Sigma$ nomeado domínio de planejamento, $s_{0}$ é a representação do estado inicial e $G$ é a representação dos objetivos a serem atingidos.

A descrição do dominio de planejamento $D$ em planejamento clássico é formalizado como a n-upla $\langle S, A, \gamma\rangle$, em que: 
- $S=\left\{s_{1}, s_{2}, \ldots\right\}$ é um conjunto finito ou recursivamente enumerável de estados;

- $A=\left\{a_{1}, a_{2}, \ldots\right\}$ é um conjunto finito ou recursivamente enumerável de ações; e

- $\gamma: S \mathrm{x} A \rightarrow S$ é a função de transição de estados que define como uma ação muda de estado.

O plano de solução consiste em uma sequência de ações $\pi=\left(a_{1}, a 2, \ldots, a_{n}\right)$ que, ao serem executadas pelo controlador a partir do estado inicial $s_{0}$, levam a um estado meta $s_{g}$ que satisfaz os objetivos definidos em $G$; isto é $\gamma\left(s_{0}, a_{1}\right)=s_{1}, \gamma\left(s_{1}, a_{2}\right)=s_{2}, \ldots, \gamma\left(s_{n-1}, a_{n}\right)=s_{g}$.

Os problemas de planejamento envolvem uma grande quantidade de estados e ações, portanto, é necessário utilizar meios simbólicos de uma linguagem $L$ para reduzir a representação explícita do domínio de planejamento. Assim, Ghallab et al. (2004) apresentam três tipos de representação: a representação em teoria de conjuntos, a representação clássica e a representação com variáveis de estado. As duas primeiras são discutidas a seguir.

\section{A.1 Representação em teoria de conjuntos}

A teoria de conjuntos representa estados e ações como um conjuntos de proposições, no qual um elemento não representado explicitamente no estado $s$ é interpretado como falso.

Seja $L=\left\{p_{1}, p_{2}, \ldots, p_{n}\right\}$ um conjunto finito de símbolos de proposição utilizados para representar a descrição do sistema de transição de estados $\Sigma$, um domínio de planejamento $D$ em teoria de conjuntos é representado como uma n-upla $D=(S, A, \gamma)$, na qual:

- Cada estado $s_{i} \in S$ é composto por um subconjunto de $L$, no qual a proposição $p$ é verdadeira se e somente se $p \in s_{i}$, e $p$ é falsa se $p \notin s_{i}$.

- Cada ação $a_{i} \in A$ é uma expressão sintática de $L$, denotada pela n=upla

$$
a=\left\langle\operatorname{precond}(a), \text { efeitos }^{-}(a), \text { efeitos }^{+}(a)\right\rangle,
$$

na qual: as pré-condições precond( $a$ ) são proposições que devem ser verdadeiras no estado corrente $s_{i}$ para efetuar a ação $a$; os efeitos negativos efeitos $^{-}(a)$ são proposições a serem removidas do estado corrente; e os efeitos positivos $\left(\right.$ efeitos $\left.^{+}(a)\right)$ são proposições a serem adicionadas.

- A função de transição de estados é $\gamma(s, a)=\left(s \backslash\right.$ efeitos $\left.^{-}(a)\right) \cup$ efeitos $^{+}(a)$. Dessa forma, cada ação $a$ aplicável num estado $s_{i}$ leva a um outro estado válido $s_{j} \in S$.

Exemplo A.1. Utilizando os símbolos t1-in-loc1 e t2-in-loc2 para representar as localizações do transporte t1; e os símbolos p1-in-loc1, p1-in-loc2 e p1-in-t1 para representar localizações do pacote $\mathrm{p} 1$. O estado inicial $\mathrm{s}_{0}$ de um problema de planejamento logístico de transporte de pacotes mostrado na Figura A.1 é representado por $\mathrm{s}_{0}=\{\mathrm{t} 1$-in-loc1, p1-in-loc2 $\}$. No problema, a ação de mover o transporte $\mathrm{t} 1$ da localização loc1 até a localização loc2 é representada pela n-upla $\mathrm{a}_{1}=\langle$ $\{\mathrm{t} 1$-in-loc1\}, \{t1-in-loc1\}, \{t1-in-loc2\} $\rangle$. 


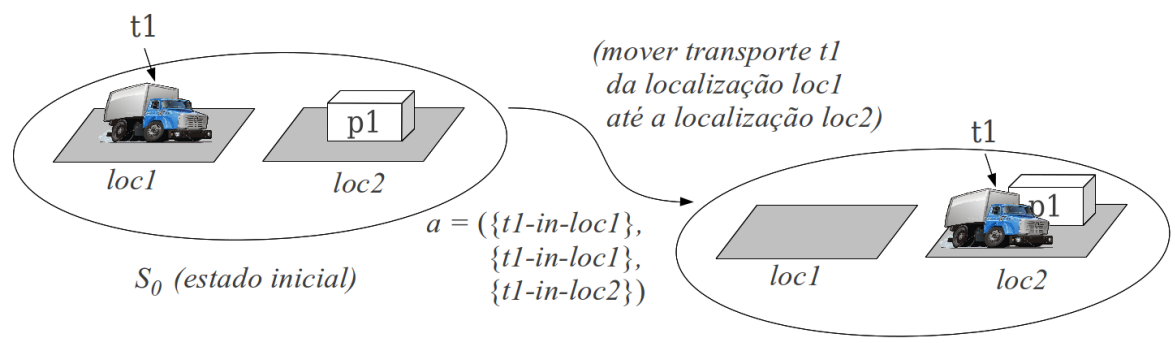

Figura A.1: Exemplo de representação em teoria de conjuntos

\section{A.2 Representação clássica}

A representação clássica generaliza a representação em teoria dos conjuntos utilizando notação proveniente de uma linguagem de primeira ordem, na qual existe um número finito de símbolos de predicados e constantes. Assim, conectivos lógicos são utilizados no lugar de proposições, enquanto os estados são representados como um conjunto de literais totalmente instanciados.

Definição A.1. Um estado $s$ é um conjunto de átomos lógicos totalmente instanciados composto apenas de símbolos de constante.

Dizemos que um átomo $p$ é verdadeiro no estado $s$ se e somente se $p \in s$; e dizemos que um estado $s_{g}$ atinge os objetivos $G\left(s_{g}\right.$ satisfaz $\left.G\right)$, se e somente se todo átomo positivo de $G$ está em $s_{g}$ e nenhum átomo negativo de $G$ está em $s_{g}$.

Exemplo A.2. Considere o problema de planejamento logístico da Figura A.2 em que há: cinco localizações loc1, loc2, loc3, loc4 e loc5; dois transportes t1 e t2; e três pacotes p1, p2 e p3. Seja $L=\{\operatorname{loc} 1, \operatorname{loc} 2, \operatorname{loc} 3, \operatorname{loc} 4, \operatorname{loc} 5, \mathrm{t} 1, \mathrm{t} 2, \mathrm{p} 1, \mathrm{p} 2, \mathrm{p} 3\}$ o conjunto de símbolos constantes, utilizamos o símbolo de predicado (em $x y$ ) para representar a localização de um determinado transporte ou pacote $x$ no lugar $y$ e o símbolo de predicado (disponível $x$ ) para representar a disponibilidade do transporte $x$. Dessa maneira, o estado inicial $s_{0}$ mostrado na figura é representado por:

$S_{0}=\{($ em p1 loc1), (em p2 loc2), (em t1 loc5), (em t2 loc3), (disponível t1), (disponível t2)\}

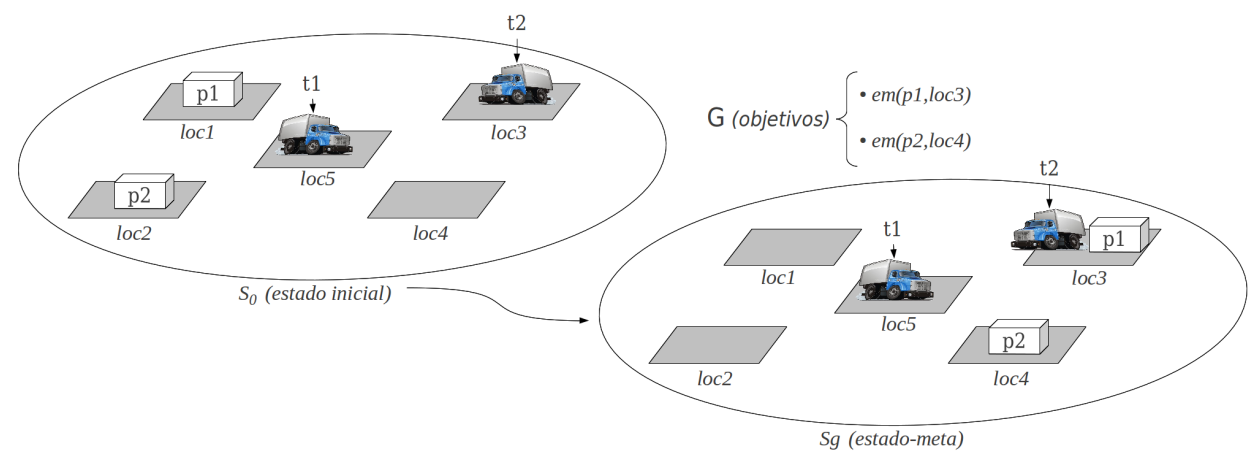

Figura A.2: Exemplo de representação clássica 
Na representação clássica, operadores de planejamento são utilizados para generalizar o conjunto de ações $A$ do domínio de planejamento.

Definição A.2. Um operador de planejamento é definido formalmente pela tripla

$$
o=\langle\text { nome }(o), \text { precond }(o), \text { efeitos }(o)\rangle, \text { tal que: }
$$

- nome (o) é o nome do operador expresso da forma $\left(n x_{1} x_{2} \ldots x_{k}\right)$, em que $n$ é um símbolo constante que define um nome único entre os operadores e $x_{1}, x_{2}, \ldots, x_{k}$ são símbolos variáveis que definem a lista de argumentos;

- precond(o) é o conjunto de pré-condições expresso por literais que determinam a aplicabilidade das ações generalizadas pelo operador; e

- efeitos (o) é o conjunto de efeitos positivos, efeitos $^{+}(o)$, e efeitos negativos, efeitos ${ }^{-}(o)$, do conjunto de ações generalizadas pelo operador.

A função de transição de estados $\gamma$ é representada em teoria de conjuntos como:

$$
\gamma(s, a)=\left(s \backslash \text { efeitos }^{-}(a)\right) \cup \text { efeitos }^{+}(a)
$$

Exemplo A.3. No domínio de planejamento da Figura A.2, os operadores para efetuar a operação logística de transporte de pacotes são:

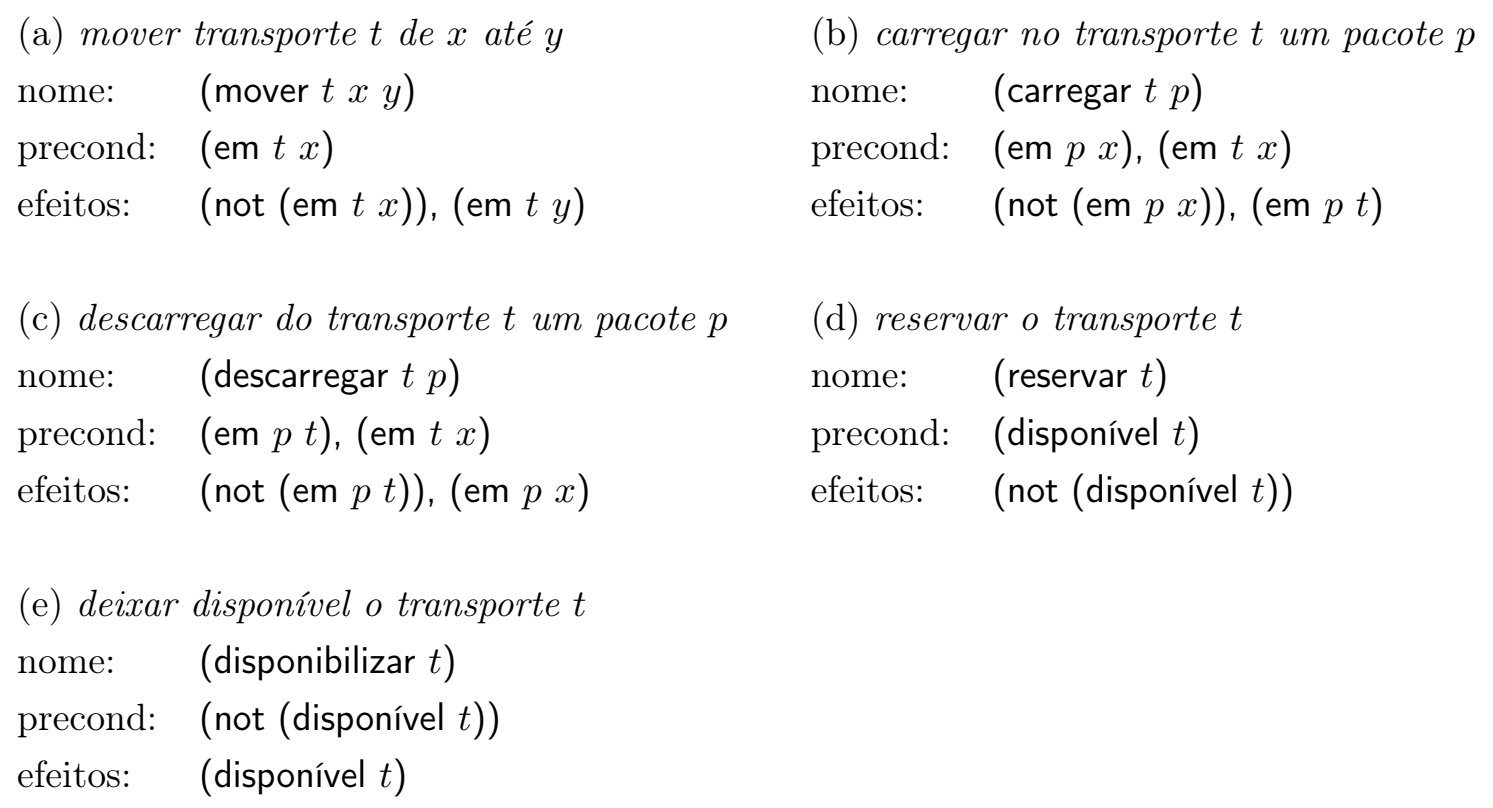




\section{Apêndice B}

\section{Formalismo da linguagem JSHOP2ip}

O sistema de planejamento JSHOP2ip utiliza as estruturas apresentadas a seguir para efetuar a descrição do domínio e problema de planejamento. Os operadores, métodos e axiomas no domínio de planejamento e os átomos e rede de tarefa inicial no problema de planejamento são compostos de expressões lógicas que combinam átomos lógicos por meio de conjunções e disjunções. Apresentamos a seguir a descrição das estruturas empregadas.

\section{B.1 Símbolos}

A linguagem de primeira ordem $L$ apresenta um vocabulário definido como a estrutura

$$
\left\langle V^{\prime}, C^{\prime}, P^{\prime}, F^{\prime}, T^{\prime}, N^{\prime}, M^{\prime}\right\rangle,
$$

em que: V' é um conjunto infinito de símbolos de variável; C' é um conjunto finito de símbolos de constante; $\mathrm{P}^{\prime}$ é um conjunto finito de símbolos de predicado; $\mathrm{F}^{\prime}$ é um conjunto finito de símbolos de função; T' é um conjunto finito de símbolos de tarefa composta; N' é um conjunto finito de símbolos de tarefa primitiva que denotam ações; e M' é um conjunto infinito de símbolos de nome. Os símbolos utilizam as seguintes convenções:

- símbolos de variável iniciam com uma marca de interrogação, por exemplo ?var;

- símbolos de tarefa primitiva iniciam com uma marca de exclamação, por exemplo !pickup;

- símbolos de constante, de predicado, de função e de tarefa composta iniciam com uma letra.

Nas estruturas a seguir colchetes representam termos opcionais a ser definidos na modelagem.

\section{B.2 Termos}

Um termo é quaisquer das estruturas seguintes: um símbolo de variável, um símbolo de constante, um símbolo de nome, um valor numérico, uma lista de termos ou um termo de chamada de função. 
Lista de termos Uma lista de termos é definido mediante a estrutura:

$$
\left(t_{1} t_{2} \ldots t_{n}[. l]\right)
$$

na qual: $t_{1}, t_{2}, \ldots, t_{n}$ são termos e I é uma lista de termos. Os termos da lista I são incluídos depois do termo $t_{n}$.

Termo de chamada Um termo de chamada de função é definido mediante a estrutura:

$$
\text { (call } \left.f \mathrm{t}_{1} \mathrm{t}_{2} \ldots \mathrm{t}_{n}\right) \text {, }
$$

onde $f$ é um símbolo de função e cada $\mathrm{t}_{i}$ é um termo. O termo de chamada de função é utilizado para efetuar cálculos complexos ou consultas externas utilizando os parâmetros $\mathrm{t}_{1}, \mathrm{t}_{2}, \ldots, \mathrm{t}_{n}$. Os valores de $f$ primitivos são $<,<=,=,>,>=, !=,+,-,{ }^{*}, /, \hat{,}$, e Member.

\section{B.3 Átomos lógicos}

Um átomo lógico é definido mediante a estrutura:

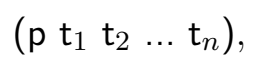

onde p é um símbolo predicado e cada $\mathrm{t}_{i}$ é um termo.

\section{B.4 Expressão lógica}

Uma expressão lógica é um átomo lógico ou uma estrutura complexa composta de conjunções, disjunções, negações, implicações, atribuições ou termos de chamada.

Conjunção Uma conjunção é definida mediante a estrutura: ([and] $L_{1} L_{2} \ldots L_{n}$ ), onde cada $L_{i}$ é uma expressão lógica.

Disjunção Uma disjunção é definida mediante a estrutura: (or $L_{1} L_{2} \ldots L_{n}$ ), onde cada $L_{i}$ é uma expressão lógica.

Negação Uma negação é definida mediante a estrutura: (not L), onde L é uma expressão lógica.

Implicação Uma implicação é definida mediante a estrutura: (imply $Y$ Z), onde $Y$ e $Z$ são expressões lógicas que definem uma implicação lógica. Isto é $(Y \leftarrow Z)$.

Quantificador Universal Um quantificador universal é definida mediante a estrutura: (forall V Y Z), na qual Y e Z são expressões lógicas e $V$ é uma lista de variáveis e $Y$ são expressões lógicas. A expressão de quantificação universal efetua a substituição da lista de variáveis $\mathrm{V}$ em $\mathrm{Y}$ para avaliar o valor de verdade nas expressões lógicas $Z$.

Atribuição Uma atribuição é definida mediante a estrutura: (assign v t), onde v é um símbolo de variável e $\mathrm{t}$ é um termo. A atribuição efetua a substituição do termo t no símbolo de variável v. 


\section{B.5 Pré-condições lógicas}

Uma pré-condição lógica é uma expressão lógica ou qualquer uma das duas seguintes formas condicionais de: primeira pré-condição satisfazível e pré-condição ordenada.

Primeira pré-condição lógica satisfazível Uma primeira pré-condição lógica satisfazível é definida mediante a estrutura: (:first L), onde L é uma expressão lógica. Se a expressão lógica L é satisfazível durante o processo de planejamento, o restante de condições alternativas não serão avaliadas.

Pré-condição lógica ordenada Uma pré-condição lógica ordenada tem a forma: (:sort-by v [f] L), onde v é um símbolo de variável, f é um nome da classe que implementa a interface Comparator de Java (os valores primitivo de $f$ podem ser $<$ e $>$ ) e $L$ é uma expressão lógica. A pré-condição lógica ordenada faz com que se efetue a substituição do símbolo variável v na expressão lógica $L$ em uma ordem especificada pela função de comparação $f$.

\section{B.6 Axiomas}

Um axioma é definido mediante a estrutura:

$$
\left(:- \text { a }\left[\text { name }_{1}\right] \mathrm{L}_{1}\left[\text { name }_{2}\right] \mathrm{L}_{2} \ldots\left[\text { name }_{n}\right] \mathrm{L}_{n}\right)
$$

onde a é um átomo lógico e os restantes de elementos da estrutura [name $\left.{ }_{1}\right] \mathrm{L}_{1}$ [name $\mathrm{n}_{2} \mathrm{~L}_{2} \ldots$ [name $\left.{ }_{n}\right] L_{n}$ são um conjunto de pré-condições lógicas $L_{i}$ com nome name ${ }_{i}$. O nome nas precondições lógicas tem unicamente propósito de depuração e não apresentam significado semântico. O axioma a é verdadeiro se $L_{1}$ é verdadeiro; ou se $L_{1}$ é falso e $L_{2}$ é verdadeiro; ou se $L_{1}$ e $L_{2}$ são falsos e $L_{3}$ é verdadeiro; ... ; ou se $L_{1}, L_{2}, \ldots, L_{n-1}$ são falsos e $L_{n}$ é verdadeiro.

\section{B.7 Um átomo de tarefa}

Um átomo de tarefa é definido mediante a estrutura:

$$
\text { ([:immeditate } \left.] \mathrm{s} \mathrm{r}_{1} \mathrm{r}_{2} \quad \ldots \quad \mathrm{r}_{n}\right)
$$

onde s é um símbolo de tarefa e os argumentos $r_{1}, r_{2}, r_{3}, \ldots, r_{n}$ são termos. Um átomo de tarefa é primitivo se o símbolo de tarefa s é um símbolo de tarefas primitiva, isto é $\mathrm{s} \in \mathrm{N}^{\prime}$; e um átomo de tarefa é composta se o símbolo de tarefa s é um símbolo de tarefas composta, isto é $\mathbf{s} \in \mathrm{T}^{\prime}$. Um átomo de tarefa sem a palavra :immediate é chamada de ordinário, enquanto se a tarefa inclui a palavra :immediate é chamada de tarefa de alta prioridade.

\section{B.8 Lista de tarefas}

Uma lista de tarefas é uma tarefa atômica ou uma estrutura:

$$
\text { ([:unordered] [ } \left.\left.\text { tasklist }_{1} \text { tasklist }_{2} \ldots \text { tasklist }_{n}\right]\right),
$$

onde tasklist $_{1}$ tasklist $_{2} \ldots$ tasklist $_{n}$ são uma lista de tarefas. Note aqui que $\mathrm{n}$ pode ser zero, assim a lista de tarefas pode ser uma lista vazia. A palavra :unordered na lista de tarefas é utilizada para 
indicar que não existe restrições de ordem nos elementos da lista de tarefas tasklist ${ }_{1}$, tasklist $2, \ldots$ tasklist $_{n}$; se a palavra não é utilizada esto quer dizer que os elementos da lista de tarefas tasklist ${ }_{1}$, tasklist $_{2}, \ldots$, tasklist $_{n}$ apresentam as restrições de ordem

$$
\text { tasklist }_{1} \prec \text { tasklist }_{2} \prec \ldots \prec \text { tasklist }_{n} \text {. }
$$

\section{B.9 Operador}

Um operador de planejamento é definido mediante a estrutura:

$$
\text { (:operator h P D A [c]) }
$$

onde:

- h é um átomo de tarefa primitiva;

- P (pré-condição) é uma pré-condição lógica;

- D (lista de elementos a ser removida) é uma lista de elementos com símbolos de variáveis definas em h e P. Os elementos de $\mathrm{D}$ podem ser:

- Um conjunto de átomos lógicos;

- Condições de proteção de átomos lógicos; e

- Expressões de forma (forall $\vee Y Z$ ), onde $V$ é uma lista de variáveis em $Y, Y$ é uma expressão lógica e $Z$ é uma lista de átomos lógicos que contém símbolos de variáveis existentes em h, P e V.

- A (lista de elementos a ser adicionada) é uma lista de elementos com símbolos de variáveis definidas em $\mathrm{h}$ e P. Os elementos de D são os mesmos da lista a ser removida; e

- c (custo) é o custo da ação. Se c é omitido, o custo do operador é 1.

As condições de proteção são expressões da forma (:protection a), onde a é um átomo lógico. $\mathrm{O}$ propósito das condições de proteção na lista é indicar ao planejador que não pode ser executada ações que removam ou modifiquem o átomo a. O propósito das condições de proteção na lista a ser removida é de remover uma condição de proteção definida previamente.

As expressões de forma (forall $V Y Z$ ) na lista a ser removida e na lista a ser adicionada representam um conjunto de átomos lógicos que são obtidos da substituição dos símbolos de variáveis de $\mathrm{V}$ pelos valores que satisfazem as condições $\mathrm{Y}$.

Exemplo B.1. A Figura B.1 mostra a representação de um operador de planejamento que representa as ações de mover um transporte ?t da localização ?|1 à localização ?l2. 


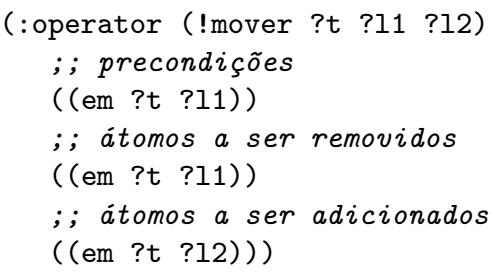

Figura B.1: Exemplo de um operador hierárquico

\section{B.10 Métodos}

Um método é definido mediante a estrutura:

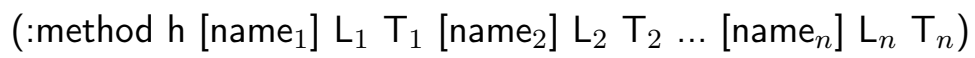

onde:

- h é um átomo de tarefa composta;

- cada $\mathrm{L}_{i}$ (pré-condição do método) é uma pré-condição lógica.

- cada $\mathrm{T}_{i}$ é uma lista de tarefas na qual o método decompõe a tarefa h; e

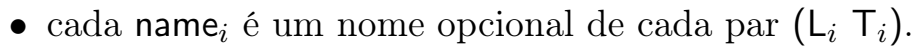

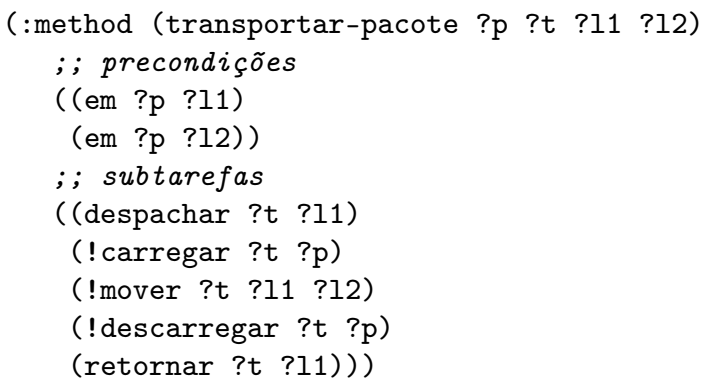

Figura B.2: Exemplo da representação de um método hierárquico

Exemplo B.2. A Figura B.2 mostra a representação em JSHOP2 de um método HTN que representa o método de decomposição (c) de transportar o pacote ?p com o transporte ?t da localização ?!1 à localização ?!2 apresentada no Exemplo 2.4. O método no exemplo efetua a decomposição da tarefa transportar-pacote nas subtarefas das linhast 5-10 despachar, !carregar, !mover, !descarregar e retornar se as pré-condições lógicas das linhas 2-4 são satisfazíveis. 


\section{B.11 Domínio de planejamento}

O domínio de planejamento é definido mediante a estrutura:

$$
\text { (defdomain domain-name } \left.\left(\mathrm{d}_{1} \mathrm{~d}_{2} \ldots \mathrm{d}_{n}\right)\right) \text {, }
$$

onde domain-name é o nome do domínio e cada $\mathrm{d}_{j}$ é um operador, um método ou um axioma.

\section{B.12 Problema de planejamento}

O problema de planejamento é definido mediante a estrutura:

$$
\begin{aligned}
& \text { (defproblem problem-name domain-name } \\
& \qquad \begin{array}{rlll} 
& \left.\left[\begin{array}{llll}
a_{1,1} & a_{1,2} & \ldots & a_{1, n_{1}}
\end{array}\right]\right) T_{1} \\
& \left(\left[\begin{array}{llll}
a_{2,1} & a_{2,2} & \ldots & a_{2, n_{2}}
\end{array}\right]\right) T_{2} \\
& \ldots & & \\
& \left.\left(\left[\begin{array}{lllll}
a_{m, 1} & a_{m, 2} & \ldots & a_{m, n_{m}}
\end{array}\right]\right) T_{m}\right)
\end{array}
\end{aligned}
$$

onde problem-name é o nome do problema de planejamento, e domain-name é o nomes do domínio; cada lista $\left(a_{n, 1} a_{n, 2} \quad \ldots a_{n, m}\right)$ é uma lista de átomos $a_{i, j}$ que representam o estado inicial; e cada termo $\mathrm{T}_{i}$ é uma lista de tarefas a ser atingidas.

\section{B.13 Plano}

O plano de ações obtido pelo algoritmo de planejamento é uma estrutura:

$$
\left(h_{1} h_{2} \ldots h_{n}\right),
$$

onde cada $h_{i}$ é uma instancia de um operador $o_{i}$ (uma ação). Se $\mathrm{p}=\left(\mathrm{h}_{1} \mathrm{~h}_{2} \ldots \mathrm{h}_{n}\right)$; então, o resultado da execução de $\mathrm{p}$ no estado inicial $s_{0}$ é $\mathrm{S}(\mathrm{p})=\gamma\left(\gamma\left(\ldots \gamma\left(\gamma\left(\mathrm{s}, \mathrm{h}_{1}\right), \mathrm{h}_{2}\right), \ldots,\right), \mathrm{h}_{n}\right)$. 


\section{Apêndice $\mathrm{C}$}

\section{Especificação IMS-LD}

A especificação IMS-LD publicada no ano 2003 pelo consórcio IMS-GLC ${ }^{1}$ é definida como a especificação baseada na Linguagem de Modelagem Educacional (Education Modeling Language, EML) que representam estratégias de aprendizagem e de instrução utilizadas na estruturação do conteúdo instrucional. A especificação descreve a estruturação do conteúdo instrucional como uma sequência de atividades a serem efetuadas pelos estudantes e docentes para alcançar objetivos educacionais (Koper et al., 2002; Olivier e Tattersall, 2005).

\section{C.1 Metáfora de roteiro de teatro}

A especificação pode ser entendida mediante uma metáfora de roteiro de teatro, na qual o roteiro é definido como um conjunto de peças de teatro. As peças de teatro são compostas de um conjunto de atos, atores que despenham papéis, atividades e ambientes. Neste sentido papéis, atividades e ambiente definem os componentes do roteiro; enquanto, cada peça de teatro é definida como uma sequência de atos.

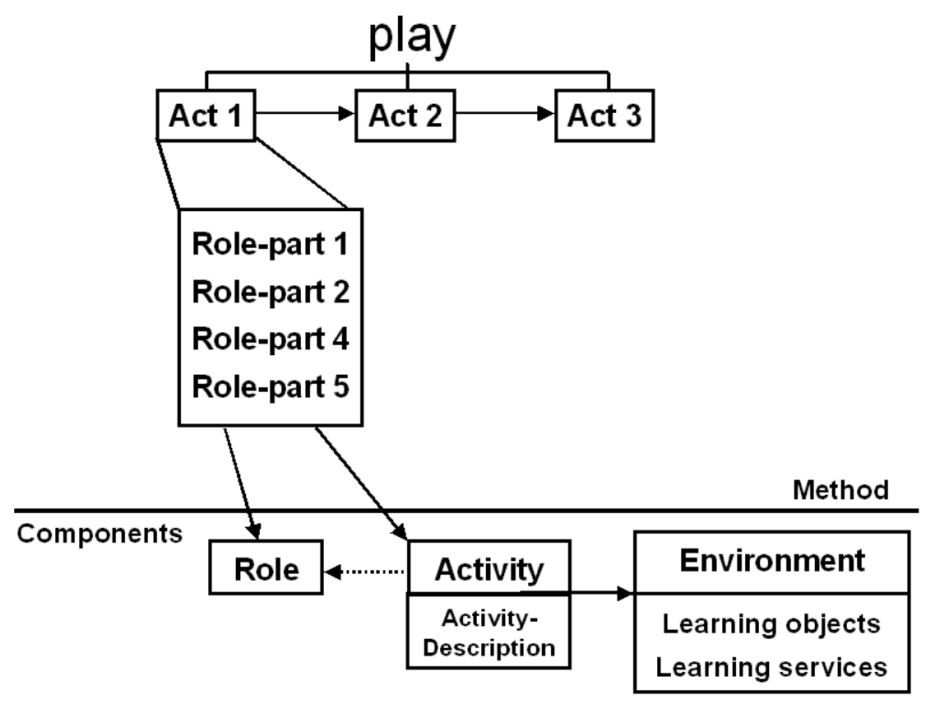

Figura C.1: Diagrama dos elementos de roteiro como metáfora de roteiro de teatro

\footnotetext{
${ }^{1}$ IMS - Global Learning Consortium - http://www.imsglobal.org/
} 
Dessa maneira, como é mostrada na Figura C.1 um estudante pode assumir diferentes papéis em diferentes atos, o inicio e final de cada ato define um ponto de sincronização no que os papéis dos participantes são mudados. Os atos são definidos como uma sequência de atividades associadas a um conjunto de ambientes de apoio à aprendizagem. Finalmente, os ambientes de apoio à aprendizagem são compostos de objetos de aprendizagem e serviços.

\section{C.2 Elementos da especificação}

A especificação IMS-LD é definida como um conjunto de regras de validação de documentos XML (arquivos XSD), dessa maneira, uma estratégia de aprendizagem e de instrução é representada em um arquivo de manifesto que apresenta a estrutura básica mostrada na Figura C.2. Assim, elementos da especificação estão localizados no elemento <learning-design > na seção $<$ organizations $>$ (linhas 15-19).

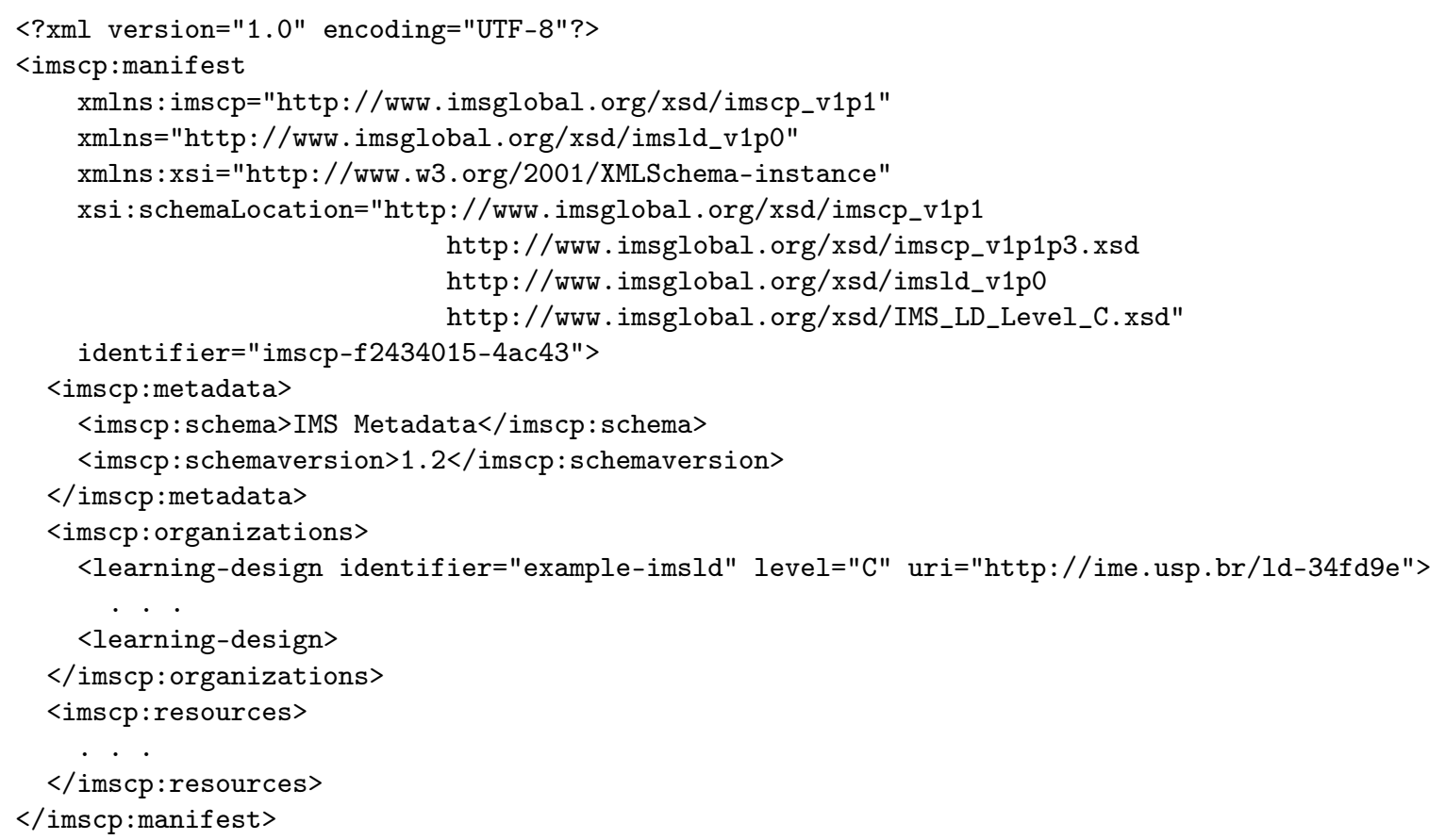

Figura C.2: Estrutura básica do arquivo manifesto

Para facilitar, a adoção e uso da especificação, os elementos do IMS-LD são divididos em três níveis $\mathrm{A}, \mathrm{B}$ e $\mathrm{C}$, sendo que o nível $\mathrm{B}$ integra o nível $\mathrm{A}$ e o nível $\mathrm{C}$ integra o nível $\mathrm{B}$ (consequentemente C integra o nível A). A Figura C.3 mostra o modelo conceitual da classificação e dos elementos da especificação IMS-LD detalhados a seguir.

\section{C.2.1 Elementos do nível A}

No nível A são definidos os elementos: títulos, objetivos de aprendizagem, pré-requisitos, papéis, atividades, ambientes de apoio à aprendizagem, peças de teatro, atos e papel-partes. 


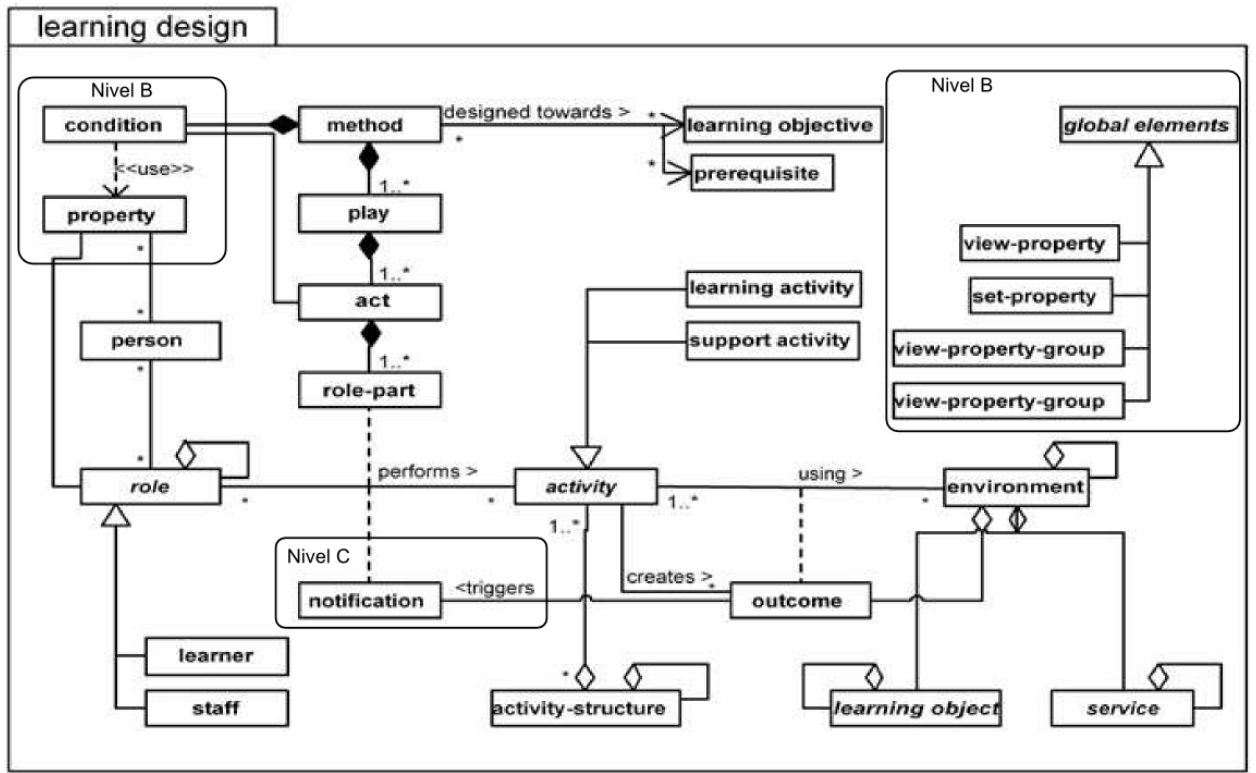

Figura C.3: Modelo conceitual dos elementos da especificação IMS-LD

\section{Títulos}

Os títulos são representados mediante elementos $<$ title $>$ utilizados para efetuar a descrição de cada elemento da especificação IMS-LD. A Figura C.4 apresenta como exemplo a definição do título no elemento $<$ learning-design $>$.

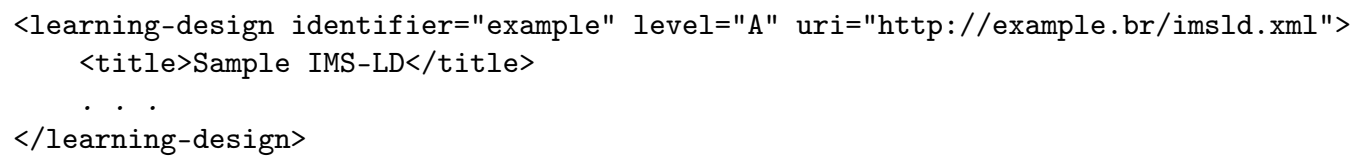

Figura C.4: Exemplo do elemento título na especificação IMS-LD

\section{Objetivos de aprendizagem e pré-requisitos}

Os objetivos de aprendizagem são representados mediante um elemento <learning-objectives $>$ que descreve os resultados esperados no processo de ensino-aprendizagem. Enquanto, os prérequisitos são representados mediante um elemento $<$ prerequisites $>$ que descreve recursos de entrada como quaisquer pré-conhecimentos necessários. A Figura C.5 apresenta como exemplo a definição dos objetivos de aprendizagem e pré-requisitos do elemento $<$ learning-desing $>$.

Nos elementos objetivos de aprendizagem e pré-requisitos, a definição dos recursos instrucionais é efetuada mediante o elemento $<$ item $>$ que apresenta um atributo identifierref como referencia a um identificador de recurso instrucional. A Figura C.5 mostra a definição dos objetivos de aprendizagem como resultados da discussão de matemática (linhas 4-6) e resultados da discussão de linguagem (linha 7-9); enquanto, os pré-requisitos são definidos como um resumo da teoria de conjuntos (linhas 12-14). 


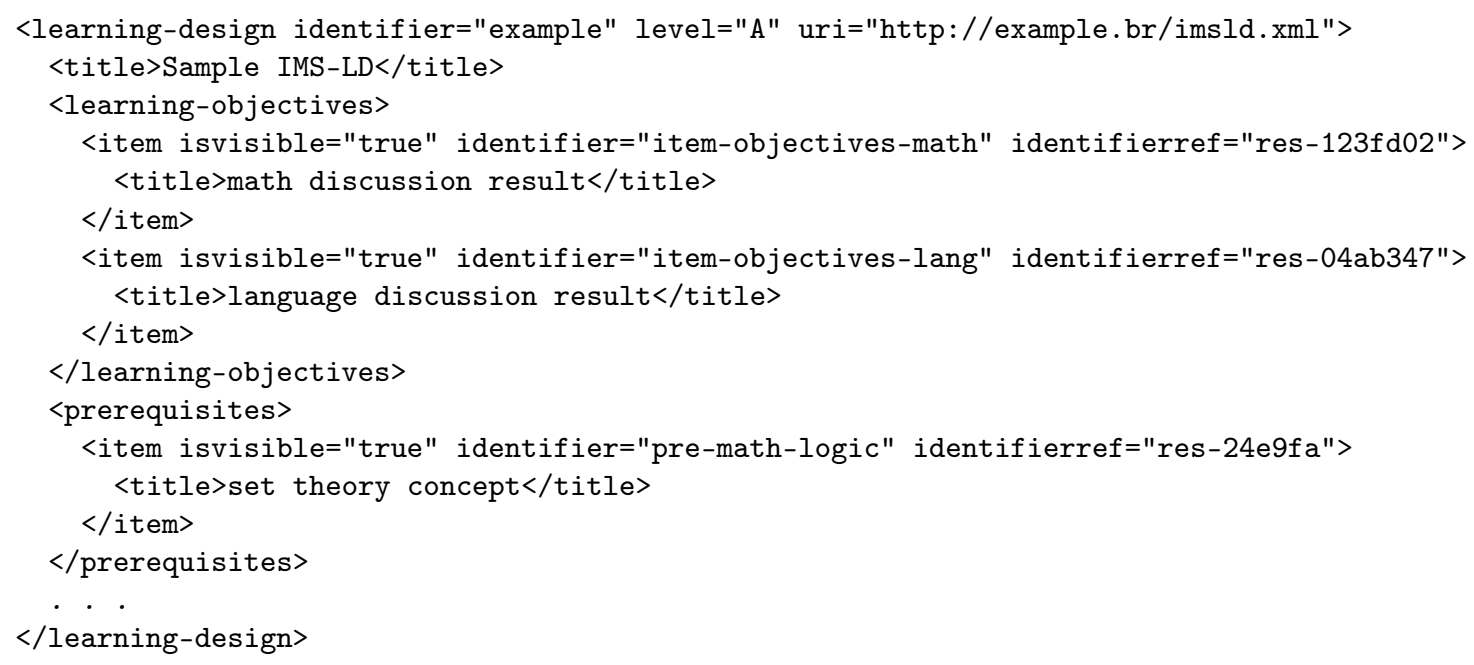

Figura C.5: Exemplo de objetivos de aprendizagem e pré-requisitos na especificação IMS-LD

\section{Papéis}

Os papéis são representados mediante um elemento $<$ roles $>$, em que é definido um conjunto de elementos <learner $>$ que representam papéis dos estudantes e um conjunto de elementos $<$ staff $>$ que representam papéis dos funcionários. Os atributos max-persons e min-persons nos papéis são utilizados para definir o número máximo e mínimo de participantes em cada papel.

A Figura C.6 apresenta como exemplo a definição dos papéis de estudante role-student (linhas 5-13), role-tutor (tutor, linhas 7-9) e role-tutee (aprendiz, linhas 10-12); e a definição de um papel de funcionário role-teacher (docente, linhas 14-16).

\section{Atividades}

As atividades são representadas mediante um elemento < activities $>$, no que são definidos: um conjunto de elementos <learning-activity $>$ que representam as atividades de aprendizagem; um conjunto de elementos de elementos $<$ support-activity $>$ que representam atividades de suporte; e um conjunto de elementos < activity-structure $>$ que representam estruturas de atividades. $\mathrm{O}$ elemento $<$ activity-structure $>$ é utilizado para agrupar atividades de aprendizagem e de suporte como uma lista de tipo sequencial ou seleção, no que os atributos: number-to-select definem o número de atividades que devem ser concluídas para dar termino à estrutura de atividades; e structure-type definem o tipo de estrutura sequencial (sequence) ou seleção (selection).

A Figura C.7 mostra a definição das atividades de aprendizagem la-math-discussion (discussão de matemática, linhas 5-9) e la-individual-study (estudo individual, linhas 10-17), e a definição da atividade de suporte sa-support-discussion (suporte à discussão, linhas 18-21).

Nas atividades definimos os ambientes de apoio à aprendizagem mediante elementos $<$ environment-ref $>$ (referência ao ambiente); e a descrição de como efetuar as atividades mediante o elemento $<$ activity-description $>$ (descrição da atividade). As atividades de aprendizagem e suporte contêm: um elemento < complete-activity $>$ utilizado para especificar quando a ativi- 


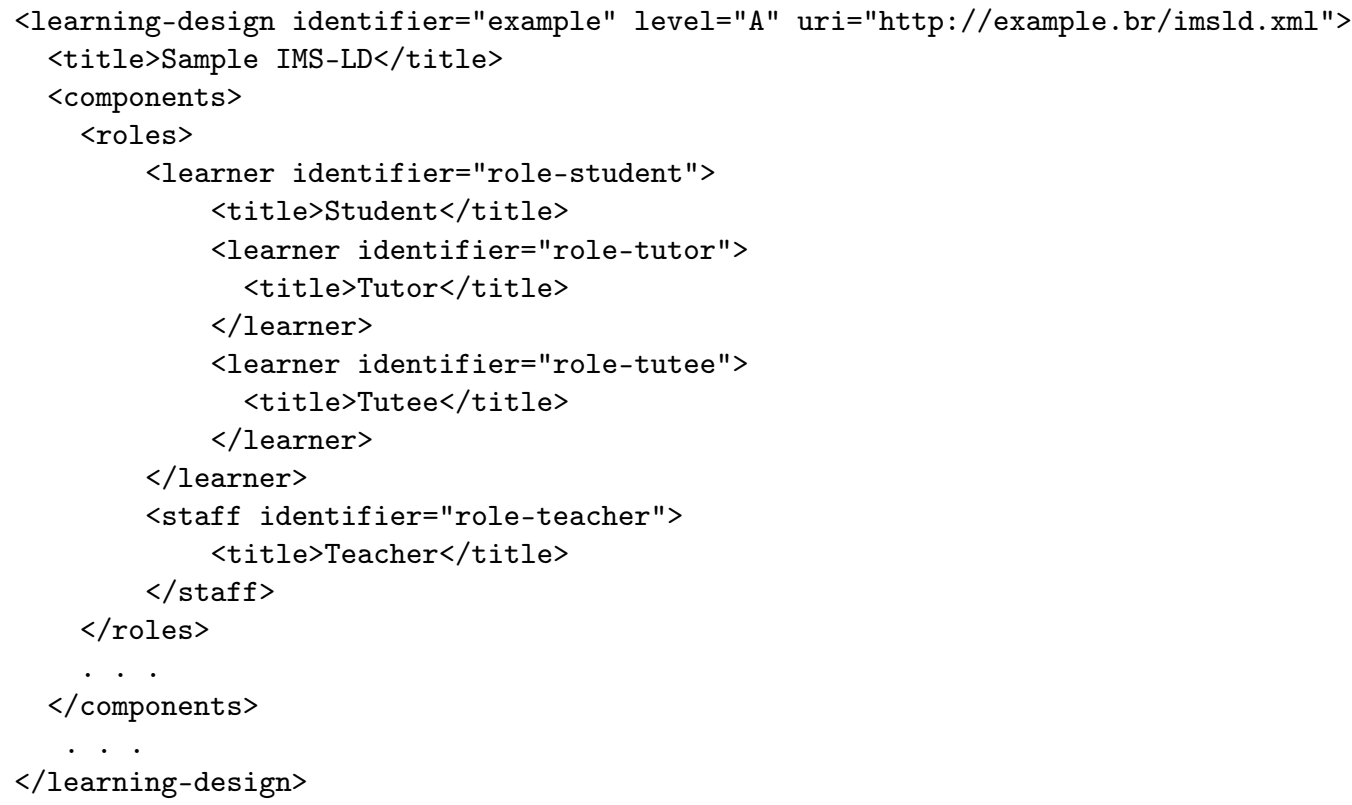

Figura C.6: Exemplo de papéis na especificação IMS-LD

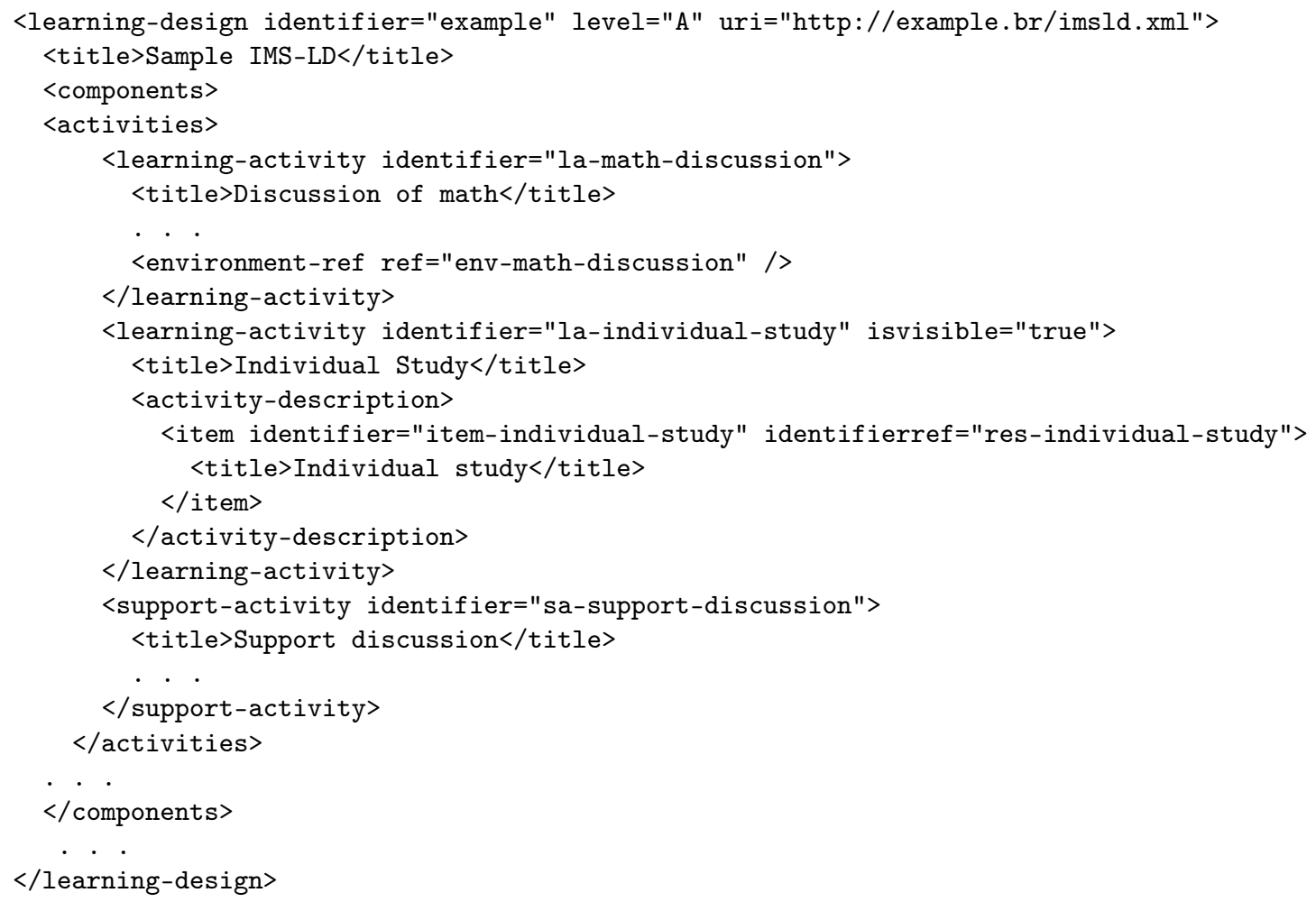

Figura C.7: Exemplo de atividades de aprendizagem e de suporte na especificação IMS-LD 
dade termina podendo ser de seleção do usuário (user-choice) ou de tempo limite (time-limit). O elemento <on-completion $>$ nas atividades representam elementos a ser executados após concluída a atividade; no nível A, o único elemento que pode ser definido é < feedback-description> que agrupa recursos instrucionais a ser apresentados ao concluir a atividade.

\section{Ambientes de apoio à aprendizagem}

Os ambientes de apoio à aprendizagem são representados mediante um elemento < environments $>$, no que são definidos elementos <environment $>$ que representam ambientes. Cada elemento $<$ environment $>$ contêm: elementos $<$ learning-object $>$ para representar objetos de aprendizagem; elementos $<$ service $>$ para representar serviços de apoio à aprendizagem; e elementos $<$ enviroment-ref $>$ para representar referencia a outros ambientes (a ser utilizados como subambientes de apoio à aprendizagem).

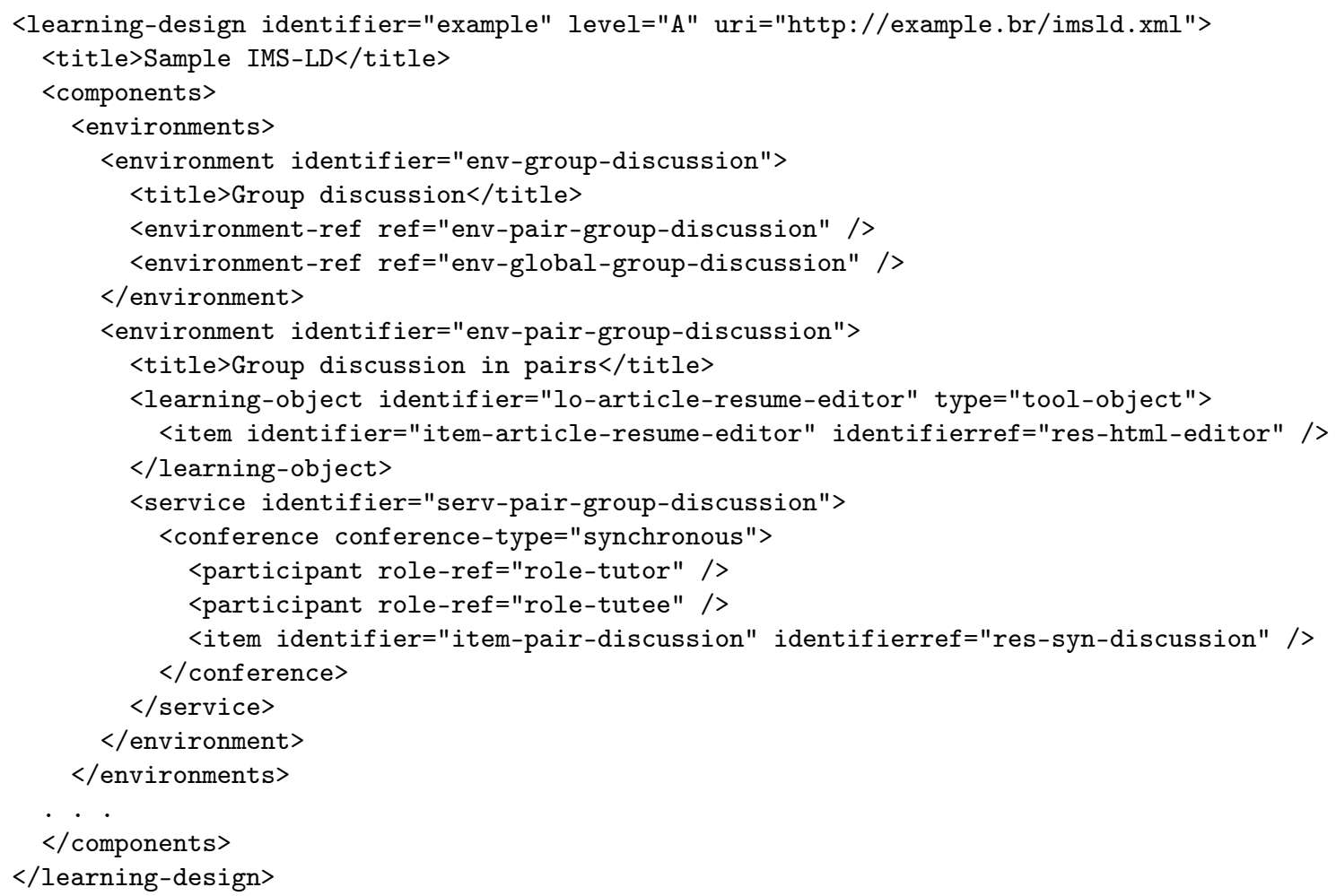

Figura C.8: Exemplo de ambientes de apoio à aprendizagem na especificação IMS-LD

A Figura C.8 apresenta a definição dos ambientes de apoio à aprendizagem env-groupdiscussion (ambiente de discussão de grupos, linhas 5-9) e env-pair-group-discussion (ambiente de discussão em pares, linhas 10-22). O ambiente env-group-discussion é composto dos dois subambientes env-pair-group-discussion e env-global-group-discussion (discussão global em grupos). $\mathrm{O}$ ambiente env-pair-group-discussion é formado pelos objetos de aprendizagem lo-article-resumeeditor e o serviço de apoio à aprendizagem serv-pair-group-discussion (serviço de comunicação síncrono para a discussão em pares, linhas 15-21). 


\section{Peças de teatro}

As peças de teatro são representadas no elemento $<$ method $>$ mediante elementos $<$ play $>$ que definem o fluxo de atividades a ser executado durante o processo de ensino-aprendizagem como uma sequência de atos. Os atributos identifier e isvisible definem o identificador único e a visibilidade do elemento. Cada peça de teatro pode conter um elemento <complete-play $>$ para definir quando é concluída a peça e conter um elemento <on-completion> para definir os elementos a ser apresentados à término da peça.

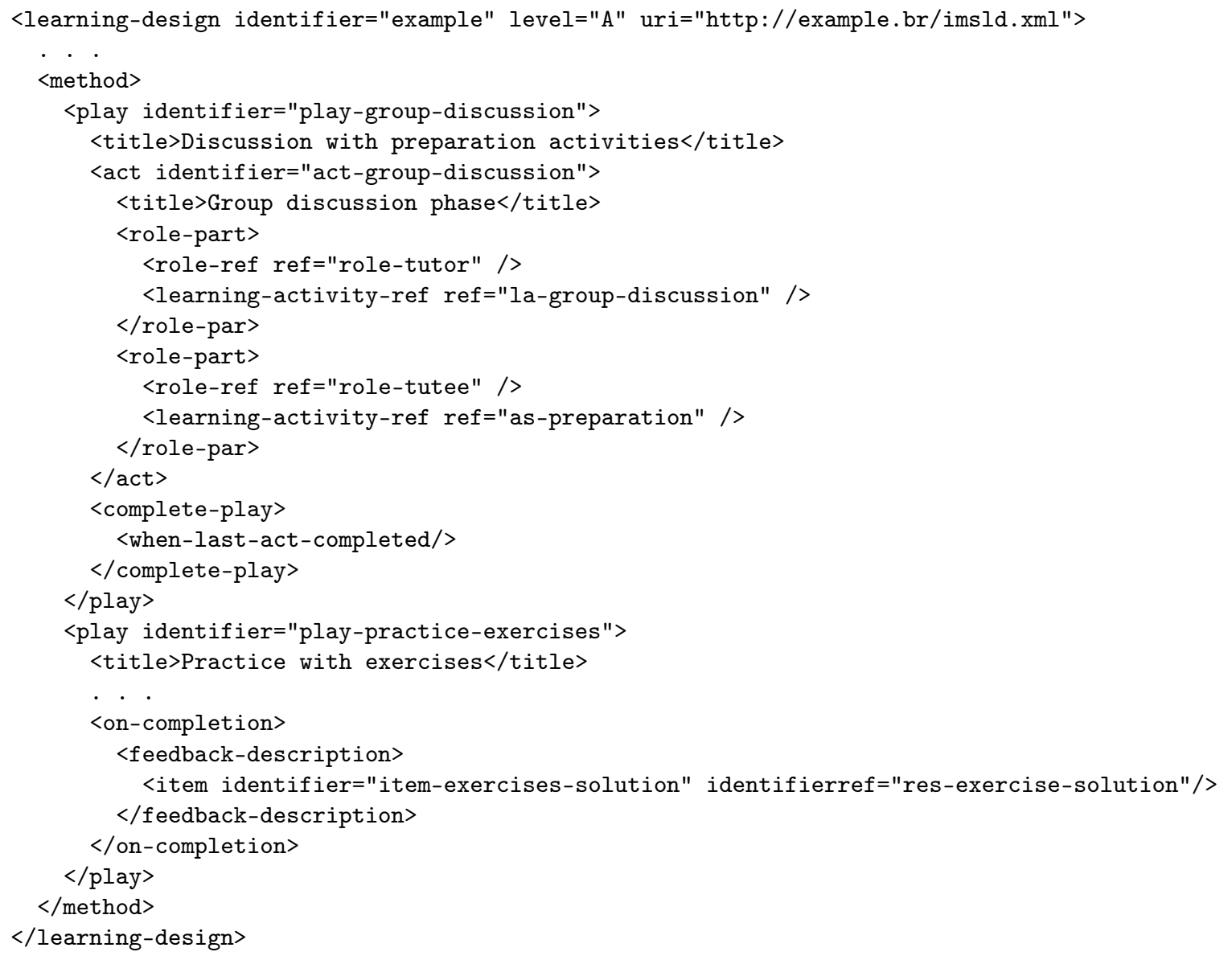

Figura C.9: Exemplo de peças de teatro na especificação IMS-LD

A Figura C.9 apresenta como exemplo dois peças de teatro play-group-discussion (discussão em grupos, linhas 4, 20) e play-practice-exercises (prática com exercícios, linhas 21-29). O término da peça de teatro discussão é definido como a finalização do último ato. Enquanto, os elementos a ser apresentados ao termino da peça de teatro prática com exercícios é a apresentação do recurso com a solução dos exercícios.

\section{Atos}

Os atos de uma peça de teatro são representados mediante elementos $<$ act $>$ definidos como um conjunto de elementos < role-part $>$ no que é definida a associação entre papéis e atividades. 
Em cada elemento peça de teatro deve existir pelo menos um ato. Quando houver mais de um ato em uma peça de teatro, estes são apresentados de forma sequencial do primeiro até o último.

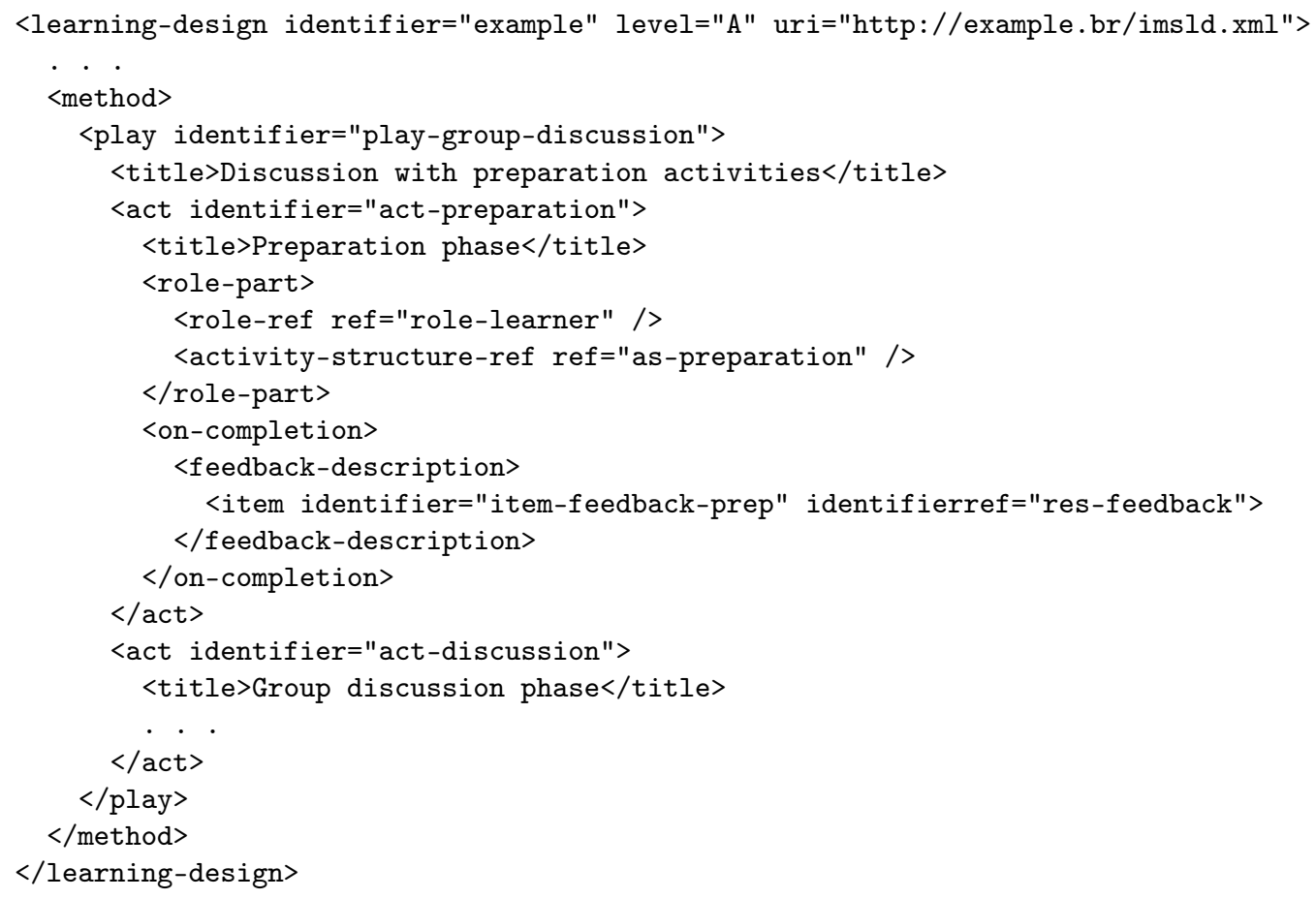

Figura C.10: Exemplo de atos na especificação IMS-LD

Na Figura C.10, a peça de teatro discussão em grupo é definida como uma sequência dos atos act-preparation (preparação, linhas 6-17) e act-discussion (discussão, linhas 18-21). No ato preparação, o elemento <on-completion > (linhas 12-16) é utilizado para apresentar ao término do ato um recurso instrucional com o feedback da preparação.

\section{Elementos papel-parte}

A associação entre papéis e atividades nos atos representada mediante elementos < rolepart>, nos quais a relação é definida por uma referência a um papel mediante o elemento $<$ role-ref $>$ e uma referência a uma atividade mediante um elemento <learning-activity-ref $>$, $<$ support-activity-ref $>$, $<$ activity-structure-ref $>$ ou $<$ environment-ref $>$. As atividades definidas nos elementos papel-parte de um ato são efetuadas simultaneamente. Quando um ato têm o atributo isVisible definido com valor false, os hiper-vínculo das atividades definidas no ato na arvore de atividades é visível, mas o conteúdo não é acessível.

A Figura C.11 mostra os elementos papel-parte definidos no ato act-group-discussion (fase discussão em grupos, linhas 7-24). Os elementos papel-parte no exemplo definem: a associação de estudantes com papel tutores com a atividade discussão de grupo (linhas 9-12); a associação de estudantes com papel aprendiz com a atividade preparação (linhas 13-16); e a associação dos docentes com o ambiente de monitoramento da discussão (linhas 17-20). 


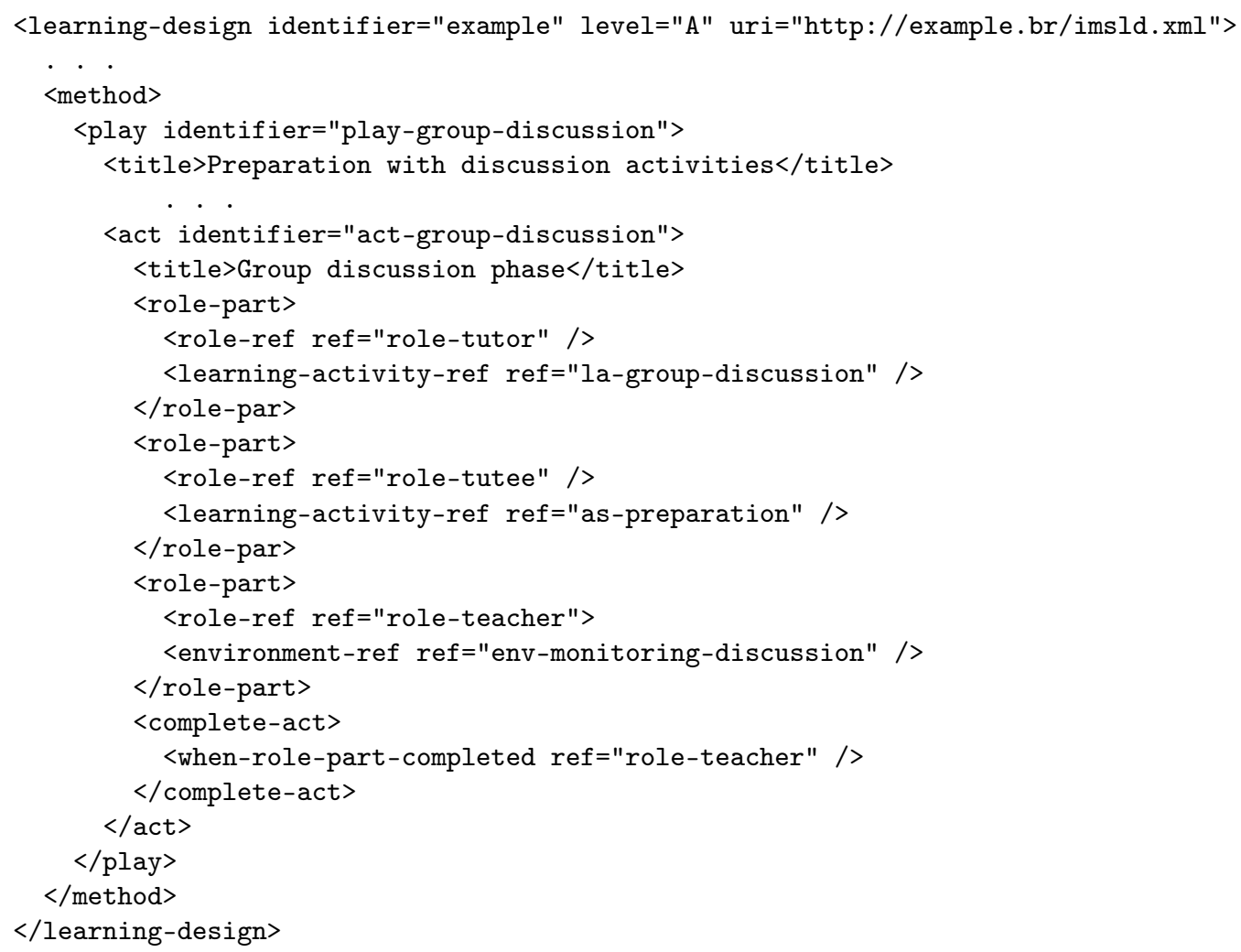

Figura C.11: Exemplo de elementos papel-parte na especificação IMS-LD 


\section{C.2.2 Elementos dos níveis B e C}

No nível B e C são definidos: propriedades, elementos externos, serviços de monitoramento, cálculos numéricos, condições, elementos < when-property-value-is-set $>$, elementos < <hangeproperty-value > e notificações.

\section{Propriedades}

As propriedades são variáveis utilizadas para manter informação do sistema, usuários e papéis. As propriedades são definidas no elemento < properties $>$ para seu uso posterior em outros elementos da especificação (por exemplo, como condição de termino de uma atividade) ou em arquivos externos XHTML de tipo imsldcontent. Os elementos definem: um título mediante um elemento $<$ title $>$, um tipo de dado mediante um elemento $<$ datatype $>$, um valor inicial mediante um elemento $<$ initial-value $>$ e um conjunto de restrições mediante um elemento $<$ restriction $>$. As propriedades são:

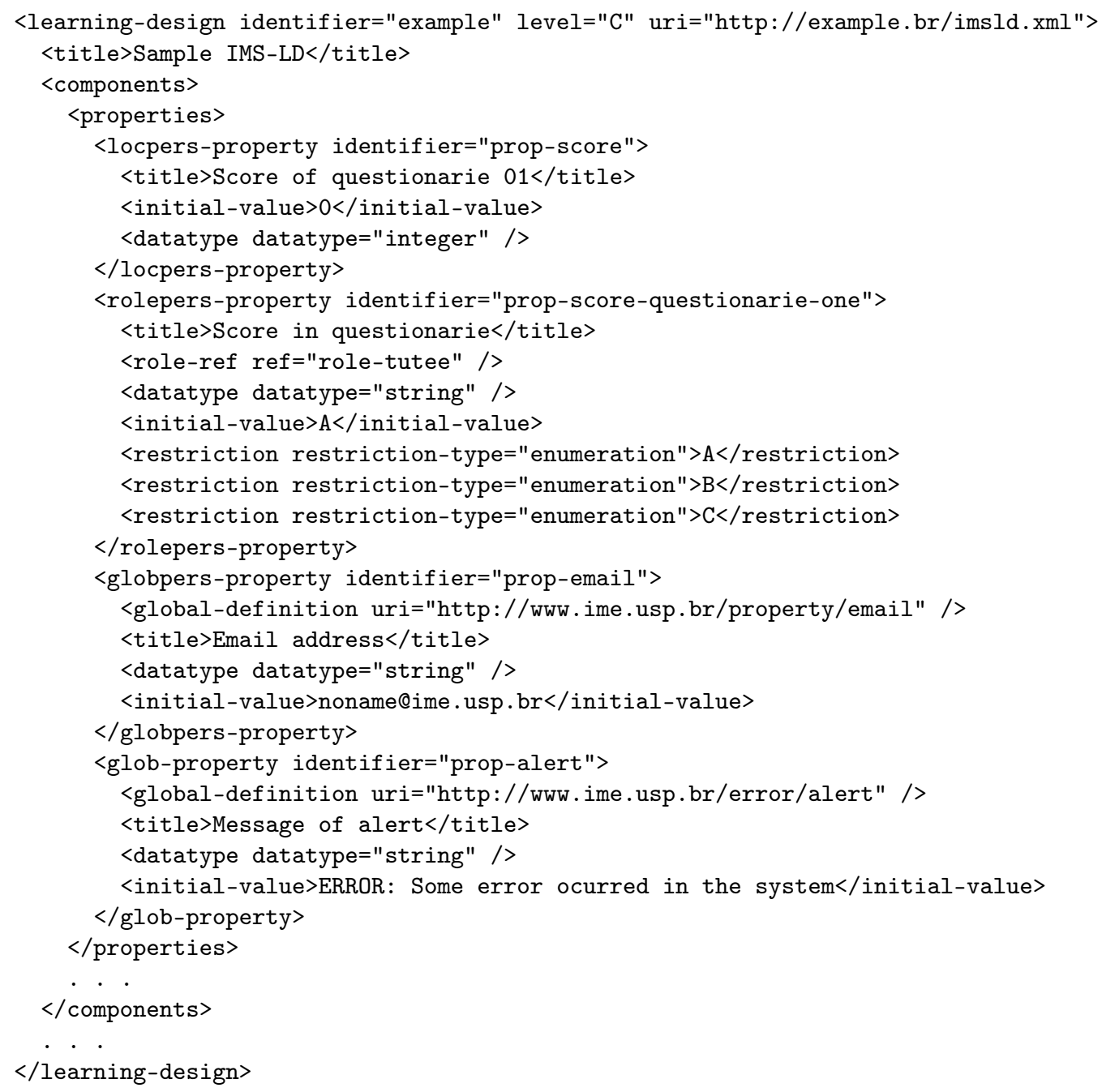

Figura C.12: Exemplo de propriedades na especificação IMS-LD 
Propriedades locais definidas mediante elementos $<$ loc-property $>$ são propriedades acessíveis unicamente no contexto da execução da unidade de aprendizagem. Isto quer dizer que propriedades deste tipo são iniciadas após a definição do conjunto de participantes e do aspeto temporal da unidade no ambiente virtual de aprendizagem.

Propriedades locais individuais definidas mediante elementos $<$ locpers-property $>$ são propriedades locais que apresentam um valor distinto por cada participante. A Figura C.12 apresenta a definição da propriedade local individual prop-score (linhas 5-9) de tipo inteiro utilizada para definir o valor atingido por cada estudante em um questionário.

Propriedades locais por papel definidas mediante elementos <locrole-property $>$ são propriedades locais que apresentam um valor distinto por cada papel. A Figura C.12 apresenta a definição da propriedade local por papel prop-score-questionarie-one (linhas 10-17) de tipo string utilizada para definir o valor atingido por participantes com papel tutee.

Propriedades globais individuais definidas mediante elementos < globpers-property $>$ são propriedades acessíveis em quaisquer contexto de execução da unidade de aprendizagem apresentando um valor distinto por cada participante. Por exemplo, na Figura C.12 a propriedade prop-email (linhas 19-24) de tipo string é empregada para definir os correios eletrônicos de cada participante.

Propriedades globais definidas mediante elementos $<$ glob-property $>$ são propriedades acessíveis em quaisquer contexto de execução da unidade de aprendizagem. A Figura C.12 apresenta a propriedade global prop-alert (linhas 25-30) utilizada para definir a mensagem de alerta a ser utilizada na unidade de aprendizagem.

\section{Elementos externos}

Elementos externos são elementos da especificação IMS-LD que podem ser utilizados em arquivos externos com conteúdo de tipo imsldcontent. Um elemento externo é utilizado para visualizar ou definir o valor de uma propriedade ou grupo de propriedades definidas na especificação. Os elementos globais são:

Visualização de uma propriedade e de um grupo de propriedades definidas como elementos < view-property $>$ e < view-property-group $>$ utilizados para mostrar o valor corrente da propriedade ou de um grupo de propriedades, onde: o atributo view com valores value ou title-value específica se é mostrado unicamente um valor ou o titulo e valor da propriedade; o atributo property-of define se a visualização da propriedade corresponde ao próprio participante (self) ou grupo de participantes relativos à propriedade (supportedperson); e o atributo ref é referido ao identificador da propriedade. A Figura C.13 mostra o uso da visualização da propriedade prop-score (linha 8) em um arquivo externo.

Definir o valor de uma propriedade e de um grupo de propriedade mediante elementos $<$ set-property $>$ e $<$ set-property-group $>$ utilizados para definir o valor de uma propriedade ou grupo de propriedades, onde: o atributo view com valores value ou title-value 
específica se é mostrado unicamente um valor ou o titulo e valor da propriedade; o atributo property-of define se a visualização da propriedade corresponde ao próprio participante (self) ou grupo de participantes relativos à propriedade (supported-person); o atributo ref é referida ao identificador da propriedade; e o atributo max-transactions define o número máximo de vezes em que é possível mudar o valor da propriedade. A Figura C.13 mostra a definição da propriedade prop-email (linha 12) utilizado para definir o correio eletrônico de um participante durante a execução da unidade de aprendizagem.

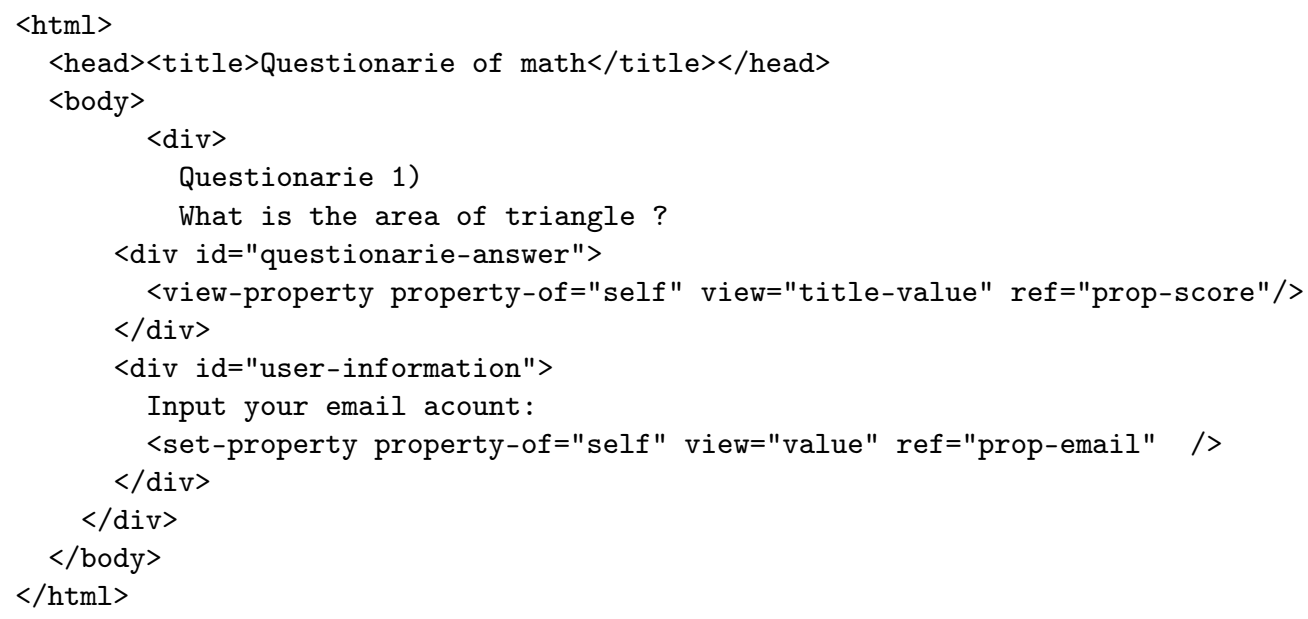

Figura C.13: Exemplo dos elementos globais <view-property $>e<$ set-property $>$

\section{Serviço de monitoramento}

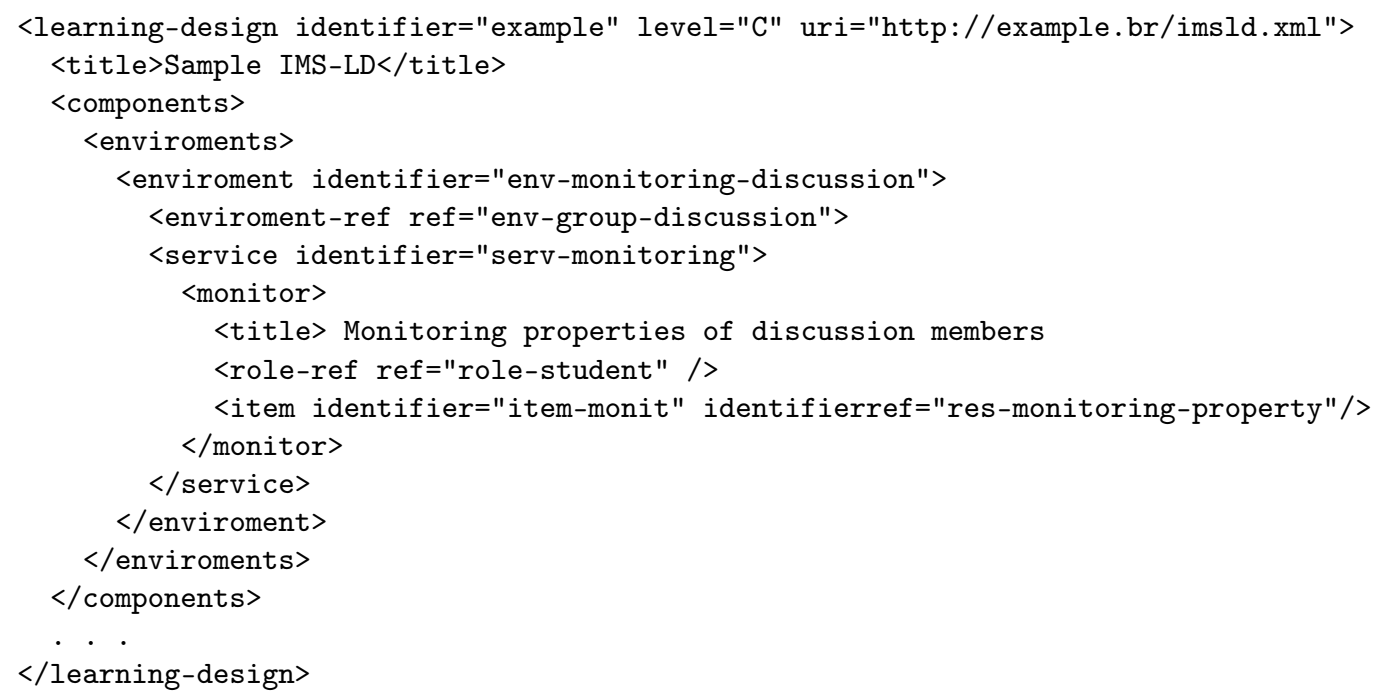

Figura C.14: Exemplo de serviço de monitoramento na especificação IMS-LD 
Os serviços de monitoramento são definidos mediante elementos $<$ monitor $>$ nos serviços dos ambientes de apoio à aprendizagem. Nos serviço de monitoramento: o elemento <role-ref $>$ ou elemento $<$ self $>$ podem ser utilizados para definir se no monitor serão visualizados e definidas propriedades do próprio participante ou de um papel. Por exemplo, na Figura C.14 é definido um serviço de monitoramento com identificador serv-monitoring (linhas 7-13), no que as propriedades mostradas pelo monitor são propriedades dos participantes com papel role-student (linha 10).

\section{Cálculos numéricos}

No manifesto da unidade de aprendizagem podem ser efetuadas operações aritméticas (adição, subtração, divisão e multiplicação) para o cálculo de valores numéricos utilizando propriedades e valores constantes, os cálculos são definidos mediante elementos $<$ calculate $>$. A figura C.15 apresenta como exemplo a operação aritmetica Total=Value1+Value2+Value3.

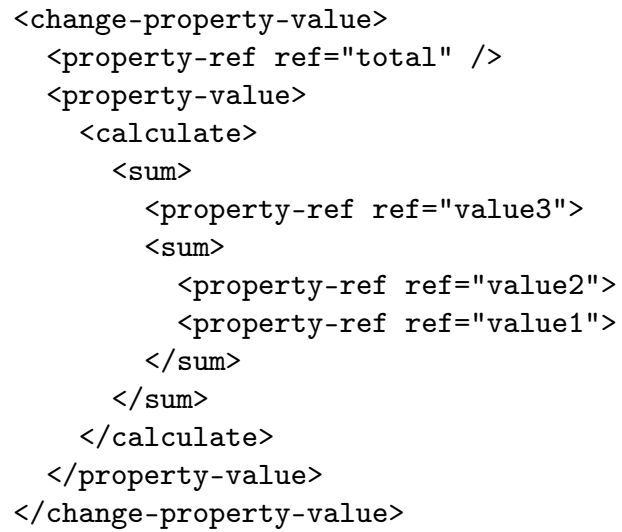

Figura C.15: Exemplo de cálculo numérico na especificação IMS-LD

\section{Condições}

As condições são definidas no elemento < conditions $>$ mediante estruturas de tipo if-thenelse, que podem ser aninhada quaisquer número de níveis (complexidade cíclica). Condições são utilizadas como forma básica de definição de comportamentos dinâmicos durante o processo de execução da unidade de aprendizagem. Todas as condições são avaliadas a cada mudança de valor em quaisquer propriedades e durante a finalização de cada atividade, ato e peça de teatro.

A Figura C.16 apresenta a definição das condições utilizadas para: (1) mostrar ou ocultar seções de classe example (linhas 6-16); e (2) mostrar a atividade de aprendizagem la-request-grade e o ambiente env-background (linhas 18-35). 


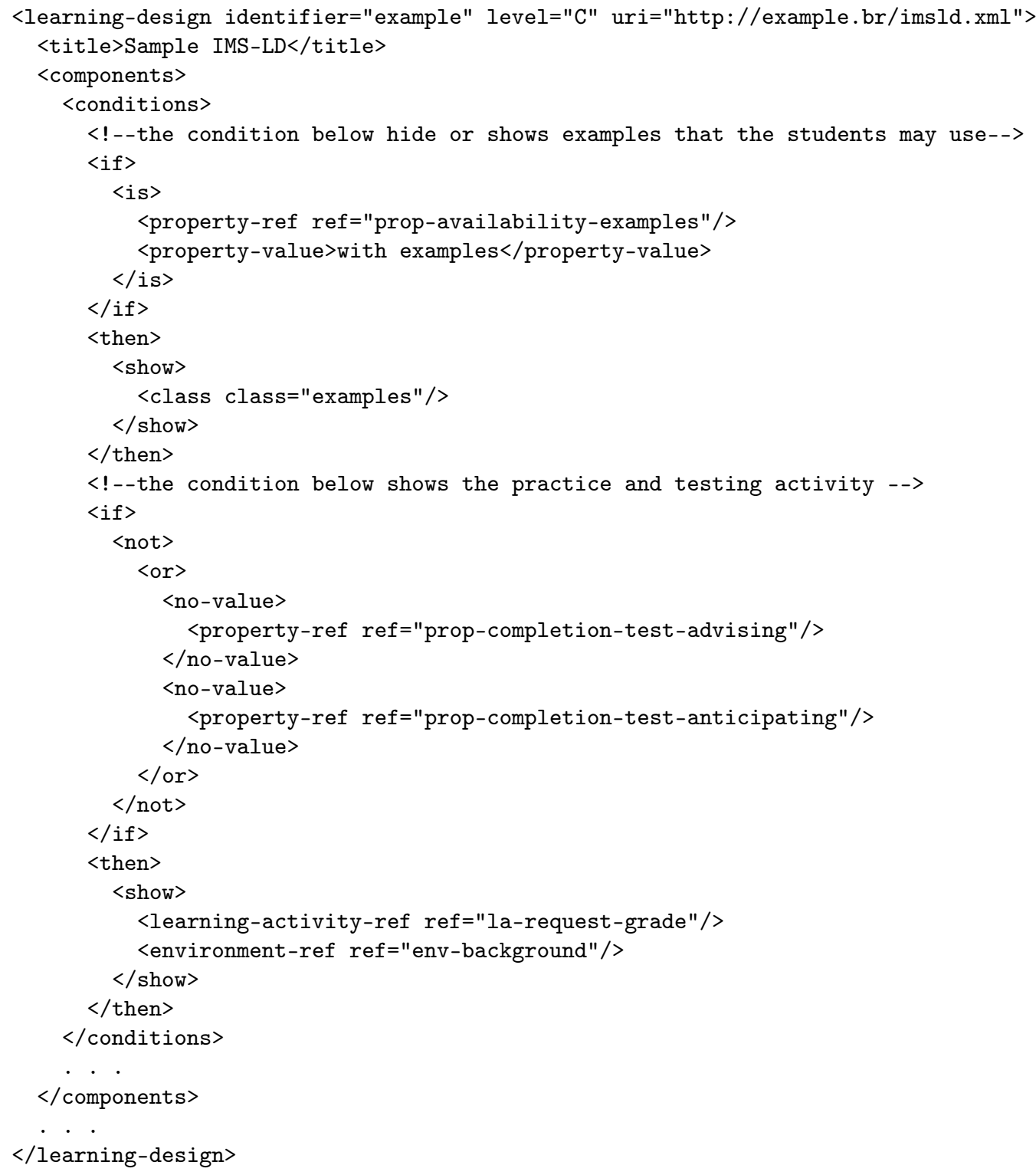

Figura C.16: Exemplo de condições na especificação IMS-LD 
Elemento $<$ when-property-value-is-set $>$

O elemento < when-property-value-is-set $>$ é empregado para definir a condição de término das atividades (de aprendizagem e suporte), atos, peça de teatros e unidade de aprendizagem mediante: um elemento de referencia a uma propriedade definido como um elemento < propertyref $>$; e um valor da propriedade definido como um elemento <property-value $>$. Assim, o elemento $<$ when-property-value-is-set $>$ é definido como parte dos elementos $<$ complete-activity $>$, $<$ complete-act $>,<$ complete-play $>$ e $<$ complete-unit-of-learning $>$.

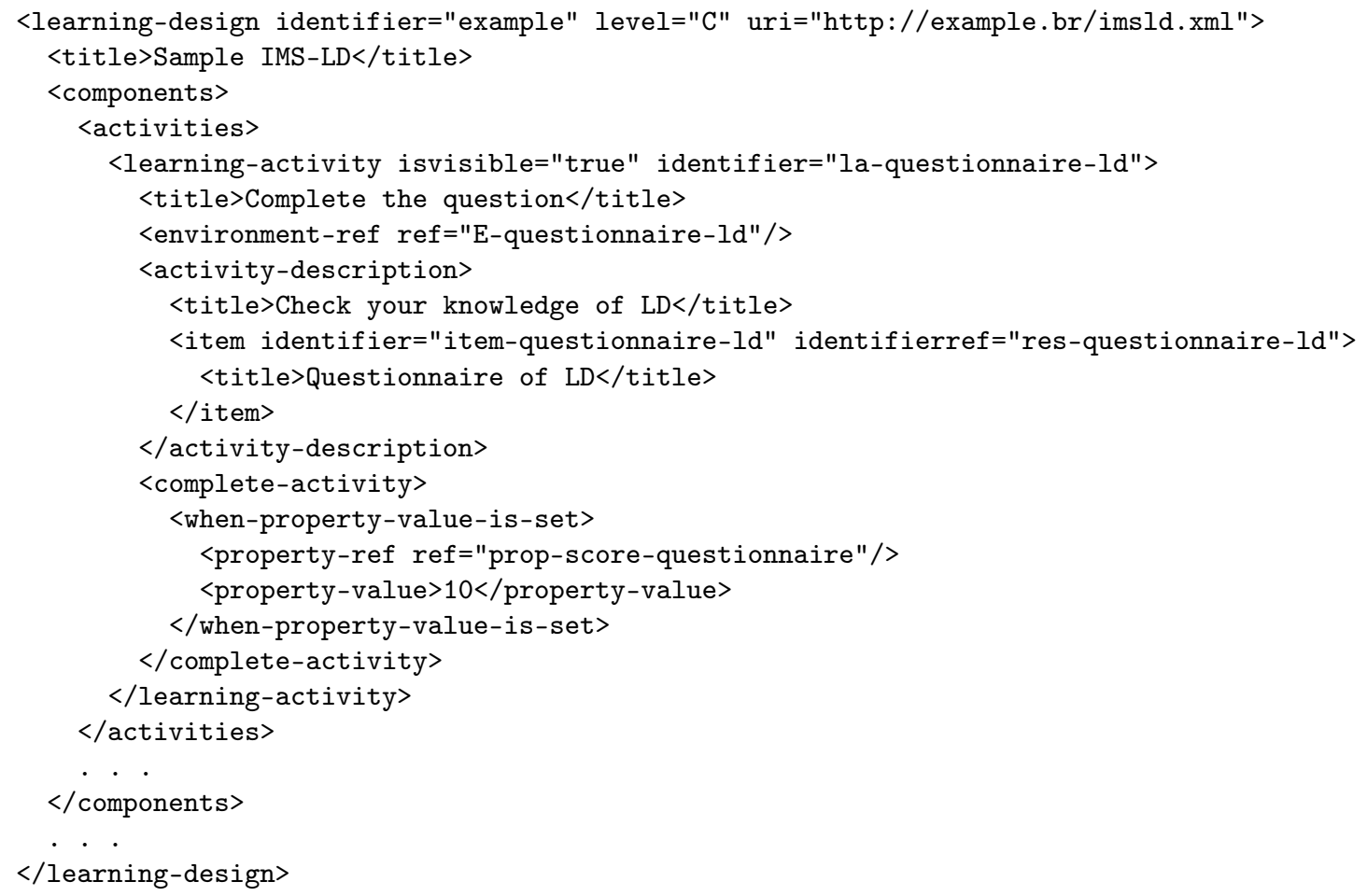

Figura C.17: Exemplo do elemento <when-property-value-is-set $>$

A Figura C.17 apresenta como exemplo o uso do elemento <when-property-value-is-set> utilizado para definir que a condição do término da atividade la-questionnaire-ld (linhas 5-18) é o valor numérico 10 na propriedade prop-score-questionnaire (linha 17).

\section{Elemento $<$ change-property-value $>$}

O elemento < change-property-value $>$ é empregado no elemento $<$ on-completion $>$ para definir a mudança de valores nas propriedades depois do acontecimento de eventos como a conclusão de atividades (de aprendizagem e suporte), atos e peça de teatro. A Figura C.18 apresenta como exemplo, a definição da mudança na propriedade prop-complete-discussion (linhas 22-25), efetuada ao término do ato discussão em grupos. 


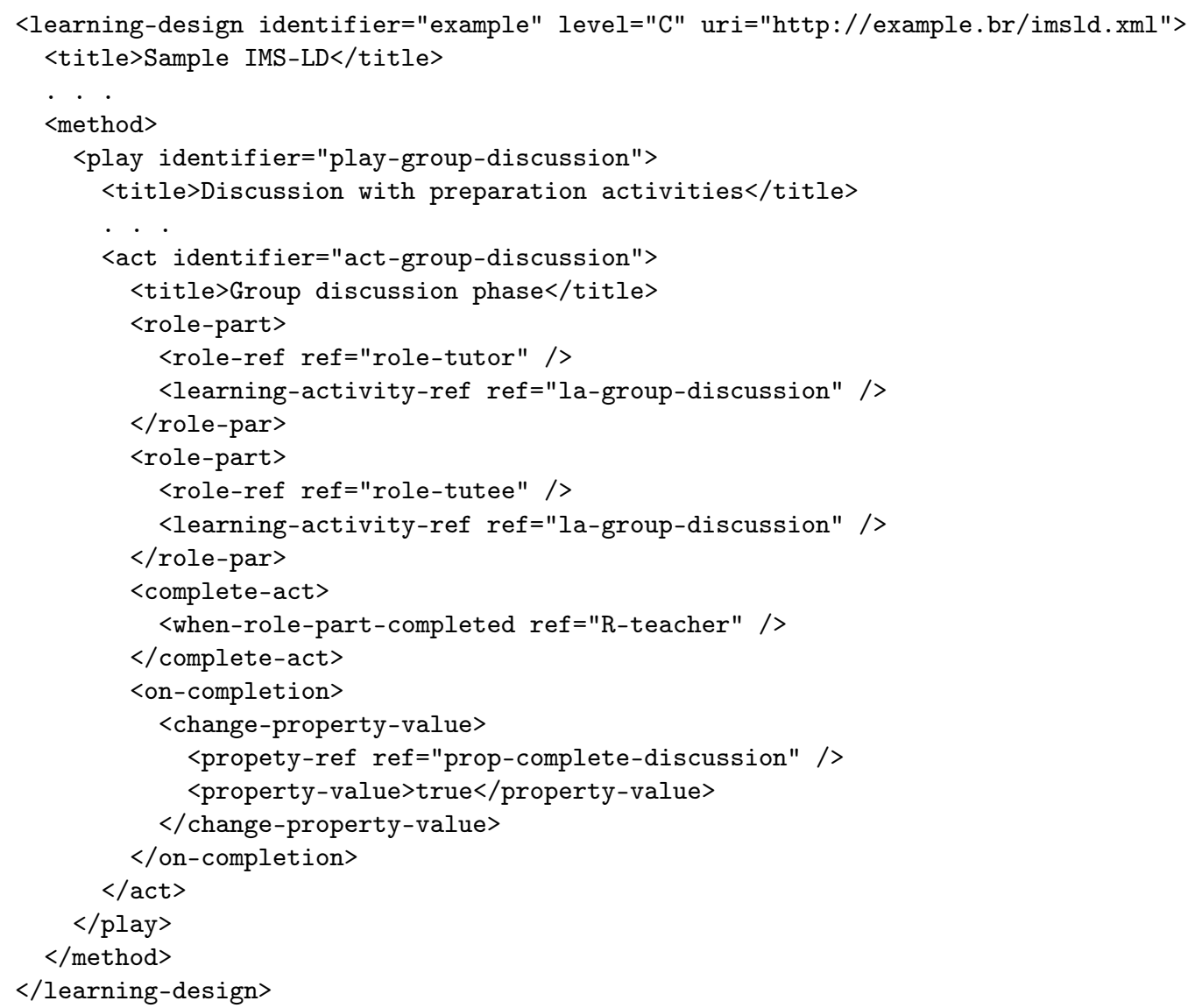

Figura C.18: Exemplo do elemento <change-property-value $>$ 


\section{Notificação}

As notificações utilizadas para efetuar o envio de mensagens ao término das atividades, atos e peças de teatro ou na mudança do valor de uma propriedade são definidas mediante elementos $<$ notification $>$. Os elementos são declarados nos elementos $<$ on-completion $>$ ou nas condições $<$ then $>$. Nos elementos $<$ notification $>$ os destinatários são definidos nos elementos $<$ emaildata $>$ por meio dos atributos email-property-ref e username-property-ref (opcional) utilizados para definir a propriedade que contem o email e nome dos participantes a serem notificados. $\mathrm{O}$ elemento $<$ role-ref $>$ define o conjunto de participantes a ser notificados. Enquanto, o assunto da mensagem é definido no elemento < subject $>$.

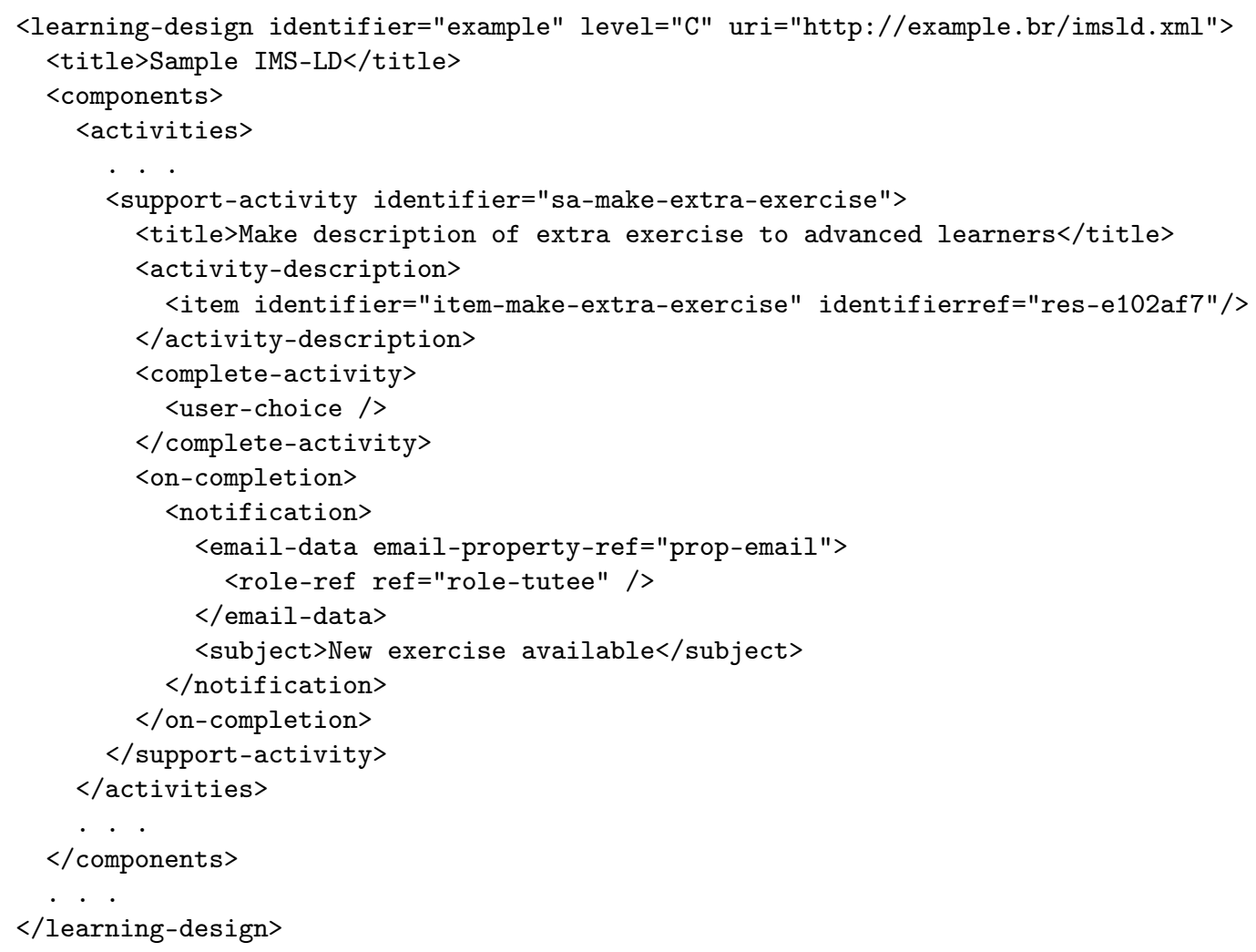

Figura C.19: Exemplo de notificação na especificação IMS-LD

A Figura C.19 mostra como exemplo de notificação, o envio da mensagem que informa que um novo exercício está disponível para todos os estudantes com papel rol-tutee (linhas 15-20); a notificação é enviada ao término da atividade de suporte sa-make-extra-exercise (linhas 6-22). 


\section{C.3 Relação com outras especificações}

A especificação IMS-LD pode ser integrada com outras especificações existentes na definição do manifesto da unidade da unidade de aprendizagem. Assim:

- A especificação IMS-CP é utilizada para definir uma unidade de aprendizagem como um pacote ZIP;

- A especificação IMS-MD é utilizada para definir a informação associadas ao elemento $<$ learning-design $>$ para sua busca, classificação etc;

- A especificação IMS-QTI é utilizada de duas formas, a primeira é efetuada na definição do elemento <learning-object>, e a segunda é efetuada mediante a referência a um recurso externo que é definido usando esta especificação;

- A especificação IMS-RDCEO é utilizada para definir objetivos de aprendizagem e prérequisitos ligados a recursos definidos segundo esta especificação; e

- A especificação IMS-SS para definir os percursos de navegação das atividades podendo ser integrada na unidade de aprendizagem.

Existem outras especificações que podem ser integradas na especificação IMS-LD, mas que não são relevantes no momento. Neste trabalho, a integração é efetuada unicamente com a especificação IMS-CP para definir uma unidade de aprendizagem como um pacote ZIP em qual são incluídos todos os recursos instrucionais necessários. Assim, como é mostrada na Figura C.20 um arquivo ZIP definido como uma unidade de aprendizagem contém:

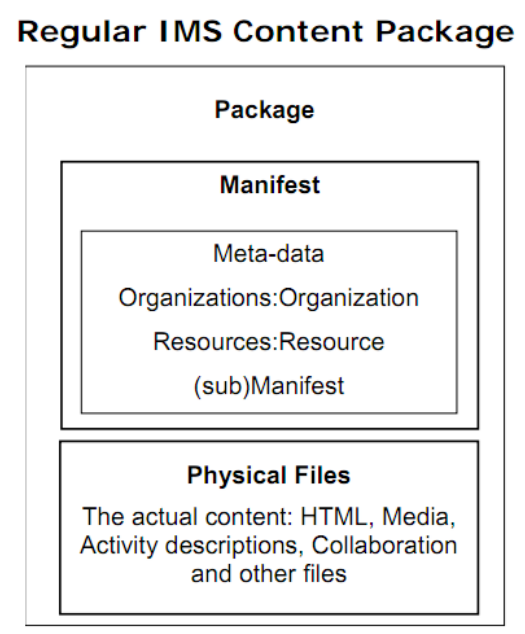

I MS Unit of Learning

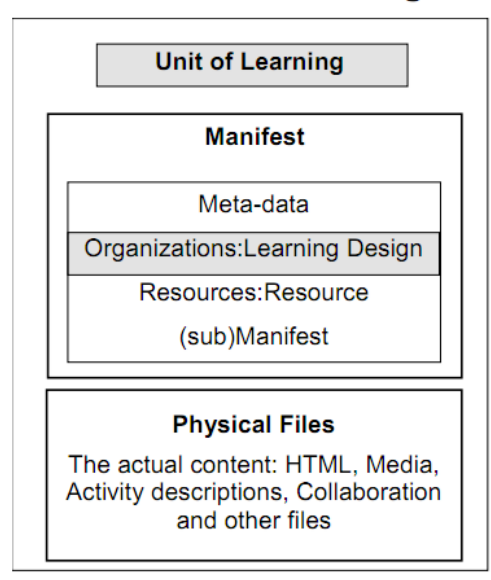

Figura C.20: Integração da especificação IMS-CP e IMS-LD

- Um arquivo manifesto em formato XML nomeado "imsmanifest.xml", que descreve a estratégia de aprendizagem e de instrução a ser empregada;

- Arquivos com conteúdos de tipo webcontent (HTML, XHTML) ou de tipo imsldcontent; e

- Arquivos e recursos de quaisquer tipos utilizados no manifesto. 


\section{Apêndice D}

\section{Axiomas e operadores de propósito geral}

\section{D.1 Teste de igualdade e não igualdade}

Os axiomas da Figura D.1 efetuam o teste de igualdade de e não igualdade de dois termos. O axioma de igualdade é verdadeiro somente se os termos passados como argumentos são iguais, enquanto, o axioma de não igualdade é verdadeiro se os termos não são iguais.

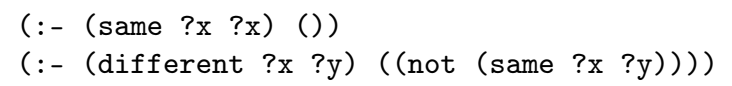

Figura D.1: Teste de igualdade e não igualdade, axiomas same $e$ different

Exemplo D.1. O axioma (same a a) é satisfazível enquanto (different a a) não é satisfazível.

Exemplo D.2. O axioma (different a b) é satisfazível enquanto (same a b) não é satisfazível.

\section{D.2 Manipulação de listas}

A Figura D.2 apresenta o conjunto de axiomas utilizados na manipulação de listas.

O axioma (first ?head list) é utilizado para validar se o primeiro elemento da lista list é igual ao valor da variável ?head; ou para atribuir o valor do primeiro elemento da lista list à variável ?head.

Exemplo D.3. O axioma (first a (a b c d e f)) é satisfazível porque o primeiro elemento a é igual ao parâmetro ?head.

Exemplo D.4. O axioma (first ?p (a b c d e f)) é satisfazível e a variável ?p é atribuída com o valor a.

\section{D.3 Substituição iterativa de um símbolo variável com os termos de uma lista}

Na Figura ??, o axioma (assignlterator ?var ?list) efetua a substituição iterativa no símbolo variável ?var de cada um dos termos de uma lista ?list. O primeiro axioma atribui o primeiro termo da lista à variável ?var, enquanto o segundo axioma é aplicado se o processo de planejamento falha efetuando a atribuição da variável ?var no primeiro elemento da lista ?list. O processo é 


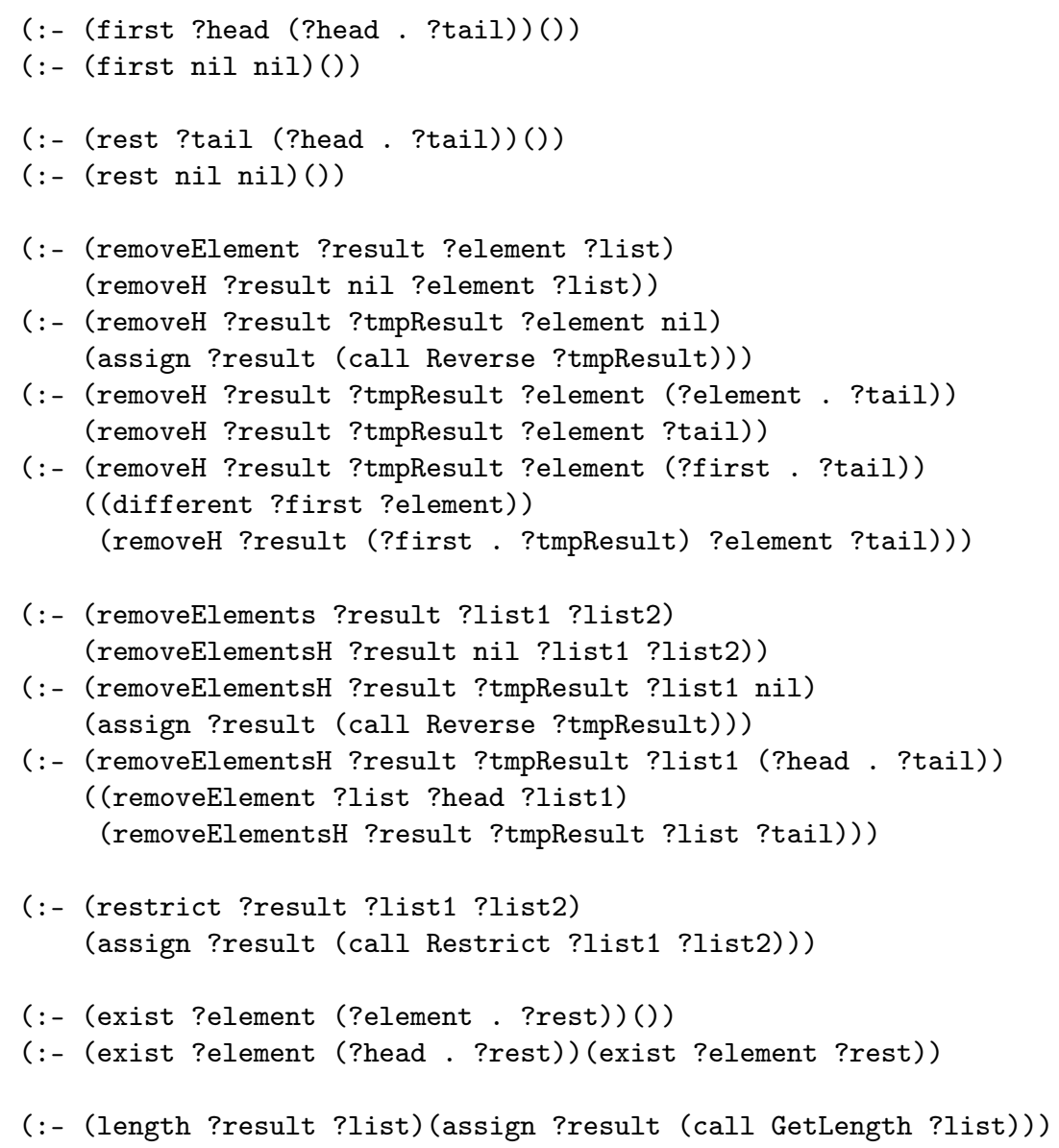

Figura D.2: Axiomas de manipulação de listas 
repetido até o final da lista. Nesse caso, se o axioma não é satisfazível no último elemento da lista o processo de planejamento efetua um backtracking.

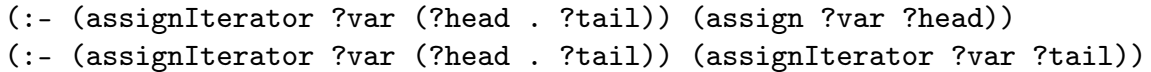

Figura D.3: Iteração em listas, axioma assignlterator

Exemplo D.5. O axioma (assignlterator ?var (a (b c d) e)) primeiro atribui à variável ?var o termo a. Logo depois do backtracking, o termo (b c d) é atribuído e finalmente o termo e é atribuído.

\section{D.4 Manipulação do estado corrente}

Os operadores apresentados na Figura D.4 são utilizados para efetuar adição e remoção de átomos lógicos na representação do estado do mundo. Assim, o operador (!!addlnWorldState ?atom) é utilizado para adicionar o átomo ?atom, enquanto o operador (!!removeFromWorldState ?atom) é utilizado para remover o átomo. A utilização de dois símbolos “!!" no operador primitivo representa que o operador é interno, desta maneira o operador não faz parte do plano de execução do agente.

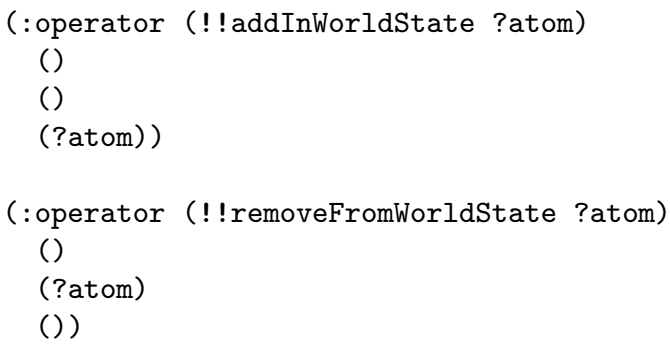

Figura D.4: Operadores !!addlnWorldState $e$ !!removeFromWorldState 


\section{Apêndice E}

\section{Axiomas de planejamento instrucional}

\section{E.1 Ordenação topológica}

O axioma (sortBy ?result ?e ?relation) efetua a ordenação topológica dos elementos ?e de acordo com a relação ?relation que define um dígrafo acíclico.

Exemplo E.1. Seja parte do modelo de domínio a ser ensinado representado pelo grafo da Figura 3.13. O axioma (sortBy ?result (lo1 lo2 lo3 lo5 lo6 lo7) isRequiredBy) devolve como resultado os elementos (lo1 lo5 lo2 lo3 lo7 lo8) no símbolo de variável ?result.

\section{E.2 Ordenação dos elementos de domínio pelo histórico do estudante}

O axioma (sortByAlreadySeen ?result ?e ?l) efetua a ordenação dos elementos ?e de acordo como o registro histórico dos estudantes ?l. Assim, os primeiros elementos da lista ?result são elementos não presentes nos registros históricos dos estudantes.

Exemplo E.2. Seja o estado corrente $S=\{$ (property 11 hasAlreadySeen lo2), (property 12 hasAlreadySeen lo3)\}. O axioma (sortByAlreadySeen ?result (lo1 lo2 lo3 lo4 lo5) (I1 I2)) devolve como resultado a lista de termos (lo1 lo4 lo5 lo1 lo2) no símbolo variável ?result.

\section{E.3 Filtrar elementos usando condições}

O axioma (filterByQuery ?result ?e ?query) efetua a filtragem de uma lista de elementos ?e que satisfazem as condições definidas na lista ?query.

Exemplo E.3. Sejam os elementos e relações mostrados na Figura 3.12 parte do modelo de domínio a ser ensinado. O axioma

(filterByQuery ?result (lo1 lo2 lo3 lo4 lo5) ((class Auxiliary)

(property hasLearningResourceType exercise)

(property hasLearningObjective comp1 s4k3))

devolve como resultado a lista de identificadores (lo3 lo4 lo5) no símbolo variável ?result.

\section{E.4 Construção de condições para consultas}

As condições da lista ?query podem ser obtidas mediante os axiomas buildPropertyQuery e buildRelationQuery. O axioma (buildPropertyQuery ?result ?name [?d] ?values ?query) efetua a 
construção de condições (property ?name [?d] ?v) para cada elemento ?v existente na lista de termos ?values adicionando o resultado à lista ?query. Enquanto, o axioma (buildRelationQuery ?result ?name ?dests ?query) efetua a construção de condições (relation ?name ?d) para cada elemento ?d existente na lista de termos ?dests.

Exemplo E.4. O axioma

(buildPropertyQuery ?result hasLearningObjective c0 (s1k1 s1k2 s1k3)

((class Auxiliary)

(property hasLearningResourceType exercise))

z devolve como resultado a lista de condições ((class Auxiliary) (property hasLearningResourceType exercise) (property hasLearningObjective c0 s1k1) (property hasLearningObjective c0 s1k2) (property hasLearningObjective c0 s1k3)) no símbolo de variável ?result.

\section{E.5 Comparar e obter valores de um nível de competência}

O axioma (equivalent (?sl ?kl) ?level) avalia os valores no nível de desenvolvimento de habilidade ?sl e no nível de aquisição de conhecimento ?kl com o identificador de nível de competência ?level. Enquanto, o axioma (getLevel ?level (?sl ?kl)) obtém o identificador do nível de competência ?level a partir dos valores nível de desenvolvimento de habilidade ?sl e nível de aquisição de conhecimento ?kl. Os valores possíveis de ?sl são any, nothing, rough, explanatory, associative e autonomous; e os valores possíveis de ?kl são any, nothing, accretion, tuning e restructuring.

O axioma (getNumericalLevel (?sl ?kl) ?level) obtém valores numéricos do nível de desenvolvimento de habilidade ?sl e de aquisição de conhecimento ?kl usando como entrada o identificador de nível de competência ?level.

\section{E.6 Avaliação do tipo de elemento de conhecimento associado a uma com- petência}

O axioma (hasKnowledgeType ?c ?t) avalia se o tipo de elemento de conhecimento ?t está associado à competência cognitiva ?c, os valores possíveis de ?t são Auxiliary e Fundamental. 
Obter o nível de competência cognitiva e filtrar estudantes por nível de competência

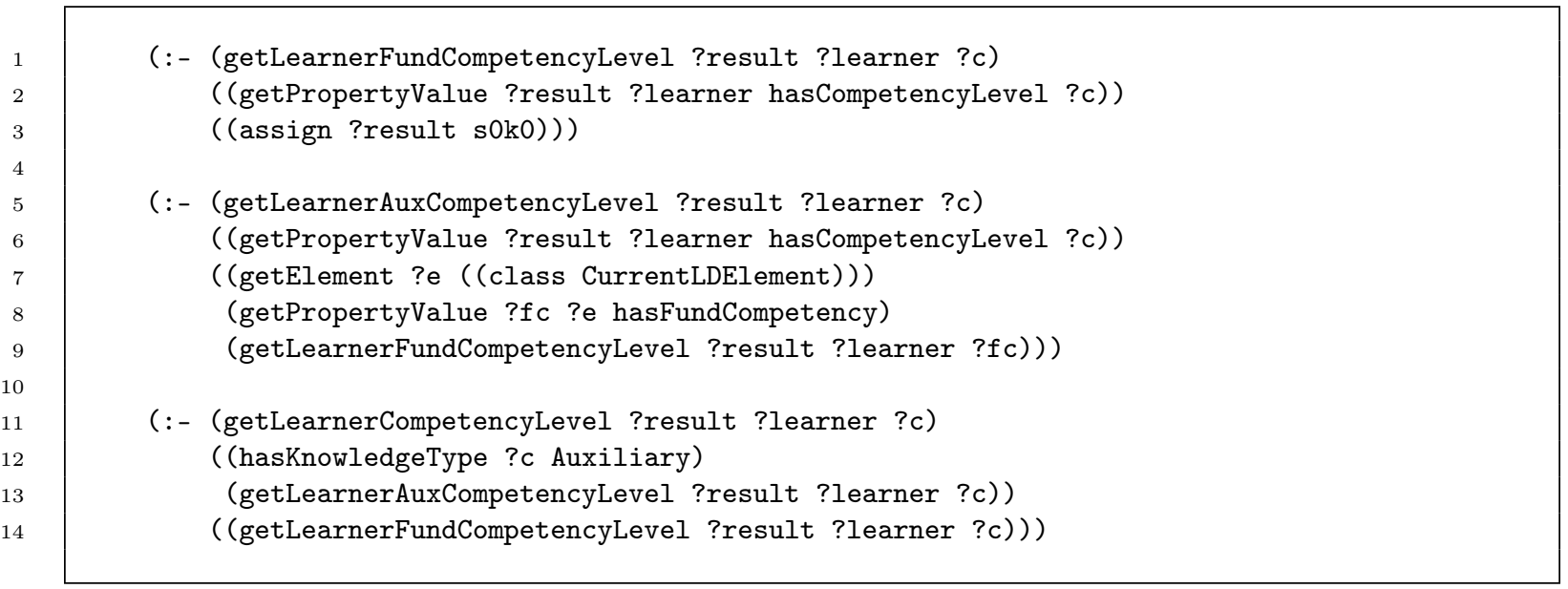

Figura E.1: Axioma de obtenção do nivel de competência cognitiva corrente

O axioma getLearnerCompetencyLevel mostrado na Figura E.1 obtém o nível de competência de um estudante ?learner relativo à competência cognitiva ?c. Se a competência ?c é associada a um elemento de conhecimento de tipo auxiliar, o nível é obtido mediante o axioma getLearnerAuxCompetencyLevel (linhas 5-9) que busca o valor no registro de competências do modelo de estudante (linha 6). No caso de que não exista um valor no registro de competências, o valor a ser obtido corresponde ao nível de competência cognitiva fundamental ?fc para o qual se efetua o processo de planejamento (linha 7-9).

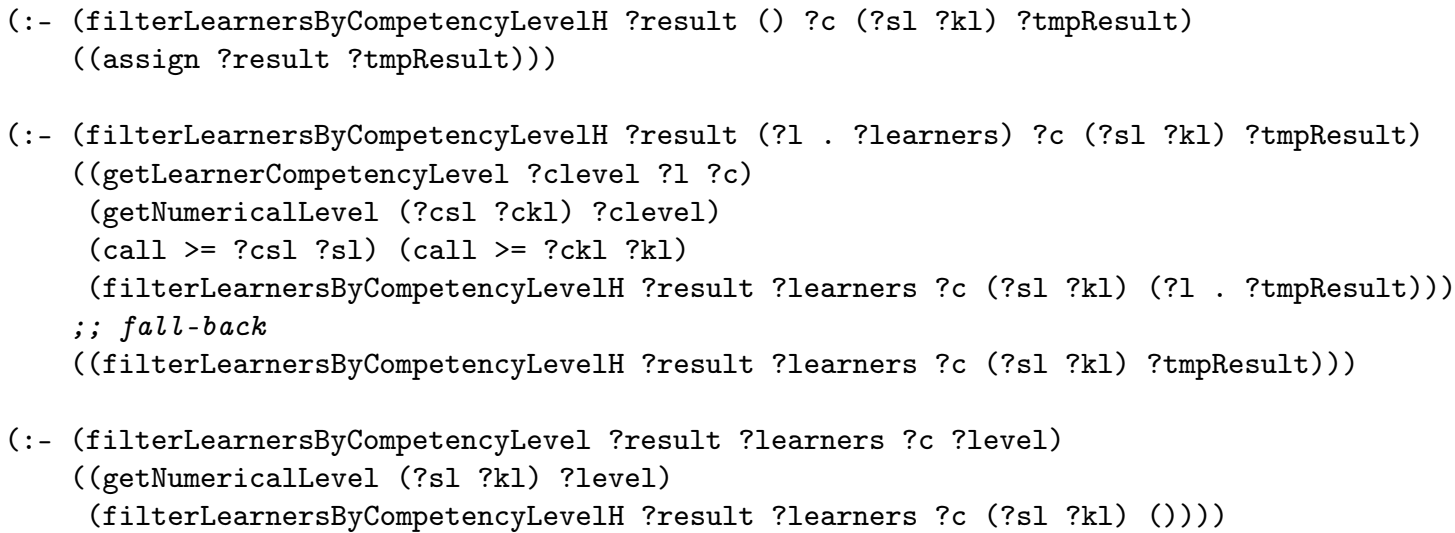

Figura E.2: Axioma para filtrar estudantes por nivel de competência

O axioma filterLearnersByCompetencyLevel mostrado na Figura E.2 efetua a filtragem dos estudantes ?learners pelo nível de competência ?level associadas à competência ?c. Os estudantes a serem devolvidos pelo axioma correspondem com estudantes que possuem um nível maior ou igual ao nível ?level (linhas 5-8). 


\section{E.7 Obter uma elemento auxiliar que cumpre as condições}

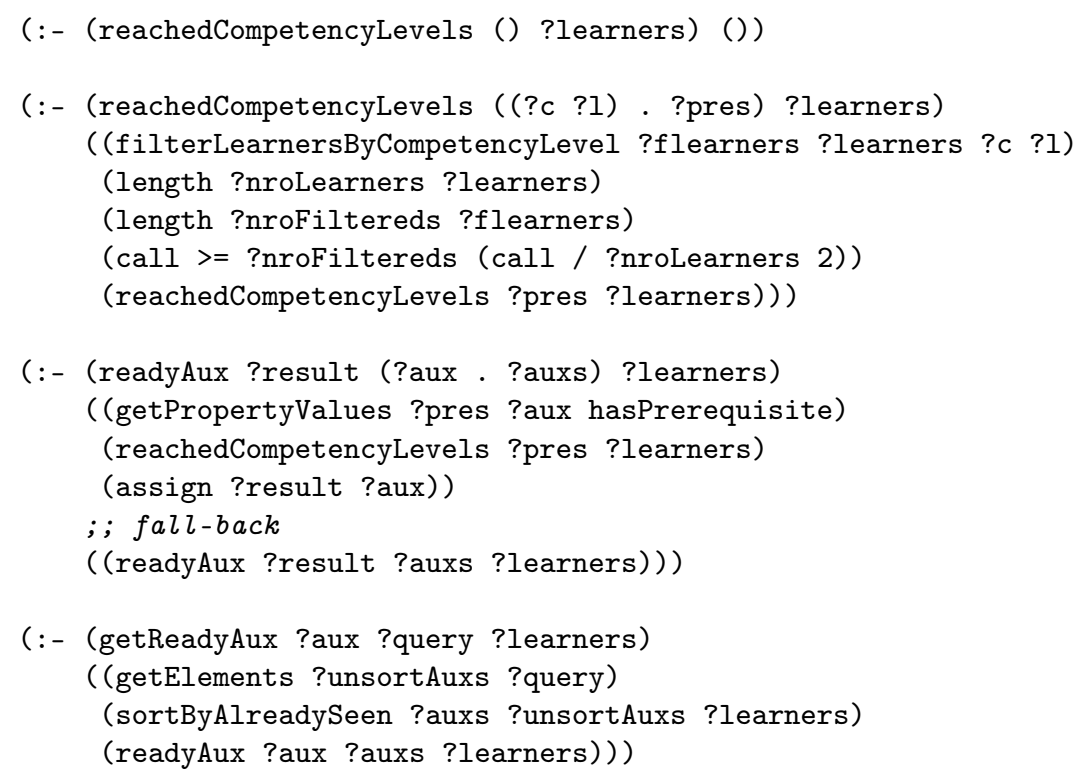

Figura E.3: Axioma para obter um elemento de conhecimento de tipo auxiliar

O axioma getReadyAux mostrado na Figura E.3 seleciona um elemento de conhecimento de tipo auxiliar que cumpre as condições da lista ?query (linha 18). O elemento auxiliar selecionado é de preferência um elemento não visualizado anteriormente pelos participantes (linha 19) e deve satisfazer os pré-requisitos de aprendizagem (linha 20). O axioma readyAux (linhas 10-15) obtém o elemento auxiliar que satisfaz todos os pré-requisitos de aprendizagem ?pres mediante o axioma reachedCompetencyLevels (linha 1-8, 12). A avaliação de cada pré-requisito de aprendizagem é dita satisfeita se a maioria dos estudantes satisfaz o nível de competência ?l (linhas 4-7).

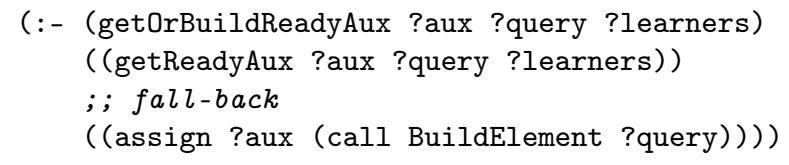

Figura E.4: Axioma para obter ou criar um elemento de conhecimento de tipo auxiliar

O axioma getOrBuildReadyAux mostrado na Figura E.4 efetua a seleção de um elemento de conhecimento de tipo auxiliar que satisfaz as condições da lista ?query e satisfaz os pré-requisitos de aprendizagem (linha 2). Caso não seja selecionado nenhum elemento, o axioma efetua a criação de um novo elemento do domínio a ser ensinado mediante o termo de chamada (call BuildElement ?query) (linha 4).

\section{E.8 Obter condições de consultas de acordo as características dos estudantes}




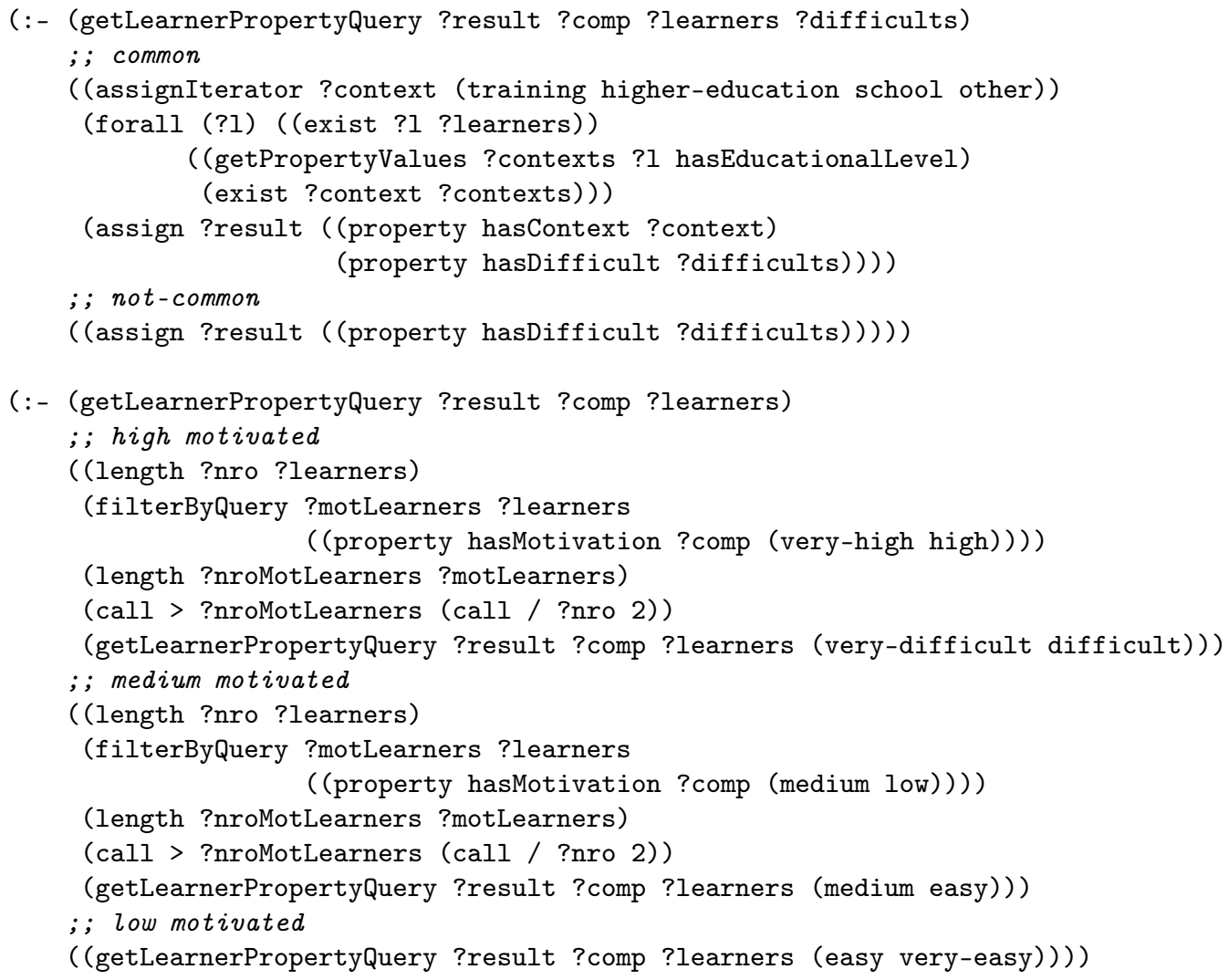

Figura E.5: Axioma para obter condições de consultas de acordo as características dos estudantes 
O axioma getLearnerPropertyQuery mostrado na Figura E.5 obtém uma lista de condições a serem empregadas em consultas ?query para à obtenção de elementos do modelo de domínio. A lista de condições é obtida avaliando as características individuais dos participantes como alto nível de motivação (linhas 14-19), nível meio de motivação (linhas 21-26) e baixo nível de motivação (linha 28). Outra característica avaliada nos estudantes é o nível de educação possuído pelos estudantes (linhas 1-10).

Exemplo E.5. Seja o estado corrente $S=\{$ (property I1 hasEducationalLevel school), (property $I 2$ hasEducationalLevel school), (property 13 hasEducationalLevel school), (property I1 hasMotivation (c1 medium)), (property 12 hasMotivation (c1 medium)), (property 13 hasMotivation (c1 high))\}. O axioma (getLearnerPropertyQuery ?result c1 ll l2 l3) devolve como resultado a lista de condições ((property hasDifficult (medium easy)) (property hasContext school)) no símbolo variável ?result.

\section{E.9 Obter competências e níveis de competência da lista de objetivos edu- cacionais}

O axioma (getCompsFromGoals ?result ?goals) obtém a lista de competências a partir dos objetivos educacionais ?goals. Enquanto, o axioma (getLevelsFromGoals ?result ?goals) obtém a lista de níveis de competência.

O axioma (getCompFromGoals ?c ?goals) é uma variante de getCompsFromGoals que obtém uma única competência associada aos objetivos educacionais. O axioma também avalia que todos os objetivos tenham a mesma competência ?c.

\section{E.10 Obter objetivo educacional de um elemento de conhecimento de tipo auxiliar}

O axioma (getGoalFromAuxiliary ?goal ?aux ?c [?!]) obtém o objetivo educacional ?goal para um elemento de conhecimento de tipo auxiliar ?aux no contexto da competência fundamental ?c. O objetivo educacional é obtido usando um dos objetivos de aprendizagem (hasLearningObjective). O parâmetro ?l define o nível de competência no objetivo educacional ?goal.

O axioma (getGoalsFromAuxiliary ?goals ?aux ?c ?levels) obtém uma lista de objetivos educacionais ?goals usando cada um dos níveis de competência ?! definidos na lista de termos ?levels. Os objetivos são obtidos no contexto da competência fundamental ?c.

Finalmente, o axioma (getGoalsFromAuxiliaries ?goals ?auxs ?c) obtém uma lista de objetivos educacionais ?goals usando cada um dos elementos de conhecimento ?aux definidos na lista de termos ?auxs. Os objetivos são obtidos no contexto da competência fundamental ?c.

\section{E.11 Obter objetivos individuais dos estudantes}

O axioma (getlndGoals ?result ?groups ?goals [?comps] [?learners]) obtém os objetivos individuais mediante a estrutura $\left(\left(\mathrm{I}_{1}\left(\mathrm{c}_{1} \mathrm{ig}_{1}\right)\right) \ldots\left(\mathrm{I}_{n}\left(\mathrm{c}_{n}\right.\right.\right.$ ig $\left.\left.\left.\mathrm{g}_{n}\right)\right)\right)$, na qual cada termo $\left(\mathrm{I}_{i}\left(\mathrm{c}_{i}\right.\right.$ ig $\left.\left.\mathrm{ig}_{i}\right)\right)$ representa o objetivo individual $\mathrm{ig}_{1}$ do estudante $\mathrm{I}_{i}$ relativo à competência $\mathrm{c}_{i}$. O objetivo individual ig $\mathrm{g}_{i}$ é representado mediante o identificador $\mathrm{s} x_{i} \mathrm{k} y_{i} \mathrm{~s} x_{g} \mathrm{k} y_{g}$, no que:

- $x_{i}$ e $y_{i}$ representam o nível de competência corrente do estudante $\mathrm{I}_{i}$; e 
- $x_{g}$ e $y_{g}$ representam o nível de competência desejável.

Seja o símbolo variável ?goals definido pela lista de termos ((c1 s1) (c2 s2) ... (cn sn)) e

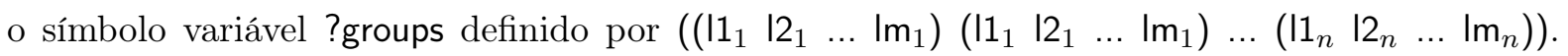
A obtenção dos objetivos individuais é efetuada mediante o relacionamento de cada um dos objetivos educacionais (ci si) e os níveis de competência dos estudantes $\left(I 1_{i} \mid 2_{i} \ldots \operatorname{lm}_{i}\right)$.

Os parâmetros opcionais ?comp e ?learners são empregados para definir a filtragem de objetivos individuais a serem obtidos. Assim, se uma competência $c_{i}$ não existe na lista ?comps ou um estudante $I_{i}$ não existe na lista ?learners o objetivo individual $\left(I_{i}\left(c_{i}\right.\right.$ ig $\left.\left.g_{i}\right)\right)$ não será incluído na lista termos ?result.

Exemplo E.6. Seja o estado corrente $S=\{$ (property 11 hasCompetencyLevel (c1 s1k0)), (property 12 hasCompetencyLevel (c1 s0k2)), (property 13 hasCompetencyLevel (c2 s4k0))\}. O axioma (getIndGoals ?result ((c1 s3k3) (c2 s4k3)) ((11 l2) (I3 l4))) devolve como resultado a lista de termos $((11$ (c1 s1k0s3k3)) (I2 (c1 s0k2s3k3)) (I3 (c2 s4k0s4k3)) (14 (c2 s0k0s4k3))) no símbolo variável ?result. Note-se que se o nível de competência de um estudante não é definido no estado corrente $S$ então o nível de competência para o estudante é s0k0.

\section{E.12 Filtragem de objetivos e grupos por competência cognitiva}

O axioma (filterGoalsByComp ?result ?goals ?c) efetua a filtragem de objetivos educacionais ?goals relativos à competência cognitiva ?c, devolvendo o resultado no símbolo de variável ?result. Enquanto, o axioma (filterGroupsByComp ?result ?goals ?groups ?c) efetua a filtragem dos grupos ?groups associados aos objetivos educacionais ?goals relativos à competência cognitiva ?c.

Exemplo E.7. O axioma (filterGoalsByComp ?result ((c1 s1k1) (c2 s2k3) (c1 s2k2)) c1) devolve como resultado a lista de termos ((c1 s1k1) (c1 s2k2)) no símbolo de variável ?result. Enquanto, o axioma (filterGoalsByComp ?result ((c1 s1k1) (c2 s2k3) (c1 s2k2)) ((I1 I2) (I3) (I5 I6 I7)) c1) devolve como resultado a lista de termos ((l1 I2) (l5 I6 I7)).

\section{Obter valor do tipo de recurso instrucional a ser apresentado}

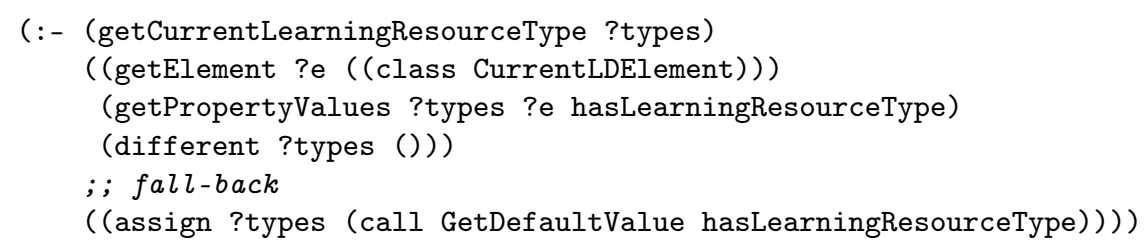

Figura E.6: Axioma para obter o tipo de recurso instrucional a ser apresentado

O axioma getCurrentLearningResourceType mostrado na Figura E.6 obtém a lista do tipo de recurso a ser apresentado no elemento de roteiro ?e (linhas 3-5). Caso não seja definido o tipo de recurso instrucional no elemento de roteiro é usado valores padrão definidos no termo de chamada (call GetDefaultValue hasLearningResourceType) (linha 6). 


\section{E.13 Avaliar objetivos educacionais e níveis de competências}

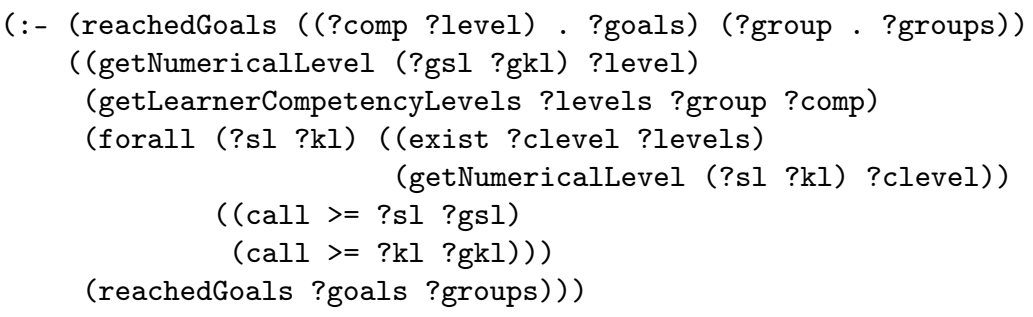

Figura E.7: Axioma para avaliar objetivos educacionais e niveis de competência

O axioma reachedGoals mostrado na Figura E.7 efetua a avaliação dos objetivos educacionais e os níveis de competência dos estudantes, retornando verdadeiro se todos os objetivos educacionais ?goals foram atingidos pelos estudantes ?groups. A avaliação é efetuada em cada um dos participantes ?group (linha 3) validando se todos os valores numéricos dos níveis de competência são maiores ou igual aos níveis dos objetivos educacionais (linhas 4-7). 


\section{Referências Bibliográficas}

Alexander et al.(1977) Christopher Alexander, Sara Ishikawa, e Murray Silverstein. A Pattern Language: Towns, Buildings, Construction (Center for Environmental Structure Series). Oxford University Press, 2 edição. Citado na pág. 15

Bhatti et al.(2000) N. Bhatti, A. Bouch, e A. Kuchinsky. Integrating user-perceived quality into web server design. Computer Networks, 33(1):1-16. Citado na pág. 116

Brusilovsky e Vassileva(2003) P. Brusilovsky e J. Vassileva. Course sequencing techniques for large-scale web-based education. International Journal of Continuing Engineering Education and Life Long Learning, 13(1):75-94. Citado na pág. 18

Cassel et al.(2008) L. Cassel, A. Clements, G. Davies, M. Guzdial, R. McCauley, A. McGettrick, R. Sloan, L. Snyder, P. Tymann, e B. Weide. Computer science curriculum 2008: An interim revision of cs 2001. Report from the interim review task force. Citado na pág. 133

Cerri et al.(1992) S.A. Cerri, E. Cheli, e A. McIntyre. Nobile: user model acquisition in a natural laboratory. Adaptive Learning Environments, Computer and Systems Sciences, LNCS, 85:325-347. Citado na pág. 153

Dillenbourg(2002) P. Dillenbourg. Over-scripting cscl: The risks of blending collaborative learning with instructional design. Three worlds of CSCL: Can we support CSCL. Citado na pág. 5,8

Dillenbourg e Jermann(2007) Pierre Dillenbourg e Patrick Jermann. Designing integrative scripts. Em Pierre Dillenbourg, Frank Fischer, Ingo Kollar, Heinz Mandl, e Jörg M. Haake, editors, Scripting Computer-Supported Collaborative Learning, volume 6 of Computer-Supported Collaborative Learning, páginas 275-301. Springer US. Citado na pág. 10, 16

Erol(1990) N. Erol. Epos collaborative learning environment. DELTA Project EPOS D7002 1C 90-02-02, ECOLE, Milano: Dida*El. Citado na pág. 153

Fernández et al.(1988) I. Fernández, A. Díaz, e MF Verdejo. Building a programming tutor by dynamic planning: case studies and a proposal. Em Proceedings of the International Conference on Intelligent Tutoring Systems., Montréal. Citado na pág. 153

Fielding(2000) R. Fielding. Representational state transfer (rest). Architectural Styles and the Design of Network-based Software Architectures. University of California, Irvine, página 120. Citado na pág. 109

Gamboa e Fred(2001) H. Gamboa e A. Fred. Designing intelligent tutoring systems: a bayesian approach. Enterprise information systems, 3:146. Citado na pág. 17

Garrido et al.(2008) A. Garrido, E. Onaindia, e O. Sapena. Planning and scheduling in an e-learning environment. a constraint-programming-based approach. Engineering Applications of Artificial Intelligence, 21(5):733-743. Citado na pág. 155 
Ghallab et al.(2004) M. Ghallab, D.S. Nau, e P. Traverso. Automated Planning: theory and practice. Morgan Kaufmann, San Francisco, CA, 1 edição. Citado na pág. 21, 23, 25, 162, 163

Goodyear et al.(2004) P. Goodyear, P. Avgeriou, R. Baggetun, S. Bartoluzzi, S. Retalis, F. Ronteltap, e E. Rusman. Towards a pattern language for networked learning. Em Proceedings of Networked Learning, páginas 449-455. Citado na pág. 5

Hayashi et al.(2006) Y. Hayashi, J. Bourdeau, e R. Mizoguchi. Ontological support for a theory-eclectic approach to instructional and learning design. Innovative Approaches for Learning and Knowledge Sharing, páginas 155-169. Citado na pág. 11

Hernández-Leo et al.(2006) D. Hernández-Leo, E.D. Villasclaras-Fernández, J.I. AsensioPérez, Y. Dimitriadis, I.M. Jorrín-Abellán, I. Ruiz-Requies, e B. Rubia-Avi. Collage: A collaborative learning design editor based on patterns. Jornal of Educational Technology and Society, 9(1):58-71. Citado na pág. 1, 156

Hernández-Leo et al.(2008) D. Hernández-Leo, J.I. Asensio-Pérez, Y. Dimitriadis, e E.D. Villasclaras-Fernández. Generating cscl scripts. Citado na pág. 15

Hernández-Leo et al.(2009) D. Hernández-Leo, ED Villasclaras-Fernández, JI Asensio-Pérez, e Y. Dimitriadis. Generating cscl scripts: From a conceptual model of pattern languages to the design of real scripts. E-learning Design Patterns Book, Sense Publishers. Citado na pág. 16

Hernández-leo et al.(2005) Davinia Hernández-leo, Juan I. Asensio-pérez, e Yannis Dimitriadis. Computational representation of collaborative learning flow patterns using. Em IMS Learning Design - Educational Technology and Society, volume 8, páginas 75-89. Citado na pág. 12

Ilghami(2006) O. Ilghami. Documentation for jshop2. Department of Computer Science, University of Maryland, Tech. Rep. Citado na pág. 27

IMS-LD(2003) IMS-LD. Ims learning design best practice and implementation guide. IMS Global Learning Consortium, 2003. Citado na pág.

Inaba et al.(2003a) A. Inaba, M. Ikeda, e R. Mizoguchi. What learning patterns are effective for a learner's growth? Em Proc. of the International Conference on Artificial Intelligence in Education, Sydney, páginas 219-226. Citado na pág. 37

Inaba et al.(2003b) A. Inaba, R. Ohkubo, M. Ikeda, e R. Mizoguchi. Models and vocabulary to represent learner-to-learner interaction process in collaborative learning. Em Proc. of the International Conference on Computers in Education, Hong Kong, páginas 1088-1096. Citado na pág. ix, 10

Isotani e Mizoguchi(2006) S. Isotani e R. Mizoguchi. An integrated framework for finegrained analysis and design of group learning activities. Em Proceeding of the 2006 conference on Learning by Effective Utilization of Technologies: Facilitating Intercultural Understanding, páginas 193-200. IOS Press. Citado na pág. 37

Isotani e Mizoguchi(2007) S. Isotani e R. Mizoguchi. Planejamento e análise de sessões colaborativas utilizando teorias de aprendizagem e ontologias. Revista Brasileira de Informática na Educação, 15(2). Citado na pág. ix, 11, 38, 157

Isotani et al.(2010a) S. Isotani, R. Mizoguchi, A. Inaba, e M. Ikeda. The foundations of a theory-aware authoring tool for cscl design. Computers Eamp; Education, 54(4):809-834. Citado na pág. 11 
Isotani et al.(2010b) S. Isotani, R. Mizoguchi, S. Isotani, O. Capeli, N. Isotani, e A. de Albuquerque. An authoring tool to support the design and use of theory-based collaborative learning activities. Em Vincent Aleven, Judy Kay, e Jack Mostow, editors, Intelligent Tutoring Systems, volume 6095 of Lecture Notes in Computer Science, páginas 92-102. Springer, Springer Berlin - Heidelberg. Citado na pág. xiii, 1, 157, 158

Isotani(2009) Seiji Isotani. An Ontological Engineering Approach to Computer-Supported Collaborative Learning - From Theory to Practice. Phd in engineering - information and communication technology, Institute of Scientific and Industrial Research - Universidade de Osaka (JP), Institute of Scientific and Industrial Research, Osaka University, Japan. Citado na pág. ix, xii, 10, 11, 51, 118

Kaplan e Rock(1995) R. Kaplan e D. Rock. New directions for intelligent tutoring. AI Expert, 10(2):30-40. Citado na pág. 18

Kirschner et al.(2004) P. Kirschner, J.W. Strijbos, K. Kreijns, e P.J. Beers. Designing electronic collaborative learning environments. Educational Technology Research and Development, 52(3):47-66. Citado na pág. 5

Kobbe et al.(2007) L. Kobbe, A. Weinberger, P. Dillenbourg, A. Harrer, R. Hämäläinen, P. Häkkinen, e F. Fischer. Specifying computer-supported collaboration scripts. International Journal of Computer-Supported Collaborative Learning, 2(2):211-224. Citado na pág. ix, 5,6

Kobbe(2005) Lars Kobbe. Framework on multiple goal dimensions for computer-supported scripts. Relatório técnico, CoSSICLE. Citado na pág. xiv, 7

Koper e Olivier(2003) R. Koper e B. Olivier. Representing the learning design of units of learning. Citado na pág. 5

Koper et al.(2002) R. Koper, H. Vogten, e H. Martens. Educational modelling language 1.1 (eml 1.1). Citado na pág. 172

Leo et al.(2004) D.H. Leo, J.I.A. Pérez, e Y.A. Dimitriadis. Ims learning design support for the formalization of collaborative learning patterns. Em Advanced Learning Technologies, 2004. Proceedings. IEEE International Conference on, páginas 350-354. IEEE. Citado na pág. 8, 12

Leo et al.(2007) D.H. Leo, J.I.A. Pérez, e I.D. Damoulis. A pattern-based design process for the creation of CSCL macro-scripts computationally represented with IMS LD. Tese de Doutorado, Tesis doctoral. ETSIT, Universidad de Valladolid. Citado na pág. ix, 15

Melis et al.(2008) E. Melis, A. Faulhaber, A. Eichelmann, e S. Narciss. Interoperable competencies characterizing learning objects in mathematics. Em Intelligent Tutoring Systems, páginas 416-425. Springer. Citado na pág. 36

Miao(2005) Y. Miao. Cosmos: Facilitating learning designers to author units of learning using ims ld. Em Proceeding of the 2005 conference on Towards Sustainable and Scalable Educational Innovations Informed by the Learning Sciences: Sharing Good Practices of Research, Experimentation and Innovation, páginas 275-282. IOS Press. Citado na pág. xiii, 156

Nau et al.(2003) D.S. Nau, T.C. Au, O. Ilghami, U. Kuter, J.W. Murdock, D. Wu, e F. Yaman. Shop2: An htn planning system. J. Artif. Intell. Res. (JAIR), 20:379-404. Citado na pág. 27, 30 
OASIS(2006) SOA Reference Model Technical Committee OASIS. Reference model for service oriented architecture v1.0, October 2006. URL http://docs.oasis-open.org/soa-rm/v1.0/ soa-rm.pdf. Citado na pág. 34

Olivier e Tattersall(2005) B. Olivier e C. Tattersall. The learning design specification. Learning Design, páginas 21-40. Citado na pág. 172

Peachey e McCalla(1986) D.R. Peachey e G.I. McCalla. Using planning techniques in intelligent tutoring systems. International Journal of Man-Machine Studies, 24(1):77-98. Citado na pág. 152

Pinkwart(2003) N. Pinkwart. A plug-in architecture for graph based collaborative modeling systems. Em Shaping the future of learning through intelligent technologies. Proceedings of the 11th Conference on Artificial Intelligence in Education, páginas 535-536. Citeseer. Citado na pág. 1,156

PISA(2001) PISA. Knowledge and skills for life: first results from the OECD Programme for International Student Assessment (PISA) 2000. Organisation for Economic Co-operation and Development. Citado na pág. 39

Sicilia(2005) M.A. Sicilia. Ontology-based competency management: Infrastructures for the knowledge-intensive learning organization. Intelligent learning infrastructures in knowledge intensive organizations: A semantic web perspective, páginas 302-324. Citado na pág. 36

Simon et al.(2005) B. Simon, D. Massart, F. Van Assche, S. Ternier, E. Duval, S. Brantner, D. Olmedilla, e Z. Miklós. A simple query interface for interoperable learning repositories. Em Proceedings of the 1st Workshop on Interoperability of Web-based Educational Systems, páginas 11-18. Citado na pág. 160

Stahl et al.(2006) G. Stahl, T. Koschmann, e D. Suthers. Computer-supported collaborative learning, 2006. Citado na pág. 1

Toska(1991) Toska. Toska final report. Relatório técnico, CEC Delta Project D1007, Friendrichshafe: Dornier. Citado na pág. 153

Ullrich(2008) Carsten Ullrich. Pedagogically founded courseware generation for web-based learning: an HTN-planning-based approach implemented in PAIGOS. Number 5260 in Lecture Notes in Artificial Intelligence. Springer-Verlag. Citado na pág. 2, 154

Van Es e Koper(2006) R. Van Es e R. Koper. Testing the pedagogical expressiveness of ims ld. Jornal of Educational Technology and Society, 9(1):229-249. Citado na pág. 4

Van Marcke(1998) K. Van Marcke. Gte: An epistemological approach to instructional modelling. Instructional Science, 26(3):147-191. Citado na pág. 2, 18, 19, 153

Vassileva(1998) J. Vassileva. Dcg + gte: Dynamic courseware generation with teaching expertise. Instructional Science, 26(3):317-332. Citado na pág. 2, 18, 153

Villasclaras-Fernández et al.(2009) E.D. Villasclaras-Fernández, S. Isotani, Y. Hayashi, e R. Mizoguchi. Looking into collaborative learning: Design from macro-and micro-script perspectives. Frontiers in Artificial Intelligence and Applications, 200. Citado na pág. xi, 16, 98

Vogten e Martens(2004) H. Vogten e H. Martens. Coppercore. SourceForge: http://sf. net/projects/coppercore. Citado na pág. 106 
Vogten et al.(2006) H. Vogten, H. Martens, R. Nadolski, C. Tattersall, P. Van Rosmalen, e R. Koper. Coppercore service integration-integrating ims learning design and ims question and test interoperability. Em Advanced Learning Technologies, 2006. Sixth International Conference on, páginas 378-382. IEEE. Citado na pág. 111

Vrakas et al.(2007) D. Vrakas, G. Tsoumakas, F. Kokkoras, N. Bassiliades, I. Vlahavas, e D. Anagnostopoulos. Paser: a curricula synthesis system based on automated problem solving. International Journal of Teaching and Case Studies, 1(1):159-170. Citado na pág. 155

Vygotsky(1978) L. S. Vygotsky. Mind in Society: The Development of Higher Psychological Processes. Harvard University Press, 14 edição. Citado na pág. 1

Wasson(1996) B. Wasson. Instructional planning and contemporary theories of learning: Is this a self-contradiction? Em Proceedings of the European Conference on Artificial Intelligence in Education, páginas 23-30. Colobri. Citado na pág. 1, 5

Weinberger et al.(2005) A. Weinberger, B. Ertl, F. Fischer, e H. Mandl. Epistemic and social scripts in computer-supported collaborative learning. Instructional Science, 33(1):1-30. Citado na pág. 5

Wenger(1987) Etienne Wenger. Artificial intelligence and tutoring systems: computational and cognitive approaches to the communication of knowledge. Morgan Kaufmann Publishers Inc, San Francisco, CA, USA. Citado na pág. 17

Wiley(2002) David A. Wiley, editor. The instructional use of learning objects. Agency for Instructional Technology : Association for Educational Communications and Technology, Bloomington, Ind. Citado na pág. 4

Wilkinson(2001) J. Wilkinson. A matter of life or death: re-engineering competency-based education through the use of a multimedia cd-rom. Em Advanced Learning Technologies, 2001. Proceedings. IEEE International Conference on, páginas 205-208. IEEE. Citado na pág. 36

Woolf(2008) B.P. Woolf. Building intelligent interactive tutors: Student-centered strategies for revolutionizing e-learning, volume 1. Morgan Kaufmann. Citado na pág. 18 